\title{
MEDITATIONS ON THE HUMAN CONDITION IN AN IMPERIAL AGE
}

\author{
By Irina V. Boca, BA Honours, MA \\ A Thesis Submitted to \\ the Faculty of Graduate Studies and Research \\ in partial fulfillment of \\ the requirements for the degree of \\ Doctorate of Philosophy \\ Department of Political Science \\ CARLETON UNIVERSITY \\ Ottawa, Ontario, \\ Canada
}

(C) Copyright by Irina Valentina Boca 2007 


$\begin{array}{ll}\begin{array}{l}\text { Library and } \\ \text { Archives Canada }\end{array} & \begin{array}{l}\text { Bibliothèque et } \\ \text { Archives Canada }\end{array} \\ \begin{array}{l}\text { Published Heritage } \\ \text { Branch }\end{array} & \begin{array}{l}\text { Direction du } \\ \text { Patrimoine de l'édition }\end{array} \\ \begin{array}{l}\text { 395 Wellington Street } \\ \text { Ottawa ON K1A ON4 } \\ \text { Canada }\end{array} & \begin{array}{l}\text { 395, rue Wellington } \\ \text { Ottawa ON K1A ON4 }\end{array} \\ \text { Canada }\end{array}$

Yourfile Votre référence ISBN: 978-0-494-33481-2 Ourfile Notre référence ISBN: 978-0-494-33481-2

\section{NOTICE:}

The author has granted a nonexclusive license allowing Library and Archives Canada to reproduce, publish, archive, preserve, conserve, communicate to the public by telecommunication or on the Internet, loan, distribute and sell theses worldwide, for commercial or noncommercial purposes, in microform, paper, electronic and/or any other formats.

The author retains copyright ownership and moral rights in this thesis. Neither the thesis nor substantial extracts from it may be printed or otherwise reproduced without the author's permission.
AVIS:

L'auteur a accordé une licence non exclusive permettant à la Bibliothèque et Archives Canada de reproduire, publier, archiver, sauvegarder, conserver, transmettre au public par télécommunication ou par l'Internet, prêter, distribuer et vendre des thèses partout dans le monde, à des fins commerciales ou autres, sur support microforme, papier, électronique et/ou autres formats.

L'auteur conserve la propriété du droit d'auteur et des droits moraux qui protège cette thèse. $\mathrm{Ni}$ la thèse ni des extraits substantiels de celle-ci ne doivent être imprimés ou autrement reproduits sans son autorisation.
In compliance with the Canadian

Privacy Act some supporting forms may have been removed from this thesis.

While these forms may be included in the document page count, their removal does not represent any loss of content from the thesis.
Conformément à la loi canadienne sur la protection de la vie privée, quelques formulaires secondaires ont été enlevés de cette thèse.

Bien que ces formulaires aient inclus dans la pagination, il n'y aura aucun contenu manquant. 


\section{Abstract \\ Meditations on the Human Condition in an Imperial Age \\ Irina. V. Boca}

The present study proposes a treatment of imperial politics in and through the concept of betrayal. While the European literature on empire projects the imperial experience beyond the unipolar horizon of power, the American approaches maintain a pragmatic, or top-down, view of power. These apparent contradictions, however, seem to work concertedly, deepening, or transubstantiating, imperial power into what might be called a politics of betrayal.

Indeed, betrayal requires a double relationship based on some form of confidence and conceit, leadership and misguidance, trust and treachery. It always involves, or invokes, a politics of the "other"; a politics that is theoretically or pragmatically attributed to friends and enemies (almost) alike; a politics of "seeming" friendly and inimical, seeming Schmittean, or Huntigntonian, by virtue of/or betrayal. In this context, betrayal appears to produce "blowbacks", back-clashing procedures, unintended effects, undesired enmities, undertaken by ghostly and imperceptible "others". To elaborate this problematic articulation of betrayal, it is necessary to slip back and forth between the abstractness of philosophical approaches and the concreteness of current imperial practices, in an effort to overcome the reduction of politics to friend-foe machinations, economics and wars. One conclusion to be inferred from the present study is that the more imperial power relies upon the fabrication of friends and foes, the more such "ghostly" apparitions it produces, succumbing, as S. Zizek would argue, to its own phantasms. 
Understanding the topic of empire is further complicated by several factors. One is that today we are witnessing, as Deleuze and Guattari would argue, a thousand plateaus of imperial advances. There is the rapidly expanding world capitalist system, and with it the globalization of needs and desires, knowledges and powers, languages and images. Another is the military venture, with its warrior techniques and machineries, its ethos, its re-generative technologies. Such imperial forms are no longer simply cooperating or contending, but seem to cooperate by contending, technicalizing, or conquering, both time and space. Another complicating factor is the fact that local support for imperial power rests on a perpetually simulative and yet simultaneously reassuring form of political spectacle, one that seeks to escape the specter of public opinion by molding, conditioning and prompting it to respond to the ever changing colors of threat/indulgent perception. Imperial space appears thus as a space of fabrication and storing, in which politically relevant experiences, or "facts", are virtualized, compacted, stocked and indulged. This constitutes a narrative of power difficult to uncover, but also already uncovering itself in many ways.

Although the present study engages in considerable analysis, the primary approach is a theoretical attempt to escape the strictness of conventional categories in order to keep under scrutiny the subject's integrity, or hypothetical wholeness. Our objective was to gain an understanding of the "big picture", complete with its complexities, its mundane nuances and metaphorically lucrative shapes. 
Table of Contents

(Pre)Face. 1

Chapter 1

The Others: from Things to Frameworks. 17

Chapter 2

The Complexity of Space 36

Chapter 3

The Spectacle .57

Chapter 4

The Concept of Empire. .73

Chapter 5

Inducing Negativity

Chapter 6

Storing and Fabricating the Real.

Chapter 7

Thinking the Fold.

Chapter 8

The Double 155

Chapter 9

De-doubling, De-structuring, De-composing the Real......168

Chapter 10

Knowledge of Practice (or the sameness of the same)......187

Chapter 11

The Practice of Knowing (or the chicken and the egg).....210

Chapter 12

The Narrative of Power (or the power of narration).........229

Chapter 13

The Truth About Friendship.

Chapter 14

The Idea of the One: time and space revisited .269 


\section{Chapter 15}

(dis)Placement and (trans)Figuration...............................286

Chapter 16

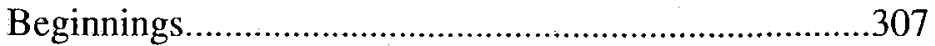

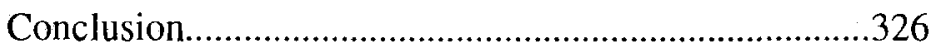

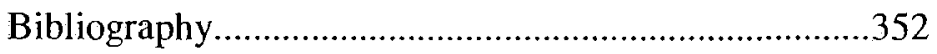




\section{(Pre)Face}

It is highly unlikely that we, who can know, determine, and define the natural essences of all things surrounding $u s$, which we are not, should ever be able to do the same for ourselves - this would be like jumping over our own shadows.

\section{H. Arendt}

There is a vast literature documenting the workings and aims of empire, its future versions and former realistic undertakings, its ideological metamorphoses and theoretical escapes from the modern imperial specter, as well as its underlying aim at bringing humanity to bear under one dominion, or one political formula. Within the literature, imperial approaches spawn from Huntington's vision of perpetual clashes among civilizations (with its Hobbsean and Schmittian origin) to post-modern theories of a spectral, or incorporeal, imperial presence (with its Heraclitean and Nietzschenean roots). Empire appears thus as a morphing background indebted to perpetual clashes, or perpetual peace, in a formula that shifts continuously from an imperial center to a two-headed imperial presence (American and European), to a triad made up of a doubly-articulated sovereignty and a potential war-machine, or to a multilateral form of domination based on networked power. Whether one takes seriously the American realist paradigm, or one delves into the depths of such a paradigm, unveiling Zizek's resolve of a "colonization of the living by the phantasmal", J. L Nancy's piercing of the imperial picture by its hidden esprit de corps, or Derrida's gift of death as a re-jointing of the imperial specter, one is still left with the most puzzling question of our time: what is empire? Is it the practice of mobilizing friendly and inimical forces in a war against terrorism, or the terror that haunts us via friendly/inimical ghosts?

In the present thesis, I will sketch out the essential traits of empire by taking into

${ }^{1} \mathrm{H}$. Arendt, The Human Condition, Chicago: University of Chicago Press, 1958, p. 10. 
account both the American and European literatures on imperial constitution, their intricate and often times controversial roles in regards to imperial practices and discourses, as well as their involvement with an essentially imperialistic "politics of betrayal". Here, betrayal will not consist of a mere breaching of a contract, or a speculative bond. Instead, my main contribution to the field of political theory will consist of a treatment of betrayal as the breaching/bonding discourse and practice that situates itself at the very heart of empire - as the constitutive imperial genre par excellence.

The most controversial example of betraying/loyal practices encountered in the literature on empire gravitates around the absence and/or presence of the imperial "other", which, in turn, appears breached and bonded by the panoply of approaches to the question regarding its role. Within the American literature, the imperial "other" is treated as a subject retreating from power (e.g., R. Kagan, C. Weber), as an essentially anachronistic and performative presence (J. Butler), or as an imperial subjectivity indebted to power (I. Wallerstein, M. Ignatieff). The "other" retreats from, performs, and indebts itself to power in such a way that power discourses and practices, in their turn, appear circumscribed to its indelible trajectory. Within the European literature the imperial "other" appears as a multiplicity that can be framed as an external/hidden articulation of power (G. Bataille, G. Deleuze, J.L. Nancy), as a visible/familiar face of power (J. Derrida, M. Foucault; J. Kristeva), as a challenging specter (E. Levinas, P. Virilio), or an absence of power (A. Badiou, J. Baudrillard). The "other" neither retreats nor indebts itself to power by moving along a familiar trajectory, but rather enters into an evasive relation with power.

Viewed from both perspectives, the imperial genre is not only a matter of betraying and saving friends and enemies alike, but also of involving them into such a colonizing, betraying, return. As such, it involves a colonization of the real by the betrayed, not by the phantasmal, as in Zizek, nor by the mad, as in Foucault, but by the betraying specters of phantasms and madness, friendships and enmities, peace and violence. It is a recurrent 
movement, or cycle, whereby betrayal colonizes and de-colonizes, or rather colonizes by de-colonizing, the real.

To such a universal, or universalizing, "regime of betrayal", Deleuze and Guattari oppose a double betrayal, a double turning away from realist (despotic-paranoid) and postrealist (authoritarian-passional) regimes, or regimentations. They propose two lines of flight, or of approach, which remain tangential to the two regimes, while also departing from them along an unfaithful destiny or an Oedipal retreat, both of which come together in the absence, or postponement, of violence and death. While I am aware of their folding strategy as a signature to post-Hegelian, or even post-Heideggerian, imperial constitution, I dare push things even further, into a less foldable horizon, whereby the universal regime of betrayal rests not only on escaping routes and returns, which are still neo-Kantian, but also on the possibility of de-routing, or de-touring these lines of flight by making them stand their ground.

Z. Bauman (among others) employed the metaphor of liquidity as opposed to modern embodiments of innocence and aggressiveness, proposing a fluid imperial presence that oversees the exodus of humanism from its technological, economic, and globalizing milieus. Deleuze's and Guattari's war machine, Virilio's mass-machine, even Bataille's clear consciousness, could be reduced to such a liquifying strategy, whereby the constant production of a Heraclitean "world in flux" turns the meaning of empire into an empire of meaning, more precisely, into a machine computing its own possibilities and deaths, its own contexts and categories, of being, or becoming, human. This is the canonical space of modern economy, the space of M.Weber's industriousness leveraged by man's struggle to overcome both his fall into technicality and his simultaneous ascent into humanism. Herewith, empire is demonized and idealized, constantly turning into both a terrifying Leviathan and a saving ark. 
My point here would be that, while empire seems to work simultaneously as a betraying and a saving specter, as an emptiness as it were, or an absence, imperial discourses and practices betray and save such an elusive, or absent, specter, by virtue of which everything appears indebted to betrayal and to its saving effects. The post-modern theme of postponements, delays, absences, or alibis, works as a double-articulation - a double engagement with and betrayal of dialectical apparatuses - but also as a clearing away, a forgetting, or postponement, of betraying/loyal practices and discourses. It is not so much an imperial theme as it is a non-theme, an imperial exodus enacted through the suspension, or postponement, of all themes - i.e. through the promise of a return "home", or through the mechanisms of promising and betraying a home cleansed of all imperfections, or of all possible betrayals.

Whether this unprecedented movement away from imperial genre, or imperial practice, could be thought of in terms of a revisitation of old themes, or of an understanding of the role played by betrayal in both theoretical and practical matters, is beyond doubt, but also, somehow, doubtful. Perhaps the best way to approach the imperial webbing of morphing genres and practices is to "stand one's ground", in a clearing of an all too familiar, but also an all too distant, encounter with what is coming by having already passed, that is, not by wondering around in Oedipean despair (even though it seems inevitable, or precisely because it seems that way), nor by flirting with an unfaithful destiny, but rather by avoiding these lines of flight, or fleeing sequences, by virtue of which different regimes of power install and sediment themselves, producing and reproducing a world pierced by despair and betrayal and saved through the clones of an Arcadian happiness and loyalty.

Could such an approach be situated among other approaches to imperial constitution? To the extent to which all approaches to the question of empire are strategic approaches, loyal and disloyal (in one stroke) towards its violent constitution, the present 
approach could not be situated in the "freezing" zone in which loyalty and disloyalty operate in carefully drafted tandems, nor in a zone in which duplicity dissolves itself carefully, drafting its absence as a presence endowed with the attributes of betrayal and of loyalty, but in the simple understanding that empire is and is not what it seems to be - i.e., a Heraclitean world in flux - that it itself opens up a zone, a path, or a territory, beyond the maze of betrayal and of loyalty, in the clearing of what might properly be called an imperial exodus from the present state of affairs.

Standing one's ground begins then with what might be called, following S. Weil's terminology, a graceful gravity, or an anti-gravitational conceptualization of empire, in which the emptiness and fullness of concepts loosen their meaning, their semiotic or categorical weight, even their seductive appearance, in favor of a less authoritative, less ideological, undertaking. A line of flight (or of approach) which bends continuously, unbending itself as it were - much in the sense in which Levinas speaks of a being-for-theother, except that now the other is everywhere: i.e. caught in an authoritative-passional circle, in a despotic-paranoid regime, or in a flight from both, oscillating between the two as a strategic, or sacrificial, articulation. It is not so much a geometrical triad that one must escape, or a gravitational fall eased by anchoring on lighter bodies, but the very notion of escape - its imprints and echoes hovering around as if in a doomsday scenario, whereby the beast of pray transpires not only as the apogee of nihilism but of ideology as well; whereby the gravity of concepts melts into a fluid night-watch vigilance; or the practice of knowing how things come into existence and disappear, turns into a magician's performance. Where, or how, does the concept of empire fit in?

The Universal convulsing on its own degrees of escape (from itself) - that might be a good definition of empire. The daily crises, the rubrics of death, the idyllic images of a home... A trail of passions and fears, a remarkable re-make not just of a dozen movies, but of a universal studio, as Coppola remarked, putting a sign of equivalence between dreams 
and American film-making. Whether one reduces empire to the thin pellicle of dreammaking, to the happiness projected and transmitted via propagandistic venues, to the industrial-militaristic complexes, or to the mass production of truth and power; or one explodes the same reduction into Hollywoodean economics, whereby happiness has a fluctuating price attached to its image, into a militaristic embargo of industries and of nomad bands, or into commodified discourses and practices, the same outcome seems to daunt us: empire reduces and expands all given milieus, it miniaturizes itself by expanding the world, and expands itself by miniaturizing the world. The Borgsean miniaturization of the world (so well, or too well, portrayed in the movie The Great Dictator), which contains everything by making it fall out place (or by reducing it to a fall), coincides with a vision (or a reality) in which all things are returned to the places from which they had fallen. It is in this context that $S$. Weil's anti-gravitational reasoning begins to make sense, working its way through a fallen world of thoughts and industries, spirits and bodies, loves and empires.

The post-imperial evasion from the "graces of reason", often times equivalent to the reduction of the concept of empire to post-imperial practice, or the other way around (G. Agamben, A. Negri), entertains such a "gravitational tandem" by virtue of which it becomes possible to think of empire in terms of betrayal and loyalty (or theory and practice). Herewith, the two faces of power begin to gravitate around their own axis as it were, attracting and avoiding one another along a path that hides and reveals itself in and through a multiplicity of graceful/evasive gravities (i.e. the circular motion of Greek timeliness, the Christian unilinearity of time, the broken line of the present, or the doted line of things to-come).

By placing "betrayal" at the heart of empire, one also places it in a direct relation with its "saving" counterpart, each working as an escape from and return to the gravity inherent in "falling bodies". An interception of such falling/fallen bodies involves an 
understanding of their former status, but also an implication of status in or with the depth, or specter, of falling and returning: i.e. with the way terrorism is enforced in our days as a constantly returning threat.

To a certain extent, Derrida's "specters" and "ghosts" imply such an imperial (recurring) status, whereby it becomes possible to envision an approach that does not fall, nor does it ascend or return to itself, but uncovers itself as such, amidst other accounts of imperial formation. Whether one folds betrayal on a vertical axis, spells it out along a horizontal axis, or duplicates it along both, the outcome seems to be the same, namely, the turning of betrayal into the motor, or esprit de corps, of everything else. To avoid such a universalistic approach to betrayal, I propose a treatment of the subject from the perspective of an already folded specter, from the perspective of a completed fall as it were, or composition, which permits the assessment of betrayal in its gravitational contexts and habitats, as well as in its fleeing appearances. Methodologically, all approaches (whether theoretical or pragmatic) to the subject of empire engage with and flee the imperial paradigm, folding and making it shift from one form of appearance to the next. The Heraclitean empire is perhaps an illusory formula for what sinks underneath the luster of appearances, or it may as well be the escaping formula from such sinking depths, or both. As such, it situates the question of betrayal in relation to its appearances, its depths, and perhaps to a possible uncovering of itself.

Betrayal always requires a relationship, some form of seduction or gaining of confidence. As such, it involves leading and misleading, trusting and treachery, faith and deceit, belief and disillusionment, affection and infidelity, all of which may be thoroughly unconscious, even unintended. Despite the fact that betrayal is continually present in every complex human political order, it appears that empire presents the clearest case of a politics of betrayal. What is a politics of betrayal?

$\mathrm{A}^{-}$genuine politics of betrayal is not a politics of befriending or hating the other, 
much less of seeming to befriend or hate the other; it simply is a politics of the other, or a politics of otherness. A politics of betrayal is also a politics of collaboration with the other (which is a form of betrayal of one's own), a politics of betraying by collaborating with friends and enemies alike. One traces here the possibility of escaping the friend/enemy divide by becoming friendly and inimical to such an extent that friendship and enmity may appear quite indistinguishable within a politics of betrayal. One may speculate that every regime of power produces its characteristic forms of betrayal, its politics as betrayal, or knowledge of betraying friends and enemies. Differently put, every regime of power appears to us as a regime of betrayal insofar as its politics and knowledge claims betray it in order to become, or to return to, what they are.

A politics of betrayal is always a politics of the other, the other of power, the other of knowing-as-power, but also the other of politics - power-as-knowledge? Politics as the other of power, as betrayal of power, or power of betrayal - this is precisely what defines the other. Passing as the other means passing as the truth of betrayal, as the betrayal of truth, but also passing as the political par excellence (i.e., as a politics of politics).

This is the primary contribution this dissertation seeks to offer to advance the literature on empire: the treatment of imperial politics not merely as a necessary ephemeralization and incarnation of friendly and inimical divisions (which of course it is), but more essentially as a politics of betraying all such ephemeralizations and incarnations of friends and enemies, as a genuine betrayal of a politics of collaborationism and divisionism. Betraying must arise as an act of politics before it can ever become a condition of truth. It is power, or a regime of power, betraying its own knowledge of itself, its own economy - its own.

As R. Sanders suggests: "a false reason or motive put forth to hide the real one," is often inciting, instrumental, conceived as mere means to an end. However, when the boundaries between means and ends tend to disappear, one is in danger of recapturing 
them through some intrinsic, or overarching, pattern. The world's military-industrial complex is perhaps a fair example of the scale within which such an evanescingrecapturing drive operates: "over the millennia, although weapons and battle strategies have changed greatly, the deceitful stratagem of using pretext incidents to ignite war has remained remarkable consistent". 2 The corporate media themselves go 'out of bounds' to ensure the success of propaganda, and politicians, to be sure, "rally people around the flag, lending their special oratorical skills to the call for [a military] response". ${ }^{3}$ The falsity of the motive plays itself out in the very motivation, or drive, to 'go out of bounds', to pretend, patternize, militarize, not only the reason hidden behind the fabrication of pretexts, but also the fabrication, or the pretext itself. As Heidegger conveys: "wherever ends are pursued and means are employed, wherever instrumentality reigns, there reigns causality.... But suppose that causality, for its part, is veiled in darkness in respect to what it is?"4 Perhaps the answer to this double-edged question is no longer a theoretical matter of causality, nor of the darkness that surrounds it, but of a blurring of their boundaries, which both effects and affects its own questions and technologies, its own pretenses, or its own veils.

What sets the $20^{\text {th }}$ Century's literature on empire apart from earlier imperialistic genres is the universal tendency to become both the norm and the exception, the structure of meaning and the attempt to escape from it, the category and its vanishing margin - in a word, its tendency to become a matter of practicality, an imperial practice, an empire in and of itself. In post-modern thought there is no singular category, and no singularity that could be attributed to imperial categories, except this precarious coexistence of content and form, concreteness and utopia, acting and thinking, all making up the universality of

${ }^{2}$ R. Sanders, "Going to war: Unraveling the Tangled Web of American Pretext Stratagem (1846 - 1989)", COAT (Coalition to Oppose the Arms Trade), issue 50, Jan. 2003.

http://coat.ncf.ca/articles/links/how to start a war.htm.

${ }^{3}$ Ibid.

${ }^{4}$ M. Heidegger, The Question Concerning Technology and Other Essays, New York: Harper Torchbooks, 1977, p. 6. 
imperial thought and practice. There will nonetheless remain some categories just as long as there are attempts to escape these categories' authority, their certitudes, their abstractness, or as long as these escapes represent a return to the fixity and certitude of categorizing. The real is such a category before escaping, or escape before categorizing, which is to say that it is both a form of category and an effort to escape from such categorizations as realism and neo-realism, structuralism and post-structuralism, modernism and post-modernism, primacy and anti-imperialism. It is an absence, as it were: a non-categorical imperative, or rather a lack of categories reflected in the imperativeness of categorizing, according to a certain presence, or certain fixity.

The division of categories into absent and present, non-categorical and imperative, fluid and fixed, is also already a non-division, or non-category, one that places such categories initially beyond understanding but also ultimately within understanding, part of it, and partaking in it. To speak of categories implies that one can recognize the possible existence of non-categories, or that he replaces categorical thinking with thinking outside the canons, outside the abstractness of thinking as it were, or outside of the categories' divisiveness. It also implies that one no longer categorizes with respect to the present, but does so with respect to the absent (as in A. Negri and M. Hardt ${ }^{5}$ ), the non-visible, noncategorizable. This is where the continental literature on empire leads, and this is where or how one finds oneself outside the canon, outside of New World modernity, and outside realism. Needless to say, this is also the moment of return, the Nietzschean moment of eternally returning to sameness, to the sameness of category, or of its vanishing interiority.

The present project seeks to capture this moment of vanishing escapes and returns, vanishing alternatives and possibilities, and to show convincingly that they are equally concrete, equally real. This study does not lead towards one alternative, or the other, but develops both, in the concreteness, or ethereality, of their politics and their betraying

${ }^{5}$ A. Negri and M. Hardt, Empire, London/Cambridge: Harvard University Press, 2001. 
narratives. From this point of venture, categories seem truly subjective, truly categorical, but also weightless, immaterial and fluid - they seem to be at once present and absent, dividing and uniting, nihilistic and positivistic, categories of the non-categorical, as it were, of the "intimate", the "invisible", the "anti-gravitational". They delimit the outside from the inside, the apolitical from the political, the friend from the enemy, at the same time at which they make the outside coincide with the inside, fusing the apolitical with the political, and the friend with the enemy. They are simultaneously unifying and dividing, liberating and delimiting, neutralizing and intensifying. This is the categorical achievement of thinking non-categorically and non-politically, the very condition of thinking outside the canon, but also at least partially within it.

To categorize the uncategorizable by making one slip into the other - this is what it amounts to - this is how one categorizes the other in the final analysis: by slipping into it, by becoming it, by striving to liberate itself from it. Whether one uncovers here a psychological space or a discursive space is less important than the fact that these spaces, or realms, already communicate, already "slip" into one another, making psychology into a language and language into a psychological condition, into the very condition of being human, being free, being there. We take as our point of departure this moment of "slippage" from psychology to language, this improbable turning of emotion into speech, or of the subject into a political category (i.e., friend, enemy) devoid of all subjectivity. Psychology and language (broadly construed), politics and speech, subject and emotion, set up the domain of concern, the very domain of new categories and new problematics concerning empire. They set up the non-categorical contours of imperial categories and problematics - the neo-realist contours of the real, the neo-positivist, neo-conservative, neo-liberal, neo-democratic, contours of positivism, conservatism, liberalism, democratism, realism, idealism, interventionism, hegemonism, isolationism, imperial primacy, anti-imperialism, and so on. 
These are nonetheless the new categories of the non-categorical, the boundaries withdrawn from things at the moment when they fall back upon themselves in the open space of empire. This withdrawal is also a joining in, joining forces, joining in essence, which is to say that their imperative is not disappearance, withdrawal, or death, but life and essentiality, affirmation, love. This Spinozism without Spinoza, this attribute without being or without essence is also in being, essential, categorical - it restores itself by betraying its own space, its own categories, but also by returning to it/them as if to an essential life of truth, to an inner dimension, or inner space of space. The universality of the categorical consists in its particularity, in its breaking out of uniformity and conformity, or its betraying the imperativeness of being categorical, being essential. It consists, moreover, in the "slippage" of universality into the particular, in their ephemeral or concrete coexistences. Thus the reader will find that this dissertation slips back and forth between the abstractness of philosophical conjecture and the concreteness of current imperial constitution, both of which strive to establish the validity and/or the terms of betrayal of the other.

In truth, there seem to be no real categories apart from the universality of categorizing, apart from the drive to put things into place, to topologize human space and language, human thought and existence. The space of the category is merely the space of the mind, the space of the will, the space of physics, and so on. It takes over the emptiness of existence, filling it with a sense of "trueness", a sense of "belonging" or "proximity". It befriends human existence by turning it into an image, a relation, or a measuring unit. It also betrays existence by distorting all images, all relations and all measuring units, by emptying them of all possible human traces. What obtains is the emptiness of categorizing, of describing and setting up, describing by setting up: a politics of the absent, the inexistent, the abstract. In this way, categorizing falls pray to its own betrayal, or its own lack of truth. The political as a friend-foe divide falls prey to its own lack of friends and 
foes. It falls prey to its own setting up (of itself) as a friendly and inimical specter of the Real. In this kind of politics the friend is always an enemy at heart; he betrays not by setting-up, but by setting-in, by appearing as the apolitical par excellence. He has no politics, no categorical imperative other than setting-in, setting-by-default. He betrays himself insofar as he turns into an enemy with a friendly heart, into a mirror image of a politics of friends and enemies.

The friend becoming an enemy and the enemy turning into a friend is possible only if one holds an Archimedean mirror through which love is made to reflect hatred (and viceversa), distant things are made to appear close, or the planets are imagined to evolve inside a mechanical planetarium. It is an optical illusion, a reversal which seems to work only insofar as all friends are turned into enemies, all proximity turned into distance, and the entire cosmos is reduced to manageable dimensions. This sounds so familiar that it no longer makes any sense to invoke antiquity to remind ourselves of who we are, or who has preceded us in the task of keeping friends close and the enemies at bay, for we have fallen out of time, out of its continuity and friendship. This falling out of time, falling out of love (in the sense in which Derrida ${ }^{6}$, or even Negri, speaks of $\operatorname{love}^{7}$ ) is also a falling in love, a non-categorical, non-categorizable, falling in, falling for - a seduction.

Tracing the political implies the tracing of this subtle, immaterial, almost fluid line of seduction, the line of falling in and out of love, the line of the non-categorical and nonuniversal. It implies the tracing of categories to their impermanencies, their dislocations, or their essence: the untimely, the emotional, the subjective. The specter of the political is this conjoining of impermanence and untimeliness, dislocation and emotionality, essence and subjectivity, whose presence invokes the grand contour of empire, but also its already

\footnotetext{
${ }^{6}$ See J. Derrida, Speclers of Marx, Routledge Classics, New York \& London, 2001.

${ }^{10}$ See A. Negri, Time for Revolution, New York: Continuum, 2003.
} 
ephemeralizing ethos. It is an apparition that might be called post-imperial, post-colonial, post-political - a ghost, as Derrida would say, of the imperial, the colonized, and the apolitical.

Throughout the thesis, the political is unveiled according to this ghostly presence of the apolitical, the spectral, the non-categorical, which is to say that it is also unveiled as their incarnation, their inescapable trap, or inescapable specter. A politics of betrayal is a powerful generative force, creating its own shadows and ghostly apparitions, its own rules of generation and power, which, if reinforced, create not a virtual, but a real effect, such as that of a movie projected on the walls of a hall full of mirrors. As we shall see, this effect has discernible consequences in and for the constitution of the new empire: the more one relies on a politics of betrayal to manufacture the economic landscape of empire, the more ghosts are likely to be produced. As the saying goes, what goes around comes around perhaps it does, but now the ghosts of imperialism include suicide bombers and pilots who learn how to fly but not how to land.

The possible and the impossible, the present and the absent, the ghostly and the spectral - these are the guiding traces of the political, the categorical envelopes falling out of place and out of time, but also the ethos, or esprit de corps, of unveiling their falling back into places and times.

Chapter One outlines the passage of otherness from things to frameworks, the passage whereby the imperial world transforms the body of the other into an indelible ghost, a simulacrum, or a war-machine, occupying the entire space of empire.

Whether it involves itself in a 'Cold War', a warm war, or a 'Long War', imperial power revolves in space as much as it revolves in time, disclosing and (en)closing the very possibilities, or coordinates, of its own constitution and destitution. This is shown in Chapter Two.

Chapter Three advances the premise that support for imperial power rests on the 
perpetual production and reproduction of a psychologically reassuring political spectacle. Since the continuity of the imperial realm cannot be entrusted to the arbitrariness of public opinion, it becomes necessary for the government to influence and mold this otherwise potent democratic force. In our age, the result is the fabrication and perpetuation of the political as the arbitrary, oftentimes highly entertaining, spectacle of an equally arbitrary and entertaining imperial constitution.

Chapter Four traces two contending forms of imperial constitution. The first is a unilateral imperial domination that rests on the projection of an imperial center, a fairly classical form of imperialism; the second is what A. Negri and M. Hardt call Empire, that is, a multilateral and non-state-centered form of imperial dominance, based on treaties, international regimes, interlocking institutions, and instantaneous forms of communication, data and money transfers, and nomad corporations. Essentially, this is the currently globalizing capitalist trading system.

The coexistence of two partially cooperating but partially contending imperial forms leads to the current lack of a clear history of empire, or of a proper constitution of empire, which in turn, permits the construction of a history, or a constitution, solely based on negativity, or on the negation of a 'lack of history'. This is presented in chapter Five.

Chapter Six portrays imperial space as a space of fabrication and storing, in which everything is virtualized, compacted, stocked, in infinite versions and alternatives of an imperial reality indebted to the presence of the virtual. Chapter Seven seeks to uncover this imperial reality from the perspective of its folding spaces and times. Above all, we note its fluidity. Chapter Eight then traces the double articulation of the imperial constitution to its vanishing horizons and enfolded centralities.

Chapter Nine seeks to uncover the colonizing nature of empire, its de-doubling, destructuring, de-composing drive. Chapters Ten and Eleven serve as mirroring devices set in between knowing and practicing, symbolizing and colonizing, politicizing and replicating, 
all of which constitute the double articulation of imperial constitution.

Chapter Twelve treats this double articulation, or constitution, from the perspective of the narrative of power. Chapters Thirteen to Sixteen explore the possibility of a politics of friendship, of a new ethos of power and of the transfigurations and displacements that may be encountered along that path. The Conclusion is of course just that, a bringing together of each possibility, each alternative, each alternate end and consummation.

Throughout the dissertation, we move continually from the abstract to the concrete and back again, and from the European to American literatures on empire, in an attempt to illustrate that they are not merely complementary, but are both necessary to an inclusive that is, both inside and outside - comprehension of the most important phenomena that have come to characterize our imperial age. In doing so, we have not sought to break either literature down into neat little categories, for our objective is to gain some understanding of the big picture, complete with its complexities, absurdities, and of course its ghosts. 


\section{Chapter 1}

\section{The Others: from Things to Frameworks}

Yet what word but 'empire' describes the awesome thing that America is becoming? It is the only nation that polices the world through five global military commands; maintains more than a million men and women at arms on four continents; deploys carrier battle groups on watch in every ocean; guarantees the survival of countries from Israel to South Korea; drives the wheels of global trade and commerce; and fills the hearts and minds of an entire planet with its dreams and desires.

Michael Ignatieff

The empire submits from the start to the primacy of the real order. It posits itself essentially as a thing. It subordinates itself to ends that it affirms: it is the administration of reason. But it could never allow another empire to exist at its frontier as an equal. Every presence around it is ordered relative to it in a project of conquest.

Georges Bataille ${ }^{9}$

The above quotations are far from arbitrary. They are not symbolic, since they do not allow poetry to elevate the burden of gravity inherent in the movement of thought, nor are they true, in the sense in which living thought, thought qua thought, seems to be true, or at least indebted, enamored, involved with the trace, the arrow, or even the corporeality of truth. And yet they have an aura of truth. As a matter of fact, they open the real before our eyes, and they do so through the silence and distance of writing. From the start, we submit to their primacy, to the truth commensurate with the weight of Ignatieff's and Bataille's words. It is not "empire" that subordinates itself to the administration of truth, but thought itself, our thought summoned by the thing called "empire", summoned, in all sincerity, by the incorporeal and utterly incommunicable ("taboo-like") spirit of imperialism, which also has a name, an incontestable materiality perhaps, or an (in)convenient way of opening up and codifying the real.

\footnotetext{
${ }^{8}$ M. Ignatieff, The Burden, http://ars. userfriendly.org/users/read.cgi?d=19836\&tid=73409.

${ }^{9}$ G. Battaile, Theory of Religion, New York: Zone Books, 2001, p. 66.
} 
It matters little whether we call it "language", "utopia", "myth" or "science". It matters even less whether we attribute to it the progress of humankind or the regresses of human consciousness, for it is certainly not a "thing" that we speak of, though it leaves its trace in all things, nor is it an imperial presence without also being an absence, a void uncovered consciously and profanely through the silent pilgrimages of thought. True, this is the mysterious voice of poetry, the voice expelled from the amphitheaters of truth, where there is only seriousness, pious quietude and servitude entangled in the human act of thinking and summoning the unknown. It is also the voice of the human heart, or rather the very possibility of thinking about having a heart in the first place.

Perhaps, in our imperial age, there is no longer anything serious about poetry, no unconquerable sensibility, or any particularity of vision. Perhaps there is only boredom, and at best only silence. In silence sentimentality is overtaken by the desire to know more, to move beyond the object of desire, beyond the "thing" that has already been placed in the order of truth, as truth. To move beyond thinghood, to move towards something else, towards another object, or another desire - this is the driving (imperial) principle, the principality or primacy of being driven, acting, at first glance, as a simple law of attraction between object and desire. It is a law that disquiets us and moves us to action, to the turning of disquietude and law into desirable dismissals, desirable negations of things and drives, desirable desires of becoming - once again, or all over again - subjective, subjected, subject.

G. Bataille, like A. Kojève ${ }^{10}$ before him, hoped that self-consciousness, clear, affirming consciousness, could transcend the given - not man, but the indelible specter of his religiousness; not his biological heritage, but the burden of turning its depth into history; not his (in)human affairs, but the irreconcilable condition of being the unconscious "I" of negation. To them, it mattered less whether it was the tool that expelled man from

\footnotetext{
${ }^{10} \mathrm{~A}$. Kojève, Introduction to the Reading of Hegel, Ithaca, NY: Cornell University Press, 1996.
} 
the animal world, or his desire of another desire. What mattered most was the expulsion as such, expulsion as violence, as history, as inalienable given.

What does it mean to say that "empire" excludes the possibility of the rise of any other hegemonic power, and that its most basic project is conquest? These are not mere suppositions, but are clearly defined objectives of current international foreign policy, current imperializations of hegemonic ghosts, or current political stakes in which exclusion and inclusion complement and articulate each other in an exceptionally volatile way. As S. Huntington seems to suggest, "empire" is but another name given to the primacy of "democracy" and "economic growth", both premised on an apparent inclusion of exclusive policies and powers. He writes:

A world without U.S. primacy will be a world with more violence and disorder and less democracy and economic growth than a world where the United States continues to have more influence than any other country in shaping global affairs. The sustained international primacy of the United States is central to the welfare and security of Americans and to the future of freedom, democracy, open economies, and international order in the world. ${ }^{11}$

In a manner very similar to Simone Weil's repudiation of gravitational law, G. Bataille and A. Kojève argued that if desire is to be directed towards a violent "non-I", the "I" too, will become violent. They both agreed that violence by itself could not transcend the given, that it merely reproduces its abominable content: the animal eating another, the shocking condition of either devouring or being devoured by the other. Broadly construed, human sacrifices, rituals, wars, states, industries, embodied and disembodied violence by veiling and unveiling the given, by turning it into a simulacrum of violent procedures into a primitive mechanism (sacrificial, ritualistic, statal, etc.) of dying and/or surviving.

Is the simulacrum less violent? Has the consciousness of simulation changed the violent content of the given, or at least its form? Did man transcend the animal condition,

\footnotetext{
${ }^{11}$ S. P. Huntington, "Why International Primacy Matters", International Security, Spring, 1993, p. 83. See also Z. Brzezinski, The Grand Chessboard: American Primacy and Its Geostrategic Imperatives, New York: Basic Books, 1998, passim.
} 
or did he remain caught within it, longing for something lost? Was this a yearning for what Freud discovered in the early stages of human life, namely, "a tendency" that arose in order to "detach from the ego anything that may give rise to such unpleasurable experience, to expel it and so create an ego that is oriented solely towards pleasure and confronts", ${ }^{12}$ an ego struggling against the "alien and menacing world outside"13?

Is man still torn between the manufactured tool and the animal world? Does he consider life within the animal world as nasty and shortish for brutes? Is he moved by his desire to be different? Is he moved by his torment or by his detachment from the nastiness, brutality and shortness of a life that is given to him undesirably and unknowingly, as if in an inexplicable moment of undesired rage?

Does he let himself be torn apart so that he may be? Does he let himself be so that he may be no longer? Can he accept this compromise as the very condition for the possibility of his thought, his life, his love?

Last, not least, is he going to break with the animal world through this simulation? Is he going to postpone devouring the other or let himself be devoured by it? In the imperial age such questions become poignant, recursive, inescapable.

Without a doubt, such a hypothetical exercise compromises mere thought, indeed, that line of flinching thought through which man manages to break with the animal world by simulating its absence, which is also a simulated "non-violence", a terminal point, a moment when the eaten animal is no longer alive and no longer sustains the violence of the eater, but rather its immutable being, the ephemeral tranquility of a life obtained through the sacrifice of the other, or through its after-life.

The despair of the thinking man, of the one who comes close to being torn apart and/or being absent, is not so much that he is torn apart but that the entire world must be

\footnotetext{
${ }^{12}$ S. Freud, Civilization and its Discontents, New York: Penguin Books, 2004, p. 5.

${ }^{13}$ Ibid.
} 
torn apart and suspended in the tranquility of life. Through despair, clear consciousness transcends the condition of life. It also restores to life the sadness of its death consciousness, at the same time at which it plots to postpone its own death. Its desires, its tools, its childishness, all postpone its immutable and inevitable death. Sometimes they appear as frail and insufficient evasions, sometimes they seem manageable and inoffensive accidents, but they are always virtually so, always paradoxically, following a trajectory of estrangement and familiarity, a concrete and ungraspable ideal, or an unrecognizable trace of desires and fantasies. ${ }^{14}$

Perhaps the tragedy of life is not so much that it cannot be justified, or that one could not come to terms with it unless he dies (virtually), but that there is only this justifying urge, this precipitous dying, or rather this urge to die precipitously, urgently, virtually. To die by postponing the very possibility of death, to live in the suspension of life, is to be dead already: pure suspension, pure consciousness, pure being. There is no beginning and no end to this purity of being, for to begin and to end there has to be something other than it, something which has already begun before it and will have already ended after it. Perhaps on the heights of despairing, one could only whisper to himself: "he who has not suffered from knowledge has never known anything...". ${ }^{15}$ But what is there to know? What to suffer so that one might know how not to begin and not to end knowing?

To transcend the given by divining a thing, indeed, by becoming a thing outside oneself, or by desiring not a thing but a desire desiring the same thing, is to remain within the animal horizon, outside its origins, but within it, longing for that which is neither a thing, nor desire, but origin - non-accidental, non-trivialized originality.

The unexplainable lies at the root of life, to be known and recreated outside itself, not in the void of nothingness from whence it came, but in the void of life, to which it stands

\footnotetext{
${ }^{14}$ S. Žižek, The Plague of Fantasies, London and New York: Verso, 1997.

${ }^{15}$ E. Cioran, The Heights of Despair, Chicago: Chicago University Press, 1992, p. 125.
} 
opposed. "Avraam gave birth to Isaac, Isaac gave birth to Jacob, Jacob gave birth to Judas...". Each chain of being reproduces its origin through the event of naming, indeed, through the event of replenishing the authority and authenticity of that which no longer exists, but which continues to deliver life, to reproduce it in such a way that giving birth (or naming) becomes, as in $\mathrm{H}$. Arendt, equivalent with the act of creation. Or it may be as in $M$. Foucault, where the genealogical reproduction fills the beginning with a sense, with a movement, or a raison d'etre, which then becomes the phantasm of the present, the genesis of the (post)modern man revived through the genealogical chains of social life.

Perhaps there is no language available to giving birth proper. Perhaps language attaches itself to the event of reproduction in the order of things, manipulating this order outside its origin, but always towards it. Perhaps language takes the form of command, or of persuasion, and reproduces the renewal of life outside the event of renewal, but always with the aim of authorizing it, always placing on it the mark of beginning, of originality and of destiny. Death and violence are summoned by this event of origins, they are reproduced in man's language, in his destiny, or his memory. They are reproduced in the tension between the nastiness and shortness of life and the Arcadian dream of eternal bliss, between the inescapability of death and the inescapable condition of longing indefinitely for the loss of something other than language and destiny, other than becoming language and destiny, command and obedience, persuasion and following. In this ethereal dialectic lies the relationship between imperial power and those whom this power subjects, either by idealizing or betraying them, by privileging or offering them the gift of death.

Ordinarily, man puts himself into language as incorporeal destiny, he understands his destiny through the presence of language, which he reduces to signs, symbols and symptoms. He reduces himself to succession and duration in an attempt to reconcile the loss of origin with his survival outside of it, in the inexplicability of existence, in the repetition of the act of living as a continuous revival of something lost, of something that 
needs to be recuperated or to which he must return. In truth, he tends to dismiss that (e.g., language, object, being) which does not facilitate his return to a desired origin, and which keeps him prisoner to a platonic world of joyfulness and fright. He is inclined to reduce his subjectivity to the mourning of this loss, to the very essence of losing, or having lost, something or someone. However, as D. Bohm reminds us, this is but a limitative projection set against the very texture of being - of being actual, being human:

In a deeper and generally more suitable way of thinking, each of these elements is a projection, in a sub-totality of yet higher 'dimension'. So it will be ultimately misleading and indeed wrong to suppose, for example, that each human being is an independent actuality who interacts with other human beings and with nature. Rather, all these are projections of a single totality. As a human being takes part in the process of this totality, he is fundamentally changed in the very activity in which his aim is to change that reality which is the content of his consciousness. To fail to take this into account must inevitably lead one to serious and sustained confusion in all that one does. ${ }^{16}$

In the darkness of his mourning, man (re)discovers, or rather remembers, his condition. He recognizes himself as the simulacrum of nature, of society, of god: the simulacrum of a simulacrum, the inversion of exteriority as well as the extrusion of interiority. Interiorizing and exteriorizing appear to him to be the same by not being the same with disappearance and appearance, with their thrust of similar and dissimilar flows, with their consuming tendencies or their distinctive temporalities. The imperial economization of similar/dissimilar couples (as in S. Žižek's work ${ }^{17}$, for example) comes forth as the new order in which man finds himself caught between death and eternal bliss, or between eternal damnation and life after death. He finds himself caught between an economy of death and an economy of eternal bliss, between language and destiny, damnation and immortality, inside and outside.

The reconciliation of death with bliss, or of damnation with immortal spirit, which is present not only in primitive rituals, but in subsequent rituals as well, simulates a "natural"

\footnotetext{
${ }^{16}$ D. Bohm, Wholeness and the Implicate Order, London: ARK Paperbacks, 1980, p. 210.

${ }^{17} \mathrm{~S}$. Žižek, On Belief, London and New York: Routledge, 2005.
} 
equilibrium between consummation and expulsion, between that which is dead and that which is alive by virtue of mere consumption. The one who lives is expelled from the order of death insofar as he himself expulses something into that order by consuming it. Man could not eat another man, but he could deliver his fellow men to death as a substitute for a life-giving substance. He could only simulate a consumption that is no longer corporeal, no longer necessarily real: a virtual consumption of his own death, which becomes an indefinite postponing of his own disappearance, his own misguidance or his own bliss.

The (in)corporeality of consumption is transferred to the dead body, to be further consummated by death, at the same time at which the living man is expelled from death and thus remains free to retain his own corporeality. The order of things and the human order intertwine at the level of the body, they are drawn together in the cycle of life and torn apart by the mysterious economy of death, that is, by an unintelligible design originating outside the body, in the darkness that presupposes it. The presence of death is always equivalent to the presence of life, they both consume and expulse one another by changing places in the fabric of reality. Man is consumed by or expulsed from death on the condition that his life becomes the force that embraces or transcends death's design - a tribe, a state, or an empire. ${ }^{18}$

Man's life turns into a general economy of the body insofar as he manages to postpone death, and it becomes a particular economy of death as soon as the body crosses the threshold of moral life by taking another life. Human sacrifices attest to this, religion in general attests to the presence of life as the answer to an economy of death, as the opening of a path that leads from the economy of the soul to its saving body: the warrior, the priest, the man of action. None of them can abolish death, but they can postpone it by uncovering and reproducing its design. By being the emissaries of death, they may protect life - they

\footnotetext{
${ }^{18}$ Empire relies on this relation between man and death, and thrives on it, or rather incarnates it by revisiting and replenishing its terror.
} 
may strike a balance between life and death, order and chaos, world and nature. As agents of death, anything less than their destiny, less than their own death, will lack the power or rather the privilege of permitting them to live the true life of freedom. Through them one uncovers the viciousness of life (be it religious or secular), that is, of a death attempting to abolish itself through an intimate economy of killing bodies.

War is such an economy of killing bodies, of willing, sacrificial bodies set against death by death itself as it were. The contradiction inherent in it (abolishing death by death), appears to be non-economical and non-sacrificial - it simply makes war into a ghost of death, or a deadly ghost. The war-machine has no limits, no ends except the complete annihilation of all enemies. Raised in between the sovereign heads of political domination, the war-machine becomes a necessary limit to their sovereignty, and also a continual threat to their domination. G. Deleuze and F. Guattari ${ }^{19}$ have envisioned the war-machine as the spatial limitation of sovereignty, but the reverse is also true: sovereignty limits the warmachine as if limiting its own spatiality, its own economy. In this unexpected economization of limits, war must encounter itself not in the death of bodies but in their sovereignty, which is to say that it must itself grow as an economy of sovereign bodies, as a general economy of bodies willing to die for the Machine. In this struggle, the willingness to die is always a potent and a detrimental factor weighting heavily on the scales of imperial constitution, or imperial warfare.

Space itself undergoes the same fall from sacredness (of life) to the profanity of death, from agricultural organizing to the strategic striations of the battlefield, or from an economy of growth to an economy of waste. Perhaps this is the most striking difference between the state apparatus and the war-machine, the fact that one operates in the ordered space of growth and the other in the "smooth" space of waste. The sacredness of the battlefield is similar to the sacredness of an agricultural field, they are not striated in

\footnotetext{
${ }^{19}$ G. Deleuze \& F. Guattari, Nomadology: the War Machine, New York: Semiotext(e), 1986.
} 
different ways (vortical movement versus causal movement), they simply serve different ends, different economies. It is the reversed/reversible operation of this ending/end that striates them differently, subordinating them to the cycles of waste and/or growth. Imperial power fosters both growth and waste, just as a resistance to it fosters them, albeit in a more ethereal manner.

Agricultural activity depends on the caprices of nature, farmers grow their crops by synchronizing natural cycles and human labor, by subordinating the former to the industriousness and constancy of the latter. Similarly, war subordinates the industriousness of states to the smoothness and constancy of battles, or rather to the vortical movements of tactical field operations. The spaces inherited by them differ in respect to a natural direction, not to the regularity and irregularity of their movements, or of their smoothness. Nature can destroy a cultivated field or a city in as smooth a manner as that of war. More precisely, war is space since its aim has always been the conquest of land, the arrest and sudden wasting of its growth. ${ }^{20}$

The numbering number appears to be a smooth measuring unit (of space as well as of time), similar to seeds perhaps, or to compressed space in general. One gets the impression that to transform the seed into a crop, all that is needed is the vorticality of nature, its collaboration, or at least its manipulation through human intervention. Similarly, one is tempted to view war in terms of a numbering smoothness, a doubling number translating the vortical, or ethereal, nature of violence into the smoothness of space (and vice versa). The compression of space due to war is a measuring unit of waste, a double of excess, a metric of availability. It is the opposite of agricultural space, of measuring its growth or at least of anticipating it. Space appears to be both growth and waste, sacredness and

\footnotetext{
${ }^{20}$ To what extent war is nature, is not clear. Perhaps G. Bataille anticipated one answer when he suggested that such a "completed enterprise is an empty framework". Perhaps giving an answer to the question of war, or of nature, is also an emptying enterprise, an inconceivable, superfluous, framework. Perhaps everything we know has already been enveloped by this inconceivability, by this superfluous framing, which is in no way recognizable, or even namable.
} 
profaneness, striation and smoothness, that is to say, an emptiness, a zero - a simple nothing.

In the unfolding of imperial logic, it may appear that to make a decision concerning space implies that one must decide in favor of either growth or waste, that he must decide seriously with regard to a general economy of bodies. It is really a matter of hazard insofar as one has at his disposal the particular economy of the number as a substitute for that of bodies. From this point of view, the war machine is a substitute for space just as religion is a substitute for divinity, they both economize, in an intimate way, the relation between sacredness and profaneness. They economize the relation between space and body, more precisely, between space understood as an economy of killing bodies and the human body understood as an economy of conquered space.

What is the arithmetic of empire? Is it all a simple matter of balancing growth and waste? Such a relation is always reducible to the sudden assemblages of the number: division, multiplication, addition and subtraction. The subtraction that one encounters here compensates for an addition elsewhere. In this way, an imperial economy balances out its operations and its space, and becomes a physics of the body, an inestimable energy. As such, it appears as a generalized economy of space, while it remains caught in the physics of a certain body, or a certain intimacy. Economy, at this stage, is no more than an arbitrary pirating of appearances, a gravitational administration of numbers and spaces - a physics of living and dying, believing and mistrusting, loving and betraying. That is why the imperial decision regarding space is so often uncertain, falling naturally to the merit of chance to favor either life or death. At the limit, life and death become almost indivisible, and so space too becomes a matter of indifference, an empty framework.

Death ends life, but before ending it, it suspends thinking about the end of life. Differently put, death appears as the inevitable termination of life even before such a termination is actualized in the real world. To terminate life in the real world, the real itself 
must be suspended, which is possible, first and foremost, in and through thinking. The relation between death and thought, death and life (which is a kind of death too), appears to us as the most intimate condition of living, the source, if one wishes, of all life. Thought appears to order life in the same way in which life orders thinking - they mirror each other in and through death, in and through an economy of death, which is also an economy of salvation: an economy of space, of growing and decaying bodies, of raising and decreasing numbers, in truth, an economy of animate and inanimate frameworks - a physics of survival against a physics of disappearance.

All such economies already refute life as the inferior condition of something higher, something which turns out to be either a form of death or of thought. ${ }^{21}$ In itself, thought is either pure death or pure life, which is to say that it is also an indirection, an impure life or an impure death by means of which their ideality or purity subsists. Thought creates indirectly by suspending the real and by subordinating it to its intimations, but it does not attempt to destroy reality, for there could be no thought in the absence of everything else. In its attempt to create, thought follows death but only to rescue itself from it (indefinitely). It economizes its existence in such a way as to resist death by dying more than once. Human logic, and more broadly human thinking, economizes death by saving itself from it. In essence, thinking is no more than a practice of dying - again, a physics of disappearance, a design for death, dying, dead(lines). Through this design thought elevates itself to the status of a sacred savior and becomes an immortal god.

The ancients conceived of philosophy as a preparation for dying, a preparation mediating the civic dimensions of life and death in such a way that thought itself never truly lived and never truly died. By contrast, the moderns considered thought as a preparation for living, a preparation in which philosophy ought to mediate all dimensions

\footnotetext{
${ }^{21}$ Perhaps this is one reason why, in respect to America's current involvement in Iraq, no one is seriously attempting to count the costs in terms of the deaths of the Iraqi victims.
} 
of life and death in such a way that only thought could live and die. Post-modernity uncovers the paradoxical nature of thought in an effort to rescue it from its own absurdities and contradictions. It makes an effort to rescue self-consciousness by freezing it, by moving over and around it, into the clearing of the future. Post-modern man absents the world by virtue of an almost omniscient presence. He too, is an expression of his time, a copy, or an image. He simply is what he thinks himself to be - an accomplished Descartean? A compromising spirit? A betraying consciousness? Some might argue that post-modernism is in no position to counterbalance the new political trend of unlimited imperialism and in that they might be right, the paradigmatic ghosts of the $20^{\text {th }}$ Century are a very good example of such an apparent and unequal footing.

In any case, self-conscious man is first and foremost a promise, a negated negativity, an intimate posture. As such, he cannot prepare himself to think about life and death. He can only prepare himself for his own living and dying in the absence of thought. The absence of thought does not mean that he ceases to think about life and death, but that he can understand living and dying only by thinking them. Thought ceases to exist by being the only dimension of living and dying. In the last analysis, the arresting of the real by thought is equivalent to its suspension in the abstract order of logic, to its transformation into a subject. This involves self-conscious and full consciousness, and both clear and intimate thinking. This involves too a promise, or an intricate illusion, which is at best an irreconcilable betrayal.

By suspending the world of things, self-conscious thought turns it into a subject at the same time at which it turns itself into an object. Self-consciousness and future selfconsciousness, both cross the threshold of the subjected world and encounter themselves as the beings of the object. They encounter themselves as objects in a world of thinking subjects. They know themselves to be suspended, but suspension is also waiting, a ready alibi, or the most perfect enclosure encountered in the act of disclosing the appearance of 
the object. They also know themselves to exist in time, in the true dimension of subjectivity, of pure formulation and pure space. ${ }^{22}$

Time is inconceivable without man, that is, without a man who differentiates between here and now, between his being here (i.e., in the middle of nowhere) and being now (i.e., in the middle of the night). He himself is inconceivable without time, for he could not be here, now, without also being in the night or during the day. Night and day do not leave the same impression on him, just as here and now do not impress him in the same way. Obviously, his being here coincides with the darkness of night just as his being there might coincide with the light of day, in a spatial order influenced by the natural movements of the stars.

It could happen that he might will the night to be something else, or here to be somewhere else, but the fact that darkness does not go away at will, that space, also, will not be different without a movement on his part, remains. If he moves from "here" to "there" this night might or might not turn into daylight, but it will continue to impress him in spite of the fact that he has moved from one place to another. In a word, space appears to be the same by nature, but is not the same by virtue of man's movement. Man perceives it at once as uniform and different, uniform in its darkness and different in its appearance as the locus of movement. He perceives it as his own, he, himself: a triad of contradictory tendencies - a subconscious passage from here to now.

The passage of time from darkness to light ensures the continuity of the world, but it is not a homogeneous continuity, for it is made of a dark and a luminous impression. It ties together space and movement, appearance and speed, here and "I". In the absence of time, space also disappears in the infinite movement of nothingness, returning to a night which is

\footnotetext{
${ }^{22}$ Consciousness, on the other hand, glues together the subjective appearance of the world of things; it gives subjectivity to the world of matter. It sacrifices itself, as it were, in the ritual of world renewal. It initiates itself as self-consciousness and inescapable creativity, without ever achieving its finality, that is to say, without achieving anything except suspension. See for example G. Bataille, Theory of Religion, New York: Zone Books, 2001.
} 
always the same, always dark. What physics tells us about time is that it is space divided by speed: a fraction, an ordinary report between space and speed. Space and time are dependent on a movement whose speed gives the fraction either to zero or to the infinite. Space is always in a direct relation to speed and time, whereas speed and time are always in an inverse relation to each other. Time zero is equivalent to infinite speed just as the absence of speed makes time infinite, and in either condition, space ceases to exist, it reaches zero.

For space to be there must be time and there must be movement also, otherwise it is not, which is to say that it is not perceived, nor differentiated from either night or movement. Man lives in space and he is at one with it, which is to say that he is depth and nothing else, for he could not be movement, or impression, but only their shadow caught in the depth and silence of a vision. He does not know either life or death, but only their ghosts caught in the mirror of space. He himself does not come from somewhere and does not go anywhere, he simply is in and through them. But where, when? What makes him be in this way and not in another? What moves him from the depth of space to the mirror-like surface?

The curious spark that prompts him to wonder away has already moved him to the surface, has already made him answer by looking into the depth of space. He has moved from one time to another time, within the same space, at different speeds, but neither time, nor speed, had satisfied his desire to escape space, or at least the notion of space he had encountered by moving from one place to another, at different speeds, or different times. His movement is doomed, just as is time, his time, his life-time. This is the condition of thought, the condition of searching for a solution or an immediate exit. This is the postmodern solution, the way-out of space, our space, our life-space. It is also the way-in: a home-coming, a return.

I. P. Culianu considered the fourth dimension in terms of its power to turn things into 
their opposites, that is, in terms of its power to give life to a reversible order. ${ }^{23}$ Today, reality itself is such a dimension, such an implausible mirroring device holding the image of a passage, the passage itself perhaps, or its illusion, but also the opposite of what one sees in it - the implausible, the abyss, perhaps even the enemy. One no longer needs to return home, home is already here, already illusorily here. One no longer needs to escape space, for space is no more than a fugitive impression, a dream, or a liberating device. In the end, the simulation of space-time becomes a memory, a therapeutic recounting, or a best-selling novel in the imperial heartland. It becomes what has been right from the beginning: a non-presence, a vision of a vision, a simple depth.

In this vision everything appears and does not appear (to be what is), everything must endure in such a way as to seem not to endure, not to go from a time (this time) to another, for there could be no other time than the present, which is already gone, already absent. In the imperial fabric of reality time becomes non-time, and space turns into nonspace in such a way that the reality of the fabric, or of fabrication, is all that is left to us an empty framework, a non-presence. H. Arendt used R. Char's words to depict such an unexpected reversal: "notre héritage n'est pas précédé d'aucun testament". ${ }^{24}$ There is no testament for the present, time has no testament to leave behind, but only itself in the guise of an empty framework, an empty dimension. In the absence of time, space and movement also disappear, becoming the condition of depth, but also of silence. Under imperialism, nothing survives, nothing dies, everything becomes whole by virtue of its nothingness, by virtue of its being depth and surface at once, despair and euphoria, time and space, cause and effect, presence and absence.

In this unexpected coincidence of contraries, or rather in their sudden compactness, choice can no longer be discerned. It has already become one with determination, it has

\footnotetext{
${ }^{23}$ I. P. Culianu, Travels to the Other World, Bucharest: Nemira, 1996.

${ }^{24}$ H. Arendt, Between Past and Future, New York: Penguin Books, 1993, p.3.
} 
already been determined not to be a choice, but instead a vague emptiness, a vague memory, or a sudden suspension. The play of its forces runs counter to space, which is also, in a profound way, suspended in its appearance as movement. Choice itself appears to be immovable, non-spatial, and non-human. It appears to be non-existent, non-apparent. There is no determination to this absence, no determined spatiality - choice is no longer there (if it ever was), no longer in the superficiality of determining one's own destiny, one's own future. It is somewhere else, perhaps in a profounder alternative, hidden away from the certitude of weighting its possibility and eventuality. Hidden.

But if under imperialism there is no time, no spatiality to choice, what is there to be pondered upon? What is the world without its timely notions of freedom and equality, without its cities and television sets? What things would define us, apart from what we hear of them, we read, or opine about them? To put it differently: is there a world of things, in the first place? Is there a world belonging to man alone - a world of choice?

Must this world be moved in one direction so that man may be awakened from his slumber, only to move infinitely more slowly in the contrary direction? And then, of what world, or part of the world, do we speak, and what man, what part of him do we discover in the sleep of our own consciousness, in the suspension of our own time?

These are simple questions, questions that should attract simple answers, well thought out, but nonetheless simplified and wanting answers that no longer account for anything except the drive to ask, to know, to discover what lies ahead of the question, ahead of man.

In the end, the reducibility of the answer to the status of knowledge coincides with its widening in the realm of the real - knowledge comprises everything by reducing it to the question of nothingness, just as nothingness envelops everything by widening its influence in the world of thought. To know is neither to know how things are made, nor to contemplate their destitution. Knowledge forces things to be known as destitute relations 
among things only insofar as it itself becomes, in an intimate way, destitute. Also, it forces things to be known as privileged only insofar as it itself becomes a privilege. However, the truth of the matter is neither in the first proposition, nor in the second. Simply put, knowledge is not "truth". Perhaps it will never be as long as it will dwell on these two propositions. G. Bataille rightly named truth the god of reason. ${ }^{25} \mathrm{He}$ did not name selfconsciousness the goddess of knowledge even though he could have done that just as easily. He did not speak the truth, but of truth, which is the domain of knowledge par excellence. Perhaps Michael Ignatieff is right in reminding us what we must think anew about the phenomenon of imperial thought:

The 21 st century imperium is a new invention in the annals of political science, an empire lite, a global hegemony whose grace notes are free markets, human rights and democracy, enforced by the most awesome military power the world has ever known. It is the imperialism of a people who remember that their country secured its independence by revolt against an empire, and who like to think of themselves as the friend of freedom everywhere. It is an empire without consciousness of itself as such, constantly shocked that its good intentions arouse resentment abroad. But that does not make it any less of an empire, with a conviction that it alone, in Herman Melville's words, bears 'the ark of the liberties of the world. ${ }^{26}$

According to Ignatieff, the new imperial power settles in through economic, political and military, grace notes, while deceiving itself through the lack of an imperial consciousness. The lack of consciousness appears then as the new 'ark of the liberties of the world', the new imperial gracing specter: sheer hallucination, sheer hubris, sheer deceit and betrayal? If newness consists in the ephemeralization of human consciousness, it appears that the concept of empire lies in a realm subsidiary to space, even though it is becoming increasingly non-spatial. An American intelligence analyst has described this process as lying beyond armed force, in a world increasingly open to the fluid penetration of imperial thoughts, knowledge and perspectives:

Take comfort, then, in the glacial emergence in the western hemisphere of a

\footnotetext{
${ }^{25}$ G. Battaile, Theory of Religion, New York: Zone Books, 2001, p. 73.

${ }^{26}$ M. Ignatieff, The Burden, http://ars.userfriendly.org/users/read.cgi?d=19836\&tid=73409.
} 
new supranational culture.... Above all, note its universality. Neither American nor Canadian nor Latin, it is an eclectic blend that slips across national boundaries like the mists of an April morning. ${ }^{27}$

27“Beyond Armed Force”, Christian Science Monitor, February 8, 1982, p. 23. 
Chapter 2

\section{The Complexity of Space}

The hard core of the idea of time in the Western tradition is its eternal Parmenideanism: the spatialization of time. The negated time is reconstructed in an illusory manner in accordance with the model of space.

$$
\text { A. } \operatorname{Negri}^{28}
$$

As we shall see, there is an intimate relationship between space and time, and as imperial power, in the broad sense of the term, begins to shape itself, the space-time relationship begins to modify its coordinates and its intimacies. Whether it involves itself in a 'cold war', a 'warm war', or a Long War, imperial power revolves in space as much as it revolves in time, disclosing and (en)closing the very possibilities, or coordinates, of its own constitution and destitution.

On the whole, human space appears to be regulated by its own sacralities and profanities, by the interplay between the sacred and the profane, whose origins go far back in time, to an unintelligible moment of differentiation. If one were compelled to imagine undifferentiated space, the mythical space of original creation, he would have to imagine the density of matter, the imperceptible movement of division that meets the eye only in the form of an explosive unity. He would then have to imagine the entire cosmos moved by this explosion of unlimited proportions, by this unity capable of overcoming all divisions and of rendering reality its smoothness and its proper shape.

For him, undifferentiated space is marked by divisiveness just as much as it is marked by unity, while there is no tangible relation between its division and its continuity. The elements of nature, related in their outer form, striate space in its interiority, they consume it from within, as it were, so that its unity could subsist indefinitely. The economization of space is based on this double movement of consumption and subsistence,

\footnotetext{
${ }^{28}$ A. Negri, Time for Revolution, New York \& London: Continuum, 2003 , p.30.
} 
of divisive production and collective survival, of profane dissipation and sacred density. By whatever shape it takes - that of the tribe, of the religious community, or of the state the wealth of space is at once division and unity, desire and possession, imponderability of the spirit and solidity of things. Its endless divisiveness produces endless unity, endless growth and sometimes endless wealth, often gained through what in our era may very well stand as the most significant development of imperial capitalism: the progressive commodification of knowledge. ${ }^{29}$

But wealth is neither dividing, nor uniting: a tool, a temple, a piece of jewelry, stands outside the sacred, it simulates its presence as it were, but it does not have the power to unite, to bind or renew it. In the classic study entitled The Sacred and The Profane, M. Eliade $^{30}$ suggests that abundance, peace and fecundity correspond to the geography, economy and history of ancient populations, that they work as a primary function against which physical force always tries to affirm itself. Most of the time, the ancient contender battles three-headed monsters, three alternatives or three adversaries. If he wins, the triad of abundance, peace and fecundity, is replaced by the unity of physical force, by the ritual through which its fury is socially contained.

The war-machine is such an incarnation of physical force at the level of a given sociability, a given society, which is no longer independent of its unity or its fury. The presence of the war-machine does not oppose the simple dualism of sacredness and profanity, nor does it complete the ancient triad of abundance, peace, and fecundity, but rather it threatens them from within or from without. All tripartite configurations of power work within the limits imposed by this economy based on abundance, peace and fecundity, they never transgress these limits without being forced to do so, without being corrupted or

\footnotetext{
${ }^{29}$ P. Lindfield and J. Alexander, "Science Technology and Strategic Management: the Bad News for Democracy", V. Subramaniam and J. Alexander, eds., The Comparative Policy Reader, Delhi: Ajanta Books, 1999, p. 361.

${ }^{30}$ M. Eliade, The Sacred and the Profane, New York \& London: Harvest/HBJ Book, 1959.
} 
interrupted by a violent force. Imperial triads, by themselves, incarnate their own demise insofar as they march towards infinite growth, toward the inevitable unity of "abundance, peace and fecundity", they rush headlong towards the affirmation of physical force and nothing more.

The substitution of the imperial triad with the dualism of Mitra-Varuna (Rudra-Siva) in G. Dumézil's work for example ${ }^{31}$, is also a simultaneous substitution of "fecundity" with Indra (the god of war). The triad is unpacked in such a way that physical force is withdrawn from the peaceful coexistence of the two deities, while remaining the sole possibility of their survival. It is a compromise, obviously, a non-militaristic conceptualization of empire at the same time at which military conquest proves to be the sole venue of maintaining the "abundance" and "peace" of the sovereign couple. It is also a dead end, a finality reached either too fast or too early - a fascinating utopia.

In this utopia, peace appears to be maintained through violence, indeed, through a violence which is at once alimented and destroyed, friendly and threatening, peaceful and abundant. Such a violence unveils the destiny of an "exceptionally slippery nature of a god of goodness", who "is divine in excluding violence by violence", and who "owes his remaining divinity to a name and to a propensity to endure on the part of that which is not destroyed from the outside". ${ }^{32}$

According to G. Bataille ${ }^{33}$, the outside is a tool, or a thing - a lost intimacy which cannot be recuperated otherwise than through the radical consumption of the world of things. The outside world seems to be in the service of interiority just as much as divinity seems to be in the service of the believer - their coincidence recalls and revives divine endurance on the part of conscious man. Also, their violent relationship empties the seat of violence and restores the mythical balance between consumption and the threat of violent

\footnotetext{
${ }^{31}$ G. Dumézil, Mitra-Varuna, New York: Zone Books, 1996.

${ }^{32}$ G. Bataille, Theory of Religion, New York: Zone Books, 2001, pp. 81-2.

${ }^{33}$ Ibid.
} 
death.

In their appraisal of the State as sovereign power capable to internalize by appropriation, G. Deleuze and F. Guattari ${ }^{34}$, uncover a "polymorphous war machine" corresponding to the outside of the state: a multitude of machines branching autonomously into the open, a multiplicity of local mechanisms, bands, margins, and minorities, flowing arbitrarily, overlapping, struggling in the interior of the exterior, in an infinite proliferation of forms of power. At all points the internal divisiveness of space is opposed to the unifying explosion of form, to the machine branching out its interiority in pure form, or the State internalizing the pure exteriority of the machine. Marginality, banditry and mechanicity are forms of resistance to this relation between internality and externality, appropriation and misappropriation, collaboration and conflict. They resist both inclusion and exclusion, internalization and externalization, as if resisting their own existence and disappearance, their own life and death.

The nomad outside the state resists the internalization of sovereignty, its appropriation of locality and exteriority, its inevitable branching out into the open. He also resists his own interiority, his own tendency to become sovereign by appropriating universally, by turning all space into smooth lineages and trajectories, smooth interiorities and operations. He becomes the reversed image of the State, its third dimension as it were, its visual incarnation - a margin, a band, a mechanism, resisting its own paradoxical nature. As such, it no longer stands opposed to the State but to itself, to its own imagery and virtuality - to its own.

Perhaps it is no accident that in G. Dumézil's ${ }^{35}$ work the one-dimensionality of Mitra and Varuna is elevated to the three-dimensionality of space through the bi-dimensionality of their relations. The structure of space is replicated in this complex relation between one-

\footnotetext{
${ }^{34}$ G. Deleuze \& F. Guattari, Nomadology: the War Machine, New York: Semiotext(e), 1986.

${ }^{35} \mathrm{G}$. Dumézil, Mitra-Varuna, New York: Zone Books, 1996.
} 
dimensional beings, bi-dimensional relations and three-dimensional machines. It is a virtual replica - a virtual space. The absorption of the war-machine by the State and of the State by the war-machine completes this virtual tour by enclosing space in the interiority and exteriority of its own dimensions. Space ceases to be an image by becoming a relation and ceases to be a relation by becoming an image - it reduces itself either to the relation of a relation or the image of an image, that is, to a virtual space of space.

This development, one of the most important in the current imperial age, rests upon the progressive commodification of knowledge. Italian political scientist R. Musto explains why this commodification has generated a strikingly new capability to create both imperial wealth and imperial dependency:

In contrast with the ordinary production of objects as commodities that, once sold, are at the complete disposal of the purchaser, knowledge, even applied knowledge, is in_principle, once produced, ready for indefinite applicability. The production of science and technology, in modern terms, is production of abstract ideas and, even in the more detailed applied cases, production not of an object but of its blue-print. ${ }^{36}$

This sudden and fictive reduction of space to its own image is conducive to the fourth dimension - that of time. P. Virilio ${ }^{37}$ speaks of the "war on Time", a war of the machine against time, of speed against mass, of movement against stasis. The closure of space corresponds to the massification of the machine, to its "killing time" as the inevitable consequence of speed - it corresponds to its becoming image, becoming flat. P. Virilio's preoccupation with "holding the streets", the great venues of traffic control, or rather the blood vessels of the "mass-machine", is a preoccupation with movement, with its arrest or with the possibility of turning it on its head - with the possibility of a Time-machine. From now on, it is not time that is killed, but space: the military-police-relation controlled by the image of the mass-machine. The imperial force acts as a military police whose favorite

\footnotetext{
${ }^{36}$ R. Musto, "Science and Democracy: Scientific Institutions in Advanced Societies", presented at the October 1990 Meeting of the International Political Science Association, Science and Technology Research Committee, Cosenza, Rende, Italy, p. 7.

${ }^{37}$ P. Virilio, Speed and Politics, New York: Semiotext(e), 1986.
} 
policy is regime change. As M. Ignatieff remarks, "regime change is an imperial task par excellence", it evades space and "assumes that the empire's interest has a right to trump the sovereignty of a state". 38

P. Virilio's work is very similar to that of G. Deleuze's and F. Guattari's, except that his mass-machine develops a time consciousness, whereas the "war-machine" can only develop a consciousness of movement, that is to say, a military-police consciousness. The roles are reversed/reversible in an intricate manner, and we must not forget that it is always a "machine" performing the reversal: the aim of the machine is to compress space-time and to project man into the compactness of another dimension. As a matter of fact, it projects man into the endless divisiveness of space, towards the more compact dimensions of potential energy. It projects him into the dimension of his own potentiality, his own compactness, his own.

In his own way, P. Virilio associates this kinetic energy of the mass-machine with the spatial configuration of its components and with their interaction with each other, in truth, he orients the mass-machine towards the compactness of its own potential energy. Mass exerts its force on the components of the machine, it consumes the machine from within as it were, while developing (or rather becoming) its function, its aim and its "esprit de corps". The kinetic energy of the machine becomes the source of its potential energy - a destructive energy directed towards another machine: space itself.

The consciousness of destroyed space becomes the potential energy of a new machine, a machine recuperating the loss of space through an attack on time. Perhaps this is what worries P. Virilio in the most profound way: insofar as machines turn into killing machines, insofar as death is their raison d'etre, life is no longer an option, no longer possible. Life affirming machines are simply ruinous ghosts of war-machines, they serve Death directly by becoming its life giving targets. There is no escape from the viciousness

\footnotetext{
${ }^{38} \mathrm{M}$. Ignatieff, The Burden, hup://ars.userfriendly.org/users/read.cgi?d=19836\&tid=73411.
} 
of the mechanistic cycles, no remedy to the violence unleashed by the compacted energy of the machine. Man rushes toward his death, toward the moment when death meets death in the compactness of the Machine.

To be a life-giving machine, the mass-machine must separate itself from the functions of the army and the police, or from the rule of the bourgeois - it must separate itself from what it can do. In truth, it must become an ideal mechanism perpetrating death by projecting itself into the image of a perfect after-life. It must become an immobile presence, an exclusion of all movement - an impossible posture already reached by the city-machines, the state-machines, the empire-machines. In the last analysis, the machine is movement marching towards its enemy: stasis. It is also an image-phenomenon (i.e., picture, film, spectacle) spreading itself into a multiplicity of relations between states and war-machines, time and space, interior and exterior, man and woman.

G. Deleuze's and F. Guattari's war machine, external to the State apparatus, is already an imperial machine operating in compact form in the open space of empire. On the one hand, it marches towards its own immobility, on the other, it becomes the ideal relation between movement and stasis - an image of an image. It cuts itself off from what it can do at the same time at which it realizes that this is the only thing it can do - to cut itself off, to do just that. ${ }^{39}$ E. R. Dodds showed that by delaying the moment of sacrifice, the victim succeeded in turning itself into the kingly figure of the capturers, ${ }^{40}$ but already in G. Deleuze and F. Guattari this turning is imposed as a limit to the sacrificial machine: as soon as it crosses the boundary, it ceases to be a war-machine and becomes a State apparatus, an optical device, a prosthesis of the capturer. In truth, its fate is sealed either way. By ensuring the survival of the State from a distance, it only gives itself the time to be absorbed by it.

\footnotetext{
${ }^{39}$ G. Deleuze, Nietzsche \& Philosophy, New York: Columbia University Press, 1983.

${ }^{40}$ E. R Dodds, The Greeks and the Irrational, Berkley, Los Angeles/London: University of California Press, 1951.
} 
Perhaps we should not forget that we no longer speak of individual victims, but of machines made up of numbered numbers, that is, of a spatial compactness capable of escaping (and enhancing) the kinetic energy of the State: the movement which affirms itself in moving bodies. This movement of movement un-doubles itself (as a means and end of power) and survives by sacrificing a victim (i.e., a moving-body, a war-machine). It is a double-edged sacrifice (as all sacrifices are), no longer on the side of power, but against it. Its unfolding imitates the appropriation of the war-machine even though it is no longer possible to appropriate it since the state is the war-machine set free from the charge of war-making.

The war-machine "is located between the two heads of the State, between two articulations, and that it is necessary in order to pass from one to the other". ${ }^{41}$ This twoheaded imperial power functions through the "madness of unchained techniques and bottomless organization of the normal men". ${ }^{42}$ It is the double of the double, at once unifying and dividing, non-identifiable and identical; it is the perfect spatial machine, turning its last dimension against itself in order to open up the compactness of the fourth dimension. As such, it marches headlong into the order of sacrifice, of the most profound and most problematic mechanism of survival of "the other". It does so by retaining a new name (war-machine) and a tendency to resist on the side of those who are not destroyed from within.

With this mechanistic conceptualization of war, the whole notion of sacrifice is turned around - it is no longer the "pure" victim that is sacrificed, but the violent, soulless machine. Indeed, the machine acquires a soul - the moment of acquisition coincides with its death, with the sacrifice it must undergo in order to retain its name. The inevitable sacrifice of the war-machine reveals the nature of war: to make war means to be willing to

\footnotetext{
${ }^{41}$ G. Deleuze and F. Guattari, Nomadology: the War-Machine, New York: Semiotext(e), 1986, p.7.

${ }^{42}$ M. Heidegger, Einfuhring in die Metaphysik, Tubingen: Max Niemer Verlag, 1953, pp. 28-9.
} 
be sacrificed, to be sanctified in the purity of fighting. It means to wage a "holy war" against impure wars, to turn violence into "perfect violence" (i.e., a machine), that is, into the lost intimacy of "fighting". In this way the purity of the victim is sanctified by the act of war, not by giving itself up to the authorities, which is the extreme manifestation of servility, but by sacrificing oneself for the sake of "fighting". In his discussion of rogue states, J. Derrida suggests that precisely because rogue means a "leading astray that calls for exclusion and punishment", the rogues "announce in their own way the decadence of the monarchic principle and, from afar, by way of a revolution and a beheading, a certain democratization of sovereignty". 43

For Aristotle, a man living outside the city turns out to be either a beast or a god: "anyone who by his nature and not by simply ill-luck has no state is either too bad or too good, either subhuman or superhuman - he is like the war-mad man...". The madness of war stands opposed to the sanity of social status, to the enduring humanism of being neither too good, nor too bad, and transcends this status insofar as it is capable of transforming goodness and/or badness into a human quality outside the mitigated domain of the political, that is, into a supernatural or an inferior presence granted by those who are neither too good, nor too bad. The outside and the inside become a matter of status, a matter of fighting over status - an indelible conflict.

The sizing of the war-machine, of its armed corpus, brings into the city the very "lack of status" that one attributes to the outsider - it brings into the city the abnormality of fighting: a furious beast or a god. The conferring of status to the art of war is also a conferring of status to the madness of war, that is to say, to the "outside" from whence the threat comes and towards which war directs its forces in an effort to terminate its own madness, or its own lack of status.

\footnotetext{
${ }^{43}$ J. Derrida, Rogues, Stanford: Stanford University Press, 2005.

${ }^{44}$ Aristotle, The Politics, New York: Penguin Books, 1962, p. 59.
} 
One extreme formulation of this view is P. Virilio's notion of the nation-state as an armed machine directed towards the termination of status-less bodies: movement justifies the termination of these bodies, it accelerates their disintegration and their gaining a warlike status. For him, the very notion of the proletariat comes out of the army, or rather, it becomes its prosthesis in a war against the limitations imposed by the priest, the king, the bourgeois: "the aristocracy, the military class, the bourgeois, each one fighting over its own proletariat", 45 give way to the greatness of assault, that is, to the increasing speed of militarized movement.

The expansion of militarized movement grants the status of war to the whole of society, to the entire world caught in the fight over its own proletariat, over "a Communism that no longer has anything Marxist about it but its name, and for which the end of the dictatorship of the proletariat was the admission of its historical failure". ${ }^{46}$ The movement of the masses towards a global quest for recognition turns them against their own ideological failures, accelerating their demise. For them, the relation between ideology and phenomena is no longer a historical instance of the spirit, but a direct act upon the history of both ideology and phenomenon. As Z. Bauman puts it, "communism died of many maladies", but "the gravest and least curable among them" is "irrelevance". 47 As a consequence, the aim of its "historical construction is not the filling of a transcendentally established space, but the constant production and displacement of the space itself". 48

With the proletariat, the structure of historical time collapses upon the structure of space, which is to say that it receives its life from the triad of markets, hierarchies and kingships: "in a purely immanent universe, thinking is (a form of) action, and the creation

${ }^{45}$ P. Virilio, Speed and Politics, New York: Semiotext(e), 1986, p.115.

${ }^{46}$ Ibid., p. 117.

${ }^{47}$ Z. Bauman, "Communism: A Post-Mortem", Praxis International, 10 (3/4), October/January 1990/1991, pp. 185-92.

${ }^{48}$ A Reply: Glimpsing the Future, Laclau: A Critical Reader, Simon Critchley and Oliver Marchart, eds., New York: Routledge, 2004, pp. 277-328. 
of new philosophical concepts itself amounts to an intervention within the sociopolitical field". ${ }^{49}$ Presumably the proletariat fights against rich markets, against the hierarchy that sustains them and the bonds of kingship through which they are renewed. The aristocracy, the military class and the bourgeois tend to turn this "fight" into a democratic activity, into a negotiable policy or "value" offered in exchange for wealth, tranquility and renewal.

Indeed, as A. J. Motyl seems to suggest, "one can draw lessons from the past if one believes that history is real, that knowledge of history is possible, and that such knowledge can be packaged appropriately". ${ }^{50}$ The theme of empire, or rather the "history of lessons" concerning empire (recently incarnated into a project proposed by the American Social Science Research Council), is overtly simplified: "the psychology of power offered here is simple enough: those who have power tend to believe in its effect and have recourse to it more readily than the weaker ones who have to make do without it". ${ }^{51}$ In the strict sense of American political science divisionism, "the way out of this circle is historical", 52 it simply proposes that the "unit in which the citizens would seek equality - and the resources to pay for it - would become the territory, not the Empire". ${ }^{53}$ In N. Ferguson's words:

American history needs to be understood in the normal language of history, the language of history which can be applied from the time of Alexander, to the time of Clive, to the time of Queen Victoria. We need to discard the language of exceptionalism and understand the United States as a normal empire, which behaves in the ways empires have in the past. ${ }^{54}$

One is led to believe, following A. Giddens, that there are two Wests: a historical

\footnotetext{
${ }^{49}$ C. Strathausen, "A Critique of Neo-Left Ontology”, PostModern Culture, vol.16, no. 3, May 2006. http://muse.jhu.edu/login?uri=/journals/pmc/v016/16.3strathausen.html.

${ }^{50}$ A. J. Motyl, "Empire Falls", Foreign Affairs, July/August, 2006. http://www. foreignaffairs.org/20060701 fareviewessay 85416 a/alexander-j-motyl/empire-falls.html.

${ }^{51}$ E. Saada, "The History of Lessons: Power and Rule in Imperial Formations", Items and Issues, vol. 4, no. 4, Fall/Winter 2003. http://www.ssrc.org/progranı/publications editors/publications/items/online4-4/saada-lessons.pdf. ${ }^{52}$ lbid.

${ }^{53} \mathrm{~F}$. Cooper, "Modernizing Colonialism and the Limits of Empire", Items and Issues, vol.4, no. 4, Fall/Winter 2003. http://www.ssrc.org/programs/publications editors/publications/items/online44/cooper-colonialism.pdf.

${ }^{54} \mathrm{~N}$. Ferguson, "Empire: The Rise and Demise of the British World Order and Lessons for Global Power", paper presented in New York, Carnegie Council, Books and Breakfast program, Sept. 16, 2003.
} 
(constitutional) West and a geopolitical formation pressured by "serious problems". ${ }^{55}$ More to the point: "the herd decides which countries to reward and which to punish, and nothing can be done about it" ${ }^{56}$ Indeed, as K. Waltz adds, "the herd has no telephone number". ${ }^{57}$ Given that the new imperial space is shaped by markets and not by governments ( $\mathrm{K}$. Waltz), the "moral dilemma of history, like its intellectual counterpart, is existential. They can be mitigated, but not resolved". 58

While the immutable law of the market is profitability, it stands to reason that the new law of the political rests on some sort of consummation. As J. Nye argues, “international order is a public good - something everyone can consume without diminishing its availability". 59 It goes without saying that the more precious the consummated (i.e., sacrificed) "thing", the better should be the reward. G. Dumézil and after him G. Bataille revived the idea of potlatch, the idea that what is given matters less than what is obtained in exchange. Sacrifice itself is turned on its head in order to benefit the sacrificer - it is no longer the victim that has the power to negotiate a divine favor but the presence of the sacrificer, which establishes a symmetric relation, a fair trade, or at least the promise of a returning favor.

For G. Bataille, Christianity brought the principles of the order of things into the intimate (human) order more than it subordinated the order of productivity to the destructive consumption of intimacy. A "new theory of religion" would then have to work backwards, to subordinate production to the intimate order of consumption, profit to sacrifice, growth to waste, divinity to the economy of the body. For him too, consumption and sacrifice oppose one another insofar as the economic principle that sets them apart is

\footnotetext{
${ }^{55}$ A. Giddens and S. Huntington, "Two Wests", New Perspectives Quarterly, 20 (4), Fall, 2003. http://www.digitalnpq.org/archive/2007 winter/index.html.

${ }^{56}$ K. Waltz, "Globalization and American Power", National Interest, Spring 2000.

${ }^{57}$ Ibid. http://www.findarticles.com/p/articles/mi m2751/is 2000 Spring/ai_61299041.

${ }^{58}$ H. Morganthau, "The Intellectual and Moral Dilemma of History", Christianity and Crisis, February 9, 1960. http://www.religion-online.org/showarticle.asp/title $=398$.

${ }^{59} \mathrm{~J}$. Nye, "The American National Interest and Global Public Goods", International Affairs, 78 (2), 2002. hutp://web.nps.navy.mil/ relooney/3040 c90.pdf.
} 
based on conflict and not on collaboration. But there could be no collaboration between "consumption" and "sacrifice", between the "arrest of growth" and the "faculty of growth", unless one is assimilated by the other in the lucidity of consciousness.

And this is precisely what A. Giddens alludes to when remarking that "the difference between Europe and the US is not a straightforward religious one, but one of politicization, the politicizing of the religious right in particular" ${ }^{60} \mathrm{He}$ was replying, straightforwardly, to Huntington's attempt at religiosizing the political by suggesting that "Americans are deeply committed to both God and country", while "Europeans seem to have rather weak commitments to both". 61

The conflict that separates "consumption" and "sacrifice" is first and foremost a conflict of inequality. Consumption and sacrifice are never on the same level, they imitate one another and bond together indirectly, through the act of imitation. Their equality is satisfied indirectly through the virtual relation between conflict and order, that is, through their imperfect and asymmetrical formations of simultaneous conflicts and alliances. ${ }^{62}$ Ancient deities stand in opposition to the world just as much as they stand by it: the sequence of growth and arrest is always a sequence subordinated to order through the mediation of conflict. From our perspective, the reverse is also true: the sequence is subordinated to a conflict capable of mediating a subsequent order. $^{63}$

If growth and order presuppose the disappearance of conflict (order is suspended conflict), there could be no alliance between conflict and order unless they too form a sequence in the world of things, a relation of violence to calmness, or of separation to bonding. From the point of view of order, violence separates and calmness binds, at the

\footnotetext{
${ }^{60}$ A. Giddens and S. Huntington, "Two Wests", New Perspectives Quarterly, vol. 20, no. 4, Fall, 2003. http://www.digitalnpg.org/archive/2003 fall/giddens huntington.html. 
same time at which the reverse is also true in respect to conflict. The double-fold nature of violence and calmness ensures the double-fold nature of the coexistence of order and conflict, growth and arrest, consumption and sacrifice. As such, it makes up for the double of the double - the shadow of the present, the antithesis of antithesis - a whole new basis for imperial allegiances and betrayals. ${ }^{64}$

As G. Dumézil puts it, "to say 'antithetical' is to say either "opposed" or "complementary", to contemplate a world of conflict or collaboration, of war and/or peace. In practice, according to Dumézil, "we have nowhere encountered conflict, but rather, in all areas and in a variety of forms, collaboration...". In practice, "history still takes the greatest pains to avoid even the shadow of a conflict between them" ${ }^{\text {"66 }}$ (i.e., between two antithetical sovereignties). Conflict is dissolved through "various narratives and scenarios of 'temporary kingship' ('false king', 'carnival king'), that is, through the story of a 'bad' or wicked king, a usurper, framed between two legitimate, 'good' reigns". ${ }^{67}$ In short, the collaborative nature of sovereignty presupposes the framing of wickedness and its expulsion from the intimacy of sovereign couples.

It also presupposes that "at least one of the legitimate rulers, either the one before usurpation or the one after, and sometimes both, is or are of the military". ${ }^{68}$ An extreme example of this approach would be W. Marshall's depiction of 'polar opposites': "if you do not like how polarized U.S. politics has become, don't just blame Republicans and Democrats. Consider two key contributors to today's politics of polarization - the military

\footnotetext{
${ }^{64}$ One good example of a double betrayal would be the Iran-Iraq war, which the Americans: "referred to as a policy of 'counterbalancing interventionism', the aim of arming both sides at different times was to prevent either side from coming out as a heavyweight power in the region". Brendan O'Neill, "America, Iran and 'Impotent Imperialism", February 16, 2007. http://www.spikedonline.com/index.php?/site/ article/ $2865 /$.

${ }^{65}$ G. Dumézil, Mitra and Varuna, New York: Zone Books, 1988, p. 113.

${ }^{66}$ Ibid., pp. 113-14.

${ }^{67}$ Ibid., pp. 114-15.

${ }^{68}$ Ibid., p. 115.
} 
and the academy". ${ }^{69}$ In a word, the sovereign couple doubles itself along the lines of "usurpation", militarism, legitimacy, succession.

It is only when taken together that the couples prove to be quite different from "military leaders": "Varuna and Mitra, Romulus and Numa are all kings in their essence, one pair by virtue of their creative violence, the other by virtue of their organizing wisdom" ${ }^{70}$ The sovereign (pair) frames and expulses "the wicked king" either through violence or wisdom, quickness or calmness - it forms its own intimacy by framing and expulsing, or rather its sole intimacy consists of framing and expulsing wickedness. Sovereignty becomes an economy of wickedness - politics, the wicked spell through which the sovereign couple revives itself.

As M. Foucault had showed in The Order of Things, in classical thought representation is simultaneously indication and appearance, truth and wealth, sign and thing, collaborating intimately and intuitively in the fabric of nature. Representation connects the thing it represents to its aim and its existence, it makes it amiable to a certain destiny, a certain raison d'etre. The represented thing is at once destiny and raison d'etre, framing and expulsing - it is intimacy pure and simple, reality, divinity, nature. The magicbinding couple, the sovereign couple, represents this intimacy, this becoming destiny, becoming raison (d'etre) of representation - a double fold, a representing representation. The collaborative (contemplative, passive) nature of representation is maintained through the framing of wickedness - it becomes this frame, this reasoning in and through (en)framing couplings and representations.

The story of wickedness is the story of conflict, the story of sovereignty embodied in the military, the police, the social bands distanced from "any system of property, debts,

\footnotetext{
${ }^{69}$ W. Marshall, "Polar Opposites", Blueprint Magazine, Feb. 9, 2006. hitp://www.ppionline.org/ndol/print.cfm?contentid=253725.

${ }^{70}$ Ibid.
} 
loans". ${ }^{71}$ Perhaps J. Baudrillard gives the most lucid expression to this (en)framing conflict between wickedness and representation: "to this murderous nature is opposed that of representation as a dialectical power, the visible and the intelligible mediation of the Real". ${ }^{72}$ The equivalence between representation and thing, collaboration and conflict, wisdom and violence, (en)frames and expulses the real from the fabric of representation. As a matter of fact, the "utopia of the principle of equivalence" ensures the simulation of the ideal by the real and of the real by the ideal to such an extent and with such intensity that reality and representation become inseparable, they become dead references, abstractions, ideas signaling the insoluble presence of absence. From the death of references there ensues the ghostly life of simulation - the end, the wicked story of simulacra.

For J. Baudrillard, this story of wickedness is strangely similar to the beginning, to a time when things were doubled by their own death, by an estranging and commanding consciousness which no longer has any place in the world of simulation. Without this alienating consciousness of death, life becomes a deterrence scenario, a death machine renewing itself through simulated terminations: "power can stage its own murder in order to rediscover a glimmer of existence and legitimacy". ${ }^{73}$ In this scenario death no longer legitimizes power but power legitimizes death: "to seek new blood in its own death, to renew the cycle through the mirror of crisis, negativity, and anti-power: this is the only solution-alibi of every power, of every institution attempting to break the vicious cycle of its irresponsibility and of its fundamental nonexistence..."? 74

Power sacrifices sacrifice, it renews, or rather it maintains itself through the simulation of its own death. Death is affirmed in place of the real, in place of power and of

\footnotetext{
${ }^{71}$ G. Dumézil, Mitra and Varuna, New York: Zone Books, 1988, p. 115.

72 J. Baudrillard, Simulacra and Simulation, Ann Arbor, MI: University of Michigan Press, 1991, p. 5.

${ }^{73}$ Ibid., p. 19.

${ }^{74}$ Ibid.
} 
life. Such an extreme affirmation of death is a double dying, a sudden erasure of death from the plane of the real at the same time at which it becomes the sole reality - a simulacra caught in the mirror of crisis, or of its own virtuality. There is no alternative to simulation, or rather the only alternative to simulation is the termination of reality through the realism of simulating processes: the victim is liberated through its own guilt and is free to restore reality through its own sacrifice. The same can be said of the machine, the band, the social milieu - they have become strata of the real, the rhizomes of another future, another possibility. Perhaps of another simulation - another sacrifice as well?

There is no solution to the omniscience of simulation, no reference except the simulation of sacrifice, that is, of the chain of events reproducing the reality of death, the simulating and simulated realism of guilt and innocence, conflict and collaboration, power and machinery. "What is essential is that nothing escapes the empire of meaning...," there is no meaning other than simulation, no empire other than the assemblage of simulated realities, simulated deaths and simulating sovereignties. Truth is no longer of the order of meaning, but of the order of simulation - as such, it entertains the equivalence of meaning and empire, division and assemblage, conflict and collaboration, reality and representation.

Since the organizing principle of the imperial whole is simulation, its essential meaning is a simulated order: one no longer discovers a Borgesian universe, an objectively exhaustive universality, but an Orwellian, or a Kafkian, milieu which is already exhausted, already consummated by the logic of simulation. The organizing principle follows blindly the sequence of (en)framing and terminating all possible wickedness. In one way or another, it usurps reality by recycling all meaning and by subordinating everything to the power of appearances. In the end, there is no mediating ground except for the space of simulation, for the empty procedure of framing and terminating space.

${ }^{75}$ Ibid., p.137. 
According to J. Baudrillard, even though the three-dimensionality of the simulacrum seems closer to the real than the two-dimensional simulacrum, it has the opposite effect: it renders us "sensitive to the fourth dimension as a hidden truth, a secret dimension of everything, which suddenly takes on all the force of evidence" ${ }^{76}$ It is not the threedimensional simulacra that threaten the real, but our sensitivity to the pressure of evidence, to the secretive dimensionality of truth and of everything else. The more dimensions one adds, the more reality one bestows on things. This is to say that reality itself is a vicious circle of addition, multiplication, division and subtraction, a play of evidence saturated through simulated conflicts and alliances, which ensures the "secret" renewal of the whole.

There are as many realities as there are simulated conflicts, dimensions and truths, but only one is "true" by virtue of its secretive nature and scope. Adding and subtracting successive dimensions becomes the new challenge of simulation, the atemporal simulacrum inserted between two identical temporalities in order to pass from one to the other. Simulation replaces the real with deadly references. Movement too is replaced by the propulsion of meaning from one defunct fiction to the other, or from an insufficient and "unreal" dimension to the next, and all that remains is a world of mathematical proportions - an automaton in the making.

Simulation is what one gets when everything else has already died, when there is nothing but death to calculate and measure death. The imprint of an imprint of dying circumstances, dying realities, dying bodies: the final passage from one dying dimension to the next. There is no "dialectic of mortification" here, death is no longer ideological, nor phantasmal, as Ziziek tells us ${ }^{77}$, but rather disseminates itself, multiplying its ideologies and phantasms, its own dying moments, or dying deaths.

This passage (from dying to death) is made possible by the sudden ephemeralization

\footnotetext{
76 Ibid., p. 107.

${ }^{77} \mathrm{~S}$. Žižek, The Plague of fantasies, London and New York: Verso, 1997.
} 
of reality into simulated instances. Passing devices, passing moods or phases, no longer discover things but suspend them between the act of simulation and the final simulacra, between science and fiction, dying and death. In truth, the passage from one dimension to the next is a closure, a simultaneous erasure and addition of contradictory realities. It would be practically impossible to tell whether one exhausts the two-dimensional world of simulation or adds more reality to it by adding another dimension, another death. In the order of simulation there are only passages, relays, evidences of the simultaneous loss and gain of reality. There are dead references substituting the passage from the death of the real to the reality of the simulacrum, or, as J. Baudrillard remarked in passing, from the real "imperialism of Reason" to the simulated "neoimperialism of difference".

Perhaps it is important not to forget that simulation responds to the need for confidence in practical activity. It is not only a hypothesis about what the world is like, but also an integral part of active human life, not only a sporadic eruption in consciousness but also a pervasive feature of experience. Simulation can thus produce strange (re)visions of the Schmittean friend-foe divide. For example, America's closest ally is Britain, and yet Britain sometimes appears to be morphing into a dangerous enemy. This seems to be due to some 400,000 British-Pakistanis, especially those who emigrated from the Kashmir region. They often return to Pakistan, and while there some are believed to receive terrorist training. They mainly speak English, and they carry British passports. Some of them have been deemed responsible for terrorist activities, acting as extremely mobile and invisible ghosts, an essentially hidden enemy within the gates of America's closest alliances. ${ }^{78}$ As E. Balibar suggests, "Internal enemies would proliferate, featuring a sort of malefic double of the external regular enemy, indicating a point where the distinction between the stranger

\footnotetext{
${ }^{78}$ P. Bergen \& P. Cruickshank, "Kashmir on the Thames", London Broil, September 4, 2006 : http://www.peterbergen.com/bergen/articles/details.aspx?id=275.
} 
and the enemy becomes irrelevant". ${ }^{79}$ Along the same lines, D. J. Finlay, O.R. Holsti and R. R. Fagen remind us that "real and imagined enemies abound in politics. Identifying and combating them is an integral part of political life, and no social system could survive for long without some defense mechanisms to protect it from the 'forces working against it" $" .80$

As the concept of imperialism deepens into the shadow of simulation, a new myth of power begins to arise within the imperial specter, replacing the now-dead terminology of Cold War with the newly tailored conception of a "Long War". The American Enterprise Institute has established that there is now a vital necessity to recognize that the world is not simply fighting terrorism, but instead is fighting to produce a revolution in "the entire Islamic world". This new myth is worth quoting at some length:

In order to succeed in a struggle that will be fought on multiple fronts and will demand sacrifices from future generations, a sound strategy for fighting the Long War must be established... The Long War will ultimately be won or lost by future administrations and future generations of Americans.... Whether or not everyone is prepared to admit it, the United States is in this struggle for the long haul, and it is time to build the foundation of a strategy that will lead to victory... President Bush initially declared a "Global War on Terrorism", driving the Taliban from power in Afghanistan without capturing or killing Osama bin Laden. Al Qaeda the organization became al Qaeda the movement. Saddam Hussein was deposed in Baghdad, but the subsequent chaos spawned a vicious sectarian war in Iraq. The War on Terror had become the Long War....

T. Donnelly and C. Monaghan have come up with an even further mystifying answer:

What does that mean? Properly understood, the Long War is a struggle for the political future of the Islamic world, especially the Arab Middle East. It is a remorseless revolutionary conflict brought about by the inability of the region's governments - the artificial, post-colonial states created in the aftermath of World War I - to establish any lasting legitimacy in the eyes of their people.... It is also a war fought in the part of the planet that supplies the energy resources for the world's industrial nations - both the mature

\footnotetext{
${ }^{79}$ E. Balibar, "Strangers as Enemies: Further Reflections on the Aporias of International Citizenship", Palinurus: Engaging Political Philosophy, http://www.globalautonomy.ca/global 1/servlet/Xml2pdf?fn=RA Balibar Strangers.

${ }^{80}$ M. Edelman, Enemies in Politics, Chicago: Rand McNally, 1967, p. vi.
} 
economies of the West and the emerging economies of India and China.... And so it is that the conduct and outcome of the Long War may be the central narrative of international politics in the coming century. The stakes for the United States - the world's sole superpower, the preeminent power in an international system aptly described as the Pax Americana, and the guarantor of stability in the Persian Gulf - could hardly be higher; friends and foes alike will take their cues from American victory or defeat. ${ }^{81}$

The key to the Long War's ultimate impact lies then in its power to mobilize friendly and inimical forces through the symbolism and militarism of an all encompassing (Schmittean, Huntingtonian) war. To explore the nature of imperial power further, we now turn to the role of symbolicity as the all encompassing and all pervasive spectacle that underpins empire.

\footnotetext{
${ }^{81}$ T. Donnelly and C. Monaghan, "The Bush Doctrine and the Long War", National Security Outlook: AEI Online March 6, 2007. hutp://www.aei.org/publications/pubID.25720/pub detail.asp.
} 


\section{Chapter 3}

\section{The Spectacle}

In imperial society the spectacle is a virtual place, or more accurately, a non-place of politics.

\section{A. Negri \& M. Hardt ${ }^{82}$}

There is a distinction between politics as a spectator sport and political activity as utilized by organized groups to get quite tangible benefits for themselves. For most men most of the time politics is a series of pictures in the mind, placed there by television news, magazines, and discussions. The pictures create a moving panorama taking place in a world the public never quite touches.

M. Edelman ${ }^{83}$

Support for imperial power rests on the perpetual production and reproduction of a political spectacle. Since the continuity of the imperial realm cannot be entrusted to the arbitrariness of public opinion, it becomes necessary for the government to persuade and influence public opinion. In our age, the result is the fabrication and perpetuation of the political as the arbitrary, often times entertaining, spectacle of an equally arbitrary and entertaining imperial constitution.

The political spectacle consists of non-events, electronically and visually mediated events, and what D. Boorstin calls pseudo-events. ${ }^{84}$ In each case, the spectacle simulates power in the fictitious arrangement of the stage by arresting and suspending the real. Since these non-eventualities stage the power to move or imitate the real, they constitute the nonplace of politics as much as they constitute the place of non-politics, non-governmentality and resistance. Perhaps the secret of any power (to attempt to erase the scene of power), is no longer a secret, as Baudrillard initially thought, but has become a common

\footnotetext{
${ }^{82}$ A. Negri \& M. Hardt, Empire, Boston: Harvard University Press, 2000, p. 188.

${ }^{83} \mathrm{M}$. Edelman, Constructing the Political Spectacle, Chicago: University of Chicago Press, 1985, p. 5. ${ }^{84}$ D. Boorstin, The Image: a Guide to Pseudo-events in America. New York: Harper \& Row, 1964. Pseudo-events are events that happen only because there is the possibility for media coverage. Also, in Žižek's Plague of Fantasies, pseudo-events are the events that are of the order of fantasy, they are lies in the guise of authenticity - the coincidence of the two views could be found in some of Baudrillard's insights into the order of simulation.
} 
understanding that power no longer erases the spectacular scene of its appearance, but reproduces it in ever more convincing and subtle versions, so as to ensure its own spectacular propagation. In this way, power no longer deletes the undesirable backgrounds, but itself - its event, its presence, and its fabricated appearance.

In the smooth space of the spectacle, power is everywhere and nowhere, it is at once presence and absence, place and non-place, reality and utopia - it moves from one to the other in the smoothness of the visual, erasing the border between virtuality and reality, places and non-places, set-ups and acts, coalitions and betrayals. As such, it becomes strikingly recursive, turning itself not into an imperial power but into a political celebrity. In the US a "celebrity" is defined as a person who is well known by simply being celebrated, advertised, and invoked. A celebrity is what mass media make of it, and mass media, as D. Carter tells us, serve as a virtual "fourth branch of government" ${ }^{85}$ For J. Barbero, however, mass media are simply "machines that produce specters". ${ }^{86}$ They reference the beautiful, the dead, the accidental victims, the happy winners, continuously molding our imaginary and our ephemeral claims for power. They fabricate the present as pure and simple choreography, pure and simple death and life scenarios. At the other end of the spectrum, by becoming choreographic, power silently erases its own movement, its own scenario, and its own spectacle - its own event. As Z. Bauman seems to suggest, its "death stands for the unique, for the irrevocable, for the irreversible, for something that can't be repeated - for the 'point of no return', for 'once and for all", ${ }^{87}$

For Negri and Hardt, "the striated space of modernity constructed places that were continually engaged in and founded on a dialectical play with their outsides". 88 By

\footnotetext{
${ }^{85}$ D. Cater, The Fourth Branch of Government, New York: Vintage Books, 1965.

${ }^{86}$ J. Barbero, "The Media: Memory, Loss and Oblivion", GSC Quarterly, no. 4, Spring, 2002. http://www.ssrc.org/gsc/newsletter4/martinbarbero.htm.

${ }^{87} \mathrm{Z}$. Bauman, "Each Time Unique", Paper presented at the London School of Economics, Modernity Lecture Series, November, 2005.

http://www.lse.ac.uk/collections/LSEPublicLecturesAndEvents/pdf/20051108-Bauman3.pdf.

${ }^{88}$ A. Negri and M. Hardt, Empire, Boston: Harvard University Press, 2000, p. 190.
} 
contrast, the present space of imperial sovereignty appears smooth and homogeneous, much like the space of the spectacle (the alibi of power, but also the condition of its evanescence). "In this smooth space of Empire there is no place of power. Empire is outopia, or really a non-place". ${ }^{89}$ Yet, if Empire is a non-place, if it is, strictly speaking, the non-place of politics, or of political crisis, power is little more than the smooth appearance of the spectacle, the utopian facade of the spectacle: a facade impossible to resist, but also impossible to sabotage. This is why in the era of imperial domination the fundamental notion of resistance seems to be primarily about desertion - "this desertion does not have a place, it is the evacuation of the places of power...". ${ }^{90}$ As such, it stimulates the problematic question of betrayal: how are the places of power to be deserted if they do not even exist, if they are from the start non-places?

In the simulated order of the spectacle every non-place appears as a place by simply attempting to imitate the real. When the relation with the real ceases to exist, there is no longer anything but the spectacle: the non-place of the real. Reality ceases to attest itself, it ceases to have a place in the world due to its having given up its relation to space, that is, to the modern space of dialectics. The binary striations of modern space are replaced by the smoothness of imperial sovereignty and from now on it is the spectacle of space and not any real space that sustains the utopia of empire. Perhaps a good example of this is $S$. Walt's politicization of the imaginary, its converse elevation to the status of "real" problems, "real" questions and contexts.

Imagine, for a moment, that you are the president of_France. You regard US policy as often naive and overweening, and your ideal world order is one in which no single state is dominant. So what do you do about the United States? Now picture yourself as the president of Russia. The only remnants of your country's former superpower status are an aging nuclear arsenal and membership in the UN Security Council. How do you improve Russia's situation in a world dominated by US Power? Or perhaps you are the prime

\footnotetext{
${ }^{89}$ lbid.

${ }^{90}$ Ibid., p. 212.
} 
minister of India. You face serious regional challenges.... ${ }^{91}$

In Deleuze and Guattari, the smoothness of nomad space allows the utopia of empire to take root in the striated space of the modern state. In their version, it is not so much the utopian project of empire that is at stake, but space as such - the dialectical space of modernity confronted by the smooth space of imperial sovereignty. Sovereign space is characterized by collaboration whereas modern space is characterized by conflict, they stand in opposition and complement one another not only by virtue of their territorial composition, but also by virtue of their political composition. Inevitably, for Deleuze and Guattari, the problematic of empire opens itself up in the absence of space. It opens up to an essentially unanswerable question: what is the political composition of empire?

If the space of empire is utopian, as in Negri and Hardt, its political composition is given by the absence and non-eventfulness of the sovereign. If the space of empire is external to the state, as in Deleuze and Guattari, its political composition comes down to the mediated coexistence of two sovereign heads. If, by contrast, the imperial space is internal, as in P. Virilio, its political composition comes down to "the aristocracy, the military class, the bourgeois, each one fighting over its own proletariat". In each case, however, the space of empire is "no longer a question of the ideology of power but of the scenario of power", ${ }^{92}$ which is to say that one no longer defines power in its relation to ideas and spaces but deals with a projected series of actions and events conducive to its enhancement or its diminution.

When J. Baudrillard says that, "power floats like money, like language, like theory", he makes the triadic presence of markets, discourses and theories, into the very substance of power. In a similar fashion, A. Negri and M. Hardt replace the panoptical diagram of modern power with an ergonomic diagram of imperial spatiality. With G. Bataille, the

\footnotetext{
${ }^{91}$ S. M. Walt, "Taming American Power", Foreign Affairs, September/October 2005. http://www.foreignaffairs.org/20050901 faessay84509/stephen-m-walt/taming-american-power.html. ${ }^{92}$ J. Baudrillard, Simulacra and Simulation, Ann Arbor: University of Michigan Press, 1994, p. 27.
} 
accursed share of modern growth (i.e., of infinite accumulation) is replaced by the accursed share of luxury discharge; the modern market is replaced by the postmodern hypermarket (J. Baudrillard, Simulacra and Simulation); the economy of the commodity is replaced by the economy of the body (M. Foucault ${ }^{93}$ ); the rights revolution is replaced by the marketability of rights (M. Ignatiev ${ }^{94}$ ). In short, where there is power, there is also a market for power, a language, and a theoretical background.

In Foucauldian terms, one could say that every regime of power has its own Market, its own Discourse and Theory. In our time, the discourse of the market has become the political and theoretical drive par excellence. It sets up the spectacle of power and of knowledge in such a way that economic reasoning becomes the sole measure of justice, or rather its sole authority. In this sense one can say that economy is the very spectacle of the political, its raison d'etre, but also its esprit de corps. In the process of politicalization, bargaining revolves around the distribution or redistribution of tangible resources. We live in an apparently democratic age, so this form of politics occurs behind closed doors, in lobbies and corridors, in think tanks and corporate boardrooms. ${ }^{95}$ The other form of politics revolves around the political spectacle, in which the public - who is left out of bargaining venues- receives continual symbolic reassurances that its interests are well looked after, and that military personnel operating in foreign imperial resource wars, is fighting for peace and democracy, values and principles, freedom, justice and equality for all.

According to A. Giddens, the presence of authority is "closely bound up with a further dimension of modernity: control of the means of violence". ${ }^{96}$ Modern power and modern knowledge appear to have given rise to a particular economy of violence, more

\footnotetext{
${ }^{93}$ See, e.g., Discipline and Punish: the Birth of the Prison. New York: Vintage Books, 1995.

${ }^{94} \mathrm{M}$. Ignatiev, The Rights Revolution, Anansi, Toronto, 2000.

${ }^{95} \mathrm{R}$. Presthus, Elites in the Policy Process, New York: Cambridge University Press, 1974.

${ }^{96}$ A. Giddens, Beyond Left and Right, New York: Polity Press, 1994, p. 12.
} 
precisely, to an economy substituting violence with authority, reality with the world market, wealth with power. In short, they give way to an economy of substitution - to a spectacle of the spectacle.

As spectacle, power punishes and liberates by inverting not only the meaning of authority and justice, but also the relation between them: "in these executions, which ought to show only the terrorizing power of the prince, there was a whole aspect of the carnival, in which rules were inverted, authority mocked and criminals turned into heroes". ${ }^{97}$ As a punishing site, "the public execution did not re-establish justice, it reactivated Power". ${ }^{98}$ Mockery, or entertainment, established the measure of liberation from the effect of power, from its crude reactivation, or its justice. In the end, what the spectacle of the execution did was to bring the executioner and the victim so close together that it became virtually impossible to tell them apart - in Foucault this coincidence is set aside in favor of an archeology of power, or rather of punishment, an archeology which culminates with the birth of the prison as the embodiment of modern power.

Modern power reasserts itself through the institution of punishment, and especially through the spectacle of such punishing institutions as the prison, the asylum, the school, the national museum. This is how it reactivates the multitude, the disciplined mass dispersed throughout the institutional arrangement of the spectacle. At this point and at this point only, the multitude promises to re-activate Power by appropriating the meaning of the spectacle. The appropriation is and remains phantasmal since the multitude is in no position to get hold of (any aspect of) power, to punish the guilty party and turn that punishment into an effect of its presence, that is, into another spectacle, another method, or another inexhaustible set-up.

\footnotetext{
${ }^{97}$ M. Foucault, Discipline and Punish, New York: Vintage Books, 1995, p. 61.

${ }^{98}$ Ibid., p. 49.
} 
Power tends to become equivalent to its effect, to its continuous reactivation as a human specter of meaning and justice. The panopticon is not only the diagram of modern power, it is also the spectacle of modern power, the concrete set-up representing the omniscience of powerful images and relations inside the institution, the market, the state. Through it, the relation between the victim and the executioner ceases to be the measure of reality and becomes the effect of capital; the spectacle itself is no longer a mere spectacle of punishment but of aesthetic terror. Through this terror the diagram of modern power migrates from the panopticonical spectacle to the spectacle of the market - i.e., one pays if one wants to see or be seen.

In G. Bataille, the management of such inevitable migrations is the work of that "self-consciousness that man would finally achieve in the lucid vision of its linked historical forms". ${ }^{99}$ General economy as the proper diagram of imperial power reflects the becoming of self-consciousness, the overcoming of the world of things through its extreme affirmation, through consumption rather than accumulation, through the revival of the intimate order rather than through the spectacle of the world of things. Intimate order is also a spectacle, the lost order of the consciousness of things, the last spectacle encountered by self-consciousness: it simulates the freedom of the unconscious, the fugitive escape from the order of things, the returning "home" of self-consciousness.

The "accursed share" no longer appears as a share, nor as a curse, but rather as the spectacle of the intimate order attempting to transfer its principle (back) to the order of things. In J. Baudrillard's words, "it is no longer even the 'accursed share', the one conceded to destiny by the system itself, and included in its general reckoning. Everything is reversed". ${ }^{100}$ From here on, human destiny (re)asserts itself in and through the dispersion of the accursed share: "the problem of the squandering of excess in Bataille is not different

\footnotetext{
${ }^{99} \mathrm{G}$. Bataille, The Accursed Share, New York: Zone Books, 2002, p. 41.

${ }^{100}$ J. Baudrillard, Simulacra and Simulation, Ann Arbor, MI: University of Michigan Press, 1994, p.113.
} 
from that of the reabsorption of remainders in a political economy of calculation and penury..." ${ }^{101}$ In truth, "there is no longer even a remainder, due to the fact that the remainder is everywhere...". ${ }^{102}$

This unexpected reversal involves a further shift of consciousness: the conservatives becoming radicals, the Americans clothing communism, the socialists becoming neoconservatives (as in A. Giddens ${ }^{103}$ ). No one or nothing remains as it was, as it is. Instead, everything is swept away by the power of appearances - everything succumbs to the intimacy of the spectacle, to the debauchery of seeing and/or being seen. Indeed, there is another world outside the scene - the absent world of the spectator, the silent, unrecoverable world of the Real, which is best captured in and through the spectacle of the real, the story, the mirror-image, the exception. Of course, the spectacle operates alongside the Real. T. R. Dye traces this operative tandem to a symbolic fall from the Real, but also to a resurrection of reality at the very heart of the spectacle:

The principal source of distortion in the [American] news is caused by the need for drama, action, and confrontation to hold audience attention. NBC news executive producer Reven Frank advised his producers in a memorandum: 'The highest power of television journalism is not in the transmission of information but in the transmission of experience - joy, sorrow, shock, fear - these are the stuff of news. ${ }^{104}$

In truth, the spectacle takes control over the imaginary, while the real order subsists only indirectly: it comes forth as a thing to be forgotten, to be put off. Like religion, the spectacle rescues the real from its own tragedy. Promise, hope, the imaginary, involve a methodical economization of the psyche, an unconditional surrender to tragedy, the tragic, tragedizing. From this perspective, Disneyland is not a deterrence machine, as Baudrillard would have it, but a saving machine, a veritable saving arch - it purifies, it anesthetizes, it

\footnotetext{
${ }^{101}$ Ibid., p. 146.

${ }^{102}$ Ibid.

${ }^{103}$ See, for example, Beyond Left and Right, New York: Polity Press, 1994.

${ }^{104}$ T. R. Dye, Who's Running America: The Carter Years, $2^{\text {nd }}$ ed. Englewood Cliffs, NJ: PrenticeHall, 1979 , p. 98 .
} 
clears the imaginary of all real imperfections. It saves man from the assault of the real by materializing his desires. In the last analysis, the aim of the spectacle is the simulation of a desirable/pleasurable reality, which does not deter the crowd, but lets it indulge the fantasy of being imagined and imagining itself.

Perhaps the real coincides with the spectacle (of the real) in the crowd, where there is no longer any difference between being real and being imagined. Perhaps the tragedy of the real is being imagined, more precisely, being imagined in such a way as to save itself from itself. Differently put, when the only escape from reality seems to be the spectacle (of the real) and the only escape from the spectacle seems to be reality (the reality of the spectacle), the only thing they have in common is an irresistible economization of the psyche, a constant devising and revising of modalities of escape from both spectacle and "paramount reality". 105

Capitalism is such an economy of salvation, such a methodical devising and revising of escapes from the poverty of existence. Since M. Weber, capitalist ethic has been coincidental with capitalist industriousness, with a working mentality, or a working class capable of devising the means of its own survival. Capital and work had become the central tenets of capitalism - the universal models of saving bodies and saving enterprises. The prison is such a saving enterprise, just as television is, or the government, the school, the hospital, the church. They do not serve, nor deter man, at least not primarily - they simply save him. In short, capitalism sets up the secular spectacle of the puritan saving himself through his own industriousness; of the Christian saving himself according to a divine plan (a sort of "selective preservation, or even reinvention, of tradition") ${ }^{106}$; of the Muslim world saving itself through a holy war; or of the Oriental saving himself through mystical practices, martial arts and meditation. Capitalism as "set-up", or (en)framing -

\footnotetext{
${ }^{105}$ S. Cohen and L. Taylor. Escape Attempts: the Theory and Practice of Resistance to Everyday Life, London \& New York: Routledge, 1992.

${ }^{106}$ A. Giddens, Beyond Left and Right, New York: Polity Press, 1994, p.12.
} 
this is the new saving enterprise, the new face of capital, the new form of betrayal of the other

G. Bataille called these capitalist enterprises "synagogues". He probably had in mind some traditional space of worship and religious instruction, not the protestant substitution of faith with money, nor the naive illusion that money can buy anything, such as health, happiness, time. Faith in money is a faith that no longer invests the divine with the power to oversee man's affairs, but invests man's affairs with the supernatural power of the divine. Man saves himself through faith in his eternal presence, even more than that, he buys himself time to deceive the other through the supernatural order of capital.

He buys and sells, he negotiates, he offers in exchange - his entire life is capital, his thoughts, his desires, his time, have become the living substance of capital. His friends and acquaintances become social capital. ${ }^{107}$ He himself is nothing more, nothing less than this living capital, this living substance selling, buying, negotiating, and exchanging itself $-\mathrm{a}$ true Heideggerian "being-in-the-world", being there, being offered. A commodity in the making, a commodifying thrust - a function, a spirit, or a consciousness of exchange?

A. Giddens pointed out that "unchecked capitalistic markets still have many of the damaging consequences to which Marx pointed, including the dominance of a growth ethic, universal commodification and economic polarization". ${ }^{108}$ The commodification of the worker, together with the economic polarization brought about by the ethic of growth, threaten the equilibrium of the system (a bourgeois idea), that is, the equilibrium of free and unchecked exchanges. However that may be, it is hard to see how uncontrolled markets could lead to a universal ethic of growth or even to an economic polarization of the world, since there is no center and no control over its economic operations. Rather the reverse is true, controlled markets/exchanges develop an ethic of growth that will

\footnotetext{
${ }^{107}$ T. Voss and M. Abraham, "Rational Choice Theory in Sociology: A Survey", S. R. Quah and A. Sales, eds., International Handbook of Sociology, London: Sage, 2000.

${ }^{108}$ A. Giddens, Beyond Left and Right, New York: Polity Press, 1994, p. 11.
} 
eventually upset the economic balance of the world-system.

However, what interests us here is not the ethic of growth but the invention of the market as a system of saving lives, saving souls and bodies - a machine overseeing all operations, all trades, and all the other machines. There is no ethic here, no growth in the human sense of the term, there is only the authority of capital, the terrifying barter of the human world:

Let heavy taxes be levied on livery servants, carriages, mirrors, chandeliers and furnishings, on fabrics and gilding, on the courtyards and gardens of large homes, on public entertainment of all kinds, on the idle professions, such as those of buffoons, singers and actors, and, in short, on that group of objects of luxury, amusement and idleness that catch everyone's eye and that can scarcely be hidden, since their whole purpose is to be on display, and they would be useless if they should fail to be seen. ${ }^{109}$

The whole spectacle of the visible succumbs to the incommensurability of desire, it makes itself into the desire of desire, as it were, into a market of desiring desires: a Kojevian milieu of biological encounters and escapes, a biological capital. The things on display give the impression of reality, their existence is desired/desirable - man himself is such a real, displayable "thing", such a desire desiring itself. He is himself a spectacle, a marketed desirability, a visible milieu (i.e., a face, a body) of infinite wealth and infinite meaning. His education is a well of "human capital", his network of friends and acquaintances are turned into social capital, and he himself becomes a means of commodifying friendship, love, capital, society, etc. Within the realms of the (imperial) spectacle, every aspect of his life is thus subjected to commodification and betrayal.

To those who are immersed in the spectacle, there is no longer any similitude, any proximity or distance attributable to things and people. They coincide right from the beginning, their worlds are brought together through the smoothness of appearances and desires - the spectacle is this coincidence of the real with the imaginary, of things and men,

\footnotetext{
${ }^{109}$ J.J. Rousseau. Basic Political Writings. Indianapolis, IN: Hackett Publishing Company, 1987, p.137.
} 
visibility and invisibility. In it, there is no distinction, no proximity other than the gaze of the actor/spectator, who embodies the (in)visibility of the visible - the stance, the posture, the volatile instantiation of a perpetual rite. The spectacle itself becomes the Play land of modern man - a scene, a set-up, a "country whose inhabitants are busy celebrating rituals and manipulating objects and sacred words, whose sense and purpose they have, however, forgotten". 110

Let's see - President Bush lands on an aircraft carrier in a 'fixed-wing aircraft' - that's military talk for 'airplane'. He hops out of it in full military flight suit looking every bit the dashing hero. The staging of this political spectacle was so well done that hardly anyone is questioning the reason behind, or the danger of, having a president land in such a fashion.

The reason is simple: He looked great doing it. And it made great TV.

In today's media environment, it's difficult to argue with a powerful image. Logos cannot drive out pathos. ${ }^{11}$

The role of ritual used to be therapeutic, to lead to catharsis. In the imperial age, however, ritual has come to acquire another role: to compress the real in such a way as to become "the potential basis for a new freedom for man". ${ }^{112}$ The machine for example, is pure compression, pure freedom. It instantiates the visible and the invisible, thing and desire, movement and immobility; it opens up a space of infinities, a non-place, an alibi of form, which is nothing but emptiness and fullness, oneness and multiplicity. The spectacle is mechanistic, but also real, even human. It is a display - an infinite potential for a new economy, a new freedom, a new tragedy. In it, "nothing will be left to chance", 113 , nothing at all - not even freedom. In it, there is only infinity, pure, apparent, infinite infinity of purity and simplicity, of speed and repose, exteriority and interiority, collaboration and betrayal.

\footnotetext{
${ }^{110} \mathrm{G}$. Agamben, Infancy and History: On the Destruction of Experience, London and New York: Verso, 2007, p. 79.

111 http://rhetorica.net/archives/001202.html.

${ }^{112}$ H. Marcuse, One-Dimensional Man, Boston: Beacon Press, 1966, p. 3.

${ }^{113}$ J. Baudrillard, Simulacra and Simulation, Ann Arbor, MI: University of Michigan Press, 2004, p.34.
} 
M. Foucault uncovered psychological terror as lying at the foundation of modern justice; it was no longer the body that needed to be punished, but the soul as the seat of ideas; it was no longer freedom that was sought but the idea of freedom as an escape from punishment, or rather from the idea of punishment. Ideology embodied the new economy of ideas, the new form of punishment and salvation - the pseudo-ethereal means of manipulation and control. H. Marcuse came close enough in suggesting that being "totalitarian is not only a terroristic political coordination of society, but also a nonterroristic economic-technical coordination which operates through the manipulation of needs by vested interests". ${ }^{114}$ But he missed the point of economic totalitarianism, of the politico-technical coordination of society through the terrorist manipulation of ideas, that is, of "the organization of a confrontation between the art of being governed and that of not being quite so governed". 115

Perhaps a good illustration of such a daunting confrontation is the organization of political space itself, the rift, or artistry, of governing by absence, by making the very concept of empire look like an Empire through a constant dismissal of its claims, its presence, its status. "Knowledge is power. But what is power?"116 ask R. Keohane and J. S. Nye, while carefully drawing a dividing line between the softness and hardness of imperial power, between informing and occupying imperial space, or between globalizing and economizing imperial subjectivity. Along the same lines, N. Ferguson agrees that "imperial denial is a fascinating condition", while claiming that America is an empire in and of itself - a confrontation in the making as it were, between the power of governing and the ghost of its denial. In the words of R. Kagan, "the US is neither an empire, nor should it become one. Rather - this is no simple semantic distinction - it is the most successful hegemon, the

\footnotetext{
${ }^{114}$ H. Marcuse, One-Dimensional Man, Boston: Beacon Press, Boston, 1966, p. 3.

${ }^{115}$ M. Foucault, The Politics of Truth, S. Lotringer \& L. Hochroth, eds., New York: Semiotext(e), 1997, p. 47.

${ }^{116}$ R. Keohane and J. S. Nye, "Power and Interdependence in the Information Age", Foreign Affairs, vol. 77 no. 5, September/October. 1998, pp. 81-94.
} 
most successful global power in history". ${ }^{117}$ As such, "we could not stop it even if we wanted to, because ideological expansionism is embedded in the American DNA". 118

Whether it is terror, the "rule of law", the democratization of values, or the mood for foreign policing, the indecision concerning imperial politics remains the most vivid characteristic of American power. Throughout the $20^{\text {th }}$ Century, both the " $\mathrm{E}$ word" and the "I word" were firmly tabooed, while the political as indecisiveness between governing and being governed turned into the decisive mark of American power, American politics and artistry.

As a matter of fact, “... these relationships between power, truth and the subject appear live on the surface of visible transformations". ${ }^{119}$ Except in the Middle East, the spectacle of the scaffold is long gone from sight as well as from our memory, it no longer threatens anyone with the unpleasant sight of decapitation, nor with the ruthlessness of the executioner as the representative of justice, but it remains live on the surface of our consciousness, it guides it as it were towards a different reality, a different truth. Indeed, there is no need to contemplate the spectacle of the scaffold to have a notion of justice, the idea of justice suffices to restore the terrifying aspects of authority, the guilt, or the inescapable sentiment of being alive due to terror. According to J. Rancière, this is precisely the manifestation of police order, the kind of sophisticated distribution of what we are and are not able to do. ${ }^{120}$ Reality, our reality, is no longer manipulated through the

\footnotetext{
${ }^{117}$ R. Kagan, "America as Global Hegemon", National Interest, vol. 2, issue 29, June 2003. http://www.inthenationalinterest.com/Articles/vol2Issue29kagan.html.

${ }^{118}$ R. Kagan, "America and Empire", Interview with R. Kagan by J. Glazov, December, 2006. http://www.frontpagemagazine.com, Dec. 2006.

119 Ibid.

${ }^{120}$ «'Rancière uses the term 'police order' to describe the major part of what we normally understand as politics - the structured embodiment of a society where everything has its place. The police order is the government or process of governance that prescribes our reality or our sensibility - in relation to the underlying norms that define what is allowed or not allowed, available or unavailable in a given situation - in the realm of perception itself. Almost like a code of conduct. There is therefore an underlying division that dictates what can and cannot be said, shown, or done. This creates permanent sets of norms which in turn establish a community that decides who is included or excluded, whose words are significant or insignificant, who is entitled to govern others and who is not".

http://www.eurozing.com/articles/2006-08-11-lieRancière-en.html; 1. Rancière, "The Police Order -
} 
spectacle of the scaffold, there is something more terrifying and more subtle than the publicity of the execution: the idea of the execution - its enlivening spectacle.

In this opening, or enlivening mood, the administration of punishment becomes indistinguishable from the economy of salvation, just as the spectacle of authority becomes indistinguishable from the administration of justice: the idea of execution brings together authority and victim, justice and injustice, punishment and salvation, in such a way that an entire economy of power is effected. The spectacle itself is little more than this economical relation of an emotion to another emotion: an entire economy of saving and punishing effects. In this economy, it no longer matters whether authority is celebrated or denigrated, or even whether the victim is guilty or innocent. ${ }^{121}$ The spectacle entertains both the illusion of authority and the presence of the victim - it economizes their relation in such a way that power is permitted to flow "like money, like language, like theory".

Finally, what could be more convenient to truth than the idea of an economy of ideas? What could produce more wealth than the idea of a wealthy truth? Ideas as the true wealth of power, as its raison d'etre - this is the Greek truth, the Greek tragedy. It is also post-modern, post-tragic Greekness: a footnote not to Plato, but to truth, to wealth, to the inalienable and insatiable presence of the tragic. Politically, economically, socially, we produce truth as wealth, "we must produce truth in order to produce wealth in the first place". ${ }^{122}$ Our tragedy is our truth, our being produced by and producing the wealth of truth, which is also, at the same time, the truth of wealth - the truth of power. But what does it mean to produce truth in order to produce wealth? Is it even possible to produce truth as wealth, truth, the truth of power?

\footnotetext{
What can be Said, Seen, and Done: An Interview with Jacques Rancière", Palinurus: Engaging Political Philosophy, issue 12, February 2007. http://anselmocarranco.tripod.com/id58.html.

121 "Plea bargaining is a significant part of the criminal justice system in the United States - the vast majority of criminal cases in the United States are settled by plea bargain rather than by a jury trial". In plea bargaining the question of guilt or innocence is simply not judicially addressed. http://en.wikipedia.org/wiki/plea bargaining.

${ }^{122}$ M. Foucault, Power/Knowledge, New York: Colin Gordon, 1998, p. 95.
} 
According to R. Niebuhr, the imperial spectacle's amelioration of social tensions through the single-minded pursuit of economic growth has created a culture in which the standard of living has become the final norm of the good life, and which regards the perfection of technique as "the guarantor of every cultural as well as of every social-moral value". ${ }^{23}$ This development sets up cultural blinders, which further militate against the very perception, or manifestation, of truth.

D. Nimmo and J. E. Combs argue that in the imperial present truth has decisively lost out to fantasy, and that due to their dramaturgical genius the imperialists are subjecting the world to their own fantasies. In their view, this is not the Age of Imperialism but instead the Age of Fantasy. So recurring are imperial fantasies that their arresting power lies firmly in the realm of the spectacular: "dramatic, sometimes credible accounts accepted at face value . . cannot be proved true or false". ${ }^{124}$ Beyond mere fantasy, however, there is a burgeoning in the imperial spectacle of designed experiences: "Designed experiences thus take mediated realities, that is, fantasies, and turn them into experienced realities....". ${ }^{25}$ The encounter between fantasy and experience is unique, irretrievable, non-reversible. It stands by-itself precisely because "death is the only meeting point between human experience and 'eternity' - a condition known to mortals solely in its denial". ${ }^{26}$

Perhaps we can trace the need for the ubiquity of fantasy and experience to the very heart of empire, to the rhythmic beating of its truth and/or of its power, or to their ambiguous and indelible absences. For that, we now turn to an examination of the concept of empire itself.

\footnotetext{
${ }^{123}$ R. Niebuhr, Irony of American History, New York: Charles Scribner's sons, 1962, p. 57.

${ }^{124}$ D. Nimmo and J. E. Combs Mediated Political Realities, $2^{\text {nd }}$ ed., New York \& London: Longman, 1990, p. 225.

${ }^{125}$ Ibid., p. 226.

${ }^{126}$ Z. Bauman, "Each Time Unique", Paper presented at the London School of Economics, Melting Modernity Lecture Series, November, 2005. http://www.lse.ac.uk/collections/LSEPublicLecturesAndEvents/pdf/20051108-Bauman3.pdf.
} 
Chapter 4

\section{The Concept of Empire}

The actual geographical possession of land is what empire in the final analysis is all about.

$$
\text { E. Said } \text { S27 }^{27}
$$

The empire, being the universal thing (whose universality reveals the void), insofar as its essence is a diversion of violence to the outside, necessarily develops the law that ensures the stability of the order of things.

$$
\text { G. Bataille } e^{128}
$$

The conceptualization of important political terms always seems to be ambiguous, filled with ghostly meanings, discordances, or sympathetic cordialities. This is certainly the case with respect to the volatile specter of terms revolving around various aspects of the intrusion of a powerful state into the affairs of a less powerful one. The major problem seems to lie in the fact that there are two contending forms of imperial constitution. The first is unilateral imperial domination resting on the projection of an imperial center, which is a fairly classical form of imperialism. The second form is what A. Negri and M. Hardt call Empire, that is, a multilateral and non-state-centered form of dominance, based on treaties, international regimes, interlocking institutions, and instantaneous forms of communication, data and money transfers. Empire, in this sense, seems to have come into its own by incarnating the globalization trend that followed the Soviet Union's collapse, and by stretching its corporeal scales into a global capitalist system. Although this incarnation of empire seems to be the prominent feature in regards to imperial domination, it nonetheless owes its prominence to the concomitant reduction of the imperial specter to its newly projected center.

The first quotation above brings to mind a definition of empire based on the fluidity

\footnotetext{
${ }^{127}$ E. Said, Culture and Imperialism, New York: Vintage Books, 1993, p. 78.

${ }^{128} \mathrm{G}$. Bataille, Theory of Religion, New York: Zone Books, 2001, p. 67.
} 
of borders as the most uncertain and undisclosing limit of geographical space. It does so by relating the finality of possession to that of analysis and by making possession the (de)limiting essence of empire. The second quotation brings to the fore the universality of empire, its hegemonic capacity to divert violence to the outside in order to obtain and stabilize the law (i.e., regarding violence) as the most intimate order of things. For E. Said, the possession of land is an immediate guarantee of stability, while for G. Bataille, stability ensues as soon as the essence of empire reveals the void within and diverts its violence towards the outside. In both cases, the essence of empire reflects the uncertain character of the world of things, its possession and its orders, or rather the intrinsic violence with which one possesses and orders human surroundings.

In 2003, The Social Science Research Council decided to consider the concept of empire and its applicability to United States foreign policy. The explanation was:

Now that the idea of an American empire has entered public discourse ... it is important to ask whether this is a helpful conceptual category with which to understand the U.S. role and project in an evidently unipolar world. The question is significant in part because the word 'empire' and its related concepts, 'imperial' and 'colonial,' carry the heavy weight of a much contested history in which colonizing Western powers, both European and American, dominated large portions of the world. ${ }^{129}$

Out of this revisitation of the concept of empire came a set of distinctions concerning how a powerful polity may intervene in the affairs of others less powerful. Most simply put, these include: "imperial (intervening in a polity without actually governing it), hegemonic (setting the rules of the game that others must follow), and colonial (governing internal affairs of a subordinated polity)". ${ }^{130}$ Given these distinctions, it is clear that imperial domination rests, often concertedly, on all of these ways.

\footnotetext{
${ }^{129} \mathrm{http}: / / \mathrm{www} . \mathrm{ssrc}$.org/programs/europe/Empire.page.

${ }^{130}$ C. Calhoun, F. Cooper and E. W. Moore, "Introduction", C. Calhoun, F. Cooper and E. W. Moore, eds. Lessons of Empire: Imperial Histories and American Power, New York \& London: New Press, 2006, p. 2. F. Cooper adds a rather severe qualification: "Yet those distinctions say both too much and too little: not enough to distinguish the vast differences in process and effect within each, too much to understand the ambiguity and the interplay among them". "Modernizing Colonialism and the Limits of Empire", Ibid., p. 64.
} 
The 'new' empire, however, is unusual in several respects. First of all, it operates on the basis of a working definition of a rogue state, "whose sovereignty is unworthy of respect", or has become an “'enemy combatant' unworthy of protection under American law or Geneva conventions...". ${ }^{131}$ Within the imperial specter, ever new distinctions are continually being made about which nations merit respect for their sovereignty and which do not, ${ }^{132}$ pointing to the arbitrariness of such distinctions or merits. Military aggressions designed to capture enemies are based on this shifting specter of distinctions and merits, sovereign worthiness or unworthiness, the presence or absence of law. Secondly, there is a contradictory trend in international policy to back up the use of unilateral power (in order to shore up the global capitalist order), while also to view unilateral military intervention as ill-justified, or ill-intended in its attempt to capture foreign resources, at a time when the extravagance of 'air shows', as W. E. Connoly reminds us, has already blown off "the roof of the territorial state." 133

One way in which the 'new' empire is not different from others is the overt insistence upon "exceptionalism", upon being different due to a higher purity of motive, an unselfish mission to bring enlightenment, civilization and democracy, to the dark places of the world. Every historical empire has made a similar claim, and so one may conclude, with E. Said and with A. L. Stoler, that "discourses of exceptionalism are part of the discursive apparatus of empires themselves". ${ }^{134}$

Right from the start, the presence of empire, in its imperial, hegemonic and colonial versions, tends to emphasize the need to posses and order biological space by controlling and directing its potential for violence. On the one hand, the overall capitalist system

\footnotetext{
${ }^{131}$ Ibid., p. 3.

132 Ibid.

${ }^{133}$ W. Connolly, "Democracy and Territoriality", Millennium: Journal of International Studies, 1991 , vol. 20 , issue 3 , p. 474

${ }^{134}$ A. L. Stoler, "Imperial Formations and the Opacities of Rule", C. Calhoun, F. Cooper and E. W. Moore, eds. Lessons of Empire: Imperial Histories and American Power, New York \& London: New Press, 2006, p. 57; emphasis in the original.
} 
includes (or rather tames) resistance by incorporating it in its guised form of paramount reality, an eternally generative and apparently generous order of things, or simply the way things are (given nature); on the other, the concept of empire, which is never stabilized, never endowed with a solid essence, operates at the level of the nation-state in a continual effort to expand its influence through the systematic use of either actual violence or the threat of violent intervention. Perhaps it is a matter of irony that any state (not just America) should stand at the head of the two forms of imperial dominance, while being incessantly torn apart by their inescapable contradictions.

American theologian R. Niebuhr might have been right in his ironical assessment of the rupture between the presence of imperial virtue and its underlying innocence: "the irony of our situation lies in the fact that we could not be virtuous (in the sense of practicing the virtues which are implicit in meeting our vast world responsibilities) if we were really as innocent as we pretend to be". ${ }^{135}$ He argued that imperialists have deceived themselves when bolstering imperial power through covert rather than overt instruments, especially the use of economic power and the secretly conveyed threat of political violence, which in turn depend upon the use of even more (covert) political and military resources. $^{136}$

Following the same lines, though in the opposite direction, E. H. Carr would argue that imperialism ought to precede empire, if only by virtue of tearing down "the whole cardboard structure of utopian thought", which is to say, by making realism real, powerful, overt, really, by making it an empire-in-and-of-itself. ${ }^{137}$ As J. A. Motyl remarks, "one common mistake is to conflate empire and imperialism, even though the first is a type of polity and the second a type of policy". 138

\footnotetext{
${ }^{135}$ R. Niebuhr, The Irony of American History, New York: Charles Schribner's Sons, 1962, p. 23.

${ }^{136} \mathrm{Ibid}$., p. 41 .

${ }^{137}$ E. H. Carr, The Twenty Years' Crisis, Wiltshire: Anthony Rowe Ltd., 2001, p.62.

${ }^{138}$ J. A. Motyl, "Empire Falls", Foreign Affairs, July/August 2006.
} 
Covert acts of violence are designed to exploit the instability of geo-political borders, while claiming to stabilize them, to ensure the universality of law, or of the diversion of violence towards the outside. To put it in N. Ferguson's words: "the periphery needs to be controlled: the borders are the danger zones". ${ }^{139}$ The expulsion of violence towards the periphery is supposed to ensure (if not legitimate) the interiorization of order, and viceversa - in a symbiotic (en)folding of spaces and concepts, appearances and essences, economies and discourses. That these are the intended effects of imperial constitution, is beyond question. The unintended effects, however, materialize in the struggle over the "reconfiguration of the homeland, its defense, and who has a right in it". ${ }^{140}$ Efforts to ferret out the enemy within have produced what the American Civil Liberties Union has called the greatest civil liberties crisis: "vigilance and suspicion join with tolerance and compassion as sources of national pride and patriotic duty". ${ }^{141}$ As A. Roy puts it:

If it isn't the Communists, it's al Qaeda. If it isn't Cuba, it's Nicaragua. As a result, the most powerful nation in the world is peopled by a terrified citizenry jumping at shadows. A people bonded to the state not by social services, or public health care, or employment guarantees, but by fear. ${ }^{142}$

A. Negri expressed the connection between the interiority and exteriority of violence in a well known sentence: "Authoritarianism is structural, fascism is constitutional". ${ }^{143}$ Depending on the direction it takes, violence develops into a structural or a constitutive ideology, into a structuring or a constitutive economy of force. In the order of analysis, empire is reduced to this economy of violence, which constitutes and preserves its universality by administering its force. Even more than being a matter of possessing land, or of directing violence towards it, empire is about re-inventing, re-constituting and re-

\footnotetext{
${ }^{139}$ N. Ferguson, introducing "Empire: The Rise and Demise of the British World Order and Lessons for Global Power”, at Carnegie Council, Books for Breakfast Program, Sept. 2003.

${ }^{140}$ A. L. Stoler, "Imperial Formations and the Opacities of Rule", C. Calhoun, F. Cooper and E. W. Moore, eds. Lessons of Empire: Imperial Histories and American Power, New York \& London: New Press, 2006, p. 58.

${ }^{141}$ Ibid., p. 59.

${ }^{142}$ A. Roy, "People versus Empire", In These Times, January 2005; http://www.thirdworldtraveler.com/Arundhati Roy/People vs Empire.html

${ }^{143}$ A. Negri, Time for Revolution, New York: Continuum, 2003, p. 83.
} 
structuring space through constant appropriation and expropriation, constant voiding and filling of both space and violence. As M. Connelly writes: "regardless of how it is justified or achieved, imperialism is the pursuit of unaccountable power". ${ }^{144}$

Bio-political space is at once authoritarian and fascist, possessive and violent, structuring and constituting: it is the mirror image of colonized space, of colonizing violence and possessiveness, essence and appearance, center and periphery. Its constitutive act is the immediate decolonization of the violent at the same time at which its structural composition presupposes the decolonization, (de)constitution, of actual possessions. Biopolitics reverses colonization by (in)violating violence and by dispossessing possession, that is, by re-constructing the archaeologies of violence and property from the point of view of peace and of communism.

From a European perspective, the expropriation and collectivization of contemporary (de)colonization is the effect of a double reduction. As Negri reminds us, the double of imperialism is terrorism. ${ }^{145}$ That is, when man is "being reduced to thinghood by the operation, all that he can do is to undertake the contrary operation, a reduction of the reduction". ${ }^{146}$ Such is the privilege of clear self-consciousness, the indubitable recognition of the fact that by "flirting with Hegel, one could say that the construction of Empire is good in-itself but not for-itself ${ }^{147}$ By contrast, in A. Negri's and M. Hardt's Empire, the transcendental and the immanent are brought together in one stroke, although for different reasons and different aims. Through their brief coincidence the concept of Empire commences its work towards liberating and economizing geographical space, towards the survival and termination of some regime or another, towards the inevitable rupture and

144 M. Connelly, "The New Imperialists", C. Calhoun, F. Cooper and E. W. Moore, Lessons of Empire: Imperial Histories and American Power, New York \& London: New Press, 2006, p. 19.

${ }^{145}$ A. Negri, "Ruptures Within Empire, The Power of Exodus, An Interview with Toni Negri by Giuseppe Cocco and Maurizio Lazzarato", translated from the French journal Multitudes (Issue No. 7) by T. Seay and "Hydrarchist": http://www.generation-online.org/t/empireruptures.htm.

${ }^{146} \mathrm{G}$. Bataille, Theory of Religion, New York: Zone Books, 1989, p. 99.

${ }^{147}$ A. Negri and M. Hardt, Empire, Boston: Harvard University Press, 2000 , p. 42. 
suture of old and new structures, without ever reaching the completion of any of these stages, without ever bringing them to a close. The concept remains vain in-itself, universally (re)constituting and (re)structuring. To a certain extent, as F. Cooper suggests, "empire is used more as a metaphor than as a category that designates a particular form of polity". ${ }^{148}$

The metaphorical alibi of conceptualizing empire rests on the constant covering up and uncovering of alternate means and ends, alternate meanings and realities of the human order and human psyche. The ambivalence of the concept satisfies its universality by categorizing and economizing the real at the same time at which it attempts to transcend the universal by reducing it to a certain category or economy. The reduction of the reduction, already equivalent to the numbering number, or to any series of so called delinquent repetitions, promises to rehabilitate the unique order of consciousness through a new economy of violence. The diversion of violence towards the outside calls for a diversion of consciousness towards the inside, while they never meet, as it were, for there to be a consciousness of violence, violence itself must become a real object, or a real threat. Needless to say, the location of violence is no longer "a battlefield or a border, but can be found in the heartland as much as in the peripheries, overseas as much as 'home', in global capitals as well as refugee camps". ${ }^{149}$ Ironical as it may seem, the globalization of violence appears to be morphing into the globalizing capital of empire.

For G. Bataille, external violence reflects the intimate order, and the more it diverts itself towards the outside, the more universal it becomes. As the intimate reflection of diverted violence, self-consciousness moves beyond the act of violence by squandering its effects. In his view, a lesser violence is done to the world of things when wasted lavishly

\footnotetext{
${ }^{148} \mathrm{~F}$. Cooper, "Modernizing Colonialism and the Limits of Empire", Items and Issues, vol. 4, no. 4, Fall/Winter 2003. http://www.ssrc.org/programs/publications editors/publications/items/online44/cooper-colonialism.pdf.

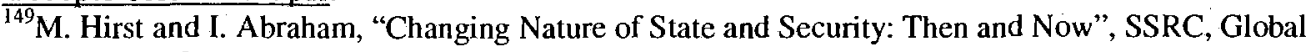
Security and Cooperation Program, Oct. 2002. http://www.ssrc.org/progranis/gsc/gsc activities/field building/hirst.page.
} 
than when taken over by human productivity - the former situation ensures the perfect adequation of man to things, the latter enslaves him to the world of things. ${ }^{150}$

Let us recall that Marx presented a classically European perspective. The Marxist critique of capitalism as the interested and arbitrary liberation of things indirectly supports the view that a disinterested orchestration of liberties would entitle man to dispose of himself as he pleases. In principle, he first disposes of things as he pleases, then of himself. The sequence is striking insofar as "disposing" becomes equivalent to "wasting": man's adequation to things involves the violence he consciously directs upon the world, that is, his potential capacity to violently dispose of everything, including himself. This is what $\mathbf{J}$. Rancière calls "a kind of transformation of the Marxist critique of consumerism in an antidemocratic way, with the idea that all is lost because of mass individualism, of democracy, which means consumerism". ${ }^{151}$ All is lost not only because man consumes (his liberties) but also because, as A. Badiou conveys, "we live in a contradiction: a brutal state of affairs, profoundly inegalitarian - where all existence is evaluated in terms of money alone - is presented to us as ideal". ${ }^{152}$ According to $S$. Žižek, this attempt at identifying the part with the whole, or of a "part of society with no properly defined place within it (or resisting the allocated, subordinated place within it) with the Universal, is the elementary gesture of politicization, discernible in all great democratic events since the French Revolution (in which le troisieme etat proclaimed itself identical with the Nation...". ${ }^{53}$

One could thus speak of positive and negative aspects of violence, of the first and the second, perhaps even the third or fourth, order of things, that is, of a changing order to

\footnotetext{
${ }^{150}$ The classic source on the United States' use of the threat of violence - including all-out nuclear attack - shows that this is both a primary and an extremely frequent form of the exercise of America's imperial power. See J. L. Payne, The American Threat: the Fear of War as an Instrument of Foreign Policy, Chicago: Markham, 1970.

${ }^{151}$ J. Rancière, "The Police Order - What can be Said, Seen, and Done: An Interview with Jacques Rancière", Palinurus: Engaging Political Philosophy, issue 12, Feb. 2007

${ }^{152}$ A. Badiou, "On Evil: An Interview with Alain Badiou", Palinurus: Engaging Political Philosophy, issue 8, Aug. 2006.

${ }^{153}$ S. Žižek, "The Political and Its Disavowals", Palinurus: Engaging Political Philosophy, issue 9, Nov. 2006.
} 
which man adequates himself by redirecting his potential for violence and hence for universality. One example of this is the newly dominant trend in international foreign policy, the impulse, or (death) drive, to forge ad hoc alliances and misalliances, to set up the scene of the political as the Schmittean scene par excellence, to include the friends and expulse the enemies, in a word, to betray the very notion of international politics by cutting it off from what it can do. ${ }^{154}$ Politics, as J. Rancière tries to tell us, involves the ability to define the situation, "when you create a stage where you include your enemy, even if your enemy does not want to be included...". ${ }^{155}$ Inclusion also means a diversion of violence towards the inside, a matching point between the particular and the universal, between the intimation of violence and its indelible spectacle.

On a different note, the organization of the army, the police, the state, entrust violence to the adequation of men and machines, to the transformation of man's consciousness into the movement and speed of the machine. The positive aspect of this adequation seems to be man's becoming an omniscient consciousness of good and evil; the negative aspect involves his becoming animal, or rather his mechanistically becoming "other". In the economy of violence these two aspects do not develop separately, instead they make up the order of things in the same way truth and falsehood establish the order of science, and in the same way in which proof and data violate and save the order of nature by separating and categorizing its betrayals and alliances. ${ }^{156}$

In the economy of violence one uncovers the trace of the sovereign couple, indeed,

\footnotetext{
${ }^{154}$ As H. J. Laski contends, "The conditions, particularly economic, of modern civilization demand the habit of organised international cooperation. We can only secure that habit by building institutions through which it may grow to its appointed purpose. Such institutions are incompatible with the existence of States which assert their will independently of the will of others". A Grammar of Politics, London: George Allen \& Unwin, 1967 [C 1925], p. 285.

${ }^{155} \mathrm{~J}$. Rancière, "Our Police Order - What can be Said, Seen and Done", an interview with J. Rancière, Palinurus: Engaging Political Philosophy, issue 12, Feb. 2007.

${ }^{156}$ In current politics, betrayal passes for hardheaded pragmatism, as in the case of the American National Security Agency bugging the phone lines and emails of United Nations Security Council delegates in the run-up to the Iraq war. See M. Bright, E. Vulliamy, and P. Beaumont, "Revealed: US Dirty Tricks to Win Vote on Iraq War", The Observer [London], March 2, 2003, p. 1. http://www.guardian.co.uk/lraq/Story/0,905937,00.html.
} 
of that conventional dyad which appears to explain so much of reality that it is no longer possible to think otherwise than in terms of complementing orders and commands, complementing thoughts and sentiments. The collaborative hypothesis is nostalgic, proletarian, disciplinary: it is inadequate to all traces of the different, the inconvenient, and the creative. Inside it, everything freezes, obsessing with a reasonable solution: survival. Collaboration and competition, friendship and enmity, trust and critique, become simultaneous with the finality of the act of collaborating or competing, of having friends and enemies, trustees and critics. There is no longer any delay between having collaborated and collaborating, between having friends and enemies, between betraying and being betrayed - these are simultaneous hypothesis, simultaneous orders. ${ }^{157}$ Their manifestations are historically strange and atemporal, and, as J. Butler suggests, "such a phenomenon inserts itself into the present as anachronism". ${ }^{158}$ Hence the need to acknowledge them, the need to escape their power, their certain unfolding, or, what amounts to the same thing, their folding uncertainties.

What is the relationship between knowledge and empire, then? Between the "passion for politics" sought by A. Negri in Time for Revolution and the unequivocal dispassion of mainstream political science, between G. Bataille's intimation of violence and $G$. Dumézil's sovereign couple? Is it even possible to juxtapose the fluidity of enchantment to the violence of imperial composition? This is a proposition as dangerous and implausible as it seems inoffensive and familiar, flirting not only with the absence of danger, but also with that of familiarity, and neutralizing, as M. Foucault argues in The Politics of Truth,

\footnotetext{
${ }^{157}$ We see this perhaps most clearly in that Indian ghost factory of Muslim terrorism, Kashmir. A. Roy has written: "Recently, a young Kashmiri friend was talking to me about life in Kashmir. Of the morass of political venality and opportunism, the callus brutality of the security forces, of the osmotic, inchoate edges of a society saturated in violence, where militants, police, intelligence officers, government servants, businessmen, and even journalists encounter each other, and gradually, over time, become each other". An Ordinary Person's Guide to Empire, Cambridge, Mass: South End Press, 2004, p. 95.

${ }^{158}$ J. Butler, Giving an Account of Oneself, New York: Fordham University Press, 2005, p. 5.
} 
"everything that might either legitimize or simply hierarchize values", ${ }^{159}$ every exercise of power, every effect or element of knowledge suspending itself in the circulation of power.

If one follows Hegel, as E. Levinas does, one becomes Hegelian, or rather takes Hegel to its absolute, to the becoming that is Hegelian by being non-Hegelian, to the being that is absolute by being common - this is the itinerary of the third way, its ontology, its secret becoming "I, you, he". This is what A. Negri calls the spatialization of time, or, what amounts to the same thing, the temporization of space, the instant passing of time into space and of space into time - the pilgrimage of time and space in and through one another, the abyssal passage, the inevitable slip of one into the other.

The passage itself is simultaneously a departure and a returning (as in Foucault's Madness and Civilization), a gazing backwards and forwards (as in Negri's Time for Revolution), a folding and a silent unfolding (as in Deleuze's Foucault or Nietzsche). It is also a non-passage, an absence, a clearing by which everything moves in the mirror of consciousness, or, as Derrida would say, in the solitary gaze of the unconscious. In this mirror, in this curious gaze of the resistant, the marginal, the subtle, are always in passing, in movement, in flux. They get hold of one another and let go, repeating the same act of identification and differentiation, the. same act of being, or of becoming, other, otherwise, otherness. Becoming other is inseparable from becoming one, which is to say that their presence is also already an absence, an inversion, a displacement. Oneness and otherness become inseparable in and through this volatile absence, which is also (already) a presence, a dynamic displacement of non-being, non-presence, non-I.

One recognizes here the condition of thought, the condition of thinking and being thought of in the absence of the other and in the otherness of absence. Perhaps one recognizes here the presence of the third, the unannounced, or unexpected, intrusion in the fabric of being, in the narcissistic (co)existence of the original and the copy, one and the

${ }^{159}$ M. Foucault, The Politics of Truth, New York: Semiotext(e), 1997, p. 81. 
other, man and image. One recognizes here the volatile presence of such an intrusion, the ghost, as it were, of all presenting, but also its absence, its passing through, passing by, as absence, death, disappearance, end.

This intrusion threatens to be simultaneously true and misleading, as in Z. Bauman's Legislators and Interpreters, where thought crosses the threshold of knowledge and falls prey to its obsession with (ideological) failure - thought and failure become complementing realities, each guided by the presence of the other as the necessary condition for its own existence. The same inconsistence threatens some of P. Virilio's insights, more precisely, his preoccupation with the defeat of communism tends to become the condition of his thought, the inevitable condition for the return and revival of ideology as the failing, or corrupt, replica of human knowledge.

Intrusion is also an abstract and concrete European theme - a veritable ontology of becoming "he", the outsider, the unrecognizable and unreadable presence of the other without and/or within oneself. The other becomes this veritable suspension of the exterior in the interior, this simulation, or spectacle of becoming indirectly, becoming the doubling double, both the original and one of its copies meeting in a fleeting otherness, in a surrendering glimpse of being outside oneself and within another. The dissymmetry, discrepancy, disunion, between being within and being distant traces the indelible other the gaze of the other, his presence, his breath. It also traces $u s$, we, ourselves, in the sense in which E. Levinas describes us - as the triadic constitution of being, always in flux, in changing, in becoming, always splitting and coming together as the original and the multitude of copies, the whole and the parts, as being and its becomings. ${ }^{160}$

G. Dumézil defines this religious conceptualization (or religiosity of the concept) of power in terms of a "zone in which variable movements, unstable relationships, are

${ }^{160}$ E. Levinas, Entre Nous: Thinking-of-the-Other, New York: Columbia University Press, 1998. 
established between two poles". ${ }^{161}$ The uncertainty of relations does not permit the concept of religion to establish itself otherwise than as pure instability, that is, as something that cannot be fixed by definition, something that is in flux and remains in flux and can only be defined as such. The rigor of science is no longer attributable to the concept but to its definition, it is no longer attributable to the instability of movement, but merely to the fixity of the poles. The instability of the poles has to do with passing or rather with the passage from one to the other, indeed, with a notion that has become central to knowledge. The poles - any opposites for that matter - are no longer autonomous, at least not in the sovereign sense, they are dependent upon one another, and so their entire existence depends on the instability and variation of the passage, on the religiosity of the passage, as it were, or on its conceptualization.

Any movement in space corresponds to a concept of passage through time, it corresponds, as a matter of fact, to the ordinary and easy passing from collaboration to competition, from friendship to enmity, from the comfort of trust to the swiping force of critique. ${ }^{162}$ The correspondence between the two is never the same, never in contact with or passing through the same things, nor occupying or traversing the same places - the only thing they have in common is the passage, its beginning, its uncertain trajectory, its end, perhaps even its fleeting appearance. Passing through, passing by, passing in (silence), appears as the measuring bit and enfolding rhythm of the given, as the involuntary, imperceptible, oscillation between appearance and depth, death and dying, (over)there and (over)here. By itself it is nothing but a passageway, a fleeting instance, an undulating line of flight opening and closing silently in the immensity of the passage.

\footnotetext{
${ }^{161}$ G. Dumézil, Mitra-Varuna, New York: Zone Books, 1988, p. 60.

${ }^{162}$ One incarnation of such a passage may be the instructions laid out by the US Congress for its restaurant complex, back in 2003: i.e. to change French Fries into Freedom Fries, French toast into Freedom toast, and to wipe out French wine from the menu. "Freedom Fries", Wikipedia: http://en.wikipedia.org/wiki/Freedom fries.
} 
In European thought, interior, exterior, friends, enemies, are no longer interchangeable terms, no longer passing from one bio-order to the other. These terms fix the boundaries of things in the same way the concept of religion fixes the domain of uncertainty: there is no religiosity here, only the ethereality of belief, establishing its own limit, its immanence, its passage. The uncertainty of the passage is ensured by the weight of spatio-temporal limitations, which is to say that we can escape the space-time ontology insofar as we become the self-consciousness of the passage. Such is the limit of passing, the passage limiting itself in and through its own weight and vanishing consciousness.

From E. Cassirer, we learned to understand the logic of the passage as being impelled by the logic of unconscious compromises surfacing in the asymmetric construction of time and space. ${ }^{163}$ So far, A. Negri went to a great deal of trouble to escape the space-time ontology; for him, there is no outside and no center, time itself constitutes the ontological fabric in which all relations of production are woven together. All relations of production constitute themselves simultaneously with the constitution of power and only as a way of resisting it. Similarly, empire (re)constitutes the ontological fabric of power relations woven together against the resistance of time: time itself becomes the ontological fabric of "relations", that is, of constitutive temporalities and constitutive consciousnesses. As Negri writes: "the dialectical illusion is the mode in which the hard-core of the selfvalorization of capital now presents itself. So here utopia is the alternative to determinism". 164

The idea of an alternation (a dialectic of alternation) is "usually faked", it flattens the asymmetry of value (space-time) by alternating deterministic immanence and utopian transcendence: the alternation is no longer between two different paradigms but between "different spatial functions of the experience of time", between different articulations of

\footnotetext{
${ }^{163}$ E. Cassirer, The Myth of the State, New York: Doubleday, Anchor Books, 1955.

${ }^{164}$ A. Negri, Time for Revolution, New York: Continuum, 2003, p. 109.
} 
space-time. The double articulation of space-time provides an ideal escape from the uniformity of ontology: immanent transcendence (in the guise of transcendental materialism) versus utopian determinism leads to a dynamic alternation of before and after, here and there, time and space.

In A. Negri, the past is no longer refracted through the lens of a space-time ontology: it is the ontological articulation par excellence, the uncertain to-come or uncertain after stripped of its utopian character. The subject recovers its objectivity by way of its transcendental position - this is a motif that Negri borrowed from Kant without hesitating to flatten its ambivalent articulation on the plane of immanence. ${ }^{165}$ This flattening of consciousness gives a sudden mobility to the immanent articulation of time (to the transcendental subject): the subject tests ontology in the to-come, he is both before and after, ontological and still to-come.

At the moment, the spatialized concept of empire rests on the double presence of the spectacle and the Machine: the immensity of space appears to be conquered and modified through speed, surveillance and electronic signaling, through the omniscience of the spectacle, industriousness and discipline, and/or through indulgence and laisser faire. One could thus be certain that it is no longer a matter of possessing land (in the end, land is a sign, a number, even a phantasm) as it is of exercising one's power over and against it. Space could be modified by speed to meet certain goals, it could be made available through constant surveillance, and it could be ordained and controlled by simply replacing its machines: a costly policy and a maneuver never quite valid. In the end, the Machine embodies and ordains an idea, a concept, an ideology: either Time against space, or Space against time; either the bourgeois mentality set against the bareness of space, or the massmachine set against the inventiveness of time - or both.

Perhaps the dynamization of space remains a bourgeois act just as the spatialization

${ }^{165}$ See A. Negri, Time for Revolution, New York: Continuum, 2003. 
of time remains a proletarian endeavor. Even better, perhaps the state-machine is no longer purely bourgeois or purely proletarian (perhaps it no longer serves purely bourgeois or purely proletarian ends, if it ever did), but has passed beyond the point at which dynamism and spatialization make any real difference in the world of machines. ${ }^{166}$ In Time for Revolution, A. Negri also suggests that fascism and authoritarianism are contradictory orders only apparently, while their "actual agreement is fully realized" in and through their disagreeing singularities. In essence, there is no contradiction between the dynamization of space and the spatialization of time, they collaborate, they coalesce and intertwine to such an extent that their agreement is fully realized (in thought or in its simulation) in and through the particularity of their displacements, in and through the singularity of their disagreements. ${ }^{167}$

In reality, space and time never fully coalesce, they never come together, nor fall apart entirely. Their relation is entertained by an absence through which we find ourselves caught between a place reminding us of another time and a time reminding us of another place. This alibi, this simulated absence of the real, suspends the world for us, it suspends it for the sake of truth, as it were, and it does so not, as J. Baudrillard believes, through the dissimulation of the real (which is still opposition, resentment, profound disagreement), but by completely wiping out the sense of the real. For us, it is no longer possible to simulate the real because there is no reality except simulation, absence, and death. Reality and simulation agree to such a complementary extent that it becomes virtually impossible to tell them apart - they are both dissimulative, deceptive, dead references of one another. In our age, the image and the spectacle constitute the real. As A. Roy tells us:

Crisis reportage in the twenty-first century has evolved into an independent discipline - almost a science. The money, the technology, and the

\footnotetext{
${ }^{166}$ This is also suggested by such pop social science writings as Peter F. Drucker's Post Capitalist Society, New York: Harper Business, 1993.

${ }^{167}$ See, for instance, D. T. Nguyen and J. Alexander, "The Coming of Cyberspacetime and the End of the Polity”, R. Shields, ed., Cultures of Intermet: Virtual Spaces, Real Histories, Living Bodies, London: Sage, 1996, pp. 99-I24.
} 
orchestrated mass hysteria that goes into crisis reporting has a curious effect. It isolates the crisis, unmoors it from the particularities of history, the geography, and the culture that produced it. Eventually it floats free like a hot-air balloon, carrying its cargo of international gadflies - specialists, analysis, foreign correspondents, and crisis photographers with their enormous telephoto lenses.

Somewhere mid-journey and without prior notice, the gadflies auto-eject and parachute down to the site of the next crisis, leaving the crestfallen, abandoned balloon drifting aimlessly in the sky, pathetically masquerading as a current event, hoping it will at least make history. ${ }^{168}$

The constitution and structure of simulation share a common denominator: the erasure of the real. As A. Roy suggests, "In this era of crisis reportage, if you don't have a crisis to call your own, you're not in the news. And if you're not in the news, you don't exist. It's as though the virtual world constructed in the media has become more real than the real world". ${ }^{169}$ Simulation does not conquer reality, it simply replaces it with dead(ly) references.

Perhaps the same could be said of space-time, perhaps time eliminates space at the same time and at the same pace at which space eliminates time, in a simulation, a reality, a speech, through which it becomes impossible to tell them apart, to affirm or disconfirm their presence, their existence and their endurance. The homogeneity of the space-time continuum is recognizable only insofar as is it is made up of interruptions, gaps, ruptures, absences and deaths, at the same time at which the compactness of its fissures and holes renders its fabric continuous and enduring. It renders its unintelligibility resolved in and through the supposition that all contraries work together in complete agreement. They work together not by resemblance (which is a quality attributable to things, see for example M. Foucault ${ }^{170}$ ), but by directly simulating all possible enmities, all possible deaths and closures. Space no longer needs to be dynamized in and through possible chains of resemblances, it has become dynamism at its paroxysm, dynamism pure and simple: stasis, absence, time.

\footnotetext{
${ }^{168}$ A. Roy, An Ordinary Person's Guide to Empire, Cambridge, Mass: South End Press, 2004, pp. 6-7.

${ }^{169}$ Ibid., p. 9.

${ }^{170} \mathrm{M}$. Foucault, The Order of Things, New York: Vintage Books, 1994.
} 
In the last analysis, the dynamization of space consists of its separation, of its becoming "other" than itself. That is why for A. Negri the relations of production constitute themselves simultaneously with the constitution of power and only by resisting it. Power affirms the separation that sets apart productivity and negativity, it affirms itself as the source of their separation, as the measure and fabric of their crisis. If productivity is the negation of power and negation is the productivity of power, the simultaneous constitution of productivity as negativity and of negativity as productivity must resist against the new constitution of power: power as negated productivity and productive negativity, power as absence, space, time - power as space-time. ${ }^{171}$

The simultaneity of the processes of power constitution, that is, the simultaneity of the processes of negating productivity and producing negativity, results in the simultaneity of resistance(s), in the simultaneous production of negativity (as enveloping power) and negation of production (as measure of power). The flattening of the schema and its materialist projection on the plane of immanence make the coexistence of productivity and negativity a major condition for innovation. The production of negativity coupled with the rejection of productivity constitutes itself as a (re)generative process of innovation. Unlike power, innovation sets in as the affirmative coexistence of negativity and productivity, as their continuity and plausible endurance against the power that sets them apart. Innovation affirms and makes itself endure in the face of a power that "sets apart", sets in absence, or in the absence of continuity, affirmation, and endurance.

It follows that power stands prior to innovation, that there could be no innovation in the absence of some power; in the absence of a separation between production and negation. In truth, the primary affirmation of production is innovation. It is never a direct affirmation, a positivistic outlook on things, for there could be no innovation prior to power (which negates itself in production). Innovation is not even possible without the

${ }^{171}$ A. Negri, Time for Revolution, New York: Continuum, 2003. 
double negation of production and of power. To negate production is to affirm some kind of power that is not subordinated to production but stands in opposition to or above it. Innovation holds and sustains a closer relationship to play rather than to work. ${ }^{172}$ To negate existing power is to affirm production and innovation (in one stroke), and to affirm at the same time the productivity of negation and the negation of productivity - a paradox, a true impossibility - but also "the unique event in which becomings are refracted". ${ }^{173}$

The productivity of affirmation and the negativity of power make up the innovation process, the process by which productivity continues to resist power and power continues to resist innovation: a chain of weaknesses which is (perhaps) necessary to ensure (or rather induce) the continuity of crisis, the passage from one displacement to the other, from one dimension to the next. The continuity of the crisis is only apparently the continuity of production and innovation; the crisis itself discontinues the process of production by negating it, that is, by transforming it either into a power or force of production. The continuity of the crisis guarantees innovation (indirectly) through the negative (re)constitution of power: at least in principle, it becomes possible for innovation to be the other side of crisis.

Such a possibility settles crisis as a prime source of progress, it settles it as the challenge and negativity of progress and/or of insubordination. Reality itself becomes a challenging crisis, a "near death" experience simulating the blind resuscitation of an already defunct event. In Negri, the concept of empire grows out of this conception of crisis and progresses from one death experience to another in a continuity that can no

\footnotetext{
${ }^{172}$ J. Alexander and J. MacAulay: "For technology to develop it is necessary that the inventor be relieved of the necessity to attend to paramount reality, because what he seeks does not exist in paramount reality, at least not in the form to be invented. As with new knowledge generally, technology arises therefore only in alternative reality work. Before that can happen, the idea upon which the technology rests must be generated in alternative identity work, that is, in some form of play". J. Alexander and J. MacAulay. "An Archaeology of Technics and the Working Life", S. Bennett, ed., Technology and Work in Canada, New York: Edwin Mellen Press, 1990, p. 140.

${ }^{173}$ A. Badiou, "The Event in Deleuze", Parhhesia, issue 2, 2007. http://www.parrhesiajournal.org/parrhesia02/parrhesia02 badiou2.pdf.
} 
longer sustain anything other than the critical (re)production of reproductive forces and powers. Not only empire but also the "mysterious empires" mentioned in the Politics of Subversion must be understood as the outcome of the irremediable challenge placed at the heart of productivity. This particularity of crisis is not meant to mislead, nor to revive any particular political configuration, but to advance as such to the status of world order. The world as crisis becomes the new heart of empire, it becomes its new impetus, its new melodramatic trajectory. To put it differently, the economic clash of civilizations migrates towards a clash of emotions, dissolving the productivity of the imperial spectrum. ${ }^{174}$

"Revolution" no longer "promises to save those that make it", as in Malraux, instead, the new economy saves everybody by reproducing all the particularities of their crises, by helping them progress from one form of salvation to the next, from one form of dying to another. Far from being a simply violent matter of land possession, as E. Said remarked, the essence of empire transforms both land and possession over it into an economy of crisis, that is, into the opposite of what they might have been in the beginning. Empire no longer affords, as G. Bataille hoped, a diversion of violence towards the outside, it rather accommodates this diversion as its fundamental challenge, as its former modality of stabilizing and destabilizing the outside. In the new economy, there is stability where there is instability, land possession where there is no violence done to it, or where there is a violent force diverted towards the inside. In principle, E. Said and G. Bataille might not be as far apart as they seem: crisis is not only the crisis of land, or of violence, but of the stability and instability brought about through their reenactment as fundamental sources of power. The more crises one produces, the more profitable the return - the more violent, intimate and possessive, one becomes. High rates of capitalist profitability compete with

\footnotetext{
${ }^{174}$ D. Moisi, "The Clash of Emotions: Fear, Humiliation, Hope, and the New World Order", Foreign Affairs, January/February 2007. http://www.foreignaffairs.org/20070101facomment86102/dominiquemoisi/the-clash-of-emotions.html.
} 
high and still increasing rates of inequality, leading to burgeoning rates of alienation, despair and violence from below. In A. Roy's words:

According to the State, when victims refuse to be victims, they become terrorists and are dealt with as such.... In the era of corporate globalization, poverty is a crime, and protesting against further impoverishment is terrorism. In the era of the War on Terror, poverty is being slyly conflated with terrorism. ${ }^{175}$

The crisis (i.e., of violence, of land) inhabits all of society with no exception whatsoever: "the entire society becomes one enormous factory, or rather, the factory spreads throughout the whole of society", ${ }^{176}$ so as to serve and discard its "general interest". This much can be said about capital, about the whole of society being capitalized, and perhaps rescued, by an economy "which acts on the will it flatters and takes possession of the person". ${ }^{177}$ Society itself becomes an enormous flattering/possessing machinery, a gigantic prosthesis of calculating and negotiating profits and losses, investments and returns, lives and deaths - a computing deity, a mere technology.

This is precisely the type of juncture, or crisis, in which G. Dumézil's and later G. Bataille's revival of the idea of potlatch begins to make sense - without the whole of society being immersed in the (super)natural order of capital, without having become the temple and the ritual of economizing all aspects of life, money could never have become the primary means and ultimate aim of human endeavours, the bartering substantive of survival and of existence in general. Being human means being capable of making one's way through a life of productivity and power, and more importantly, through a life that could be negotiated and purchased at any moment - a life of profits and losses, investments and returns, in short, of capitalization. As E. Levinas puts it, "what is perceived by the thinking being as exteriority inviting it to labor and assume ownership is experienced by

\footnotetext{
${ }^{175}$ A. Roy, An Ordinary Person's Guide to Empire, Cambridge, MA: South End Press, 2004, p. 12.

${ }^{176}$ A. Negri , The Politics of Subversion, Cambridge, Polity Press, 2005, p. 204.

${ }^{177}$ E. Levinas, Entre Nous On Thinking-of-the-Other, New York: Columbia University Press, 1998, p.

37.
} 
the living being as its substance, co-substantial with it, essentially immediate, an element and an environment". 178

The whole of imperial society presents itself as a capital making environment, a money making machinery with its own rites and practices, and since there is no other reality to be compared with, it itself becomes the sole reality, the sole capital in the fabric of capital. If it offers itself up in exchange for a return, it does so with the hope of surviving through a given situation, a given crisis. Potlatch helps one overcome this moment (at least hypothetically), this dramatic situation of being immersed in the order of capital and being forced to find a way out solely by economic means. Differently put, potlatch is bribery at its absolute - an absolute trickster. It doubles the flattering/possessing economy by (re)circulating its excess, by obliging and binding even more than taxes do, even more than all the mechanisms of debts and loans put together. Potlatch betrays the economy of capital by offering it as a gift, that is, by turning its violence into an incalculable measure of prestige. At best, one buys oneself time, at worst, one merely accelerates the circulation of commodities and their inevitable demise.

Potlatch appears not only as a current means of subsistence but also as a new economy of the prestigious, a new economy of the non-economic. The exchange in commodities too belongs to this new economy of offerings and gifts, of flattering and possession, of short-circuited profits and losses. One no longer invests in the classical sense of the term, he simply obtains something by offering something else in return: a sum, an exchangeable value. He no longer profits, nor does he lose anything - his entire life is little more than an inestimable barter.

These are rough approximations, of course, the labor power one exchanges for one's living is increasingly becoming the measure of one's life, the most veritable gift that one could possibly offer in exchange for the flattering possession of capital. However that may

\footnotetext{
${ }^{178}$ Ibid., p. 13.
} 
be, perhaps it is half a measure of truth to be speaking of life as an exchangeable commodity, for death too is becoming increasingly costly in a world where dying has become the genealogical proof of being alive.

For J. Habermas, "the liberal model (in truth one based on petty commodity exchange) had envisaged only horizontal exchange relationships among individual commodity owners". ${ }^{179}$ As a consequence, it succeeded in exchanging the private sphere for the public without any regard for the vertical distribution of commodity ownership. The horizontal relationship between privatizing and publicizing the circulation of commodities had constituted itself into a model of exchange that no longer had any competitors - it constituted itself into an absolute model of ownership. The relation between the visible and the invisible (public-private), so readily constitutive of the bourgeois state, had turned exchange into the sole condition of ownership, a point beyond which, in truth, one could no longer attribute any relevance to the term "free trade".

Some sort of visibility had to be traded in exchange for invisibility: this was the business of the gods, the church, the state, the modern institution. Through them things tended to become purely tradable forms, commodities exchanged between visible and invisible deities, powers and ownerships. The state (secular or otherwise, no real matter) constitutes this veritable (en)folding of the absolute (commodity), absolute visibility, in which "the real exchange of labor and value has become a symbolic exchange, the simulation of life and an image of death". ${ }^{180}$ The universality of the void receding in the circuit of things, of commodities and of values - this is the movement of capital, its great empire reflected in the singularity of having become a simple commodity by being replicated in and through the endless circuits of human desires and realities. It is also a possession, a taking possession of, or possessing - the void, voidance, voiding.

\footnotetext{
${ }^{179}$ J. Habermas, The Structural Transformation of the Public Sphere, Boston: MIT Press, 1991, p. 144.

${ }^{180}$ A. Negri, The Politics of Subversion, New York: Polity Press, 1989, p. 201.
} 
The collaborative relationship between visibility and invisibility appears to be tradable - it constitutes itself into the very essence of being, while turning essence into a tension, an appearance, a politics, of becoming (in)essential, becoming (a)political. The political trades its intimacy for its appearance, its friends for its enemies, and its capital for its economy. It becomes a veritable economy of betrayal - a veritable betrayal of the economic (principle). Politics and economics coincide as it were, in the betrayal that enriches capitalists and impoverishes the multitude. The nature of politics and economics turns out to be negotiable, exchangeable, extendable - a double articulation of the already betrayed and the already polarized. Publicity and secrecy, appearance and essence, simulation and reality, all succumb to this double articulation of being betrayed, being commoditized, being exchangeable - being "in principle".

For G. Dumézil, this sort of bartering proves to be inferior to potlatch, which aims at recognition, at an economy of gifts entertaining itself for the sake of prestige. As such, potlatch needs time, it needs the passage of time to turn its gift-economy into a durable economization of prestige, into a recognition of power based on the non-economic, nonexchangeable, nature of prestige. However, time is a luxury it does not have, and this constitutes a double binding ${ }^{181}$ simultaneously recognizing and betraying, presenting and hiding, quantifying and qualifying, the presence, or power, of prestige. It is a promiscuous operation, always indirect, always occurring on the part of those who disapprove of indirection. Through it, time implicates and betrays contradictory realities - contradictory endeavors and assertions; it implicates by betraying and betrays by implicating all possible assertions and realities. This is how time becomes whole, plain, zero - how it becomes platonic all over again.

Time as Platonism of the betrayed, as the negative-image-of-negativity, projects

\footnotetext{
${ }^{181}$ J. F. Lyotard, The Differend: Phrases in Dispute, Minneapolis, MN: University of Minnesota Press, 2002, p. 5.
} 
itself at the heart of history. Post-modernism tries to rescue this image (of time, of modernity, of negativity), from within itself, from within its own negation and negligence. In a word, it tries to dislocate the negative from the beating heart of history and to carve it inside its own destiny - i.e., as the proper absence of time. The induction of negativity-asdeath spreads across boundaries, profiling itself as the post-mortem presence of histories and destinations, modernities and antiquities, timelines and eternal apparitions. It spreads across its own disappearances, or its own possibilities, marking the end and the beginning of imperial presence.

There is no comprehensive history of the imperial, no proper constitution, only absence-spreading-across-death, like a shadow, or a mythical specter. And so it is this specter to which we must now turn, to examine the status of negativity. 


\section{Chapter 5}

\section{Inducing Negativity}

But if Freedom is ontologically Negativity, it is because Freedom can be and exist as negation. Now in order to negate there must be something to negate: an existing given...

$$
\text { A. Kojève } 182
$$

For Kojève, negativity thus understood is the very essence of freedom. The productive power of negation is liberating...

$$
\text { V. Descombes }{ }^{183}
$$

A. Negri defined post-modernism as a special relation of the negative to the positive. He attributed to post-modernity the negativity of crisis, or rather he considered the recognition of the current political crisis to be the essence of post-modern thought. The relation between knowledge and power (in essence a relation between ideas and forces) appears to be mediated by crises, which is to say that both thought and force have crisis as their essence, or the recognition of crisis as their intimate order. The relation between ideas and forces stages the relation between knowledge and power, or rather the recognition of the question of knowledge as a promiscuous equivalent to the question of governance. In this ephemeral relationship, the confrontation of power from a position of powerlessness leads to what Descombes has termed "mystical renunciation", the stance of the Stoic or the Christian martyr developed or dispersed into an Augustinian cosmopolitanism.

Powerlessness appears to be overcome either by an alliance with power (by an alliance with the cause/effect of thought) or by exacerbating the crisis placed at the heart of power (thought itself). The relation between power and knowledge is defined by alliance and/or betrayal, or at least appears to be so in the light of the fact that neither could subsist in the absence of the other. Indeed, the relation between the two is at once binding and organizing, despotic and legislating, while constituting itself into a sovereign unity

\footnotetext{
${ }^{182}$ A. Kojève, Introduction to the Reading of Hegel, Ithaca, NY: Cornell University, 1969, p. 222.

${ }^{183}$ V. Descombes, Modern French Philosophy, Melbourne: Cambridge University Press, 1994, p. 32.
} 
"lacking a mythology of conflict". ${ }^{184}$ As a matter of fact, the mythology of conflict is expulsed from the function of sovereignty, and immediately takes the form of the warmachine: crisis and conflict part company in such a way that it becomes possible to invent a mythology of crisis internal to sovereignty and opposed to the externality of war.

The war-machine, at least the abstract war-machine, confers the illusion of the third dimension, it lets itself be moved and administered by imaging, not by the force of externality, nor by technology, but by imaging, that is, by the "visual enclosure of the nonvisual spaces and senses". ${ }^{185}$ To follow McLuhan's argument further, the "darker purpose" has indeed become the subdivision of politics, itself a subdivision of the One. The dark periphery of power and wealth is reconstituted as the three-dimensional perspective of the One: "the arbitrary selection of a single static position creates a pictorial space with vanishing point". ${ }^{186}$ As M. McLuhan argues: "it is the sense of sight in deliberate isolation from the other senses that confers on man the illusion of the third dimension" ${ }^{187}$, while enclosing him within the non-visual dimensions and senses. This is what the third dimension, or at least the illusion of the third dimension, does: it dominates visually over non-visual spaces and senses.

To do so, it needs language, precisely the language that still immerses itself in dialectics, while tending to emerge from it as its absolute master. Habermas? restoration of the absoluteness of language is, first and foremost, a restoration of the third dimension, of the illusion gathering all human senses under the authority of sound. By itself, language establishes truth in the absence of reality, it becomes reality's truth as it were, while taking over and transforming it into pure noise. The production of the perfect sound, like the production of the perfect dialogue ${ }^{188}$, aims at replacing the violent relation between subject

\footnotetext{
${ }^{184}$ G. Deleuze and F. Guattari, Nomadology: the War-Machine, New York: Semiotext(e), 1986, p. 1.

${ }^{185}$ M. McLuhan, The Gutenberg Galaxy, Toronto: University of Toronto Press, 1962, p.43.

${ }^{186}$ Ibid., p. 16.

${ }^{187}$ Ibid.

${ }^{188}$ See L. Strauss, What is Political Philosophy, Chicago: University of Chicago Press, 1997.
} 
and object with the incorporeal violence of words. The former trauma of physical violence is replaced by the psychological trauma of dialect(ics), a replacement based on the idea that words are far less harmful than guns, that language can wound and disarm without employing real (i.e., expensive) "weapons" - in a word, language could economize violence, provided it itself becomes its echo, or its beating heart.

The whole edifice of communication rests on the production of language and its technologies. It is the new production of terror coming out of the extermination camps, the use of sophisticated weapons making way for the new technology of the psyche - man terrorized by terror, manipulated through the language and image of terror, while internalizing every bit of information, every detail, every eccentricity of terror. This is the indelible trace of the Negative - the conscious production of terror, the pursuit of and hunt for terror as the most common experience of being human. Z. Bauman has captured its esprit de corps in the hunter's utopia:

A bizarre utopia indeed, if measured by orthodox standards; the original utopias promised temptingly the end to the toil - but the hunter's utopia encapsulates the dream of toil never ending.

Strange, unorthodox utopia it is - but utopia all the same, as it promises the same unattainable prize all utopias brandished, namely the ultimate and radical solution to human problems past, present and future, and the ultimate and radical cure for the sorrows and pains of human condition. It is unorthodox mainly for having moved the land of solutions from the 'far away' into 'here and now'. Instead of living towards the utopia, hunters are offered a living inside the utopia. ${ }^{189}$

On a different note, R. Slotkin has argued that encounters with the wilderness produced a national mythology steeped in blood and violence, and that this myth has led repeatedly to an uncanny form of cultural regeneration: " the means to that regeneration ultimately became the means of violence, and the myth of regeneration through violence became the structuring metaphor of the American experience". It was largely through these acts of violence, and their reverence toward its heroes - Daniel Boone, Davy Crocket,

\footnotetext{
${ }^{189} \mathrm{Z}$. Bauman, "Living in Utopia", paper presented at the London School of Economics, Melting Modernity Series, Oct. 2005.
} 
Wild Bill Hickock, etc. - he argues, that the Americans formulated their identity, their history and their imagined community. ${ }^{190}$ In this interpretation, today's various foreign interventions are less based upon imperialism than upon the devotion to a "national blood sport', which produces a recurrent urge to hunt.

Perhaps this is why, aside from wanting to keep down official numbers of American dead, the military has opened up Iraq to unprecedented numbers of mercenary "contractors", which by 2004 numbered some 20,000, operating outside any system of rules or regulations. As P. Singer has reported, private contractors have been acting as combatants, interrogators and torturers:

Also playing a role in this deeply disturbing episode - in which Iraqi prisoners were beaten, raped and forced to perform simulated sexual acts were private contractors, hired to serve as interrogators. That private contractors are serving in U.S. military prison camps should be surprising enough. This takes our experiment with the boundaries of military outsourcing to levels never anticipated. ${ }^{191}$

The negativity attributed to the essence of our time consists in the new hunt for terror and terrorists, or rather in the accumulation of terror as the psychological weaponry against the threat of barbarism, un-democratic regimes, or simply mass annihilation. The emphasis on communication, the awareness of producing a new means of terror through language and its technology, comes close to a romantic revival of terror, to a Freudian reinvigoration of the social complex (Oedipal). It is an unprecedented response given to the proliferation of weapons, to the physical extermination within the $20^{\text {th }}$ Century concentration camps, and the subsequent psychologization of the body. Language effaces the weapon, the camp, the prison, while (re)constituting and (re)charging them psychologically. In the last analysis, one could even say that language becomes the weapon, the camp, the prison, the

\footnotetext{
${ }^{190}$ R. Slotkin, Regeneration Through Violence: The Mythology of the American Frontier, 1600-1860 (Middletown, CT: Wesleyan University Press, 1973, pp. 4-5.

${ }^{191}$ P. Singer, "Beyond the Law", The Guardian, Monday May 3, 2004. http://www.guardian.co.uk/Iraq/Story/0,2763,1208259,00.html.
} 
new psychology, of post-modernity. An uncanny lesson came out of Vietnam, due to the continual, greatly exaggerated, body count of dead "insurgents" there. By contrast, in Iraq, the practice is not to count the insurgent deaths at all, which stands as a direct violation of the Geneva Conventions on Warfare. As J. T. Kelly puts it:

Dead Iraqis need not even be counted, let alone individualized. But the names, pictures, life histories, and interviewed relatives of U.S. war dead are routinely and recurrently news, a virtually sacred story that can be renewed every day. ${ }^{192}$

Language as production of negativity - take for example the word barbaric, which no longer means "of another land", "foreign", "speaking another language", or even "bearded", but has acquired an entirely negative energy, an entirely dismissive, nullifying function: today, the word barbaric has come to denote inferiority, ignorance, ignobility, or to put it in slang - "raghead". ${ }^{193}$ By implication, the term barbarian also hallows a positive connotation, the impression that man has evolved from a state of barbarity to a state of civilization due to human effort and progress. In short, the word barbaric charges historical emancipation with the positivity of technical success, while also charging it with an undesirable regression, or critical mass, that needs to be redressed and remedied. Language qua language seems to carry within itself this double fold of meaning, which is to say that it charges its attributes positively and negatively, making them into its ghosts, into the very condition of its disappearance and return.

\footnotetext{
${ }^{192}$ J. D. Kelly, "Who Counts: Imperial and Corporate Structures of Governance, Decolonization and Limited Liability", C. Calhoun, F. Cooper and E. W. Moore, eds. Lessons of Empire: Imperial Histories and American Power, New York \& London: New Press, 2006, p. 172.

${ }^{193}$ Wikipedia defines Raghead as "an ethnic slur used against Arabs, Muslims, and Indian Sikhs denigrating them for wearing traditional headdress such as turbans or keffiyehs". http://en.wikipedia.org/wiki/Raghead. This is a civilian term, but it has a military variant. U. S. soldier Aidan Delgado reports on gratuitous violence that he witnessed routinely being inflicted by American soldiers on ordinary Iraqis. He said: "'Guys in my unit, particularly the younger guys, would drive by in their Humvee and shatter bottles over the heads of Iraqi civilians passing by. They'd keep a bunch of empty Coke bottles in the Humvee to break over people's heads.' He said he had confronted guys who were his friends about this practice. 'I said to them: 'What the hell are you doing? Like, what does this accomplish?' And they responded just completely openly. They said: "Look, I hate being in Iraq. I hate being stuck here. And I hate being surrounded by hajis". 'Haji' is the troops' term of choice for an Iraqi. It's used the way "gook" or "Charlie" was used in Vietnam". Bob Herber, "From Gook to Raghead", New York Times, May 2, 2005, final Late ed., sec. A, p. 2l, col. 5. http://select.nytimes.com/gst/abstract.html?res=FA0613FC34550C718CDDAC0894DD404482.
} 
The signifier, the signified and the sign, constitute the three-dimensional space of language, the ideal semiological system in which the word composes itself as an ethereal liaison between concept and image, form and function, crisis and discourse. The word, as we have seen, can be doubly charged, depending on the tip of its arrow: the weight of the word "barbaric" already establishes the direction of its arrow, the direction of thought, or of judgment. So does the image of a village, a picture of a poor woman, an object coming from the third world.

R. Barthes used this generic way of conceiving language to designate some basic capacity of things to transmit messages. He charged two semiological systems (language and metalanguage) with the formation and transmission of messages, or rather with the study of "ideas-in-form" (ideology and semiology charge myth with the capacity to overview them), that is, with the manufacturing of ideas in the form of objects, articles, paintings, everything that surrounds us by signifying something to which we relate mythically, ${ }^{194}$ or spectrally, as Derrida would argue. ${ }^{195}$ The positive-negative charge organizes the three-dimensional pattern in such a way that myth is granted the alibi of an unexpected absence: "[T]here is therefore one language which is not mythical, it is the language of man as producer: wherever man speaks in order to transform reality and no longer to preserve it as an image, wherever he links his language with the making of things, metalanguage is referred to as language-object, and myth is impossible". 196

However, this might prove to be a misleading strategy since myth on the left is inessential. Since it produces "reality", the Left is incapable of producing its own mythology. Its speech is an exaggerated and yet impoverished version of the bourgeois mythology, a non-proliferating, convenient, vision of the ideality of speech (or of image). Fundamentally, the oppressed are unable to fabricate, to invent, to lie; "lying is a richness",

\footnotetext{
${ }^{194}$ R. Barthes, Mythologies, New York: Hill and Wang, 1972.

${ }^{195} \mathrm{~J}$. Derrida, Specters of Marx, New York: Routledge Classics, 2006.

${ }^{196}$ R. Barthes, Mythologies, New York: Hill and Wang, 1972, p. 146.
} 
which presupposes "property, truths and forms to spare". ${ }^{197}$ For R. Barthes, the essence of the bourgeois myth is precisely this exuberance of excess, of sparing, of proliferating truths. By contrast, in its leftist version there is nothing more alien to the manufacturer of reality than the spoiling of excess.

Bourgeois language affirms excess, while the proletarian version transforms it into its promiscuous end. From the point of view of myth, their supposedly dialectical relation based on the administration of excess is nothing more than the arbitrary accumulation and re-investment of excess terminology and excessive means (i.e., of accumulation). The bourgeois excess set against the poverty-stricken reality of the proletarian - an excessively abused economy of language (language understood as the property, truth and form, of bourgeois mythology) set against the convenience of poverty and ignorance; an ingenuous system of pillage based on the virtuality of gifts and exchanges, or rather on contractual rewards mitigated through the ideality of a collective effort. The inoculation of the bourgeois myth, as R. Barthes suggests, "immunizes the contents of the collective imagination by means of a small inoculation of acknowledged evil". ${ }^{198}$ In this way (i.e., concealing the "principal evil" by admitting an "accidental evil"), it protects itself from an eventual subversion by balancing the economy: "the smaller shares - in law but not in fact - compensate the big ones". ${ }^{199}$ The compensation is accidentally granted, not as a squandering of excess but as a cover up for the economic principle. Can we find concrete instances of the workings of the bourgeois myth in the imperial space of today? $\mathrm{G}$. Steinmetz is very positive on this score. He writes:

We also need to investigate the ceremonial trappings of U.S. power, the practices and scattered signifiers that give American life its increasingly imperial flavor. One the one hand there is the militarization of the culture in ways reflective of empire: civilians driving Humvees, the navy welcoming almost 8,000 civilians aboard its vessels for publicity purposes in a single year,

\footnotetext{
${ }^{197}$ Ibid., p. 148.

${ }^{198}$ Ibid., p. 150.

${ }^{199}$ lbid., p. 151 .
} 
universities and high schools (under the 'No Child Left Behind' Act) being compelled to admit military recruiters or risk losing federal funds, and the enrollment of 500,000 high school students in the Junior Reserve Officer Training Corps of the army, navy, and air force. ${ }^{200}$

As H. Morgenthau tells us, historical problems "tend to appear to us not as members of a chain organically tied to the past and growing into the future"201, but as sudden ruptures of ideality, or harmony, "occasioned by evil men and evil institutions". ${ }^{202}$ In his view, by doing away with "those men and institutions", we solve not only the present historical problem but the problematic theme of history itself. The rupture of historical harmony to which Morgenthau alludes in order to weaken its rather polemical hold, charges "evil men and institutions" with the responsibility for having terminated history. E. H. Carr takes us a step further (which is also a step away, perhaps even a step backwards) into the labyrinth of history, reminding us that:

"this eventual harmony was preceded by a struggle for life between individuals, in which not only the good, but the very existence, of the loser were eliminated altogether from the picture.... The whole ethical system was built on the sacrifice of the weaker brother". ${ }^{203}$

Bourgeois myth is only apparently (not to say polemically) excessive; in essence it embodies the very image of poverty - of that excessive poverty against which it sets itself as norm and ideal. The proletarian struggle emerges from the start as a surrogate ghost of this "principle of evil" which presents itself as norm and ideal, or rather as the economization of excess mythology which is, first and foremost, a mythology of conflict. The economization of excess resolves itself by exceeding its own economy: either the economy is turned into the raison d'etre of history (as in Marx), or history is turned into the raison d'etre of the economy (as in Foucault). In conflict mythology the administration of

\footnotetext{
${ }^{200}$ G. Steinmetz, "Imperialism or Colonialism? From Windhoek to Washington, by Way of Basra", C. Calhoun, F. Cooper and E. W. Moore, eds. Lessons of Empire: Imperial Histories and American Power, New York \& London: New Press, 2006, p. 139.

${ }^{201}$ H. Morgenthau, "The Intellectual and Moral Dilemma of History", Christianity and Crisis, February, 1960. http://www.religion-online.org/showarticle.asp?title=398 ${ }^{202}$ Ibid.

${ }^{203}$ E. H. Carr, The Twenty Years' Crisis, Wiltshire, UK: Anthony Rowe Ltd., 2001, p. 62.
} 
accidental evils works as a cover up for the principal evil (conflict as an economic principle, or what amounts to the same thing, economy as a conflicting principle), whereby the inequality of conflicting forces is compensated by law, that is, law as a punishing and rewarding mechanism, eternally objectifying the causes and effects of conflict.

Law hallows power with an aura of order (as opposed to crisis, conflict, accident) and peace (as opposed to war), that is, with an exceptional, (extra)ordinary, disposition to assist people in making their living by working on and consuming the available resources (natural or otherwise). From the point of view of law, punishment obliterates the evil accident, while promoting the hallowed good of order - in our time, however, law mitigates conflict in such a way that death is no longer possible except as an occasional high point within the overall spectacle. The anticipation of death seems much more profitable than life, each time the self is prompted to anticipate death "by giving to it or conferring upon it a different value". ${ }^{204}$ The myth of the bourgeois allows the prodigy to rebel against tradition, it allows the rebels to tear down some tainted flag in the south, but it always draws the line between these "accidents" and its own, unequivocal, aim. The economy/law of conflict promises to save those who endorse it. This promise, however, involves some calculus that needs to be made in order to salvage appearances - not reality, but the appearance of being real, genuine, truthful, when one is merely lawful. As J. S. Nye suggests:

A wide range of public opinion surveys report that a plurality or majority opposes policies aimed at further liberalization of trade, immigration and foreign direct investment. These attitudes - which align strongly with labor market skills, with lower-wage employees more likely to be negative - reflect not simply ignorance of the benefits but a feeling that the costs of economic insecurity may be more important. ${ }^{205}$

The economy of conflict migrates into a domestic economy of enlightenment (or

\footnotetext{
${ }^{204}$ J. Derrida, The Gift of Death, Chicago \& London: University of Chicago Press, 1996, p. 40.

${ }^{205} \mathrm{~J}$. S. Nye, "The American National Interest and Global Common Good", International Affairs, 78 (2), pp. 233-44.
} 
saving) by imposing a sign of equivalence between ignorance and low-wage employees, labor market skills, or negativity in general. While promising to save the masses from their own destitution and misery by advancing a subtle notion of enlightenment, this kind of reduction operates against its own claim. Even more than that, it hallows modernity with an economic nimbus not far removed from the religiousness of the Church, from the erudition of the clergy or the immutability of divine principles. The best one can make of it is that man appears to operate his own damnation and salvation indirectly - always mediating his relation to the real through an economy of self which imposes its own rule of transit on the irreversible passage of time. The self is prompted to economize itself inasmuch as it wants to survive in the unrecognizable world of passages and negativities; even more, it is prompted to push itself to the limit in order to recuperate a sense of immobility (or stability), a sense of evading the very passage, transition, flux, into which it has been thrown. "Here there is only one possibility", as Heidegger reminds us, "to recognize the emptiness of the world and let it go at that". ${ }^{206}$

To remain within the Heideggerian horizon, beyond but within it, one must envision the world as an immobile network of relations enclosing the extreme mobility of a neurological structure which computes, relativizes, and moves itself in all directions, so as to cover all spaces and all possible movements in the absence of which there could be no passage and no emptiness. The economy of passage requires a trading mentality, a neurological structure folded in such a way that all contracts must end in breaching, treachery, and trespassing. When all contracts have been breached, transgressed and trespassed, man can do no more than return to the empty law of passage by which "states must band together in order to maintain the production of these machines that are subject only to the law of speed". 207

\footnotetext{
${ }^{206}$ M. Heidegger, An Introduction to Metaphysics, New Haven, CT: Yale University Press, 1987, p. 76.

${ }^{207}$ P. Virilio, Speed and Politics, New York: Semiotext(e), 1977, p. 46.
} 
Speed and passage, movement, acceleration, trespassing - they all push man towards "banding", that is, towards the nomadic or sedentary packs whose law is contractual bonding. In whatever shape or form, the pack plies itself around an authoritative figure, forming the spirit that ensures the preservation of the whole. Unlike centralized formations, the pack sinks into the rhizomatic - it disperses power instead of concentrating it in a stable center. M. McLuhan describes this "darker purpose" of delegating authority from the center to the "peripheries of power and wealth" through the isolation of the visual sense, that is, through a kind of blindness which confers on man the illusion of the third dimension (i.e., of Reality with a capital R).

As such, the (illusion of) third dimension escapes the circularity and flatness of the center, operating by diffusion rather than by reference to centrality. The isolation of the visual brings about the diffusion of power, or rather of the psychological "filling of the field of attention by one sense only". ${ }^{208}$ In the claustrophobic atmosphere of man's vision, sight is reinvigorated, but only as a psychological recompense to the loss of power. Deleuze's and Guattari's depiction of bands derives its strength from this loss: "that is why bands in general, even those engaged in banditry or high society life, are metamorphoses of a war machine that differs formally from all State apparatuses or their equivalents". ${ }^{209}$

The internalization (appropriation) of the visual corresponds to the diffusion of power from center to periphery: it is the movement that characterizes modern thought, or at least the appropriation of thought by the modern State. It differs from classical, structural networking by evading its very premises. If, according to M. Castells, a network is a set of interconnected nodes, whereby curves intersect themselves in the absence of a center and with the aim of contributing to "the network's goals" 210 , for someone like Deleuze (and

\footnotetext{
${ }^{208}$ M. McLuhan, The Gutenberg Galaxy, Toronto: University of Toronto Press, 1962, p. 17.

${ }^{209}$ G. Deleuze and F. Guattari, Nomadology, New York: Semiotext(e), 1986, p. 13.

${ }^{210}$ M. Castells, "The Network Society: A Cross-Cultural Perspective", 2004. http://www.allnoble.net/articles by manuel castells.htm.
} 
Guattari), the node (i.e., or nomad thought) is not grounded in an all-encompassing totality, but rather it "is deployed in a horizonless milieu that is a smooth space, steppe, desert, or sea". ${ }^{211}$ When the military deploys its forces to the frontiers, however, the 'network's goals' and its horizonless presence, melt into concrete, war-time, profits. As A. Roy puts it:

As America's show business gets more and more violent and warlike, and America's wars get more and more like show business, some interesting crossovers are taking place. The designer who built the $\$ 250,000$ set in Qatar from which General Tommy Franks stage-managed news coverage of Operation Shock and Awe also built sets for Disney, MGM, and Good Morning America. ${ }^{212}$

In his Defense of North America, G. Grant depicts American cities as topological encampments on the road to economic mastery. In his view, an economic power that has so quickly gained a technologically driven esprit de corps is doomed to encapsulate itself in the very technology it develops. It is the conquest of space not space qua space that one reproduces and sustains through both technique and technology, that is, the economic mastery of a world of objects refracted in modern psychology, language, and thought, and leading to the industrial mechanization and automatization of the body, leading to the becoming object/dispositiv/node of the body. In the imperial, post-industrial, era space is already encapsulated and economized in such a way that technological mastery no longer depends on the costly and unsafe conquest of space but on a human nature conquerable through indirect and volatile means rather than solely through physical force and terror: “. . . to know, even in one's flesh and dreams, the results of generations of the mechanizing of the body; to see all around one the excesses and follies now necessary to people who can win back the body only through sexuality, must not be to forget what was necessary and what was heroic in that conquest". 213

Whoever (en)trusts technology to create empire, identifies reason with the liberation

\footnotetext{
${ }^{211}$ G. Deleuze and F. Guattari, Nomadology, New York: Semiotext(e), 1986, p. 48.

${ }^{212}$ A. Roy, An Ordinary Person's Guide to Empire, Cambridge, MA: South End Press, 2004, p. 58, citing Frank Rich, "Iraq around the Clock", New York Times, March 30, 2003, p. 2, col. 1. http://select.nytimes.com/gst/abstract.html?res=F40710FD38540C738FDDAA0894DB404482.

${ }^{213} \mathrm{G}$. Grant, Technology and Empire, Toronto: Anansi, 1969, p. 25.
} 
of mankind and proceeds to sterilize both its value and freedom. ${ }^{214}$ The nihilistic corrosion of liberalism corresponds to a new form of domination, a new horizon within which man (re)creates the world of conquest and (re)makes the will to technology into the sole content of that world. G. Grant suggests that "in the appeal to capitalism as tradition it is forgotten that the capitalist philosophers dissolved all ideas of the sacred as standing in the way of the emancipation of greed". ${ }^{215}$ Technological domination incarnates the world of capitalism by annihilating human values and freedoms, by "closing down [of] all thinking which transcends calculation", ${ }^{216}$ and all desires that do not lead to the mastery of the future. It fills its own creation with a sense of greed, with a sense of mastering the future on economic and technological terms alone.

Unlike any other human horizon, the technological horizon becomes synonymous to sustaining and fulfilling liberal principles, liberal consciousness, which is neither European, nor Asian, but purely technological - pure will to mastery. Indeed, there is a nihilistic tendency inherent in the American will to mastery, or rather a refutation of nihilism as an underlying human order - there is, at work, an ethereal nihilism, a spectral, liquefying negativity, incessantly turning itself into a positive assessment of the American experiment: the "us, we, ourselves" in the sense in which Levinas is using these terms, that is, in the sense in which the world makes sense only as a "totality of me's, at once without conceptual unity and in relationship to one another"217

By contrast to European nihilism, American nihilism covers itself up in the positivity of not being Europeanized, of not carrying the weight of European history and experience. ${ }^{218}$ History and experience become the enemies of an odd nationalism, a ghostly

\footnotetext{
${ }^{214}$ P. Emberley, "Technology, Values, and Nihilism”, J. Alexander, ed., Science, Technology \& Politics, Ottawa: Institute for Technology Policy, 1988, pp. 41-58.

${ }^{215} \mathrm{G}$. Grant, Technology \& Empire, Toronto: Anansi, 1969, p. 66.

${ }^{216}$ Ibid., p. 40.

${ }^{217}$ E. Levinas, Entre Nous: On-Thinking-of-the-Other, New York: Columbia University Press, 1998, p. 27.

${ }^{218}$ S. M. Lipset, The First New Nation: The United States in Historical and Comparative Perspective,
} 
nationalism endorsed by the will to economic mastery. Man's values are weighted at the stock exchange, his ideals, however, are settled for a little more than that. The death of ideology too often associated with imperial expansion, is no longer a mere slogan; it is the very success of a technologically and economically driven empire. What sets it apart from older empires is not the strategic and rather rapid destruction of any target whatsoever, not even the spontaneity of conquering the world over, but the incredibly ethereal relation to space, the unrecognizable and unprecedented relativity of places and targets already removed from reality by virtue of profitability and calculation.

To understand these developments in their historical context, let us recall the vision that originally sparked scholarly research into social engineering, which began with the work of Polish legal scholar Leon Petrazycki (1867-1931). His goal was to bring about efficient social change without having to obtain attitude changes. In 1925, he set out a concise formulation of the task at hand:

It concerns the gradual transformation of the human race through elimination of thousands of dissonances and disharmonies. It intends to do so by adjusting the transformation to a new rational basis. This should occur through the utilization of a scientific approach and with an understanding of causal relationships. ${ }^{219}$

In its post-modern and high tech version, imperial social engineering makes for a veritable ritual to intervene, to remove, and to strategize the world over. It has become somewhat of a rite to create the illusion of a real battle, a real intervention, a real strategy. Ritual simulation has become the ritual itself - an underlying reality of imperial power. The space of simulation coincides with the smooth space of the ritual, with the suspension of movement in the presence of death, or with the disappearance of time at that moment at which there is nothing else to be remembered but death - the rejuvenating, incalculable,

New York: Basic Books, 1963, esp. chap. 7.

${ }^{219}$ Translated and quoted in A. Podgórecki, "Sociotechnics: Basis Concepts and Issues", A. Podgórecki, J. Alexander and R. Shields, eds., Social Engineering, Ottawa: Carleton University Press, 1996, p. 24. 
imprecise, death of the real. The imperial machine does not operate in the striated space of modern states like the empires of old, but instead operates in the smooth space of the virtual, at the very heart of modern consciousness, where the spirit of the West ends up by being the sole ideology of social creation, the genesis of (post)modern man.

The virtual space of social engineering technique appears to be much more profitable than real space: it isolates sight and concentrates it on the commands and movements of the machine, on the reduction of reality to mere calculus, movement, division, emptiness. Its smoothness consists in the obsessive (pre)occupation with the body, in the actual transformation of the body into an organic prosthesis of information and movement. This is the essential project of social engineering, which includes what $R$. Boguslaw calls the "New Utopians": system engineers, operations researchers, software designers, management professors and policy analysts. ${ }^{220}$ From an economic point of view, social engineering helps man overcome undesired obstacles (distance, slowness, disease), an undertaking that often requires a discourse of conflict (man confronted by the vicissitudes of daily life), or rather an economy based on the indefinite accumulation of conflict. As K. E. Dahlberg recounts, the social engineering ethic contains five main traits: rationalization, exploitative control, perfectionism, functional specialization, and the desirability of highly mobile standardized persons. ${ }^{221}$ It is no longer this or that machine aiding man in his confrontation with nature, with life, or society, but all the machines, each having a precise and minute role in occupying the time and space of one's life.

It is no longer the rhythm of production that measures man's lifetime, but his dependence on the machine as the primary capital of life. It is a paradoxical situation, as all mechanistic existence is, for the pace at which these gadgets are replaced by better

\footnotetext{
${ }^{220}$ Here, imperialism has firmly and fully entered into the realm of social engineering. The now classic study is R. Boguslaw, The New Utopians: a Study of System Design and Social Change, Englewood Cliffs, NJ: Prentice-Hall, 1965.

${ }^{221}$ K. E. Dahlberg "Technological Ethic and the Spirit of International Relations", International Studies Quarterly, vol. 17, no. 1 (March), pp. 55-88.
} 
performing ones is incredibly fast, pushing continuously towards the uniformization of production and consumption, that is, towards the deadlock of economic dialect(ic)s. The machine itself is not economical, it is a piece of metal, rubber, or silicone, on which one spends his money, his trust, his pleasure. It saves him from having to decide where and how to spend his time and money. This is the negative (perhaps even superficial) way of looking at the emerging economy of the machine: the machine as a means of extortion based on an illusory exchange of qualities.

Man spoils his qualities manipulating a machine which is supposed to replace them with better ones - take for example driving, which replaces man's being outside with being inside the automobile, with being always separated from the "outside", from walking, running, moving around. Indeed, it changes man's mobility, or rather it exterminates it by suspending the movement of the body. It is as if the immobile body becomes the source of the greatest mobility: man no longer needs any qualities to move from one point to another, all he needs is to remain immobile and to coordinate the peripheral movement of hands and feet in such a way that the greatest speed, the greatest mobility, is achieved with minimum of effort. The street is no longer a simple venue of traffic (as Virilio puts it), but a prosthesis of the machine: the traffic that occupies the street is its very soul, emerging in ever more ethereal and rapid versions of itself. As Žižek tells us: the street belongs to "the spiritualist prospect, casting off our ordinary bodies, turning into a virtual entity which travels from one virtual place to another". 222

For P. Virilio, to occupy the street means to occupy the machine, to move in its stead and bring its speed to zero. It means to be the outsider, living in the exteriority of the social machine, inside another machine, that of war. Camus' outsider suffers the greatest immobility of thought, of psychological confinement, or of interrupted communication his crime is gratuitous, but so is his entire life. His movement is nonexistent but so is his

${ }^{222}$ S. Žižek, The Plague of Fantasies, London and New York: Verso, 1997, p. 130. 
ethereal mobility, that is, the sort of mobility attributed to saints or to the beasts of the desert, which no one ever sees, but always hears of them, implies them, makes them present through absence alone. It is this sort of absence that Barthes attributes to the study of ideas in motion, to modern mythology, which is itself a moving idea, a fluid chain of semiotic (or symbiotic) relations. It is this sort of absence that Derrida attributes to specters, ghosts and spirits - to thinking perhaps?

The immobility of thought is compensated by the speed with which ideas are created and manipulated. In this way, thought gains its rewarding omniscience - it covers the whole of society without ever moving itself, without really becoming other. Perhaps this is the ideal stance of the outsiders, the humans metamorphosed into the satellitic machines, about which Baudrillard tells us that "what is primary is their serial, circular, spectacular arrangement - the future model of social relations". ${ }^{223}$ The future model is no longer the Panopticon, for there is no longer a physical relation defining the space of confinement, but a psychological relation between the invisible and the visible, the inhuman and the human. The visible results from the act of some invisible, immobile confiner; it moves in (in)determinate ways, always between the genetic and the satellitic forking of the real (as in Baudrillard), always confining and liberating its imperial subject. In truth, the visible is no longer purely visible, nor purely invisible, but a hybrid of visibility and invisibility, of psychology and language, periphery and center, reality and virtuality. The hybridization of reality reaches an artificial synthesis (at least in principle), a compromise forced between the inner motion of genetics and the outer motion of communication (as a means of control rather than as a binding mechanism), splitting the whole of history into the dialectic of the visual and the invisible, into the very substance and form of human genesis.

The more one communicates, the better are the chances of becoming visible,

\footnotetext{
${ }^{223}$ J. Baudrillard, Simulacra and Simulation, Ann Arbor, MI: University of Michigan Press, 2005, p. 77.
} 
successful, powerful. Language does that, it creates the illusion of visibility, of height and power, the illusion of living in a world resting entirely upon the invisibility and immateriality of sound. Language is a double illusion, obviously, for there is nothing that could retain its sense and reality inside the Machine, itself a microscopic or a satellitic form of illusion, an optical or an auditory apparatus producing endless evidence, or at least endless effects of evidence (e.g., of visible invisibility, as generated by the military's night vision devices). Against the machine, language itself is no more than frequency and wave, breaking into so many things at once, into so many tonalities and messages bearing the arbitrary mark of truth, the echo, or dissident mark of pure sound, pure interruption, and pure noise.

So it is language that in the end must prove our complexity, our desire to become part of something other than ourselves by giving life to sounds and things. One example is last century's fascination with orchestra, with the harmonious orchestration of social and political assemblages, of psychological and corporeal ensembles. The romantic notions of psychological and economic control shared the same artificial positivity of orchestrated bodies and instruments, the same tendency to release their tension through the professional management of sounds and movements. The "conductor" appeared as the symbolic incarnation of the enlightened despot, the man of romanticized rituals and auras capable to orchestrate vast assemblages of bodies and instruments. His movements, his masks, his reveries, were effected by a sound, a move, or a body, which was itself the equivalent (effect) of speaking, moving, masking and revering.

On stage, the presence of sound is mediated by the singer, the conductor, the orchestra - there is always a sense of discovery hidden through the spectacle of sound, a gravitational energy ameliorated in the performance, in the very presence of bodies and instruments producing certain sound-effects. The bareness of sound is elevated by the pleasure of performance, by its own platonic odyssey. The self-referentiality of sound like 
the self-referentiality of mystic experience, crosses over into the world of pure reflexivity: everything floats in the inner space of sound, in the very performance of its acoustic undulations.

The ideality of sound borders on the ideality of the religious, of escaping the tyranny of things in favor of its immaterial spirit (of tyranny). Language and even myth are believed to work in such a way that the powerful, the weak, the imagined, are never what they seem to be - language beholds the thought and the sentiment of being something other than seeming, other than the simple replica of power and weakness. It sets itself up as the substance and form of events, as the acoustic mirror in which things appear to be identical to themselves by exceeding their identity. In Las Meninas the royal couple is visible to us through this kind of mirror in which the difference between the painter, the art critic and the novice is completely obliterated. The royal couple coincides with $u s$, just as is the man walking through the door, the woman and the children playing on the surface of the painting, the nun. The pressure (or mirage) of our presence is dissolved by the visual liberation of simultaneous assemblages - the child playing with the dog, the dwarf, Velasques himself.

M. Foucault had described this painting, situating its language in an infinite relation to its content: "it is in vain that we attempt to show, by the use of images, metaphors, or similes, what we are saying; the space where they achieve their splendor is not that deployed by our eyes but that defined by the sequential elements of syntax". ${ }^{224}$ Arranging or discovering things in a certain order makes them ripe to be arranged and discovered through language. It is not language that carries the image but the image that speaks in a certain way even before the order of things is established through language. The inescapability of language is dissolved through the magic of its image - speech is suspended and recharged in the interiority of the painting, in the silent gazes and postures

\footnotetext{
${ }^{224}$ M. Foucault, The Order of Things, New York: Vintage Books, 1970, p. 9.
} 
communicating through shades and colorful contours.

The problem of post-modernity is precisely this production of languages-as-images (or images-as-languages), and the subsequent transformation of their negativity, their imprints, into permanent sources of innovation. The fixation on language, on communication, on the irrational, is the landmark of a deeper concern with the negativity inherent in production, with the enveloping and confining role played by negativity in the order of production. Language ceases to convey a particular message (precisely because it conveys it all the time) and charges all things with the capacity to sustain their own messages - the language of production (which negates the given) becomes indistinguishable from the production of language (affirmation of the given). As such, it exhausts itself through its own production in the same way in which Borges' empire gets exhausted in the production of its own cartography.

Producing language, or at least endowing things with a language of their own, submits from the start to some accumulative aim, some arithmetic or measure of being communicable. The more things language begets, the more it becomes their measure, moving from the foreground to the particularity (the genetics) of things, realities, events, horizons. In our time, a time "out of joint" as Derrida would argue, the presence of things is attested first and foremost through language; their numbers and their colors depend on the language used to make them desirable and useful, to make them what they are (and also what they are not), simple things to which we reserve a place in our vocabulary and in our thoughts, things that surround us, things for nothing, nothing at all, except our sense of possession, our sense of sight and our willingness to walk the line of life always enamored, always spelling and desiring something other than our languages and images.

Language itself becomes such a desire, whose distinctiveness no longer makes the mark of our being in the world, no longer lets us be otherwise than numbered, colored, categorized as desirable or useful or not, as certain things dispersed among other things, 
speaking their own languages and occupying their places, things with no connection to us except the language which produces us, through which we are made into speaking objects, signs and horizons. These things are negative insofar as language discovers them outside its order and strives to give them meaning, to give them a name and a place in the immensity of its own thought and space. Conversely, their positivity derives from their identification with language, which is not always in good shape, not always true to its archetypes - but always, as Kierkergaard says, "in an absolute relation to the Absolute".225

The ethical is thus suspended from all language relations, forming the paradox of faith, the parable in which everything stands in an absolute relation to language, while also appearing above it as a particular this or that. The world and the order of language appear on the same plane, deceivingly clinging to the absolutism of relations, to the Absolute as existing and speaking object. This is the high point of language, the absolute relation entertained not only with the things around, but also with itself, with its own negativity. The suspension of the ethical gives language its mythological (in the sense in which Barthes defines mythology, as a leap of faith) and faithful (in the sense in which $\mathbf{J}$. L. Nancy defines faith, as an unexpected leap of joy) appearance, the sort of infinite relation (infinite imprecision, as in Foucault, or Kristeva) to the things it encounters. When, on the other hand, it operates inside the ethical by ascribing a name to each thing and by dispersing itself across the whole field of representation (as Baudrillard explains), then it is science in the form of "nomenclature and taxonomy", ${ }^{226}$ the very negativity it wants to avoid and ideally succeeds in avoiding by simply immersing itself in it.

What is the relationship between language and the 'real', or negativity? In 1954, cybernetician $\mathrm{N}$. Wiener answered by giving a predictive account of their affair:

It is the thesis of this book that society can only be understood through a study of the messages and the communication facilities which belong to it; and

\footnotetext{
${ }^{225}$ S. Kierkegaard, Provocations, Farmington: Plough Publishing House, 2002, p. 26.

${ }^{226}$ M. Foucault, The Order of Things, New York: Vintage Books, 1994, p. 120.
} 
that in the future development of these messages and communication facilities, messages between man and machines, between machines and man, and between machine and machine, are destined to play an ever increasing part. ${ }^{227}$

A case in point might be a fragment of a speech given by G. W. Bush at West Point:

We cannot defend America and our friends by hoping for the best. We cannot put our faith in the word of tyrants, who solemnly sign non-proliferation treaties, and then systemically break them. If we wait for threats to fully materialize, we will have waited too long. (Applause.)

Homeland defense and missile defense are part of stronger security, and they're essential priorities for America. Yet the war on terror will not be won on the defensive. We must take the battle to the enemy, disrupt his plans, and confront the worst threats before they emerge. (Applause.) In the world we have entered, the only path to safety is the path of action. And this nation will act. (Applause.) 228

In retrospect, this appears to be quite familiar. It is one fugitive example of a man communicating effectively with the war machine.

Therefore, let us now turn to what lies beyond prediction, in the virtual space of the Real.

\footnotetext{
${ }^{227}$ N. Wiener, The Human use of Human Beings, Garden City, NY: Anchor Books, 1954, p. 16.

${ }^{228}$ G. W. Bush, "President Bush Delivers Graduation Speech at West Point, United States Military Academy, West Point, New York" (press release). http://www.whitehouse.gov/news/releases/2002/06/20020601-3.html.
} 


\section{Chapter 6}

\section{Storing and Fabricating the Real}

Enframing means the gathering together of that setting - upon which sets upon man, i.e., challenges him forth, to reveal the real, in the mode of ordering, as standing-reserve.

$$
\text { M. Heidegger } 229
$$

In addition to the conditions under which life is given to man on earth, and partly out of them, men constantly create their own, self-made conditions, which, their human origin and their variability notwithstanding, possess the same conditioning power as natural things.

\section{H. Arendt ${ }^{230}$}

"Storing" is no longer a verb denoting the accumulation of static electricity, or the quasi-administration of natural resources, it is a rather common denomination of the real, of that accumulative and organizing reality which has itself as the sole object of maneuver. By stocking its resourcefulness, its space and its objects, reality turns itself into the kind of virtualization that Baudrillard refuses to take into consideration precisely because it seems real. The real of the real ordinarily appears to be virtual - it simply stores itself up and accumulates all of itself, accumulating its own apparitions and illusions, its own obsessions and betrayals. Differently put, the virtualization of the real means, in essence, the stocking of infinite versions and alternatives of events, or of their languages, carving themselves in the relativity and density of the given, in the moving image of that novel and unquestionable fixation of meaning called "absolute", "eternal", "unmoving". As D. T. Nguyen and $\mathrm{J}$. Alexander suggest, the age of digitized information has gone beyond the connived appearance of the spectacle, by changing the very way we experience its reality:

Our civilization's goal of wisdom (perfect knowledge) has warped into a deluge of information. While valid knowledge is inescapably human because it resides tacitly and actually in bodies, machine-readable information is technical. Technology abstracts us from our existence as physical beings in the

\footnotetext{
${ }^{229} \mathrm{M}$. Heidegger, The Question Concerning Technology and Other Essays, New York: Harper Torchbooks, 1977, p. 20.

${ }^{230} \mathrm{H}$. Arendt, The Human Condition, Chicago: University of Chicago Press, 1958, p. 9.
} 
world. We ignore the boundedness of experience that leads to knowledge. Without limits, we have just information and data. ${ }^{231}$

In our information age, struggle has become a virtual race for the soul of the machine to create and exploit new realities, to define and construct the situational aspects of paramount reality. Communications technologies have opened up enormous spaces for the free consumption of human knowledges, advancing the Internet as the prosthetic world brain, in which the ideology of information flows and distributes itself freely, invoking, if only virtually, anti-prohibition movements of peer-to-peer sharing of entertainment sources. Back in the mid-1990s, J. P. Barlow, anticipating the day when the Internet would become the primary form of information exchange, made a then-seemingly audacious prediction:

Once that has happened, all the goods of the Information Age - all of the expressions once contained in books or film strips or newsletters - will exist either as pure thought or something very much like thought: voltage conditions darting around the Net at the speed of light, in conditions that one might behold in effect, as glowing pixels or transmitted sounds, but never touch or claim to 'own' in the old sense of the word. ${ }^{232}$

In military terminology, there is always a mismatch between offense and defense, advent and retreat, victory and loss. While the advent of the Internet appeared to have given some advantage to the newly empowered 'wired masses', it also prompted the capitalist trading system to remedy the revenue losses brought about by information piracy, by enacting far more drastic copyright and patent laws - which almost immediately proved very difficult to enforce. At long last, with the introduction of Microsoft's Vista ${ }^{\mathrm{TM}}$, the piracy battle has been fully joined, at least at the level of the operating system. More generally, the capitalist trading system thrives on the very commodification of knowledge it seeks to contain (by pirating its commodifying ideology and selling it back). As J. P.

\footnotetext{
${ }^{231}$ D. T. Nguyen and J. Alexander, "The Coming of Cyberspacetime", R. Shields, ed., Cultures of Internet: Virtual Spaces, Real Histories, Living Bodies, London: Sage, 1996, p. 99.

${ }^{232} \mathrm{~J}$. P. Barlow, "The Economy of Ideas: a Framework for Rethinking Patents and Copyrights in the Digital Age (Everything You Know about Intellectual Property is Wrong)", Wired, vol. 2, no. 3, March 1994, p. 86.
} 
Barlow puts it, ". . this comes at a time when the human mind is replacing sunlight and mineral deposits as the principal source of new wealth". ${ }^{233}$

The information age has brought with it the problem of information overload, at the same time at which it has given reality an infinitely malleable character. ${ }^{234}$ There are now enormous virtual warehouses of the real, often in the form of hard disks, streaming tape, CDs, DVDs, and superdisk "jukeboxes", simultaneously storing up versions of the same event, same thing, or apparition, which has been real (at least up to a point) by virtue of its resistance to the very fiction of its appearance.

There are, of course, also virtual languages of the virtual, virtual or rather circular productions of the real, in which what is being said coincides with what is being memorized, transmitted, and stocked. The virtuality of the real is the real of the virtual, and they stand, as one might guess, in the same relation in which a certain event stands vis-àvis its blueprint. In principle, this standing in opposition resembles the playfulness of a "cat and mouse" game - a virtual game in which the mouse threatens the cat with equal chances of winning. The virtual nature of the game permits a joyful reorganization (or complementarity) of the real, an animating but also strictly ruled/ruling evacuation of the real. The game compensates for the loss of the real by making its rules the sole reality of the real - it is as if everybody played the same game without ever being able to prove that such a game even exists.

J. Baudrillard once believed that reality disappears altogether, that somehow we are left with the threat (the sensation) of something real, with the intuition of having to search for it in and through the virtual. The return of the real, already present in "reality TV", in rave dances, in films, reproduces mentally the terror and joy of a body deprived of its functions. The mind acknowledges the real based on screened violence, or rather on the

\footnotetext{
${ }^{233}$ Ibid.

${ }^{234}$ Such software programs as PhotoShop ${ }^{\mathrm{TM}}$ and SoundForge ${ }^{\mathrm{TM}}$ permit one to morph, transmogrify or counterfeit both sight and sound in virtually any desired manner.
} 
favorite actor's violence, on the images and sounds of violent encounters, or violent effects caused by someone else, by an apparition or a ghost conjured to suspend/threaten the real indefinitely. The storage of reality is possible on account of this fright, or frightening conjuration of non-real-realities and non-violent-violence, which in turn become the sources of "real" capital, "real" power, "real" politics - the real sources of the real as it were, the real pure and simple: a game, a rule, a phantasmagoric deployment of effects. From communications research we find that the relationships involved here are both quite simple and very complicated. P. Watzlawick depicts this situation as being somewhat paradoxical:

Our everyday, traditional ideas of reality are delusions which we spend substantial parts of our daily lives shoring up, even at the considerable risk of trying to force facts to fit our definition of reality instead of vice versa. And the most dangerous delusion of all is that there is only one reality. What there are, in fact, are many different versions of reality, some of which are contradictory, but all of which are the results of communication and not reflections of eternal, objective truths. $^{235}$

The fabrication of the real settles in as a contradiction in terms just as ideology does, or freedom of the press, or some other conventional denomination by which what is meant is not something true but the apparition (the event) of truth - a vague sentiment of truthfulness, the memory of witnessing the formulation of truth, the exquisite image of a true adventure, and so on. These sentimentalities, memories, images, these vagaries, embody the very lines of flight by which one ceases to be what he is and begins to fabricate himself/herself. These peripheral modifications of the order of being in favor of fabrication, trueness and performance, make up the volatile map of the present. Through this map, one uncovers the tension between the question of habituation, the Aristotelian question of habituating the new generations to the rhythm of labor, and the question of repetition, of the molecular return of the same in and for the different. One uncovers the

\footnotetext{
${ }^{235} \mathrm{P}$. Watzlawick, How Real is Real: Confusion, Disinformation, Communication, New York, Vintage Books, 1976, p. xi.
} 
present as question and answer, difference and repetition, fabrication and performance - in a word, one uncovers it as a fabricated set up: a form, an emptiness, a framing contour.

Beyond this synthetic dialect(ic) of question and answer, difference and repetition, which conjures the ghost of the present, there is no real presence of the present. Just as a product is something other than the process of its production, the fabrication of the present is something other than the present. The present as fabrication is just another contradiction in terms, another delaying instance by which what is meant is not something true about the present, but rather the present as truth. Fabrication as truth, man as homo faber of the present, of our present understood as the fabrication of truth in and through lies, the fabrication of knowledge in and through ignorance, or of power in and through powerlessness.

As J. P. Barlow argues, "notions of property, value, ownership and the nature of wealth itself are changing more fundamentally than at any time since the Sumerians first poked cuneiform into wet clay and called it stored grain". ${ }^{236}$ This is the present, our present, which no longer produces wealth but the fabrication of wealth, the simulation, the technology of wealth. The present as knowledge of wealth, knowledge of simulating and fabricating it - knowledge of knowing how, of a set of knowledges that operate in and through wealth, in and through the wealth of questions and answers, differences and repetitions, truths and lies, alliances and betrayals.

As digital technology progressively detaches information from the physical plane, the concept of intellectual property changes too. In the traditional paradigm what was protected was the specific expression of an idea, like protecting the bottle but not the wine. Today, we are reversing that paradigm, transforming ideas into wine. J. P. Barlow illustrates this 'paradigm shift' as follows:

\footnotetext{
${ }^{236}$ J. P. Barlow, "The Economy of Ideas: a Framework for Rethinking Patents and Copyrights in the Digital Age (Everything You Know about Intellectual Property is Wrong)", Wired, vol. 2, no. 3, March 1994, p. 86.
} 
Since it is now possible to convey ideas from one mind to another without ever making them physical, we are now claiming to own ideas themselves and not merely their expression. And since it is likewise now possible to create useful tools that never take physical form, we have taken to patenting abstractions, sequences of virtual events, and mathematical formulae - the most un-real estate imaginable. ${ }^{237}$

This is how we package both reality and unreality, and sell it back to willing consumers the world over. However, it is not only the packaging that problematizes our new realities, but also the commercial choices through which realities become worth packaging and promoting. The present then, is made up of all these reflected, fabricated, stored, wasted, refracted, packaged realities and protected unrealities, and it is through their operations that we find traces of an event, which is no longer known to us. Like Tolstoy's soldier, we walk on foot into the foggy war-zone of the present, and the only thing we know about him is that "he cannot have the experience of the war he is waging nor of the battle he is fighting because the only 'global' traces of the war are inscriptions notably maps and statistics". 238

Inscriptions belong from the start to the simulation of order, to that particular apparition of truth by which everything is made to appear different while remaining the same. This is, indeed, the specter of the different, the scene and the event of performing truth to the best of one's abilities - the space of the jester. The perfect jest, or space, lies hidden right in the heart of simulation, where the only reality is the absence of the real - its spectrality, its haunting spirit. The jester manages an entire economy of "absences", always "excusing" something which is never there or is not there yet; he manages "delirious themes which remain separated and do not compromise reason's totality"239; or he disperses himself into inexplicable and disconnected memories, into random images storing nothing but randomness, disconnectedness, inexplicability.

\footnotetext{
${ }^{237}$ Ibid., p. 88 .

${ }^{238}$ G. C. Bowker, "The Past and the Internet", Items and Issues, winter 2003/2004. http://www.venus.co.uk/gordonpask/.

${ }^{239}$ M. Foucault, Madness and Civilization, New York: Vintage, 1988, p. 118.
} 
It is conventional to treat and understand any advance in technology in terms of a break in the degree of uncertainty between cause and effect, truth and power, virtuality and reality. At this point, however, we might want to (re)consider technology not as the arbitrary reproduction of the nervous system, but as its arbitrary conjuration: a nervous system conjuring its own reproduction in a world devoid of all reality except its own synoptic activity. Perhaps it is not the schizophrenia of the world, but the world of schizophrenia that is reproduced through technology (anyway, who can tell the difference?) - a world of wealth, indeed, where the only thing that is produced is the wealth of simulation, or the simulation of wealth. ${ }^{240}$ The end product is no longer the result of human labor but of the simulation of labor, of the process in and through which men become no more than the simulacra of production - the very end of productivity.

Man gets assimilated by technology, by the simulation of his own synoptic activity, and then by the inertia of this simulative activity. He consciously transforms himself into the object of economy, into the subject of his nation, his community, his religion. As such, he no longer has the capacity to perceive of himself as belonging to this or that nation; he adheres to it cerebrally, or rather symbolically: "the larger unit to which he feels himself related is a crowd or a crowd symbol". ${ }^{241} \mathrm{He}$ is no longer a member of a group, a student, or a husband; he is an adherent - the very image of distance and simulation, the very presence of institutionalized absence. This is the man we know: man as effect, effecting himself in and through his own absence, in and through his own performance - man performing and absenting his own life, his own familiarity with things, or with his own.

To him, life itself appears as mere accumulation of realities, mere economy, mere business. There is no longer a cause-and-effect relationship between events, or rather that

\footnotetext{
${ }^{240}$ As Pat Buchanan likes to remind Americans, in the long run, "You cannot run an empire on borrowed money". "The Retreat of Empire", The American Conservative, September 13, 2004. http://amconmag.com/2004 09 13/buchanan.html.

${ }^{241}$ E. Canetti, Crowds and Power, New York: Penguin, 1960, p.199.
} 
relationship appears to be of the order of jests; what is sought is no longer the event but the impression left by it, the trace, the imprint, the memory. ${ }^{242}$ The result is not the succession cause-effect, but the breaking up of that succession through the uniformity of effects. This accumulation of eventful effects, this conjuration of reality to the immensity of possibilities, puts an end to reality proper, to the possibility of the impossible as it were, or to the realism of its own disappearance. Reality continues to hover around like a ghost, or a specter, only to hunt down the event of its own apparition - a ghost hunting ghosts hunting ghosts hunting... in an interminable procession of effects and eventualities, pseudo-events and eventfulness, alliances and betrayals.

These are the innumerable plateaus imagined by Deleuze and Guattari, the multifaceted dimensions of being different, being repeated, being haunted. ${ }^{243}$ These are the intimate lines of flight transcending the limits of consciousness and reflecting themselves back upon the surface of the skull: man moves somewhat unconsciously from one plateau to another, from one fatal dimension to another. He moves through his life as if through the life of another, as if through the death, the disappearance, or interposition, of another. This is why he leaves one setting and hunts the other in search of his lost emotions, his thoughts, his desires and perceptions. He ceases being the prisoner of the Real - he finally escapes paramount reality by shattering it to pieces. The selection and storage of the pieces of the Real becomes the new intellectual challenge, the new archival ordeal, the new desire to grasp the seriousness, or gravity, of this change - is it real, is it simulated? Is it really a change/challenge to the real?

Paramount reality rests on this challenge, or rather on its dispersion as a set of established constructions through which we filter the world and come to see life as orderly,

\footnotetext{
${ }^{242}$ P. L. Berger and T. Luckman, the Social Construction of Reality, Harmondsworth, Middlesex: Penguin, 1972.

${ }^{243}$ G. Deleuze \& F. Guattari, A Thousand Plateaus: Capitalism and Schizophrenia, Minneapolis, MN: University of Minnesota Press, 2003.
} 
stable and even normal. As Berger and Luckman see it:

This is the reality of everyday life. Its privileged position entitles it to the designation of paramount reality. The tension of consciousness is highest in everyday life, that is, the latter imposes itself upon consciousness in the most massive, urgent and intense manner. It is impossible to ignore, difficult to weaken its imperative presence. ${ }^{244}$

What does it mean to break down the real, to store it and manipulate it as if it were no more than a piece of wood, or a table of contents? One's presence, his actions, his intentions, reflect his ability to accumulate bits and pieces of reality and fit them together as if in a living puzzle, or a living specter. This is the success story entertained by all types of constructionisms (really, the re-writing, or rather the sinking in, of the positivism that flourished at the beginning of the $20^{\text {th }}$ Century, itself a version of the death of God), it is, of course, the ideologized "drive" of constructing, in the absence of God, the perfect human order. As W. Connolly tells us, "these constructions function to conceal the paradox of politics; they depoliticise life just where a more active politicisation is needed". ${ }^{245}$ As a matter of fact, they do politicize life in the most profound and volatile way: in this perfect human order, perfection is no longer separable from the struggle to bring it about, to stabilize or overturn it - perfection is imperfect, human, constructable. Ideology incarnates the failure, or the imperfection, of man's attempts at constructing an eternal order.

Ideology is precisely this imperfect and unsuccessful ordering of perfection and success, perfection as success, perfection in success. Its order not only proliferates imperfect versions of the world, of truth, of consciousness, but it becomes their reality, their (re)source, their haunting ethos - it becomes the ideal of imperfection, the ideal of successful unsuccess, the opposite of what it had hoped itself to be. Ideology does not manipulate ideas, it rather reflects them in the motion of its imperfectability, in the

\footnotetext{
${ }^{244} \mathrm{P}$. L. Berger and T. Luckman, The Social Construction of Reality, Harmondsworth, Middlesex: Penguin, 1972, p. 35.

${ }^{245}$ W. E. Connolly, "Democracy and Territoriality", Millennium: Journal of International Studies, vol. 20 , no. 3, 1991, pp. 463-84. http://www.ingentaconnect.com/content/mpg/miis/1991/00000020/00000003/art00011.
} 
impossible and inevitable tracing of ideality and success. The ideality of ideology does not rest with the motion of ideas, which is nothing more than a wave, a fashion, or a spectacle, but with the apparition of ideas, with their production, their productivity and innovation, in a word, it rests with the non-ideological, non-ideal, presence of ideas.

As ideality of ideas, ideology falls into the trap of its own making - there is no ideality, no real, palpable ideal. Perhaps only religion could speak of it and delude itself into believing there is an ideal world beyond and above the human world of ideas and forms, ideas in forms, ideas as forms. From the point of view of ideology, the relation between ideality and the world is one of identity, of energy and efficiency - the old ideologue does not distinguish between the imperfections of ideas and the imperfections of the world; for him, imperfection results from his failure to control these two realms. It results, more precisely, from his failure to get ahead of them and erase their imperfections. To stoically reduce the world of things to the world of ideas, or the distant to the near, as Foucault would argue, insisting on the necessity of a break with reality and on the equivalence of this break with the order of things (the world as an escape from ideality; the world as transition from ideality to reality) - this is what the ideologue wants to do: to control and manipulate real ideas, the real in ideas, the real as idea(s). Here, as R. Ashley suggests, "the issue is not the truth or falsehood of assumptions. The issue is a practical matter, intimately and always a part of the problem of order in modern global life". 246

However, since he cannot reduce the world to his ideas, he reduces his ideas to the world by turning all possible versions and alternatives of an event into copies or reflections of the event of thinking - the event itself is nothing more than a form, an empty vessel, or a ghost of eventfulness. The conjuration of this form, this vessel, this eventfulness without a body, becomes the event of events par excellence: it becomes real, reality, realistic. It

\footnotetext{
${ }^{246}$ R. Ashley, "Untying the Sovereign State: A Double Reading of the Anarchy Problematique", Millennium: Journal of International Relations, vol. 17, issue 2, 1998, p. 229.
} 
becomes what the ideologue had always wanted it to be - a perfect form of ideality, a perfect world. To use R. W. Cox's words, the world order appears to be: "neutral as regards the nature of the entities that constitute power; it designates an historically specific configuration of power of whatever kind". 247

The ideological event impacts the real by reducing it to the idea of its own eventfulness, to the very activity of adjusting, storing, stocking, accumulating, and, of course, perfecting. Communism turned this tendency into a masquerade of the worker's liberation movement. The industrialization of the peasant's mind turned into a distorted replica of enlightenment, while his capacity to work became the sole guarantee of the event of living: the very reality out of which the model of the techno-citizen (as the apogee of discipline and industriousness) was going to be forged. The techno-citizen appeared as the next hybrid, or prototype, of the technological revolution, the artificial avant-garde of the rights revolution, as M. Ignatieff had described it, weighting by it the imperialistic stakes of the $20^{\text {th }}$ Century. ${ }^{248}$

The fact of the matter is that the present is always fugitive, fragile, ungraspable. It presents itself through the names of the objects surrounding us, in the language with which we pretend to be in control over this or that reality, or this or that theoretical perspective. Today we witness perhaps less a revolution of rights than a betrayal of rights, or an alliance between the two, resulting in the shifting horizons of bio-politics, techno-citizenry, warfare, nano-technology, global-warming, global order, etc. It is the loss of the real as it is also something other than losing and gaining, something which is never quite clear, never quite in a position to be grasped and described through the intervention of language.

Reality in the present is no longer describable, no longer graspable in terms of what presents itself to us. There is no longer a future promising redemption, no longer a past

\footnotetext{
${ }^{247}$ R. W. Cox, "Multilateralism and World Order", Review of International Studies, 18, 1992, p. 161

${ }^{248} \mathrm{C}$. Taylor, the Malaise of Modernity, Toronto: Anansi, 2003.
} 
sinking into our consciousness - there is no longer a model to cling to, but the disappearance of the Model, its dissolving amidst the infinity of light and noisy modalities, modals, models. The present cannot be a model to and of itself, it cannot endure otherwise than by making itself into the flinching image of endurance, into the very replica of disappearance, disappearing models, disappearing events. It is this particular form of endurance that makes the present into something other than itself, into the lavish squandering of one's energy and resources, which is a sort of continuity of the discontinuous, a sort of presenting (enduring) by being absent, indifferent, ghostly.

C. Mueller highlights this new tendency in a strictly mundane style:

Political phenomena do not exist in isolation. The question of loyalty to a political system, for example, touches upon factors that are more refined than those forming the standard stock of the social sciences. Concepts such as plausibility structures, socialization strategies, language codes, ideological configurations, political impression management, and legitimating and counterlegitimating rationales provide a better grasp of political behavior and its underlying motivational basis than an analysis that restricts itself to the usual factors like education, occupation, and religion. ${ }^{249}$

However, what interests us here is not the formulaic assessment of the present - the continuity of the discontinuous - but rather "the present" as such, the dissolving of the Model into modeling/modeled realities and energies. The coming forth of the present in the guise of a certain language, or rather the coming forth of language in the present, as the present - the coming forth of the theme of centrality (in language), the centrality of language as opposed to the centrality of psychology, to the centrality of the psychological in the coupling of technology and capital, politics and culture, nationhood and empire.

M. Weber linked this (re)formative, or rather (per)formative, reduction (in our case the reduction of the present to its language) to the accumulation of capital based on the psychological modification of the value of work. He had reduced man's (re/per)forming

\footnotetext{
${ }^{249} \mathrm{C}$. Mueller, The Politics of Communication: a Study in the Political Sociology of Language, Socialization, and Legitimation, London: Oxford University Press, 1973, p. vii.
} 
role to the psychological transformation of the productive value of capital. ${ }^{250}$ The present is still Weberian in that it reduces reality to the linguistic value of the same reduction by which contemporary man denies the productive value of the psyche, by which he is no longer the man of (psychological or linguistic) permanence, but of impermanence and discontinuity, the man speaking to himself and to others through an intermittent, or rather ruptured, monologue. It is not speech that he denies, but rather Language, not the lack of productivity in the body, but the non-productive traits of human vocabulary and psychology. "Subjectivity is about impersonation", 251 as C. Weber puts it, about drag performances, citational processes, normativity, texts, and contexts. It is also about "spilling over", reinforcing, (re)enacting, itself as such. Along the same lines, G. Deleuze would argue that Subjectivity, Knowledge, Power had lost their ideal contours in favor of being a "series of variables which supplant one another". ${ }^{252}$ The loss itself embodies, or eternalizes, the very subjectivity, or ideality, it proposes to lose: "It highlights the richness and complexity of the interconnections which transcend states and societies in the global order". ${ }^{253}$ Or, as J. Der Derian contends, the boundaries of knowledge and power rest on an intertextual approach, “... in the sense of a critical inquiry into an area of thought where there is no final arbiter of truth, where meaning is derived from the interrelationship of texts, and power is implicated by the problem of language and other signifying practices". 254

Capitalistic, subjective, accumulation no longer links itself directly to the denial of eternal works (leading to its eventual ephemerality), instead it encourages an assault on

\footnotetext{
${ }^{250} \mathrm{M}$. Weber, The Protestant Ethic and the Spirit of Capitalism, London \& Boston: Unwin Hyman, 1930.

${ }^{251}$ C. Weber, "Performative States", Millenium: Journal of International Relations, vol. 27, issue 1, 1998, p. 77-95.

${ }^{252}$ G. Deleuze, "What is a Dispositif?", Two Regimes of Madness, New York: Semiotext(e), 2006, p. 338.

${ }^{253} \mathrm{D}$. Held and A. McGrew, The End of the Old Order? Globalization and the Prospects for World Order, London: British International Studies Association, 1998, p. 232.

${ }^{254}$ J. D. Derian, "The Boundaries of Knowledge and Power in International Relations", International/Intertextual Relations, J. J. Derian and M. Shapiro, eds., Toronto: Lexington, 1989, p. 6.
} 
itself through the constant condemnation of the non-productive, non-imaginative, psyche. In short, it presents itself as an ongoing assault on the illiteracy and non-productivity of technological man - which is its heart, its brain, its corpus operandi. Already out of fashion, technological man is being replaced by the marginal, the imprisoned, the diseased. He is being replaced by the technicality of marginality, imprisonment and disease, in a word, by the failing versions and inversions of its own technological development and organization. "A specter haunts Europe: the dissident", 255 would argue Kristeva, politicizing and de-politicizing the very notion of dissidence, or of political organization. In reply, R. K. Ashley, R. B. Walker, J. Der Derian, C. Weber, M. Shapiro, W. Chaloupka (among others), "stake out no territory to be defended", they "issue no promises", and "bear no flag"256. They celebrate: “. . . difference, not identity; the questioning and transgression of limits, not the assertion of boundaries and frameworks; a readiness to question how meaning and order are imposed, not the search for a source of meaning and order already in place....". 257

The present is being organized technologically and 'meaningfully' according to the principles of rationality and technique; it is stocked in parallel and serial rows of variants, dimensionalities, and alternatives, functioning (if only artificially) as a time-machine capable of changing the past and the future by modifying its speed, its position, and its direction. Time itself appears to be no more than an interference, an interruption, a hole, in the fabric of natural processes and phenomena. The present comes forth as this incessant striving, this break with, break from, time as interruption, time as hole. As such it opens up the real, the eternal, history. It opens up to itself - to its own event, its own history, which is an event and a history of disappearance. The organization of paramount reality is this

\footnotetext{
255“A New Type of Intellectual: The Dissident", The Kristeva Reader, New York: Columbia University Press, 1986.

${ }^{256}$ R. K. Ashley and R. B. Walker, "Speaking the Language of Exile: Dissident Thought in International Studies", International Studies Quarterly, 34, 1990, p. 264.

${ }^{257}$ Ibid., italics mine.
} 
history of absence, this ghostly becoming in time, as time.

Man's intervention in the history of his own disappearance, his action against this unhappy historicity, is essentially technical, essentially peremptory. His paramount reality, his present, obsesses with imperfection, immateriality, injustice. It obsesses with the apparition of stocking places, stocking maneuvers, stocking verbs, to such an extent that his life becomes a living warehouse, a machine, a drugstore. He himself becomes the stocking space of his sentimentality and reasoning, the vehicle of his thoughts, or the drug of his happiness. He lives, indeed, by investing all these "realities" with some calculable chances of success, by playing the game of the machine, the virtual game of the real, the financial games of free enterprising. He survives by investing life with the power to profit from his presence, his memory, his disappearance. He simply becomes profitable material, profitable emptiness. In a word, he becomes a thing.

Man is not only techno-economically organized (a machine), he must also perform different tasks in exchange for survival, happiness, or a better future. During the performance, he encounters himself in the image of the worker, the intellectual, the business man, whose qualities get stored in a present that does exactly the same thing, on a grander scale, with greater speed. He no longer becomes the member of a group, the mobile worker, the isolated intellectual, but increasingly becomes all of them, in an effort to adapt to the technological, the atemporal and commercial milieus of contemporary societies. He does not glide from one dimension to another, nor does he move smoothly from one sphere to the next (as in Deleuze and Guattari); he himself seems to be made of gliding fragments, trajectories and dimensions, whose impressions get stored in his memory as his paramount realities and/or fantasies. He hypnotizes himself as it were, in order to move, or glide, from one apparition (e.g., of the event of himself) to the next.

Technological man is not the man of the machine, nor the hologram of a man maneuvering a machine; he is the man storing himself as machine, hologram, maneuvering 
technique (itself a storing or preserving process), the man of technicity and relativity, the hybrid moving from one fashion to another, from one alliance to the next. A man's life is relaying, fixing, haunting, picturing, itself in the making - or as Deleuze puts it, that is how "one becomes capable of performing the action, one becomes equal to the image of the action". ${ }^{258}$ The law of the crowd, as E. Canetti suggests, is precisely this sort of equality: "a head is a head, an arm is an arm, and differences between individual heads and arms are irrelevant. It is for the sake of this equality that people tend to overlook anything which might detract from it". 259

However that may be, it is not only the action itself that he is pursuing (the organization of the real, its storing, its fixity or fixation), but the image of always being engaged in some storing/fixing activity, in some imaging of acting. Man not only stores the image of his being a man; he becomes this image insofar as there is nothing uncommon about it, insofar as there is no interruption, no discontinuity, no accident, no hole - insofar as the operation takes place in the smooth space of the imaginary, or of virtuality, which is to say that it takes place symbolically, through that particular suspension of reality which has become paramount to our time. ${ }^{260}$ Once again, to quote E. Canetti: “a nation's consciousness of itself changes when, and only when, its symbolicity changes". ${ }^{261}$

It is no accident then that spaces have become smooth, or at least seem smooth from the perspective of the political - they are no longer real spaces but simulations, holograms, stored images and shapes, making up the extra-ordinary map of the human psyche, the residual will to survive, or the symbolic inertia of the techno-man. Space itself has become symbolic, pliable, flexible, metamorphic, its sole reality, or esprit de corps, consists in folding, imaging, mirroring, surfacing, simulating, while its presence is reduced to the fold,

\footnotetext{
${ }^{258}$ G. Deleuze, Difference and Repetition, New York: Columbia University Press, 1994, p. 295.

${ }^{259}$ E. Canetti, Crowds and Power, New York: Penguin, 1960, p. 32.

${ }^{260}$ See, for example, G. Deleuze and F. Guattari, A Thousand Plateaus: Capitalism and Schizophrenia; also S. Žižek, The Plague of Fantasies; and J. Baudrillard, Simulacra and Simulation.

${ }^{261}$ E. Canetti, Crowds and Power, New York: Penguin, 1960, p. 199.
} 
the image, the surface, the mirror, the TV screen, the computer monitor.

The grand assemblage/storage encountered in Las Meninas entertains this parallelism between man and space: the volatile figures in the painting are ingenuously doubled by our gaze, and the only relation we can have with the painting is becoming it; becoming the image in front of us, its identical copy, or its embodiment. Yet, the grand storage is not to be found in the depth of the painting (where it can only be represented, symbolized, dispersed) but in the depth facing, doubling, mirroring, absorbing, the painting - in the space becoming like the painting.

In J. L. Nancy's wonderful description of Pontormo's Visitation, we encounter the same suspension of gravity, the same reflection of the invisible in the visible (the invisible doubles doubled within in the space of the visible), unfolding in a visual magnetism of images and colors, shades and gazes, postures and passages. The intertwining of painting and reality, image and presence, "is neither present nor absent", but passes in-between, filling up space - by touching, gazing, leaping (i.e., for joy) ${ }^{262}$

There is no story to this space (or the story tells itself), no recognizable form mediating our relation to the surroundings (as in Las Meninas). The given meets the eye just as it is, right there, in front of us, waiting for us silently to become the vibrant reflection of everything, of space, of the world, or of the given. "Identification reigns absolutely", as Lyotard says, by maintaining the equivalence between signs and names, narratives and authority, that is, by making equivalence into the sole authority of all narratives, or all space. ${ }^{263}$ The audience no longer identifies with the story, with a particular character in the story, or even with the narrator, but rather makes itself into the mirror image of the story and of each particular character weaving itself into that story. The equivalence reigns absolute, maintaining the perfect identification of reality with its

\footnotetext{
${ }^{262}$ J. L. Nancy, The Ground of the Image, New York: Fordham University Press, 2005, pp. 109-18. ${ }^{263}$ J. F. Lyotard, The Post-Modern: Explained, Minneapolis \& London: University of Minnesota Press, 1997, pp. $31-3$.
} 
narrative, of each spectator with all the characters in the story. The spectator is the mirror image of the spectacle, the instantaneous replica of all the movements and expressions composing the spectacle.

A. Badiou had described this replication of the spectacle in Metapolitics (itself a spectacle of the spectacle): "what is certain is that the subject prescribed in the name of 'politics' will be called a world-spectator. It is as if, let it be said in passing, the theatre were situated, not in relation to what authors, actors and directors do, but solely in relation to the audience" ${ }^{264}$ We might add that the world-spectator is no longer the passive shadow of some projected action, nor of some formulaic morality; he is, finally, the "conductor" of all actions and moralities, the very image of action and morality, the very image, or theatre, of their inexplicable (or smooth) coincidence.

His subjectivity, formerly founded on the unequal relation between the inside and the outside, is now founded on their coincidence and equivalence - the greater the power of reflection, the more precise the equivalencies between the folds. He is neither inside, nor outside, but rather the reflection of interiority in the exterior and of the exterior in the interior, a brief and fragmentary reflection giving life to the osmotic relation between two forms of subjectivity. These two forms of subjectivity entertain "familiar" relations, as in Foucault, where sight and sound constitute the identical worlds of intentionality and ontology, or explosive, estranging, ethereal, relations as in Deleuze and Guattari, where the sense of sight swirls itself towards the fourth dimension. The closure of the fold (or of the present) is reflected either in flattening compositions (as in Foucault and Negri), or it pushes forward towards the last dimension of reflexivity: the double of the double. ${ }^{265}$

The relation between man, reality and the imperial world appears to be indebted to this fold, or doubling. Every step forward seems to double, invoke, or evoke, a ghost, a

\footnotetext{
${ }^{264}$ A. Badiou, Metapolitics, New York: Verso, 2005, p. 12.

${ }^{265}$ See, e.g., Antonin Artaud, The Theatre and its Double, New York: Grove Press, 1958.
} 
specter, a return. To this invocation, or doubling, we must now turn in order to understand it in relation to man, his world, and his imperial claim in and of the present. 


\section{Chapter 7}

\section{Thinking the Fold}

But as a force among forces man does not fold the forces that compose him without the outside folding itself, and creating a Self within man.

$$
\text { G. Deleuze } e^{266}
$$

The particular composition of subjectivity mentioned by Deleuze appears to be the result of force, the reflection, as it were, of man's relation to himself, which is identical and simultaneous with his relation to the outside. It is a double indirection, a reflection that works backwards as it were, incessantly composing what has been termed as the Fold. Deleuze's suggestion regarding Foucault, that he defined Greekness in terms of an invention of "relations between forces based on the rivalry between free men (the government of others through self-government)" ${ }^{267}$ is based on this identification of the inside with the outside, of the real with the represented, or of the Self with the Fold. Man's conflicting interiority reflects and is reflected by outside forces, or rather by their inarticulate rivalry, which is, in Foucault's case, the irreconcilable separation between sound and light, language and thing, exterior and interior, the very condition for the appearance and endurance of the Self as the expression of this irreducible separation.

This is "the strategic domain of power as opposed to the stratic domain of knowledge", ${ }^{268}$ the image of praxis, indebted to the informal passage from one form of struggle to the other. The three dimensions (knowledge, power and self) imply one another and yet remain ontologically distinct: knowledge is effected by the audio-visual forms, inasmuch as they are indebted to its limited existence within a given stratum. Similarly, power is being effected in the relations between forces, and so varies depending on their

\footnotetext{
${ }^{266}$ G. Deleuze, Foucault, Minneapolis, MN: University of Minnesota Press, 2000, p. 114.

${ }^{267}$ Ibid.

${ }^{268}$ Ibid., p. 112.
} 
qualities, while the self is effected by the process of subjectivation, that is, by thinking within the space reflecting and engulfing the fold. The doubling is always the doubling of space, the sixth-dimensional structure of the Fold ${ }^{\mathrm{x}}$, or rather the sovereign couple glued together through the mirror surfaces of the ontological planes, or through the struggle to pass from one sovereign head to the other.

The stratified reflection of the struggle is always in connection with the forces engaged in the battle, just as the stratified self relates, or rather becomes the reflection of knowledge-power relations. In short, the three-dimensionality of space replicates itself in the more complex structure of knowledge-power-self, where each force is the reflection of the other two, and each relation between two forces reflects the possibility of a third alternative. In the last analysis, each form appears to be pure duality, or pure double of the double. It is also indirectly knowledge, power, and self, which is to say that each reflects a potential alliance with or betrayal of the other two. The self is always in a tension doubly articulated, a quadruple figure reflecting the absence and presence of power-knowledge encounters. The same holds true for power, which is a relation between self and knowledge, between knowledge of the self and the self of knowledge - in Foucault's case, their relation corresponds to an economy of power, to the modern-postmodern folds of imperial power. ${ }^{269}$

The strategy of power coincides with the stratification once reserved to knowledge, to the infinite fold of consciousness within the finite limitations imposed by knowing, or rather by the relation between knowing and doing. The rigidity of dogma is here exploded into the fluid interlacing of knowledge and the subject, into their interdependence, or, in Hegelian terms, into the gradual formation of the in-itself of knowledge. The bending of the self through knowledge and the bending of knowledge through the self constitute a

\footnotetext{
${ }^{269}$ It was Foucault's follower, E. W. Said, who applied the approach to the historical study of imperialism in the Middle East. See Said's, Orientalism, New York: Vintage, 1978.
} 
double movement of power, a double relation based not only on the conflict between knowledge and the self but also on their tacit collaboration.

So far, the three-dimensional economization of power-knowledge-self relations constitutes the ontological structure of the real, the complex act of folding force through the intricate interlacing of dichotomies. The whole structure folds around its own economy (never quite the same), cultivating its regime through the manipulation of collaborative forces and of forces of resistance. Its regime corresponds to a certain economy of force, which folds the real by following the simultaneous traces of conflict and collaboration, contraction and dissipation. In principle, such a regime revitalizes or sterilizes these lineages, or circularities, by turning each force into the absent image of the other. This is the mythical operation par excellence - myth at its absolute, or myth pure and simple. There is no doubt that myth tends to dissolve betrayal by turning it into a collaborative operation (and vice-versa), and no doubt that each element passes through the fourth dimension and changes completely into the "other", always emerging in the "newness" of the story.

Myth alters reality in such a way that it continually negotiates its passage through the fourth dimension, it continually turns reality into the opposite of what it is/was. The two planes (mythical and 'real') are connected through the story of their separation and separated through the story of their coincidence; their relation alternates with the story; it becomes one with the abstract operation of the story, or, differently put, it needs the story in order to exist. The separation of myth from reality, their irreducibility to one another, coincides with the story of their betrayal, with the becoming-image of each conflictual instance separating or drawing them closer. It should be emphasized that we are speaking here not about individual reactions to changed conditions, but instead, as D. F. Pocock writes: "about the nature of society as a complex of meaning maintaining itself against forces that would devalue it, render it meaningless. Forces which are nevertheless 
conditions of its existence". 270

The disappearance of the real (e.g., in Baudrillard) is equivalent to the coincidence of the story with itself, which is to say that there is nothing but the doubling of the simulated (itself a story in the making) by the story of simulation. They stand in opposition only superficially and only for the purpose of creating the illusion of betrayal and of its resolve. The real is reduced to the story, or rather to the simulation of story-telling, to the sound, the image, the form of whatever seems appropriate at a given moment. Man becomes the story; he becomes the "whole" story by simulating his conflicts with "wholeness". He becomes the complete image of the story - the simulacrum of the story of simulation. In a word, he no longer distinguishes himself from his narratives, from whatever he is intimately or overtly betraying, or embracing, at a given time. He is, in the last analysis, a pure simulative act - a performance guided by the ever changing threads of the narrative.

There is an interesting narrative threaded by F. Fukuyama, and penned as the declaration of his defection from the neo-conservative governing circle, to which he belonged, and which gained control over the American foreign policy, producing the fall from the narrative called Iraq and the equally controversial Bush Doctrine. He writes, attempting to trace the symptoms of such an ascending to and descending from the graces of power:

Four common principles or threads ran through much of this thought up through the end of the cold war: a concern with democracy, human rights and, more generally, the internal politics of states; a belief that American power can be used for moral purposes; a skepticism about the ability of international law and institutions to solve serious security problems; and finally, a view that ambitious: social engineering often leads to unexpected consequences and thereby undermines its own ends. ${ }^{271}$

It is a bit uncanny to think of a group of former communists having captured control

\footnotetext{
${ }^{270}$ D. F. Pocock, "The Anthropology of Time-Reckoning", J. Middleton, ed., Myth and Cosmos: Readings in Mythology and Symbolism, Garden City, NY: Natural History Press, 1967, p. 309.

${ }^{271}$ F. Fukuyama, “After Neoconservatism”, New York Times Magazine, February 19, 2006. http://rempost.blogspot.com/2006/02/after-neoconservatism.html.
} 
over America's global policy, but this is nonetheless what happened. They had applied their skeptical stance toward social engineering mainly to such domestic policies as affirmative action, busing and welfare. On the world stage, however, the belief in using American power to foster democracy came to prevail over the previous doubts about social engineering. The neoconservative consensus was that the root cause of terrorism was a lack of democracy in the Middle East, and that the U.S. had the ability to fix this problem fairly quickly and easily through the use of military force. ${ }^{272}$

How or why this happened is beyond the scope of this work. Suffice it to say that it is a very peculiar thing to have happened in a land whose governmental system is characterized by checks and balances. A partial answer would be that the neo-conservative vision of world order dovetailed nicely with the standard realist argument 'that the best way to achieve defense against possible raiders is for your society to dominate all others...". ${ }^{273}$ Escaping the neo-conservative sinking ship, Fukuyama declared:

The neoconservative position articulated by people like [William] Kristol and [Robert] Kagan was ... Leninist; they believed that history can be pushed along with the right application of power and will. Leninism was a tragedy in its Bolshevik version, and it has returned as farce when practiced by the United States. Neoconservatism, as both a political symbol and a body of thought, has evolved into something I can no longer support. ${ }^{274}$

Such a brief lifting of the curtain covering the depths of the power-image reminds us that the twin domains of myth and reality (i.e., language and things) have become mere

\footnotetext{
${ }^{272}$ From Fukuyama's narrative, it is clear that the neo-conservatives had no clear idea of what they were getting into. Imperial policy had helped recent democratic transitions, in the Philippines (1986), South Korea and Taiwan (1987), Chile (1988) Poland and Hungary (1989), and Serbia (2000). It was also to have some degree of success in Georgia (2003) and Ukraine (2004-05). The lesson the neoconservatives had failed to absorb was that one cannot decide when and where democracy will come about. One cannot impose democracy on a country that has no domestic impetus in this direction. The impetus must be domestic, and not imposed from outside. F. Fukuyama, "After Neoconservatism", New York Times Magazine, February 19, 2006.

http://rempost.blogspot.com/2006/02/after-neoconservatism.html.

${ }^{273}$ C. N. Murphy, "Agriculture, Industry, Empire, and America", C. Calhoun, F. Cooper and E. W. Moore, eds., Lessons of Empire: Imperial Histories and American Power, New York \& London: New Press, 2006, p. 243.

${ }^{274}$ F. Fukuyama, "After Neoconservatism", New York Times Magazine, February 19, 2006. http://rempost.blogspot.com/2006/02/after-neoconservatism.html.
} 
reflections of a fall from the graces of the image. Language as the image of things (as in Barthes) or things as the images of language (as in Bataille) no longer work as complementary ideals, for they too have already fallen into the depths from which they rose. In the last analysis, myth and reality cannot be told apart, for there is no palpable difference between the sacred and the profane until their images separate and create the illusion of an irreducible gap between language and things, between speaking about things and seeing them. In its own terms, this is what simulation does - it puts a sign of equivalence between speaking and seeing. It perpetuates itself as image, thing, sound, surface.

At this point, story telling is no longer possible, for each thing is a story telling itself, a gradual becoming image of the image, indeed, a phantasmal coincidence between speech and sight. Everything is real by virtue of its being spoken of and (immediately) sighted; everything is mythical by virtue of its being seen, valued and (immediately) spoken of; these two simultaneous processes lead to the coincidence between the language of and (in)sight into the order of simulation. Power in the new order, appears to be this coincidence of speech and sight, the image of its own death, as Baudrillard calls it, pointing to the very essence of simulation. Power ceases to be a relation between forces, and becomes instead a relation between images and sounds designating the presence of force. To govern others, one no longer needs to govern himself (as in Foucault), all one needs to do is to manage successfully the plethora of speeches and images making up the story of governing. ${ }^{275}$

In the imperial (im)age, one creates and re-creates the world in his own image, encountering nothing but himself, speaking of nothing else but himself. The production of the real follows no particular model, or rather there is no real model governing the world,

\footnotetext{
${ }^{275}$ When asked by a reporter what acting role he had most enjoyed playing, Ronald Reagan was rumored to have replied, without hesitation but with a boyish grin: "Well, I guess that role would have to be President".
} 
no adverse production upsetting the course of events, there is only the eternal productivity of the present, or rather the eternal presence of production reflecting itself in the mind of the producer. The creator is no longer the warrior, the priest, god; he is the producer of a world of sounds and images - a complex world of taboos, endlessly reflecting and restricting one another. The worker is no longer subjected to the direct power of the sovereign, no longer living in the shadow of august terror or benevolence, he has become a civic ensemble of imperial effects, a ghost or a hologram putting on the show of individualism and of consciousness.

The institution, the group, the corporation, to which one adheres, rests precisely on this ethereal effect of sovereign terrorism and benevolence, it rests, more precisely, on a strange absence. As C. Taylor puts it, "the whole background notion of order has disappeared for us", ${ }^{276}$ deriving its strength from within (ourselves) and not from "a supposed cosmic order in which we are set". ${ }^{277}$ However, one might add that the "whole background" has become an (inner) cosmic order, at once present and absent, terrifying and benevolent, sovereign and subjected.

J. Ellul has sketched this new situation in unequivocal terms: "every modern man expresses his will to power in records he has not established himself' ${ }^{278}$ This is true not only for modern man, but also for the forms of political and economic organization to which he had affiliated himself in order to represent and record his power. The emptiness of his performance reflects the emptiness of political affiliation, or of corporative organization, which is nothing more than an arbitrary ensemble of effects recording the performative establishment of power. Power establishes itself through the organization and administration of recorded numbers, images and sounds, and in doing so it becomes its own record: "[I]n short, man creates for himself a new religion of a rational and technical

\footnotetext{
${ }^{276} \mathrm{C}$. Taylor, "Foucault on Freedom and Truth", Political Theory, vol. 12, May 1984. ${ }^{277}$ Ibid.

${ }^{278}$ J. Ellul, The Technological Society, New York: Vintage Books, 1964, p. 303.
} 
order to justify his work and to be justified in it". ${ }^{279}$ More than that, he becomes the new religion, the embodiment of rationality and technicality justifying and being justified in and of itself.

As such, he is no longer a force, but rather has the perplexing aura of a number, an institution, a recording mechanism chosen to express the particularity of his presence. He depends on the ghostly apparitions surrounding him, on their manipulation and control, which require him to record their manifestations (numbering; identifying; measuring) as the inalienable proofs of his (will to) power. He does not fold back upon himself, for there is no self to fold back upon in the first place; rather this absence is folded back upon the world by engineering the effect of such an operation. The fold is no longer about repeating the event of power, no longer about man governing the outside through self-controlling practices, but about engineering the psychology of power through the event/effect of the fold. "To see the world as a text", among other things, "is to confront the issue of meaning in a radically new way". ${ }^{280}$ This is precisely the sort of reduction, or inversion, by which meaning, or the event of meaning, is folded and turned into mere eventfulness - mere appearance. Of course, it might happen that sudden changes could disrupt the colonized self to such an extent that one might begin to notice discrepancies. As Leo Panitch argues:

It is certainly the case that there are citizens and semi-citizens of the U.S. empire as Susan Strange once put it; a Canadian cannot avoid noticing this.... Canadians who work in the Canadian Defence Department - and, I would add, in the Canadian Finance Department - who walk the streets of Ottawa but have a degree of influence on American foreign policy and economic policy are semi-citizens of the American empire. It is a type of empire which has penetrated other sovereign nation-states and which, in turn, does indeed include them in decision-making ... except at a clear moment of crisis. ${ }^{281}$

This is also called a "reversal", an operation performed in the absence, or sudden

\footnotetext{
${ }^{279}$ Ibid., p. 324.

${ }^{280}$ J. D. Derian and M. Shapiro, International, Intertextual Relations, Toronto: Lexington Books, 1989, foreword: p. xix.

${ }^{281}$ P. Gowan, L. Panitch and M. Shaw, "The State, Globalisation, and the New Imperialism: A Roundtable Discussion", Historical Materialism: Research in Critical Marxist Theory, vol. 9, autumn 2001. http://www.theglobalsite.ac.uk/press/201gowan.htm.
} 
alternation, of reality, in a space ordered by the logic of numbers, institutions, mechanisms, dispositifs, sovereignties, each occupying its mundane place in the overall assembly of prosthetic "realities". Without a doubt, this is why Deleuze kept reproaching Heidegger:

... to discover this outside as limit, the last point before Being folds. Heidegger rushed things and folded too quickly, which was not desirable: this led to the deep ambiguity of this technical and political ontology, a technique of knowledge and a politics of power. ${ }^{282}$

One is led to wonder if there can be such a thing as a politics of knowledge (as opposed to a technique of power) in the first place. No matter to what length he is willing to go in his ontological search, one is likely to encounter only its effects, only the effect of knowing, of being (indirectly) powerful, of folding that which in reality has become virtual by virtue of his search. In this respect, J. D. Derian might have gotten closer to truth than he intended. In a chapter entitled "The Boundaries of Knowledge and Power in International Relations", he advises that "after two hundred years of textual accumulation, it is time for a theoretical investigation of the scripted representation of international relations". 283

A politics of knowledge already closes the possibility of knowing, turning it into mere method, doctrine, ideology. It is no longer an event, but an effect that is sought in place of the event; no longer a process by which one learns about the world around, but a world that is effected in order to know how to master and control it. This sounds so familiar, so close to home that it is impossible to miss the point, impossible not to wonder whether it is even possible to fold, not as Deleuze thinks, at the point of thought, but to fold at all since there is nothing to fold except the effect of being folded (itself a failing politics of knowledge), and nothing to fold upon but the event of effecting the (illusion of the) fold. The fold does not recover the past, it is the past insofar as it is effected by it in

${ }^{282}$ G. Deleuze, Foucault, Minneapolis: University of Minnesota Press, 2000, p. 113.

${ }^{283}$ J. D. Derian, "The Boundaries of Knowledge and Power in International Relations", from International, Intertextual Relations, J. D. Derian and M. Shapiro, eds. Toronto: Lexington Books, 1989 , p. 4. 
order to (re)capture the future: tradition does not disappear, as A. Giddens thinks, under the pressure of fashion ${ }^{284}$, but rather tradition repeats itself in the very disappearance of fashion.

Today, it is the fashion of evanescing forms and compositions that calls for the presence of tradition, not the other way around. The inalienable fixity of tradition is already a contradiction in terms, but nonetheless one that works very well towards the justification of change: it is change that challenges tradition, itself already a challenge to changing. It is a privilege to be challenged, to be different, but already this privilege belongs to an entire tradition of evanescing privileges and challenges. The point at which one decides to scrutinize the interplay between tradition and fashion is the point at which he decides to make one fold back upon the other, the point at which the irreducible difference between language and things is erased and the two coincide not only in the story of their becoming but also in their becoming the only story known to us. However that may be, there is still room for the innovation of something other than language and things, other than politics and technicality, and that is, without a doubt, the invention of the Fold. As J. Der Derian puts it: "the method is to disturb habitual ways of thinking and acting . . the goal is to provide new intelligibilities and alternative possibilities to the field...". ${ }^{285}$

Things fold, time folds, spaces fold. There is an entire tradition of folding, packing, plying, an entire fashion caught up in the process of effecting reasonable, aesthetic, humanitarian foldings, and, of course, there is an entire vocabulary entertaining the notion of becoming other by folding otherness upon sameness, exteriority upon the interior, difference upon tradition (and vice-versa). As C. N. Murphy puts it:

Time (along with space) has been compressed, accelerated, as a consequence of our abilities to reach out to the ends of the earth. The current American empire is connected with a shift in industrial capitalism that relies

\footnotetext{
${ }^{284}$ A. Giddens, The Runaway World, New York: Routledge, 2003.

${ }^{285} \mathrm{~J}$. D. Derian, “The Boundaries of Knowledge and Power in International Relations", International, Intertextual Relations, J. D. Derian and M. Shapiro, eds., Toronto: Lexington Books, 1989, p. 4.
} 
upon the transformations that have made the world smaller: we live in a world that is closer to the [Adam] Smithian vision of a global factory than anything that has come before. ${ }^{286}$

The Fold is the envelope and the repudiated category, the invention and the end, the condition for the existence and evanescence of power - it is, in a word, the prison and the event of escaping it, or rather the genealogy of imprisonment and escape, the very act of justifying (faithfully?) the new order through the constant reinvigoration of old canons. It is indeed the grand rehearsal that everyone talked about for more than a century, the grand return of the same, which is hardly more than a subjective genealogy, or a (political, economic, military) technique in the service of whomever needs it (the state, the corporation, the war-machine, the techno-citizen). Its celebration surfaces here and there, as an already ghosted, convertible, outlet. As such, it becomes a familiar sight, a familiar indulging of the fantasy of reversing: "reversing the arms race not only promises greater security, but also allows (our) governments to free resources needed to address pressing social, economic, and environmental problems across the globe". 287

The conversion of politics into technique, which finds its apogee in authors like C. Taylor, M. Ignatiev, A. Giddens, and I. Wallerstein (among others) corresponds to the conversion of names into acts, of epistemology into phenomenology - the very phenomena that M. Foucault tried to reverse, obtaining the other conversion (already present in Heidegger) - of technique into politics. Tradition never remains in the same place, it practically splits between two groups (G. Dumézil turns this inevitable succession in timespace into a simultaneous [retroactive] presentation of events), each time turning itself into "fashion", each time unfolding itself with a view to something other than mere unfolding, or mere fashion. This is precisely what V. Descombes failed to point out in his account of

\footnotetext{
${ }^{286}$ C. N. Murphy, "Agriculture, Industry, Empire, and America", C. Calhoun, F. Cooper and E. W. Moore, eds., Lessons of Empire: Imperial Histories and American Power, New York \& London: New Press, 2006, p. 250.

${ }^{287}$ M. Renner, "Who are the Enemies?" State of the World, New York: W.W. Norton, 1989, p. 107.
} 
French philosophy - the simultaneity of distinct generations of thinkers, the virtual wars waged between them so as to complete the most abject and most necessary tasks entrusted to them. The simultaneous coexistence of tradition and innovation, or rather the simultaneous "clashes" and betrayals between tradition and innovation (today no more than a strategy), is no longer anything else but fashion, the most common way of reducing and metamorphosing the social by fragmenting and obliterating it. Tradition and novelty already belong to fashion, this is all that is left of them, all that is left to ponder upon: the magic of fashion on the one hand, the sordid combination of patterns on the other.

The moment tradition is discarded, some new model arises to take its place in less than a month, a week, or even an hour - this has become the most common critique launched against fashion, the most regrettable image of tradition handed down to us. In short, tradition has become inconceivable outside fashion just as truth has become inconceivable outside science. One speaks about tradition in the same way one speaks about atoms (which are in and out of fashion, depending on their implicit advantages). More importantly, one speaks of an atomist tradition as if it were an eternally returning trend: "the American mode of atomic fantasy evolved further in The Man who Rocked the Earth", producing "scenes interchangeable with descriptions recorded by survivors". ${ }^{288}$ This septic image of traditionality no longer has anything to do with the notion of tradition held by thinkers like L. Strauss, H. Arendt, or G. Grant. There is an enormous discrepancy between the continuity of tradition (with its inevitable genealogical corruption) envisioned by those thinkers, and the fashion of envisioning tradition as the image of a fragmented past, and of truth as the moving image of an eternal fractioning mood. As C. Taylor puts it: "purposefulness without purpose requires a certain kind of explanation to be

\footnotetext{
${ }^{288}$ H. B. Franklin, "Fantasies of Power", appeared originally as "Fatal Fiction: A Weapon to End all Wars", Bulletin of Atomic Scientists, November 1989.
} 
intelligible, ${ }^{289}$ and nothing more.

Essentially, tradition presents itself as the forking of the one into its doubling and the transposition of the double into oneness. It appears, most importantly, as the absolute identity of the past and the future. This identity is gapped by innovation, which inverts tradition; it sets the past and the future in opposition, pushing forward towards more and more complex schemas (e.g., the post-Marxist schemas in comparison to Hegel's infinite bifurcations). The Fold is already tradition in $\mathrm{H}$. Arendt, in her butterfly-like sketches, but it does not permit (as in Foucault) the collapse of the outside upon the inside (of the future upon the past). Differently put, in Foucault the butterfly no longer claps its wings (it is not an external folding), but makes them collapse one into the other so that they become one with the body. This folding on the vertical axis (as opposed to A. Negri's folding on the horizontal axis $^{290}$ ) amounts to the collapse of the structure of space, to its reduction to Hegel's (or Spinoza's) circular schema of absolute Being, ${ }^{291}$ where Being and Power are one and the same thing. It is also, as Deleuze had shown ${ }^{292}$, a sketch, or imprint, of the self caught between the strata of the archives - the very image it wants to escape and eventually succeeds in escaping by making power into its raison d'etre.

The three-dimensionality of space collapses into the one-dimension of time, if you wish, simultaneously with the reflection of the latter into the former. The identity between past and future is dissolved through their reduction to the present (their images converge and collapse in the present), while the present reflects itself in the two diametrically opposed manifestations belonging to the past and the future. The schema (of the accordion) does not do away with the time-trap, but it does put in motion the untimely triad of past, present and future (which is a long shot from, say, Kojève's identical pasts and futures).

\footnotetext{
${ }^{289}$ C. Taylor, "Foucault on Freedom and Truth", Political Theory, vol. 12, May 1984.

${ }^{290} \mathrm{~A}$. Negri reverses space-time and flattens it along the horizontal axis; see Time for Revolution, New York: Continuum, 2003.

${ }^{291}$ A. Kojève, Introduction to the Reading of Hegel, lthaca, NY: Cornell University Press, pp. 117-19.

${ }^{292}$ G. Deleuze, Foucault, Minneapolis: University of Minnesota Press, 2000, p. 120.
} 
Indeed, the schema is all motion and stasis, an alternation played at such a rapid tempo that it becomes pure sound exploding in the face of things, exploding, as Deleuze and Guattari have shown, in a thousand plateaus of multiplicities and diferrends, which is to say that one no longer pays any attention to origins (originality, originals), but concentrates on their effects, turning them into the raison d'etre and mode of justification of everything that is. The representational field switches from being an enveloping veil to being the measure of reality (or of its effects): the plateaus connect the present with the past and the future; they are the synchronic and asynchronic reflections of eternity traveling through time, the Platonic images traveling back and forth through the history of thought, constantly composing and decomposing it. ${ }^{293}$

The general guideline of the present is this indirect Platonism, this post-modern revival of Platonic formulations and intelligibilities, this inescapable footnote to antiquity, to historicism and anamnesis. One escapes the present, or rather the absence that is the present, by giving a form to it. At least this is what post-modernism does. It gives absence a form and makes of form an indubitable absence. In a word, post-modernism Platonizes things all over again. It makes them whole by emptying or forgetting them. One forgets by remembering forgetting, as it were, by making forgetfulness into its sole reality, sole authority. This is the point at which Platonism (i.e., love of forms) becomes political, the point at which it ceases to be a philosophy, a knowledge, and becomes politicized, political, politics. This is the point of interest for the present, but also of disagreement, the point at which Platonism turns against itself as it were and ceases to be Platonic, formulaic, antic (i.e., by becoming all of them). In W. Cox's words:

Multilateralism can only be understood within the context in which it exists, and that context is the structure of world order. But multilateralism is not just a passive, dependent activity. It can appear in another aspect as an

\footnotetext{
${ }^{293} \mathrm{~A}$ cross-section of the structure of time would be similar to the ripples that form on the surface of a lake after throwing a stone, only that now they travel simultaneously in both directions, towards the center as well as away from it.
} 
active force shaping world order. The agent/structure dilemma is a chickenand-egg proposition". ${ }^{294}$

Along the same lines, J. S. Nye would argue that such "a presumption in favor of multilateralism need not be a straightjacket. ${ }^{295}$

Multilateralism proposes as many realities as one can imagine - this is perhaps the most surprising (if not intimidating) conclusion proposed by Deleuze and Guattari, a conclusion that rules out the protective role played by representation (a role still present in Foucault) in its relation to the Real. The horizon of representation disappears altogether, collapsing in the multitude of plateaus. Strictly speaking, what disappears is the Form, the grand Contour (concept) of thought identifying its domain with the protective shield of representation instead of the unprotective domain of the real (the optical illusion versus the presence of the optical dispositif). The Fold is dissolved in the constant folding and unfolding of realities (lines of flight), in the constant retreat from the tripartite and double configurations of the Real to the flat surface of the whole, where "everyday life is ideological in an ontological sense" ${ }^{396}$

The way back is ensured by the vortical movement of becoming-other (animal, woman, machine, dispositif, etc.), by the transposition of the double to the one and the subsequent depth resulting from it (the abyss described in the third novella ${ }^{297}$ ). The speed at which these seemingly new variations in the compositions of the Real retreat and explode into one another is not only the becoming-other of thought but also of the statemachine: one no longer needs to presuppose with Levi Strauss that this kind of bilateral unity cannot stand on its own, one already knows it to be so, and proceeds to transpose it

\footnotetext{
${ }^{294}$ R. W. Cox, "Multilateralism and World Order", Review of International Studies, 18, 1992, p. 161. ${ }^{295}$ J. S. Nye, "Seven Tests: Between Concert and Unilateralism - International Relations", National Interest, Winter 2001. http://www.findarticles.com/p/aticles/mi m2751/is 2001 winter/ai 81765310.

${ }^{296}$ J. D. Derian and M. J. Shapiro, eds., International/Intertextual Relations, Toronto: Lexington Books, 1989, p. xx.

${ }^{297}$ G. Deleuze \& F. Guattari, A Thousand Plateaus, Minneapolis, MI: University of Minnesota Press, 1987, p. 200.
} 
further to the oneness of the whole. ${ }^{298}$ As I. Wallerstein argues in "America and the World: The Twin Towers as Metaphor", one chooses to build these structures, one decides whether or not to build them, whether or not the factors that enter them "were, are and will be, very, very many". 299

These figures of supple segmentary and polyvocal becomings, "the binary, circular, and linear, are bound up with one another, even cross over into each other, changing according to the point of view". ${ }^{300}$ The demarcation between tradition and modernism vanishes, imposing its ethereal mark upon "the binary, the circular, and linear". It is no longer a question of succession from one form of representation to another, nor of retroactively imposing the simultaneity of formations, but rather of encountering both tradition and modernism in their successive simultaneities and simultaneous successions, that is, in their historical disintegration in which "everything is political" and "every politics is simultaneously a micropolitics and a macropolitics". 301

The division of the political into micro and macro politics raises the question of their double articulation, which sweeps them towards or away from that which is vanishing either as horizon, or center, of power. On this questioning of the possibility of a double articulation of the political we shall now focus, in a search for a better understanding of what is at stake in the imperial formation of both vanishing horizons and centralities.

\footnotetext{
${ }^{298}$ Ibid., p. 210.

${ }^{299}$ E. Wallerstein, "America and the World: The Twin Towers as Metaphor". http//www.binghamton.edu/fbc.iwbk/n02.htm.

${ }^{300} \mathrm{G}$. Deleuze \& F. Guattari, A Thousand Plateaus, Minneapolis, MI: University of Minnesota Press, 1987 , p. 209.

${ }^{301}$ Ibid., p. 213.
} 


\section{Chapter 8}

\section{The Double}

The triple structure weakens the polemical punch of the doublestructured antithesis. Therefore, soon after a period of order, exhaustion and attempts at restoration, when the battle began again, the simple doublestructured antithesis prevailed again.

$$
\text { C. Schmitt }{ }^{302}
$$

I read in the newspapers of the tragic situation of two European infants who are Siamese twins. The doctors say that, since the twins have one heart and one lung, they can only be separated in such a way that one twin lives and the other dies. The doctors also say that if they do not separate the twins, both will die within months.

\section{Wallerstein ${ }^{303}$}

In less than a century, B. Constant's impulse sauvage and calcul civilise, which denominated the succession of two diametrically opposed historical periods (war and peaceful exchange), came to denominate two simultaneous orders opposing one other, two adverse perspectives waging a permanent war against each other. C. Schmitt found the Marxist antithesis between the proletariat and the bourgeois the most prominent and most effective historically because it concentrated all the energy on the final battle between two irreconcilable orders. By contrast, G. Dumézil found the antithesis between the god of night (Varuna) and the god of day (Mitra) expressive of the collaborative nature between natural and supernatural orders; he turned their historical succession into their simultaneous coexistence, into the sovereign couple that binds and exchanges, wills and knows, acts and decides, and, most importantly, forms a perfect double with the Roman couple (Romulus and Numa), with the "terrible and the Ordered, the Violent and the Correct, the Magician and the Jurist....". 304

Under the overarching canopy of imperialism, succession and simultaneity no longer

\footnotetext{
${ }^{302} \mathrm{C}$. Schmitt, The Concept of the Political, Chicago \& London: Uni versity of Chicago Press, 1995 , p. 74.

${ }^{303}$ I. Wallerstein, The Decline of American Power, New York \& London: New Press, p. 130.

${ }^{304}$ G. Dumézil, Mitra-Varuna, New York: Zone Books, 1988, p. 64.
} 
separate into two diametrically opposed orders, for each has become the mirror image of the other, functioning as a double articulation of conflict and collaboration, war and peace, bonds and exchanges. According to Dumézil, the two successive orders (i.e., Rome under Romulus and Numa) are simultaneous with the presence of the divine couple (Jupiter Stator and Fides); they "borrow" the collaborative quality of the divine couple, becoming the sovereign (simultaneous) heads of the human order. They become the "twins" living on the same set of organs (same order) for an indefinite period of time. ${ }^{305}$

To put it differently, the Hegelian antithesis between master and slave passes through the successive stages of the family, of civil society and the state, bringing them together in the imperial synthesis. The successive orders fold back upon one another (Foucault's accordion structure), becoming one indivisible order in which the master-slave antithesis is simultaneously dissolved and (re)composed in ever new configurations (family versus civil society, civil society versus the state, etc.). This is precisely what the American avantgarde of post-statist thinkers has not taken into consideration, namely, the mobile, ethereal, simultaneous and successive, nature of sovereignty as opposed to such categories as structure, international order, anarchy, unilateralism, or even multilateralism. One brief and perhaps metaphorical example of this complete immersion in the strictness and inescapability of categories, is R. K. Ashley's account of anarchy:

Anarchy is not a problem to be solved but a fixed background.... ${ }^{306}$

When one holds to the sovereignty/ anarchy dichotomy, and when he observes that there is no encompassing sovereign centre capable of reconciling conflicting interpretations of international life, then it follows that international political life must be regarded as an anarchic domain. ${ }^{307}$

J. Habermas traces the inconsistency between simultaneous, yet successive,

\footnotetext{
${ }^{305}$ I. Wallerstein's simile refers explicitly to the European situation, to the present dilemma of European politics.

${ }^{306}$ R. K. Ashley, "Untying the Sovereign State: a Double Reading of the Anarchy Problematique", Millennium: Joumal of International Studies, vol. 17, issue 2, 1988, pp. 239-40.

${ }^{307}$ Ibid.
} 
materializations of the master-slave antithesis inside the bourgeois family, civil society and the state, emphasizing that all successive transformations of the public sphere were possible by dint of that sphere's absorption into the two antithetical orders - the bourgeois family and the state. In the triple structure (family-society-state) the middle term is always absorbed by the other two, forming a new couple, a new reality (or order). The ever changing antithetical couples, backed by the triple structure of their successive transformations, lead to the isolation and absorption of the structure's third element - it is a closed system in which each element goes from isolation (oneness) to coupling, to tripling, and back, without ever changing its place, but only its function. This is the structural response to the ontological question of being, the middle term between philosophy and science, which is (as all such terms are) both successiveness and simultaneous coexistence of two opposing theses. The middle term is as much a hybrid of the two alternatives as it is the "novelty" directing the process of their competition and homogenization. ${ }^{308}$ In E. H. Carr's words, "when no single Power is strong enough to dominate the world, and supremacy is vested in a group of nations, slogans like "collective security", and "resistance to aggression" serve the same purpose of proclaiming an identity of interest between the dominant group and the world as a whole in the maintenance of peace". ${ }^{309}$ Today, as F. Cooper concludes: "the idea of empire as a transformative mechanism is indeed available, but one has to be careful about how one locates it". 310

More to the point, the bourgeois-proletarian antithesis gives rise to the war machine (in Deleuze and Guattari), it gives rise to the police (in P. Virilio), or to the public sphere (in Habermas), at the same time at which the war machine, the police, the public sphere,

\footnotetext{
308 J. F. Lyotard, The Post-Modern Condition, Minneapolis, MN: University of Minnesota Press, 1984.

${ }^{309}$ E.H. Carr, "The Realist Critique", excerpted from The Twenty Years' Crisis. http://www.mtholyoke.edu/acad/intrel/carr.htm.

${ }^{310} \mathrm{~F}$. Cooper, "Modernizing Colonialism and the Limits of Empire", Items and Issues, vol. 4, issue 4, Fall/Winter 2003.
} 
threaten to become the sovereign elements in the system, while simultaneously being threatened to be absorbed by both the bourgeois and the proletarian states. The structural response, while intellectually challenging, falls pray to $\mathrm{H}$. Arendt's observation that only buildings have structures, that no matter how much we calculate and how many predictions we produce there will always be a human element that remains outside the reach of certainty. The war-machine, the police, the public sphere, are a blend of impulse sauvage and calcul civilize, they are hybrid-machineries acting inside and outside the state, society, or the family - they are the new machines that have no boundaries and no souls, acting, as S. Žižek tells us "within the space of the death drive". 311

They no longer operate locally as sovereignty does, but go beyond the borders of the state apparatus, into the open space of empire. Through them, war no longer plays the supportive role it formerly had, but rather betrays and limits the operations of the state: "just as Hobbes saw clearly that the State was against war, so war is against the State, and makes it impossible". ${ }^{312}$ Even though state and war seem mutually exclusive, they turn into reciprocal formations evolving simultaneously throughout history, limiting and challenging one another. The warrior type, which is an in-between type (half military leader, half warmachine) is "at once eccentric and condemned". ${ }^{313}$ He falls in love and betrays by falling in love (e.g., Achilles), he loves and is willing to sacrifice himself for love. He is the third element in the structure, the "sacrificial" element, or as Bataille suggests: "the thing - only the thing". ${ }^{314}$ According to J. S. Nye, however, when it comes to war, there is no third presence involved in imperial and international politics. Instead, "the main battle lines are drawn between two kinds of internationalists: those who advocate unilateral tactics and

\footnotetext{
${ }^{311} \mathrm{~S}$. Žižek, The Plague of Fantasies, London \& New York: Verso, 1997, p. 89.

${ }^{3 / 2} \mathrm{G}$. Deleuze and F. Guattari, Nomadology: The War Machine, New York: Semiotext(e), 1986, p. 11.

${ }^{313}$ Ibid., p. 7.

${ }^{314} \mathrm{G}$. Bataille, Theory of Religion, New York: Zone Books 1992, p. 43. "The thing - only the thing, that is what sacrifice means to destroy in the victim".
} 
those who prefer multilateral ones". ${ }^{315}$ Perhaps this is one reason why G. Dyer would conclude, in reference to the Iraq war, that: "It was never about Iraq. It is not really about terrorism any more either, though the terrorists are still there. Suddenly, to the vast surprise of practically everybody, it is about the whole way we run the world". 316

Far from "weakening the polemical punch of the double-structured antithesis", the third element is always there and not there, or at least appears to be so since the entire structure could collapse without it, and no double-structured antithesis could work indefinitely without being threatened from within. The passage from the threedimensionality of power to the double-structured opposition, or to the one-dimensional relation of self to self, is at once threatened and preserved, sacrificed and saved, through the presence of an absence (or an absent presence). However, because of its "sacrificial" status, the third element tends to become neutral. Some examples are: R. Barthes' space of the alibi, the neutral zone of the "neither-nor" choices; $H$. Arendt's emptiness placed inside the onion-like structure; Foucault's notion of a human self caught between the strata of the archive; Deleuze's and Guattari's smooth war-machine; Derrida's third friend, and so on.

What catches our attention is that the third element (each element becomes the "third") plays both the role of a betrayal and a cathartic sacrifice capable of purging the whole structure of tensions and conflicts. In the last analysis, it is not simply the element that occupies the third dimension that is threatened or threatening, but the tension within, the "threat" brought about by it in the first place. The third dimension is the dimension of war, the dimension of depth, which is given through some tension or conflict and is maintained as such in relation to the other two dimensions - i.e., the Mitra-Varuna couple, the complementary, antithetical (and here antithetical means collaborative) couple that

\footnotetext{
${ }^{315}$ J. S. Nye, "Seven Tests: Between Concert and Unilateralism - International Relations", The National Interest, Winter 2001, italics mine. http://www.findarticles.com/p/articles/mi m275l/is 2001 Winter/ai 81765310.

${ }^{316} \mathrm{G}$. Dyer, Future Tense, Toronto: McClelland \& Stewart, 2004, p. 1.
} 
maintains itself by "sacrificing" conflict, that is, by turning it into a "thing" to be sacrificed. R. O. Keohane and J. S. Nye overlook this possibility when claiming that military power remains important in critical areas of international relations. Perhaps they would agree that military power remains important insofar as its purpose, as R. Kagan suggests, is "not to enslave but to bring liberty and progress". 317 As Kagan argues elsewhere, "the phrase 'manifest destiny' arises in this context", but only as a renewed declaration made by "the slave-owning part of the nation". 318

Left by itself, the double-structured antithesis, which had always been a conflicting duality, turns against its own nature, as it were, dissolving it into a final battle, against one last enemy: itself. This is the extreme alternative, the nihilistic version that remains outside the reach of science precisely because science is an indirect form of nihilism - i.e., it attempts to prove the real by disproving it. The weapon, or nihilism in pure form, enters the domain of science in order to protect it (i.e., from itself); its relation to science is one of mutual collaboration; it cannot destroy the source and scope of its creation, but also it cannot stand its threatening nature. Differently put, the weapon is both the embodiment of conflict and its resolve. It is the neutral space of the alibi, the shell covering up the emptiness inside, but also the exterior materialization of this emptiness, its being projected outside of itself, in the concreteness of a destructive function. The warrior is the bearer of the weapon, at once maneuvering and strategizing its uses even though he is twice removed from real conflict. On the one hand, conflict is equivalent to the use of weapons, on the other, the weapon ceases to be the embodiment of a threat and becomes its resolve. There are essentially two kinds of uses for weapons: the first is the weapon deployed for use in the field; the other is the weapon on the wall, whose function is pure threat. As is

\footnotetext{
${ }^{317}$ R. Kagan, "America and Empire: Interview with R. Kagan", J. Glazov, December, 2006: http://www.Frontpagemagazine.com.

${ }^{318}$ R. Kagan, “America as Global Hegemon", The National Interest, June 2003, vol. 2, issue 29. http://www.aei.org/events/filter.,eventID.428/summary.asp.
} 
widely recognized, the latter weapon tends by far to be the more effective. ${ }^{319}$

The warrior is no longer the classical hero throwing spears and cannonballs at the enemy, but the modern technocrat of arsenals and mobility, acceleration and speed. He is no longer the architect of the battlefield but the engineer of the army camp, for whom the victory on the battlefield is only a matter of routine ${ }^{320}$ Classical war, as has been stressed so many times, is at an end. In its place we are dealing with the advent of the "machine", with its equipment and capabilities, with its range and speed, with every single quality and property that sets it closer to victory, closer to its own end. The imperial war of today is a fabrication of victory, the very process by which the victors lose their ability to engage in a battle otherwise than by manufacturing the source of conflict, the landscape, the enemies, and their weapons. Victory itself is nothing more than this process of manufacturing and managing dissenting landscapes and peoples, the very guarantee that any war is a winning war, that, indeed, war and victory are synonymous terms referring to the same process by which man produces and spoils his freedom.

When not turned against itself (which is always perceived as an "end"), the antithetical structure seems to work in the name of history, peace, freedom, justice, all concepts that no longer have any other real referent except for the assembly lines where history and peace, freedom and justice, are produced so that in the end one prevails upon the other - perhaps in the same way in which the proletariat prevailed over the bourgeois state (i.e., by accelerating the process of industrialization). Whether that victory had been won or not is not the subject of the present project, but it does relate to it in a manner much more profound than a simple ironical statement. The present de-acceleration of industrialization plays back the same process by which the proletariat was erected in the

\footnotetext{
${ }^{319}$ See M. Dver, The Weapon on the Wall; Rethinking Psychological Warfare, Baltimore: Johns Hopkins University Press, 1959.

${ }^{320}$ In the case of the American empire, this is also due to the fact that the U.S. imperial forces primarily choose to attack only very weak countries. See M. Boot, The Savage Wars of Peace: Small Wars and the Rise of American Power. New York: Basic Books, 2002.
} 
first place. It is precisely the folding of the event of proletarianization understood as a class struggle against the bourgeois state, which is not a promise, least of all a manifesto - it is the same victory that troubled us earlier playing itself off against dissenting people by manufacturing their landscapes and weapons.

It is even more than that, for the consciousness of failure is also the consciousness of victory, of another kind of victory than the simple production of its appearance. In any case, the failure of the bipartite system is not only the failure and end of the Cold War, though in some respects it is identical with the failure of the proletariat to grasp the importance of wealth, or of wealth as the raison d'etre of the state, but also the failure to maintain two equally suited competitors in an ambush very similar to the American rush for gold. The only conclusion to be drawn from the former bipolarity of the world is that the former communist states have gained their right to live at the very limit of subsistence. It is possible to make them poorer, yes, to fabricate their revolutions and coups d'etat, or even to propel them into some undesired coalitions, but one can no longer get rid of them, for to get rid of them is to exterminate the very source of wealth. As a matter of fact (or of irony), one seems better off by being a communist rather than a liberal or a conservative one enjoys the privilege of politics by default, that is, he is moved by the promise of a will to power and not by the will to power as such.

What does it mean to be political, then? It means absolutely everything, or at least this is what some of the most important thinkers of the $20^{\text {th }}$ century seem to have suggested. It is not just the polls, the electoral campaign, the seat in the parliament, but the gas price, the ozone layer, global warming, the fashion show; they are all connected in a way that is essentially political, essentially will(ing) to be or remain a handmaiden to power. One does not become political by getting accustomed to the world around him; it is one's will to power that moves him from the closed world of the animal to the political 
condition of being a voter, a member of parliament, or a gas-station owner. Of course, none of this is true - or at least not entirely. Could one leave the animal condition and become a voter by simply willing power? Could a man occupy his seat in the parliament by sheer will? Schopenhauer would have said yes. He would have tried to convince us that everything human is a matter of will and representation, that there is nothing more essential and more desirable than the will: "the will determines itself, and therewith its action and its world also; for beside it there is nothing, and these are the will itself". 321

But the will is no longer pure and simple willing, it has become essentially political, essentially will to power, for to will the world or to act according to one's will is already to invoke power. Power, as Foucault would argue, is the world, it inscribes itself as the genesis and raison d'etre of everything human, intelligible, forceful. In its realm, conflicting alternatives compose the human horizon by separating it into light and sound layers of the will, into the language and articulation of a powerful versus powerless self. Such is the power of the present as the most familiar and most abstract formulation of the will. On the one hand, lies the world as empire, on the other, the world as willingness (i.e., for imperial representation), or powerfulness of the will. We see two mirror images celebrating the rebirth, not of the tragic, but of its immediate ally: the will to power. The world as representation exhibits the potential for resistance, but it lacks the potential for a greater will to power, of a will to power decanted through the archival layers of the present - it lacks the in-itself of power, the historical consciousness of being something other than human truth. Conversely, the world as power exhibits the potential for representation, but it lacks the potential for a greater will to represent; it lacks the for-itself of representation, the historical consciousness of being something other than human power. The world as will and representation is the imperial world, the completed circle of willing and representing

\footnotetext{
${ }^{321}$ A. Schopenhauer, The World as Will and Representation, New York: Dover Publications, 1969, p. 272.
} 
the will or, what amounts to the same thing, of representing and empowering representation.

The imperial world of subjects as opposed to the incarnation of their will in the objects, the world of the savage as opposed to the quiet world of the civilized man, these are two antithetical orders founding the empire of the will, the ephemeral empire of willing and representing power as the omnipotent relation between one's will and his representation of it. This couple is always a willing couple, an antithesis (in the making) driven by the will to power, which is to say that each party must will and represent/incarnate power in opposition to (or collaboration with) the other. Their worlds are both represented and willed, powerful and weak, they are, for the first time, more than pure negation or pure differentiation; they incarnate a double articulation of the will: to empower and represent itself as such.

It is not the desire of another desire that makes man leave the animal world by setting himself in conflict with it, which is a relation impossible to represent, but the desire of representation, of making that desire known by giving a form to it, by placing it in relation to other things and other desires, by confronting them and giving form and meaning to their confrontation. Now, to represent desire is one thing, and to desire the representation of the same desire is another: their conflict arises from the fact that desire and representation have been, for a very long time, equivalent. If man desires something, he represents it, and if he represents something, it means he desires it. This parallelism (or equivalence) of desire and representation, so characteristic of the classical age, is now turned around: man represents what he does not desire and he desires what he does not or cannot represent - both desire and representation belong to him indirectly, by being the negatives of one another.

This negative coupling (representation of a non-desire and desire of a non- 
representation) hides its own negativity, its own beginning, as it were - its being a representation of desire and a desire for representation, that is, a double articulation between desire and representation (the real and the imaginary). It hides from it, no doubt, in search for something better than the unsettling vacillation between reality and imagination, desire and the thing. Violence is no longer a simple desire, or representation, which is to say that man no longer desires (with Kojève) another man's desire, or (with Bataille) another man's object of affection, but the violence of that desire, or object of affection, which he cannot appropriate without a fight. Fighting incarnates/represents the violent appropriation of the violent content of desire - it directs its forces against everything that separates man from the violence of his desire. The end of violence marks the coincidence between man's desire and the consciousness of its violence, the victory of science over the world of objects, its complete takeover as the last act in the mythological encounter with and representation of a violent other.

H. L. Nieburg's classic study of violence begins with a sobering and yet somehow mythical reflection upon the human condition:

There are in human affairs great natural forces, comparable in their power to destroy to hurricanes or earthquakes. Highly organized societies, for all their power and magnificence, are delicately balanced organisms. All the inherent powers of human relations are brought together in a volatile fusion. Social cohesion does not come about automatically and cannot be taken for granted; it requires continuous attention and concern. ${ }^{322}$

Within the vortex of these 'great natural forces', one can no longer meaningfully speak of any excess (for everything is excess), nor of any real tension between desire and violence, but only of victory, coincidence, and speed, each modifying the cardinality of power, its relation to the (in)different productivity of society, sociality, socialism. In this context, the only relation that power entertains with the social realm is a relation of production (of violence), an irreversible process of knowing how to produce and make use

\footnotetext{
${ }^{322}$ H. L. Nieburg, Political Violence: the Behavioral Process, New York: St. Martin's, 1969, p. 3.
} 
of an entire world of objects and violent desires. To acquire power is no longer an art, nor an ingenious folding of force, but a mere knowledge of production, a knowledge of objects and desires - a social technology. It is in this respect also that one could no longer speak of excess, for technology is incapable of dealing with the incalculable and the uncertain. It must deal with the limited, the finite and the measurable - anything other than this is already a transcending consciousness, already something other than technology. ${ }^{323}$

The relation between power and science, or power and technology, is implicit in this "lack" of consciousness, or rather it is based on it to such an extent that it produces its own knowledge and its own world around it. This is the sterile world described by G. Dumézil, the world-object oriented towards infinite growth and destruction - the violent sovereignty operating locally, in the (ever) closing space of empire. Without a doubt, its authority is challenged by its "wise" counterpart, or at least by the impressive simulation of some kind of wisdom - a ritual by which power is tempered through the remembrance of what it needs to know. This intermittent challenge is never poignant, never capable of rejuvenating culture, the economy, or even power. It is a simulation (of a lesser violence) and nothing more, a random reemergence of passion during the processes of work, production, or violent creativity. Its essence is characterized by powerlessness, though it is always invested with the power of truth, with the energy and expectations of real life events.

The double is always the mirroring image of the singular, the different, the distinctive. The former follows the latter everywhere, like a shadow on the ground, mutating and silencing everything in its way. In this sense, the Platonic world of shadows is no longer mere invisibility, it has never been perhaps, but all the same - it is a mere shadow. The shadow follows something other than itself within the order of the visible, it follows silently, almost indistinctly, perusing the surfaces of things in an indefinite and

\footnotetext{
${ }^{323}$ It is in this context that Bataille's insistence upon transcending the consciousness of things (by squandering them) begins to make sense. see G. Bataille, Theory of Religion, New York: Zone Books 1992.
} 
indifferent display of movement. There is only performance, surface, spectacle, each emerging out of symbols and realities, scenes and portals, sacrifices and newness, each becoming thing and ghost - a distinct phenomenon: the doubling. The human body itself might be said to be nothing but the mirror image of the head - a map perpetually folding back upon itself, folding the real and the unreal, the sign and the signified, the will and its representation - folding folds, as it were, folding the body within the mind and the mind within the body, the image within the mirror and the mirror within the image.

To go back, to travel backwards towards the split, means to unearth the symbols, to modify reality to such an extent that existence becomes impossible (by virtue of being the only possibility). The real ${ }^{324}$ is no longer out there, it has been replaced by all the words and nuances, and images, and portraits, by all the things (a piece of advertisement; a love scene; a poem) capable of conveying and annulling their own messages and realities. We encounter a world of fragments, a world of indistinct things and shadows - an arbitrary spectacle of the double, one in which nothing happens except the split, the clearing, the death of the real.

As Žižek suggests, death becomes "the symbolic order itself, the structure which, as a parasite, colonizes the living entity". ${ }^{325}$ This colonization of the living by death is the topic on which we now focus in an effort to (un)cover the colonizing nature of empire.

\footnotetext{
${ }^{324}$ In S. Žižek's sense: "Real is that which resists, that which is not totally malleable to the caprices of our imagination”, On Belief, London \& New York: Routledge, 2001, p. 51.

${ }^{325}$ S. Žižek, The Plague of Fantasies, London and New York: Verso, 1997, p. 89.
} 


\section{Chapter 9}

\section{De-Doubling, De-Structuring, De-Composing the Real}

Hegel remarks somewhere that all facts and personages of great importance in world history occur, as it were, twice. He forgot to add: the first time as tragedy, the second as farce.

$$
\text { K. } \operatorname{Marx}^{326}
$$

There is a growing dependence on deconstructing, decomposing and de-doubling the imperial world, a growing concern with the former unity of all constructions, compositions and doublings, an enchantment with the trial of time which seems to act upon the world as if in a fit of rage, demolishing its own representations, its own images and languages. There is nothing as fashionable as the constant dissolving of all fashions, nothing as meaningful as the permanent eradication of meaning, and, of course, there is nothing as important as the insignificant other, nothing as expressive and efficient as the dismantling of excessive "otherness": the portrait, the insignia, the advertisement of the 1960's, each symbolizing a world of lies, an insincere or imperfect past in need to be sanctioned, rewritten, and re-lived, in such a way as to leave no place for unsettling differences, no place for questions, for forgiveness, for being human.

This is an uncommon form of fascism, de la politique du pire, an almost supernatural conjuration of an absent authority reflected in a world devoid of any meaning except the condemnation and elimination of the "guilty" party. Its novelty consists in the fact that there is no longer any authority dictating the course of action - the action itself is the course, the hunting down of mistakes, of errors and lies. As C. Taylor puts it, "to give an absolute priority to the structure makes exactly as little sense as the equal and opposite error of subjectivism, which gives absolute priority to the action, as a kind of total beginning". ${ }^{327}$ The world itself is turned upside down, the meaning that made sense of

\footnotetext{
${ }^{326} \mathrm{~K}$. Marx, "The Eighteen Brumaire of Louis Bonaparte", Selected Writings, Indianapolis \& Cambridge: Hackett Publishing, 1994, p.188.

${ }^{327}$ C. Taylor, "Foucault on Freedom and Truth", Political Theory, vol. 12, May 1984, pp. 152-83.
} 
things is no longer there, no longer making up the world of morals and justice, no longer making up much except the dense texture of immorality, injustice and imprisonment, of everything that stands opposed to our taste for decomposition and destruction, de-doubling and de-structuring, de-railing and demeaning.

According to A. Wendt, there is no logic to this type of volatile anarchy, "apart from the practices that create and instantiate one structure of identities and interests rather than another; structure has no existence or causal powers apart from process. Self-help and power politics are institutions, not essential features of anarchy. Anarchy is what states make of it" ${ }^{328} \mathrm{He}$ then proceeds to show how "identities and interests are developed under anarchy: by the institution of sovereignty, by an evolution of cooperation, and by intentional efforts to transform egotistic identities into collective identities". ${ }^{329}$ In his view, people do not make decisions based on worst-case possibilities (even though his primary assertion is a worst-case scenario), but on the "basis of probabilities", which are produced solely by interactivity, "by what actors do". This is precisely the strict performative lens through which $\mathrm{C}$. Weber also tries to peruse the landscapes of identity/sovereignty formation, a lens through which all subjects seem alike in a "cultural jamming", which does not permit a differentiation between "self" and "other". ${ }^{330}$ In their own ways, they both seem to suggest that there is a volatile in-betweennes running through the whole specter of the political, a ghost, as it were, which cannot be understood unless grounded in performativity. The question of what kind of performative ghost is at work in the interplay between sovereignty and the subject seems to be left aside in favor of an affirmation of either anarchy (as in Wendt), or imaged anarchy (as in Weber) - both grounds of dissent

http://links.jstor.org/sici?sici=0090-

$5917 \% 28198405 \% 2912 \% 3$ A2\%3C152\%3AFOFAT\%3E2.0.CO\%3B2-V\&size=LARGE.

${ }^{328}$ A. Wendt, "Anarchy is What States Make of It", International Organizations, vol. 42, no. 2, Spring, 1992, pp. 394-95.

${ }^{329}$ Ibid., p. 404.

${ }^{330} \mathrm{C}$. Weber, "Performative States", Millennium: Journal of International Studies, vol. 27, issue 1, 1998, pp. 77-95. 
from and return to the question of an elusive imperial presence.

What seems to trouble the "performative" approach is that the "other" already occupies the outside and the inside, the constructible and the de-constructible spaces of empire, the margins and the center. It has no specific place, no specificity in time, but flows continuously from everywhere to nowhere, drawing the imperial map of the present, its signs and its ethereal symbols. The spirit of this map is the drive to de-code and destructure itself, to de-value and de-compose its identities and languages - it is, without a doubt, the ethereal empire composing itself out of the fractured lineages of meaning and movement, structures and symbols, signs and codes. As in Negri and Hardt, there is no sovereign authority here, no sign of it at least, but only fragmentation, genesis, strata formation. At this stage, authority remains diffused and dispersed - a (nations)state or a beast of prey. As K. Waltz reminds us, paraphrasing C. Powell, the only thing to be feared in either situation is that one might "run out of demons", or run "out of enemies". 331

The performative freezing of this moment of formation brings about not only the disappearance of demons and enemies (i.e., by virtue of having to deal solely with demons and enemies), but also of the sense of the present itself - time itself becomes nothing but demonizing and production of enemies: an eternal demon, or enemy. The general object of imperial studies rests precisely on this formation of eternity, on this shifting ground between a former construction (or demonization) and its necessary deconstruction, between ontology and deontology, history and the future, language and objects. It is all excess, intimacy, finality, but also poorness, publicity, beginning. Demonic eternity and time collaborate and escape one another as the freezing zones in which there is no longer any time left, nor any eternal principles, but mere interruption and causality, crisis and entertainment, the verticality and horizontality of being nothing and everything, void and

\footnotetext{
${ }^{331} \mathrm{~K}$. Waltz, "Intimations of Multipolarity" The New World Order, London, 2000, p. 2.
} 
betrayal, demon and enemy. Indeed, as K. Walts writes: "theory obviously cannot explain the accidental or account for unexpected events". ${ }^{332}$ In a world of accidents and unexpected events, theory becomes the accident and unexpected event par excellence.

The doubling movements of eternal and accidental compositions of imperial spaces, confront each other in the very spaces they want to delimit or (de)liberate, running their courses towards and away from both eternal horizons and accidental singularities, to become a blend of both, but also over and against them: pure eternity, pure accident. Eternity passing into/as accident and the accidental passing into/as eternity - this is the present fold, the Rousseaunian moment at which demons and enemies, unequal as they are, become united by a "common will", that is, by a specter of equalizing inequalities and inequalizing equalities. The event of the Fold (already of a tremendous weight in Foucault), passes over and against its unequal/equal foldings alike, returning them to the night (or negativity) from which they stem. Nothing is gained and nothing lost, while everything falls back upon the gain and loss of nothingness.

As W. Connoly tells us, the key to the ethos of democratization (or common willing) is that "it embodies a productive ambiguity at its very center, never allowing one side or the other to achieve final victory: its role as a mode of governance is balanced and countered by its logic as a cultural medium of denaturalization of settled identities and conventions". ${ }^{333}$ Indeed, neither the demons, nor the enemies, could achieve victory due to the very culture that balances and counters their demonic and inimical identities and conventions. This is precisely the kind of "embodiment of ambiguity" that Connoly (among others) strives to overcome and (apparently) succeeds in overcoming, by either inserting it in a center (following H. Arendt), or volatilizing it into a "common will". One

\footnotetext{
${ }^{332} \mathrm{~K}$. Waltz, "Realist Thought and Neorealist Theory", Journal of International Affairs, vol. 44, issue 1, Spring/Summer 1991. http:/www.irchina.org/en/xueren/foreign/view.asp?id=204

${ }^{333}$ W. Connoly, "Democracy and Territoriality" Millennium: Journal of International Studies, vol. 20, issue 3,1991, p. 477.
} 
might even argue that the new ethos of democracy is no longer the embodiment of the will of the people, but of their ambiguous will towards both victory and unsettling conventions, commonalities and differences, multiplicities and singularities. The new ethos incarnates the very demon it wants to scare away and the very enemy it wants to betray, which is to say that it becomes their double, their recruiting sergeant, at once demonical and inimical, ghostly and embodied.

It is this doubling by death, or nothingness, that marks not only the new (imperial) beginning but also its loss of reality (as in J. Baudrillard, P. Virilio, and S. Žižek). Dedoubling the real means de-doubling death, discovering life where there was death, and vice-versa, in an unnatural, simulated, cycle of living and dying. This cycle is further destructured and de-composed in such a way as to give priority to its double, to the nonsimulated, natural, cycle of structuralization and composition. Composition and decomposition become simultaneous rhythms of the same event, simultaneous movements striating the entire space of existence. A neoliberal escape from liberalism becomes a return to it (and vice-versa), a neo-constructivist escape from constructionism becomes a return to it (and vice-versa), etc., in an infinite proliferation of escaping and returning routes, or loops, in which each opponent becomes the demon and the enemy of the other, each encountering the other in the briefness of their appearances and depths, or of their alliances and betrayals. In trying to come to terms with this volatile notion of a double betrayal, L. Lomarsky asks a rather rhetorical question: "is betrayal carried out on liberalism or carried out by liberalism?"334 The answer seems equally volatile, equally indebted to rhetoric, but also, perhaps, equally liberal: "let our resistance be as transnational as capital". 335

To contradict means to trace back and forth a dissimilar argument, to force upon it

\footnotetext{
${ }^{334}$ L. Lomarski, "Double Betrayal", Reason Magazine, http://www.reason.com.

${ }^{335} \mathrm{H}$. Maiba, "Social Movements in the Age of Globalization", GSC Quarterly, Spring 2003. http://www.ssrc.org/programs/gsc/gsc_quaterly/newsletter8/content/maiba.page.
} 
the logic of another, the act of another. In contradiction one traces the event of vulnerability and of power, the infinite chains of being and becoming either vulnerable or powerful by going beyond good and evil, and by tracing them back and forth, as if in two simultaneous orders, two simultaneous histories. By tracing the contradictory, one traces himself in tracing the other, in hating and loving the other, in desiring, awaiting, thinking of, the other. One frames and expels the other, one makes it whole and "unwholly", true and false, real and simulated; one makes it, with Heidegger, into truth as forgetting, into the truth of what goes by, what disappears, what is no more. One makes it, with H. Arendt, into an emptiness placed at the heart of things, at the heart of time; with Lacan, into a hole through knowledge, a hole in the fabric of knowing; with G. Bataille, into an intimate order, an absence, a nostalgic anamnesis of that absence; with R. Barthes, into the alibi of language, of the neutral zone of speaking about the other, about oneself as the either/or of the other; with J. Derrida, into the presence of the third, the always apparent, always estranging and indebting ghost of the unconscious; with J. L. Nancy' into the opening, the birth, the coming forth of spirit.

The contradictory by itself (and only by itself) has no sense, no destiny, no weight, it is a complete non-sense, a lack of density, or an easiness which one might attribute to saints, to angels, to god, in any case, not to mortals, not to the people following a destiny and a sense for it, a sense of weight, of contradiction and/or of (com)promise. Tracing the contradictory means tracing that absence which is a hole, an interruption in knowledge, an emptiness. It means tracing language through its insignification, its lack of signs. It means tracing the history of an ahistorical present back and forth, through the hole that is in knowledge, through language. When one says another - another language, another history - one is no longer here, no longer in this language, in this history, but in another, unknown, empty, non-sensical and indifferent. One makes of it a hole, an interruption, a clearing. 
This example is perfect for knowledge, perfect for the history of knowledge, for the history of contradicting and locating oneself in the other and the other in oneself. It is perfect itself-in-itself, perfectly full of imperfections and (im)perceptions, a history which is both familiar and estranging, collaborative and inimical, a history of becoming other in one and one in the other, for another.

This is the canonical history of betrayal, or rather the economy of betraying oneself together with the other through the leap, or void, that is this history, this economy of escaping, of speaking, or resenting. The circularity of notions, their forms, their becoming engaged, becoming familiar, is also their clearing, their indifference, their termination in the face of time. There is no history of the circular, or rather history becomes this clearing, this betrayal, this absence in knowledge, through language, and around the other. Here is where one wants to begin another ethics, another narrative, another history, where the present receives life from the past and the future and gives them life by giving them death, by giving them the option of betrayal, the life of the ones who "must hate and betray what is most lovable". ${ }^{336}$ Hate slips into love in this economy of betrayal, and love slips into hatred, making the most distant look familiar, and the most familiar look distant - making an enemy of the friend and a friend of the enemy, making, if that is still possible, still conceivable, another history, another beginning.

We are, as Morgenthau asserts: “... in flight from history and whenever history catches up with us, as it did intermittently before World War II and has done continuously since, we endeavor to gain freedom from it by obliterating in one great effort the issue that blocks our way". 337

However, the issue that blocks the way is no longer (if it ever was) of a concrete or analytic nature; it has mutated, as Carr seems to suggest towards the emotional:

\footnotetext{
${ }^{336}$ J. Derida, The Gift of Death, Chicago: University of Chicago Press, 1995, p. 64.

${ }^{337} \mathrm{H}$. Morgenthau, "The Intellectual and Moral Dilemma of History", Christianity and Crisis, February 1960. http://www.religion-online.org/showarticle.asp?title=398.
} 
In the nineteenth century, it was commonplace for British opinion that Germans were efficient and enlightened, and Russians backward and barbarous. About 1910, it was ascertained that Germans (who turned out to be mostly Prussians) were coarse, brutal and narrow-minded, and that Russians had a Slav soul. The vogue of Russian literature in Great Britain, which set in about the same time, was a direct outcome of the political rapprochement with Russia. The vogue of Marxism in Great Britain and France, which began on a modest scale after the success of the Bolshevik Revolution in Russia, rapidly gathered momentum, particularly among intellectuals, after 1934, when it was discovered that Soviet Russia was a potential military ally against Germany. ${ }^{338}$

This emotional economy of betrayal is also an economy of salvation, an economy of exchanging death for life, or rather of making the death of the other look eternally living and promising in our own life. It is an economy of love - an economy of falling in and out of love, a secret tracing of being in love and being loved, perhaps a new indirection, a new economy of the indirect, the fragile, the vulnerable. Betrayal engenders a new ethic, a new becoming - another way of economizing the living and the dead, the future and the past; another way of betraying the present, of making it lovable. This expansion that is in love, through love, is also a contraction, a contradiction that one traces between betraying and saving, a reminiscence of another time, another love, another memory altogether. In it, one finds the source of hatred and betrayal, the source of becoming hateful, becoming untrusting - the source of all economy, of all economization of the distant, the silent, the absent.

In their book Empire, M. Hardt and A. Negri depict an ethereal sovereignty rooted precisely in this kind of ergonomic striation of space, on the habit of separating and including people based on their (use)value. In the last analysis, this is what de-composing, de-structuring, de-doubling, is about: emptying, eternalizing, making valuable. As A. Motyl remarks:

Many scholars agree that empires should be defined as polities with a peculiar kind of relationship between a dominant 'core' and subordinate and

\footnotetext{
${ }^{338}$ E. H. Carr, "The Realist Critique", excerpted from The Twenty Years' Crisis. http://www.mtholyoke.edu/acad/intrel/carr.htm.
} 
distinctive 'peripheries'. The core is not simply larger and more powerful than the peripheries, nor does it simply influence them in some heavy-handed manner. It actually rules them, either directly or indirectly, through local surrogates.

No less important is the absence of significant relations between or among peripheries. In empires, the peripheries almost exclusively interact through the core. The resulting arrangement resembles a rimless wheel, consisting of a hub and spokes. The idea of all roads leading to Rome actually describes the imperial structure. ${ }^{339}$

We can throw away Machiavelli's Prince and inhabit our space without remembering how and when we did such a thing, which will permit us to re-live spatial occupation, spatial expansion, spatial rehearsal. We can occupy space in the absence of all forms of sovereignty and make of it nothing but sovereign space - indeed a "rimless wheel". This is the irony of having to make a decision between life and death, between the death of space at the expense of time or the death of time at the expense of space - it is an ironic trade, no doubt, but also tragic - perhaps the most tragic and most profound condition of contemporary thought.

What does it mean to de-compose, de-double, de-construct? Does it mean that one returns to the beginning by way of a virtual termination? That everything stands and/or falls depending on its capacity to elaborate death? If so, there can be no talk of "friendship", collaboration, or even politicization, but only of decomposing friendships, collaborations and politics, only of de-structuring circuits of friendliness and adversity, of love and hatred. Of course, there would be a delay in the re-composition of the concept of friendship (or of any concept for that matter), a freezing moment, an emptiness placing itself not at the heart of things, but in their stead, postponing their appearance, their emergence out of the negative stance of necessary and incontestable decomposition. Such a

\footnotetext{
${ }^{339}$ A. J. Motyl, "Empire Falls”, Foreign Affairs, July/August 2006.

http://www.foreignaffairs.org/2006070lfareviewessay $85416 \mathrm{a} / \mathrm{alexander-j-motyl/empire-falls.html.}$ The idea of an absence of 'relations among peripheries' might need to be reconsidered in light of the fact that the decision to attack Iraq sparked a coordinated global protest demonstration involving almost 800 cities and towns, and more than twelve million people (on February 15, 2003). This was, according to the Guiness Book of Records (2004), the largest mass protest in history. P. Bennis, Challenging Empire, Northampton, MA: Olive Branch Press, 2006, pp. 1-2.
} 
freezing, or rather neutralizing stance (already here, already freezing us) surrenders everything to the happy chance of an end, or, as H. Arendt would say, to the perplexing event of man's disappearance.

Time itself freezes, while speed and space increase proportionally - P. Virilio mentions the passing from the accumulation of violence to the accumulation of movement, from knowing-power to moving-power, but what really happens is the overcoming of time itself. There is no longer any sense of time, but only of infinite or indefinite variation (of movement), a ghostly formula for the banding of peoples, of disparate groups, and/or of individuals. G. Agamben mentions the Gnostic model of time as opposed to the Greek (circle) or the Christian (line), a model which "can be represented by a broken line"340, a trajectory, a presence (or lack of it) that does not aim at preserving the cosmic law, but at breaking it.

The advantage of the formula rests with its ability to hide, or to make absent all circular and linear temporalities - there is no longer an enveloping Time, but only timeproduction based on speed, the very measure of rupturing and consuming Time. To be sure, there could be no such thing as "killing time", for time itself cannot be killed, it can only be "frozen", neutralized, involved in its own decomposing process. The passage from the accumulation of speed to the accumulation of space is marked by this breaking down of Time, by this tacit production of decomposing temporalities, which can be understood either in terms of a return (ideological or otherwise) to or a continuation (genealogical or otherwise) of beginnings. It is not just any kind of return, nor any kind of linearity, for they both betray and keep alive a tradition threatened from all sides by decomposing, failing, or breaking up, temporalities.

The weight of decomposition, its swiping tour of force, cleanses the process of time

\footnotetext{
${ }^{340} \mathrm{G}$. Agamben, Infancy and History: On the Deconstruction of Experience, London \& New York, Verso, 2007, p. 110.
} 
production (or of the time of production) of its excess, or its arbitrariness. It is an event that one cannot expect to endure, but also one that could not be done away with. The excess of time is invested elsewhere, perhaps where one least expects it, perhaps somewhere else, but the fact remains: one passes from the accumulation of time to the "squandering of excess", that is, from time-subsumption to displacement, from knowledge to knowledgein-movement, in a chain of investments subordinated to the production and squandering of excess. The excessive consciousness is the consciousness of having to produce excess at all costs: "it doesn't matter if a cat is red or white; what matters is that it catches mice". ${ }^{341}$

There is a linguistic contratemps inherent in the process of time formation and dissipation, a split between the beginning and the end, a frozen zone treated so lightly ( $\mathrm{J}$. Derrida) that it becomes practically impossible to distinguish between vulgar and masterly compositions (or connections), between common and courtly love, or even between white and red, which is to say that there is always something to stand opposed to opposition itself - a group, a band, a song, an ordinary number. Based on such an opposition to opposition, there is always an affirmation underlying the beginning or even the termination of things, a kind of Nietzschenean celebration of tragedy, a somber surrender to decadence, rupture, interruption, and dismemberment.

In this somber celebration of tragedy, nihilism and affirmation extend, invert, rupture, the psychological limits of the body. Indeed, they become such psychological limits insofar as bodies are turned into nihilistic and affirming corporalities, insofar as they are occupied (territorialized, possessed) by despair and/or courage, by fear and/or ignorance, or by their incessant struggle, which is always (de)limiting, always dependent on something other than the body itself - power, friendship, enmity, fantasy? Perhaps this is the beginning of what might be called the resurgence of the organic, the

\footnotetext{
${ }^{34 i}$ D. Xiaoping, from S. Žižek, "The Political and its Disavowals", Palinurus: Engaging Political Philosophy, issue 9, November 2006. hitp://anselmocarranco.tripod.com/id46, html.
} 
"deterritorialization" of the "full" body, the de-composing, de-structuring, de-doubling, of the human limits of the body (or of the bodily limits of the human) by the machine. In Deleuze's and Guattari's work, this is the abrupt interplay between schizophrenia and capitalism, between the unfathomable becoming-woman and the unrecognizable becoming-animal, which is never quite unique (from the point of view of choice), never quite true, since all becoming is singular (and "true") by virtue of blending together all possible oppositions and tensions.

The limits of the body are also the limits of the human, they coexist in a tension that crosses everything, or rather makes everything shudder under the pressure of coexistence and limitations. To make truth appealing one needs to appeal to the senses in one way or another. To make it appalling one needs to do the same, which means that limits stand or fall by their appealing and/or appalling qualities, by their being made to please or disturb. In this way, limits are no longer immutable (if they ever were), they are no longer the intrinsic qualities of things but their appearance, their form, their energy. Beyond the pleasures of the body, or beyond the pleasurable body, there is an intrinsic drive of decomposing pleasures and bodies, of de-composed truths and human qualities - the horizon itself is being de-composed and de-territorialized, in other words: it is being sterilized. ${ }^{342}$

This sterilization is achieved by making all its embodiments less interesting than a supposedly original archetype, and by turning all bodies into bodies of fear and/or failure. It is not a "secret" action, but a public one, a public ritual (or machine), spreading across in ever new forms and guises, while sterilizing the already existing forms and meanings. ${ }^{343}$ It

\footnotetext{
${ }^{342}$ In the Socratic/Platonic sense; also Dumézil treats this sterility of the body in relation to the decomposition of the social horizon (in Mitra-Varuna).

${ }^{343}$ In Mitra-Varuna, G. Dumézil speaks of the ritual meant to replicate Remus' and Romulus' misfortune with the cattle thieves, a ritual that makes people run naked through the city in search of a dignity that belonged to their leaders: a dignity that had the quality of covering up their naked bodies (the recovery of the cattle as the cover up of the naked body, a ritual which Dumézil discusses in relation to the sterility of the Sabine women). My view here is that sterility rituals (cover ups; tension releasers) spread across boundaries, wiping out the remnants of culture. De-composing, destructuring, de-doubling the ritual has become the rite by which one no longer seeks to cover up one's
} 
ritualizes the de-territorialization, or de-clothing of the body - its complete (universal, public) nakedness, but also its re-territorialization through a "secret", or indirect, restoration of its dignity - the recuperation of the body without organs, the floating body of the unconscious.

The de-territorialized body (the naked body) serves as a sterile cover-up to the equally sterile re-territorialization of its narcissistic double. Strictly speaking, there is no escape from the circularity of ritual, but only delaying (freezing) instances, incorporeal flows and relays of the clothing/de-clothing body, of the sterilizing/de-sterilizing mood. The de-clothed body sterilizes the mind and vice-versa, in an unconscious chaining of routes and relays, trajectories and versions, all of which make up the territory of the one in the absence of the other, a topography that is never fixed, never entirely capable of measuring the distance between the two. Distance itself works doubly by stabilizing and de-stabilizing the (imperial) body, by making it dependent on its absence and presence, or on the interplay between them.

Bodies, human bodies, are folded and unfolded in such a way that they are simultaneously stabilized and destabilized, simultaneously pushed towards and away from their own limits, without ever giving them the chance to endure otherwise than through their arbitrary appearances and disappearances. In this respect, the Narcissistic consciousness is the consciousness that endures by forgetting, either forgetting everything for the sake of its own image, or forgetting that image in order to be able to fall in love with it indefinitely. I believe this is the sense in which A. Negri refers to the return of the Narcissistic consciousness and later on to the passing from the Promethean consciousness to the Narcissistic, which is to say that they are (already) simultaneous bodies engaged in the ritual of their succession. But this, again, belongs to the topography of the imperial

nakedness but to display it publicly without attempting to recover its dignity (dignity is caught up with the nakedness of the body, not as its clothing mechanism, but as its unclothing instance - the ritual is the nakedness of the body - the getting naked of the body.) 
psyche, to the spatialization of time (and temporalization of space) so characteristic of modernity that it no longer makes any sense to speak of succession otherwise than in the context of simultaneity, in the context of its relation to spacetime, which is nothing other than the double articulation between two diametrically opposed forces, or appearances, themselves nothing other than splitting movements, tensions, struggles, rituals, bodies.

The relation between these forces, or appearances, is a relation of power (or at least it appears to be so) - of inequality - which is always destabilized and deregulated so as to ensure its proper reproduction at the conscious level. The body itself is controlled by this inequality, by this (un)/bending force which finds itself in constant tension with its other. When B. Russell defined power as "the production of intended effects", he had in mind this unbending psychology of power over and against the other, but also the vast production of intentions and effects through which such a psychological condition becomes possible. ${ }^{344}$ Since then, one can no longer speak of power without also speaking (at the same time) of the lack of power, of the psychological composition and decomposition of the subject habituated to laboring and consuming, to the productivity of exploitation and consummation, which becomes its nature, the very effect of power, the very intention of producing the condemned and condemning body of the powerless. Power changes based on the powerlessness of the subject, it organizes itself differently, it shapes itself according to the qualities or lack of qualities in the subject, always producing its own particular effect (almost like a signature), its own psychological regime.

The psychology of power used to derive its strength from the ideal unity of the whole, while it rested on the separation of body and mind, subject and object, reality and imagination, but also on their constant convergence, on their constant and uncontrolled nullification, as it were. As such it constituted itself as the psychology of the different, as

\footnotetext{
${ }^{344}$ B. Russell, Power, London \& New York: Routledge, 2004; p. 23.
} 
the abnormal form of political organization belonging to a privileged hierarchy and constantly mutating in order to combat and refresh its universality. Psychologically, power had constituted itself against multitudes and multiplicities, it had become their mirror image, the spectacle of turning their submission and powerlessness into some form (or incarnation) of mythical leadership. What modernity has established in both politics and philosophy is the notion of power based on the psychological constitution of the subject: there are democratic regimes, authoritarian regimes and fascist regimes, and they all intersect, overlap, confront, one another in their struggle for power, obscuring the fact that they are its intended effects, the very means and ends of its appearance and endurance.

Beyond this modern inheritance, one discovers "naked power" - the sheer force of the subhuman, perhaps even the resenting psychology of the "other", the very source for the fabrication of civilization. There is also the "power of the State over rebels and enemy combatants", in practice often the very opposite of the "power of the State over loyal citizens". ${ }^{345}$ The split between them is the condition of the constitution of power just as it is the condition of its actual destitution. The constitutionality of power understood as the positive conclusion of struggle turns into the negative struggle against all positive constitutions - a switch instead of a reversal, an automatism inherent in the (in)formative composition of power, but also a decomposing mood clothed in formal terms, the kind of reduction that is expansive, explosive and reversible, while constraining and narrowing power in such a way as to "control" its own compositions - a contradiction that hides the formula of power, or rather makes it even more unstable, or more emotional. What obtains is a politics of emotions, a deconstructive, destructuring, mood aiming at its own destruction - a power decomposing itself in search of invulnerable and neutral traits.

\footnotetext{
${ }^{345}$ Ibid. However, in the United States' Constitution the rights and legal protections given are not restricted to citizens, but are given broadly to a "person" or to "people" (Amendments 1, 2, 4, 5, 9, 10), or to "the accused". (Amendment 6). Thomas E. Patterson, The American Democracy, $7^{\text {th }}$ ed. Boston, MA: McGraw Hill, 2005, Appendix "The Constitution of the United States of America", pp. A14-A15.
} 
However, the emotions are never quite stable, never strong enough to be turned into invulnerable and sovereign powers, but they can turn power into a vulnerable politics of the emotions (i.e., psychology) with the help and/or representation of the immutable, which is gradually turning towards the incorporeal.

A far cry from what is really at stake here is, perhaps, $\mathrm{K}$. Croke's advice:

Pay attention to soft power. Any effort to win hearts and minds will have to make use of America's tools of soft power-economic aid, trade preferences, diplomatic leverage, public diplomacy and the attractive power of American ideals, domestic political institutions, and international alliances. ${ }^{346}$

It is a truism that all battles between enemies and the state are battles for opinion, but hearts and minds are no longer about "tools", nor about "attractive" ideals, they have been removed from within their grasp and placed into the openness of the incorporeal, the peripheral, the imperial - they have become the very specter of tooling and attracting, leveraging and domesticating, aiding and preferring. Any attempt to categorize or institutionalize them falls short of its own devices, becoming as F. Adamson shows us, a simple outcry among many: "if terrorism is a political tool used in the context of international political mobilization, there is a need to both de-legitimize and criminalize this political tool...".347 The reduction of politics to legitimizing/de-legitimizing, soft/hard, domestic/ international, "tools" is simply inapt in cooping with the fluidity and incorporeality of imperial formation. It simply discards its presence, favoring the "tool" as the embodiment and resolve of political/imperial constitution. As G. Bataille puts it: "the developed tool is the nascent form of the non-I". 348

To a certain extent, the entire Western tradition establishes itself as a politics of the emotions, a psycho-political organization of the social, whereby power subdues the

\footnotetext{
${ }^{346}$ K. Croke, "Rethinking the War on Terrorism", Progressive Policy Institute, November 2006, p. 4. http://www.ppionline.org.

${ }^{347} \mathrm{~F}$. Adamson, "International Terrorism, Non-State Actors and the Logic of Transnational Mobilization: A Perspective from International Relations", SSRC, Global Security and Cooperation Program. http://www.ssrc.org/programs/gsc/themes/globalization.page.

${ }^{348} \mathrm{G}$. Bataille, Theory of Religion, New York, Zone Books, 1992, p. 27.
} 
powerless other(s) by shattering its(their) harmony. On this point, H. D. Lasswell is very subtle: "we are prepared to recognize as power whatever relationships involve the expectation of severe deprivations...". 349 The social constitutes itself as the (multilayered) psychological replica of power, while power constitutes itself into the psychological unity, or harmony, of the social - the symmetry of the event celebrates science as the "predictive" instrument in the composition and organization of the political.

The imperial scale of such an asymmetrical composition, however, remains uncategorizable; it can no longer sustain the symmetry between the political and the social, nor can it impose it worldwide by physical conquests; so it moves beyond them, into the incorporeal. From now on, power belongs to the molecular but also to the indefinite. It is no longer about the possession of tools, lands, capitals, or technologies, but about the incorporeal, the molecular and molar dimensions of possessing or wanting to posses all these things as a guarantee for stability, invulnerability and endurance.

The incorporeality of possession gathers and disables its composing narratives and struggles: the divine, the world, the human, the object; the three partitions of history or three psychological metamorphoses undergone by the nihilists (the lion, the camel and the child); the three worlds encamped on the road to greatness (I, II, III); the fold; the genealogy of good and evil; the perfect (prodigy, regime, model, etc.). It sounds like a cooking recipe and in most of the cases it does become a recipe for human evolution and progress, even though it is just a lifeless compilation of living interrogations and possibilities. The mood to deconstruct, disrupt, de-structure, is the mood of the unhappy (always fewer, always nihilists by chance), the mood that characterizes thinking, the world, the only world of thought available to the multitudes, to the chancy multitudes of imperialistic formations and deformations. The mood as such becomes a commodity to be

\footnotetext{
${ }^{349}$ H. D. Lasswell, Power and Personality, New York: Viking, 1966 (@1948), p. 13.
} 
acquired and offered in exchange - a fashionable posture of the thinker or, at best, an overlooked reality.

This posturing reality is also already our present, our spirit, to which J. L. Nancy addresses a familiar, and perhaps an already-overlooked, remark: "how spirit is the finite that finds itself to be infinite in the exposition of its finitude, this is what is to be thought which is to say, this is what to "think"', ${ }^{350}$ By thinking the becoming infinite of its finitude, the spirit affirms the "restlessness of the negative: its insistence in itself, without renunciation or evasion, its praxis, and the conatus of its being". ${ }^{351}$ It thinks, as G. Bataille suggests, its being or becoming a "non-I".

By contrast, G. Agamben claims that Marxist praxis, as concrete manifestation of essence and origin (i.e., I make "tools"), keeps man from falling into the trap of time (as in Hegel, Nancy, or Bataille), that it keeps him within the grasp of history, as historical being (i.e., the being whose essence is the making of something) who can "fall into time, temporalizing himself". ${ }^{352}$ The problem of modern man, as G. Agamben sees it, is not the fall into time but the "expropriation of experience" to which he has fallen pray:

For modern's man average day contains virtually nothing that can still be translated into experience. Neither reading the newspaper, with its abundance of news that is irretrievably remote from his life, nor sitting for minutes on end at the wheel of his car in a traffic jam. Neither the journey through the netherworld of the subway, nor the demonstration that suddenly blocks the street. Neither the cloud of tear gas slowly dispersing between the buildings of the city center, nor the rapid blasts of gunfire from who knows where, nor queuing up at a business counter, nor visiting the Land of Cockayne at the supermaket, nor those eternal moments of dumb promiscuity among strangers in lifts and buses. ${ }^{353}$

Experience has been expropriated by the "tooling", or knowledge, of experience, through which they have become indistinguishable, inseparable imprints of one another. In

\footnotetext{
${ }^{350} \mathrm{~J}$. L. Nancy, Hegel: The Restlessness of the Negative, Minneapolis/London: University of Minnesota Press, 2002, p. 31.

${ }^{351}$ Ibid.

${ }^{352} \mathrm{G}$. Agamben, Infancy and History: on the Destruction of Experience, London and New York:

Verso, 2007, p.109.

${ }^{353}$ Ibid., pp. 15-16.
} 


\section{T. Frank's words:}

The wiring of every individual into the warm embrace of the multinational entertainment oligopoly is ... the crowning triumph of the marketplace over humanity's unruly consciousness.... We will be able to achieve no distance from business culture since we will no longer have a life, a history, a consciousness apart from it.... It is putting itself beyond our power of imagining because it has become our imagination, it has become our power to envision, and describe, and theorize, and resist. ${ }^{354}$

The intelligible and the sensory, the divine and the human, the one and the many, have become identical portraits of one another, identical replicas of concrete and psychological "expropriation". As such, they expropriate one another in a process, a history, a tandem, of proximities and distances, faiths and fated encounters, which lose their significance and their sense in the darkened, or rather unfriendly, mirror of the present. Let us now examine this mirror in which knowledge and practice meet.

\footnotetext{
${ }^{354}$ T. Frank quoted in M. Berman, The Twilight of American Culture, New York: Norton, 2000, p. 4.
} 


\section{Chapter 10}

\section{The Knowledge of Practice} (or the sameness of the same)

The two meanings (the single original and the multipliable copy) cohabit here, they are - or seem to be - the same, and that is the whole story, the very condition of survival.

\section{J. Derrida ${ }^{355}$}

One of the contemporary thinkers who strove to overcome the Schmittean friendenemy divide is J. Derrida. To a certain extent, he succeeded in doing that by exacerbating the conflict between the spectral world of knowledge (i.e., of the political) and the concrete world of tools and performativity, by making the two worlds of meaning and polemics, words and deeds, coalesce beyond all possible divides and all possible coalitions. In Derrida's Politics of Friendship ${ }^{356}$, the Schmittean divide is overcome by making friends and enemies coalesce in an unnatural juxtaposition of friendly and inimical suggestions, conjectures, presuppositions, and discourses, each of them giving way to its ghostly complement, its apparition, as it were, or its indelible specter. Knowledge begins at this point of coalescence of friendly and inimical specters, friendly and inimical variants of becoming non-Schmittean, non-friendly, and non-inimical.

Why overcome this particular divide between friends and enemies, this fashionable emotion of being pro or against it, pro and against it? Why attempt to overcome this inevitable failure of post-modernity, this shortsightedness of the intellect, or of intellectuality? Why look for another way out, another impossibility, another absurdity, or circularity?

The aim of these questions is not to provoke the scientific rigor of possible answers, nor to pursue the abstract pedantry of philosophy, but rather the aim is the rehabilitation of

\footnotetext{
${ }^{355}$ J. Derrida, The Politics of Friendship, New York: Verso, 2005, p. 4.

${ }^{356}$ Ibid.
} 
what Kristeva (among others) had found lacking in the constitution of contemporaneity, of man, or of the world, namely, a "psychic space". In Specters of Marx ${ }^{357}$, Derrida sketches this rehabilitation of the human psyche by returning to the friend-enemy dichotomy, more precisely to the apparition of its specter, or to the waiting that precedes it. Unlike Foucault, who sought to change the "political, economic, (and) institutional regime of the production of truth",358 without changing people's consciousness, Derrida sought to awaken this consciousness to the presence of the other - the specter, the ghost, the returning phantoms of man's knowledge and institutions, discourses and acts, fears and desires.

Perhaps the most illustrative example of such a political/politicized specter is reflected in C. Johnson's notion of "blowback", defined as the "unintended consequences of the US government's international activities that were kept secret from American people". ${ }^{359}$ C. Simpson also defines "blowback" as the "unexpected - and negative effects at home that result from covert operations overseas". ${ }^{360}$ Blowback, in other words, deals with the negative, the covert, the distant. It operates at home, unintentionally, or indirectly, converting the cause-effect sequence into the fluidity of a distant negativity, which appears to be the undesired consequence of an internal, or domestic, negativity. It operates in circles, returning to the source of its dissemination as a ghost, or specter of the negative. It appears as a "surprise, apparently random and without a cause", 36 or, as $\mathrm{Z}$. Bauman would say, it hits "out of the blue", when no one can "take precautions and avert the catastrophe since no one would expect a thunderbolt from a cloudless sky" ${ }^{362}$

If the catastrophe cannot be averted, it can certainly be documented, evidenced,

\footnotetext{
${ }^{357}$ J. Derrida, Specters of Marx, New York: Routledge Classics, 2006.

${ }^{358}$ M. Foucault, Power/Knowledge, New York: Pantheon Books, 1980, p. 133.

${ }^{359}$ C. Johnson, "Blowback", The Nation, September 2001 , http://www.accessmylibrary.com/coms2/summary 0286-10225935 ITM. ${ }^{360}$ C. Simpson, Blowback, New York: Weidenfeld \& Nicolson, 1998, p. 5.

${ }^{361}$ Wikipedia, - http://en.wikipedia.org/wiki/Blowback.

${ }^{362}$ Z. Bauman, "Living in Utopia", Paper presented at the London School of Economics, Melting Modernity Series, October 27, 2005, p. 1.
} 
proved, in retrospect. In this sense, it becomes superfluous to ask, for example, "why did this happen" or "how could it happen" that the World Trade Center was attacked ${ }^{363}$ One version, among many, is that back in the 1980 s, the U.S. developed a terrorist network to resist the Soviet invasion in Afghanistan, and to force the Soviet Union to experience a situation analogous to what the Americans had faced in Vietnam. After the Soviets had withdrawn, and Al Qaeda (the Base) had come under the control of Osama bin Laden, the network was soon to reach 'global proportions. It came to have units in: "Algeria, Egypt, Morocco, Turkey, Jordan, Tajikistan, Uzbekistan, Syria, Xinjiang in China, Pakistan, Bangladesh, Malaysia, Myanmar, Indonesia, Mindanao in the Philippines, Lebanon, Iraq, Saudi Arabia, Kuwait, Bahrain, Yemen, Libya, Tunisia, Bosnia, Kosovo, Chechnya, Dagestan, Kashmir, Sudan, Somalia, Kenya, Tanzania, Azerbaijan, Eritrea, Uganda, Ethiopia, and in the West Bank and Gaza". ${ }^{364}$

This is a classic case of blowback, but also of breeching the friend-enemy divide by expanding it to 'global proportions' and volatilizing it under the generic term "terrorism". As G. Dyer tells us, "terrorism certainly wasn't a big enough threat to justify defence budgets on a Cold War scale in the early 1990s (and it still isn't), so in the absence of plausible great-power enemies the default option was 'rogue states'", 365

In this awakening to the volatile threat of terrorism, in this lack of consciousness, or failure to grasp its importance, there lies hidden another possibility of becoming conscious, becoming responsible, becoming political. This becoming beyond the failure of consciousness, beyond its indirect awakening in the face of truth, commences in the present, as the presenting of absence or the absence of presence. Apparently it commences

\footnotetext{
${ }^{363}$ I. Wallerstein, "America and the World: The Twin Towers as Metaphor". http://www.binghamton.edu/fbc/iwbk/n02.htm

364 Anon, "Blowback", July 26, 2001. http://www.janes.com/security/international security/news/jir/jir010726 I n.shtml. ${ }^{365} \mathrm{G}$. Dyer, Future Tense: the Coming World Order, Toronto: McClelland \& Stewart, 2004, p. 120 , italics mine.
} 
as a play of words, as an illusory slippage of one discourse into the other ${ }^{366}$, but also as a concrete possibility, as an alternative, a variant of the already present, already illusory. The return of the theme of empire is but another variation of the return of its ghosts, its phantoms, and its specters - the return of man to manhood, the return of friendship to its inimical substantiation, the return to difference, the return of the same, or of the eternal. The concept of empire varies with each detour, each haunting, as it were, or search for true friendship, true difference. It itself becomes variation, friendship, difference - it becomes in-and-for-itself.

The political ceases to incarnate the friend-enemy divide, the divide par excellence, and becomes haunted by its returning ghost, its apparitions, its effects. The political, as G. Dumézil had showed, commences its collaboration with the apolitical, the religious, the super-natural. It commences by returning to the politics of the apolitical, to the religiosity of the atheist, or the super-natural presence of nature - to the novelty of transcending all divisions by remaining the same, by returning to the same, as the same.

The friend-enemy divide commences as a political proposition situating itself within the apolitical, or rather as the apolitical par excellence. It commences with the pressing question of political composition, political structuring and destructuring of psychological spaces and languages, with the inevitability of politics, or of the apoliticality of consciousness and speech, with the apolitical constitution of political consciousness, of political speech, and politics. The apolitical as the fundamental entity of the political, not as its dividing force, but as its secret, its interiority, its power - the apolitical as the most universal expression of a politics of secrets, interiority and power, or as the most familiar

\footnotetext{
${ }^{366}$ See, for example, Derrida's insistent return to all ambivalent discourses on friendship and enmity; the postmodern insistence on the importance of language; the Kristevian (or Deleuzian) tension between psychology and language; and Žižek's insistence on the double articulation of fantasy, ideology and desire.
} 
expression of the unfamiliar, the distant and powerless. ${ }^{367}$ The apolitical as the essence of the political, or what amounts to the same thing, the political as the substantiating variation of the apolitical - this is the (French) conception of différence, its proposition, its beginning.

A politics of friendship is a politics of arbitrariness, or rather an unexpected putting to the test of arbitrariness and faith (or love), a putting to the test of Machiavelli's fortuna which is never to be trusted, but also never to be mistrusted. In Derrida one finds the opposite of Foucault, the opposite of Machiavelli, the friend instead of the enemy, trust instead of mistrust, alliance instead of war, but also the hidden face of the friend, the hidden face of trust (or faith) and alliance, the very distinction between the politics of collaboration and the politics of war - both of which are met with the same indifference, the same stupefaction or inability to decide between them. For C. Schmitt, the friend-foe distinction situated the political - it promised to move the political from the stage of the Hobbsean "war of all against all" to the stage of the contract, without developing a proper politics of friendship. As a matter of fact, friendship is unthinkable in political terms - once it becomes politicized it ceases to be friendship and becomes something else - "a programmme or a causality, a development, a process without an event". 368

One does not take chances any more, but calculates them in cold blood - this is how politics supposedly works, this is how it survives. Perhaps this is the Machiavellianism of all political decisions, perhaps not. Here, the philosophy of the "perhaps" may bring together hesitation and contestation, cunning and insinuation, mystery and indifference, all qualities of the uncertain, undecided, undetermined, future. "To-come" means that the future $i s$ and is not here yet, but it does not mean that it is already something other than a

\footnotetext{
${ }^{367}$ For example, a simple statistic survey reflects the progressive consolidation of global capitalist Empire, a nonpolitical fact that carries profound political implications: "by 1996, the 447 richest people on the planet had assets equal to that of the poorest 2.5 billion - 42 percent of the world population". M. Berman, the Twilight of American Culture, New York: Norton, 2000, p. 24.

${ }^{368}$ J. Derrida, The Politics of Friendship, New York: Verso, 2005, p. 29.
} 
category, a placement in time, a prediction. The future might be both prediction and event, present and "to-come", a verb, an action which is not necessarily a thinking action but simple movement, routine, programming - a succession and inversion of acts leading to time through time, leading backwards from the future and forwards from the past in such a way that each moment might be reflected back on itself, reflecting the uniqueness and commonality of passage and interruption, presence and absence, timeliness and timelessness. ${ }^{369}$

The double binding, double quality of time reflects itself further in the double articulation of power, in that power which is no longer about the "last Europeans", no longer about "free spirits", but perhaps about the "first Europe(ans)", the first "spirits" - a fold perhaps, a revolution in the passage through time, a philosophy of uncertain beginnings. Still, that which has come to pass in place of time has become something other, a remorse, a sadness, a secularized Antigone. It has (re)placed the sense of time within the sense of failure, within the unmistakable feeling of having to repeat the same event until it comes out right, perhaps better and faster than last time, perhaps more accurate, or rigorous; an event that would overcome and subdue all other events, an omnievent, a supra-event of the passage from end to beginning, from future to past, in and through an indefinite and unrecognizable present.

The present as the engine of newness, of new beings, new methods, new ideologies this is the movement and noise of passing into newness directly from the future or from the past, the excitement of passing through the opening of time into its unrecognizable closure. The psychology of closure, the psychology of the "first" (not of "free") spirits is the psychology of the number; the conversion of freedom into the psychological condition of the slave, into the first spirit without a psychology, the first spirit without a name or a piece 
of property.

But we already know that, we have already gone through that, indeed, not without fearing a certain inclination for survival, a certain numbness of the spirit, which is also a signature of the future, an ineradicable presence of the already gone, already passed, already present in the "coming" future. The future comes and this is not a category or an act of naming things "to-come", at least not yet, not here, for there are as many futures as there are calculations to be done, as many possibilities as there are closures and impossibilities. Time freezes -' without a doubt it has already begun to do so by making itself appear as the opening (J.L. Nancy), the escape (M. Foucault), the (imponderable) saving arch, of all failures and ages.

The philosophy of the perhaps explores the openings and closures, the escape routes and cules de sac, the possibilities of salvation and of death, it weights them in order to decide for the future, in the future. The present is already opened, already closing in on itself. Which present, which closure of the present should attract our attention before we make the decision regarding the future? The closure that is also an opening, the escape that is also an imprisonment, the saving arch that is also doomed to sink into the depths of the unconscious - these repetitive, often times maddening coincidences no longer mean anything, they have distanced themselves from us, and more importantly, they have distanced $u s$ from the present, from the future, from time altogether. We are passing through them, in them, by opening and closing them through us, in us. Time coexists in time, with time, as time. The future is coexistent with the past and the present, without succession or interruption, without duration.

The order of time is the order of the non-time, the anti-time, the anti-order of the present or the future. There is no continuity without interruption, no future without a disappearing present - the orders are reversed, inverted psychologies of numbers and 
possibilities, copies and inventions. But also, there is no discontinuity without the flowing of time into time, no present without a disappearing past - the orders are reinvented, casual psychologies of the one, the impossible, the different. This is the mockery of time, our time, the succession of times hidden behind strategic (but fluid) interruptions, the sense of duration amassed underneath the noise of the moment - the economy of the present as the intended effect of liberating languages, the coming future as the unintended economy of a language of freedom.

There is a sense of disillusion, of tragic ends and renunciations, a sense commemorating an impossible memory, a time which has not passed for us (we were not there) and will never pass (we will never be there), but which is here as passing and coming, as the sole trace of the possible, as the singular event of being here and there at the same time at which we are not here and not there. The communion of contraries washes away the sorrow and the tragedy of being, it washes away time and existence by implanting them somewhere else, in the opening of some other time, some other sorrowful being. The emotion of the tragic travels in time and through time, washing away the being that is time, washing away the sorrow of being in time.

Perhaps the mockery is also serious. Perhaps emotion also travels in non-time, through non-time, filling the being that is non-time with the happiness of being outside time. Perhaps seriousness is also mocked and emotion travels simultaneously through time and non-time. Perhaps we can only say "perhaps" three times, returning as it were to the same beginning of the series, to the same perhaps-ness of the possible from which time flows into the undecided, variable, specters of the perhaps. There is a sense of indecision, a predominant indecision and indifference that gives time the luster of mystery, of poetry and frailty. ${ }^{370}$ There is a sense of disillusionment, indeed; but also of joy (as in Nancy). In

\footnotetext{
${ }^{370}$ The ancient Chinese had a far different conception of time than is experienced in the current
} 
the end, it is not about having friends and enemies but about the possibility of conjuring them, about the courage of imagining and recognizing their coming, their mystery and poetry, their disillusionment and joy. The neutralization of our choice is also their choice, the coming into being of one possible version against another, of one weakness against another, one cheek against the other - the interlacing of curios possibilities, the event of time itself.

Perhaps the seriousness of mockery is also, again, mocked, in a different chaining of events of friendship and enmity, inside a present which is also future, passing through as an unrecognizable past, as an absurd genesis of this very moment. This is also time - a trace, a convolution (of events), an apparition. There are no delineations, no categories, no margins - only flows, traces, signatures, shadows. It is almost impossible to say if they are coming or going, if they are approaching or getting away from us in an effortless move from one dimension to another, from one possible friendship to its counterpart, from us to them, or from them to $u s$. This impossibility encompasses within itself all the possibilities of passing through, all the moments and stages of the possible impossibility. The reverse is equally complicated, equally transparent and true. Their coincidence freezes our thought, burning it instantaneously in the coldness of indifference, deference, and boredom. Yet, we already know them as the possibilities and absurdities of the future, as the incorporeal traces, the spirits, or ghosts, enunciated long before they begun to haunt the possible.

Our memory is their memory, our time is also theirs. The friends missed by us are already theirs, the enemies that cross our path might not cross theirs - this is the end, the last ripple in the fabric of our being, the last word on time: "the race is finished in advance

\footnotetext{
imperial age: "They did not apprehend time as a linear succession of numerical units, but an orderly and inherently meaningful cycle of defined and limited segments of life itself". Dan Thu Nguyen, "Technologies of Time Measurement and Ethics: The Case against Mechanical Timekeeping in Ancient China", J. Alexander, ed., Science, Technology and Politics Yearbook, Ottawa: Odda Tala Press, 1990, p. 85. This difference should make us humble when dealing with the subject of time.
} 
and this is future-producing". ${ }^{371}$ "In advance" is also the present, in the future - it is already here, as all future is. But we pass through it, in it, so that it passes through us, in us. The race is us, finished in the future and already future-producing. We are producing our own end, our own future of the end. Whose end, whose future? The question is half serious, half mocking. It is the beginning of another future, of another possibility, which begins in advance and produces the future by beginning. The play ${ }^{372}$ of words is also the play of time, the interplay, the intermezzo of the present for the future, that future which begins and ends in advance, as if already here. It is here already, and we should not tire of repeating that, we should not tire of seeing to it that it is here and also is not here by virtue of the fact that it is already finished, already of the future.

The decision, our decision, is the freezing of this moment, the indifference of having to make a neutralizing choice, but also the sorrow of having already made that choice - the abyss in between immerses us and the decision we made in the (in)certitude of having been there (and here, and nowhere) in the blink of an eye. These are separate instances, but always connected, united, (un)recognizable. Through them one realizes that a "certain aristocracy is analytically encompassed in the arithmetic of the choice", ${ }^{373}$ that uniqueness not only encounters the number but grows out of it and depends on it just as much as the number retains its ambivalent role of choice and weight. The turning point is the point at which the analytic is reversed and choice loses its quality under the pressure of the multitude. The specificity of decision is no longer important, no longer belonging to this or that order, but already omniscient, vague, and threatening. One might automatically conclude that a certain plebianness is genealogically encompassed in the orders of numbers. And if it is, there is no turning point to its power of analysis, or of choice.

\footnotetext{
${ }^{371} \mathrm{~J}$. Derrida, The Politics of Friendship, New York: Verso, 2005, p. 31.

${ }^{372}$ In the sense in which G. Agamben uses it (following Levi Strauss) - play as the transformation of structures into events; see. Infancy and History: On the Destruction of Experience, London \& New York: Verso, 2007, p. 82.

${ }^{373}$ lbid., p. 20.
} 
But there is always something other than "this", something belonging to an adverse order, a friendly one perhaps, another world to which one can return after a long pilgrimage, or another city-state against which he might turn in his search for meaning, corrupting the future but also the past and the present, the lineages that connect and disconnect them in an ongoing movement towards and away from this moment, or this order, which is an illusion, a coincidence, a choice that is made in vain, for they are the same, the order and the moment, the friend and the enemy, the pilgrimage and the turning against one's own. The "other" is so conspicuously present in the "here" and "there", in the "now" of time, that there is nothing else to think of except the being of this other, the moment, the choice, the order of this extremely important "other", which survives all tests and all imagination, passing indifferently in hiding, in pilgrimage - perhaps even in remorse.

The thought of the passage no longer corrupts the otherness of the other, but the other in (his own) otherness, for there is no longer any otherness outside or without the other, without pushing the other towards the null of choice and away from otherness (or from its end). The other is the identical, the twin, the Narcissistic image floating on the surface of the water: its pilgrimage is our pilgrimage, its identity is our identity in the negative. There is no future for us, no decisive moment for our coming together - we can be friendly, floating from one to the other almost incestuously, in a search for nothing but coincidence, coming together, identity. But there could be no coincidence, no coming together, no identity.

The image and the original face each other through the coincidence of their separation, in the coincidence of having been separated in such a way that they look the same; they come together through distance, in the distance of togetherness, and they are identical by not having the same identity. The boredom of repetition, of having them face 
each other as if in an archaic mirror, corrupts their sense of friendliness but also of enmity - they no longer face each other but a friend or an enemy, always a strange, endearing or insufferable image. This is the image of the other, the otherness as pure reflection in the mirror, the friend and the enemy - within and/or without.

N. Chomsky has frequently held the mirror toward the imperial subject, and satirically, or sarcastically, declared that, given the official definitions of terrorism, it should be declaring war on itself. ${ }^{374}$ However, what differentiates the friend from the enemy is not only a matter of satire, nor a sentiment, or an uncontrollable mood of seeing the other as friend, but also, and most importantly, the faith through which the other is encountered as a friend, the constant trust in which friendship is forged and to which it must return in order to maintain itself as such. Faith works both ways, obviously, one also encounters his enemies in and through the mirror of faith, forging their continual betrayals so as to produce even more enemies, more faith (in betrayal), more conflict.

All contractual theories are based on this type of faith, they set themselves pro or against an omniscient enemy to which they owe their entire existence. They reach their apogee in positivism and nihilism, and their end in the solitude of such a final position. There is no escape from the contract except through war, through the inevitable and necessary destruction of the contractual order: the warrior against the businessman, the violent order of the war-machine against the friendly order of capital, the terrorist against the citizen. Two versions of the same contract, two orders of a power which is never in that place, never in that faith, as faith, or place, but always somewhere else, always as something else, perhaps already "other", already of the future.

\footnotetext{
${ }^{374}$ N. Chomsky, "Terror and Just Response", James P. Sterba, ed., Terrorism and International Justice, Oxford: Oxford University Press, 2003, pp. 69-87. His bill of particulars includes terroristic activities carried out by successive administrations against the Sudan, Palestine, Libya, Lebanon, Afghanistan, Iraq, and many countries in Latin America, most notably Cuba, Nicaragua and Haiti. Chomsky concludes that a just response would be to permit those countries to retaliate by bombing the United States.
} 
What can be said about one(ness) cannot be said about other(ness): the friend is always surrounded by silence, always in truth, whereas the enemy is surrounded by noise, by the violence of lies and deception, betrayal and vengeance, always turning us into "bands" glued together by hatred and mistrust. The enemy as the "other" is the embodiment of mistrust, the embodiment of resentment, the inevitable manifestation of being "different", "distinct", "superior", perhaps even "friendly" by default. Enmity is already embodied in the "otherness" of being woman, animal, black, uneducated, savage, bold, iconoclastic, and so forth. Enmity has a body. It has a place, a face, a linguistic specter. $^{375}$

In the words of R. Kagan, it also has an atavistic impulse that can be played upon:

Maybe concern about America's overweening power really will create some energy in Europe. Perhaps the atavistic impulses that swirl in the hearts of Germans, Britons, and Frenchmen - the memory of power, international influence, and national ambition - can still be played on. Some Britons will remember empire; some French still yearn for la gloire, some Germans still want a place in the sun. These urges are now mostly channeled into the Grand European Project, but they could find more traditional expression. ${ }^{376}$

The present is always uncertain, always in the process of becoming future, becoming other. Here is also there, to a certain extent; it is also the uncertainty of being here and/or there, the variation between them, the becoming of one through the other and in the other. Friendship and enmity become through one another the friend and the enemy of one and the other, they become the other of the one and the one of the other, in an intricate chaining of events and futures. Becoming is always becoming this or that, here and there, now and

\footnotetext{
${ }^{375}$ In this respect, the becoming woman is seen as subtle, softening, dream-like. It prepares the way for the "other", the way of the "other" as the embodiment of seduction, forgiveness and forgetfulness. As a friend, the woman is in danger of taking off her clothes (the clothes of truth) and terminating an existing friendship. As an enemy, she fosters resentment and is in danger of never taking off her clothes, of never ceasing to be or to appear inimical and revengeful. Perhaps the problematic becoming-woman is not at all about softness and gracefulness, not at all about the dream-like becoming other than "man". Perhaps it is just another variation in the becoming-friend of the enemy, and the becoming-enemy of the friend - another hope, another becoming altogether: a coincidence.

${ }^{376}$ R. Kagan, Of Paradise and Power: America and Europe in the New World Order, New York: Knopf, 2003, p.101.
} 
then - it becomes by trusting either this here-now, or that there-then. The reduction is obviously simplifying, it makes becoming into make-become the other, whereas it is always the other way around - the other makes becoming become. However, perhaps it is possible for a while that they act together, simultaneously, as if in a concert: what matters, really, is their reducibility as much as their irreducibility to one another (i.e., the becoming of the one who makes and the making of the one who becomes), the interplay between them, the fragile lines of their encounters - the horizon and place of such an encounter.

We move in the middle, in-between the other and the one, in the non-present of the non-future, that is, in the becoming other than "this" or "that", other than becoming maker and becomer, other than the one and the double, the negation and the affirmation, the beginning and the end, the egg and the chicken. By moving in-between, one uncovers the variations of the reduction, the transplants of the one into the other and of the other into the one: the microscopic genealogies of singularities and multiplicities, their transfigurations and displacements. It is here that one encounters the uneasiness of having to make a choice between oneness and otherness, between oneness in otherness and otherness in oneness, between the invincibility and frailty of the one or the other, between their friendship and enmity, or even their present and future.

The decision modifies the real instantaneously (i.e., being in the present or in the future by loving or resenting it). It also modifies the past by linking it instantaneously to the present and the future. Of course, this is a gross exaggeration, a gross adaptation of wishful thinking to the transparency of the real - in principle, the decision is always suspended, always delayed by the desire to remember or forget it. The real is modified by this remembering and forgetting, by their simultaneous unfolding as the direct effects of a decision in favor of life and/in time. All that is, in the end, suits life in the presence of time - in all of time, as it were. The decision affirms life as time in the closure of their 
equivalence. At the very moment at which the decision is made, it is also forgotten and remembered as forgetfulness.

The question of the future becomes more ardent than any other question, more important than the question of the present, which is always thought in its connection to the "coming" of something or somebody. Even when it appears to be thought in its own terms, the present indirectly raises our concern for the future, our indiscreet and unfriendly curiosity for the faith of that which has yet to come. Not knowing who is a friend and who is an enemy is not only the condition of life, but also the condition of politics, of the new politics which is no longer determined by the coming of new arrivants, ${ }^{377}$ new friends, new brothers, but by our incertitude of having either friends or enemies, by our (re)living through the same present, but also, always, through the future, the possible, the probable.

Between "friends, there are no friends" and "enemies, there is no enemy", Derrida slipped in a Nietzschenean perhaps ${ }^{378}$ : perhaps the friends are the enemies and the enemy is the friend; perhaps the world is no longer divided in or among friends and enemies, but in and through enmities and friendships, forming themselves as enclaves of the past, in the present, but also in the future, in that future which is no longer friendly or adverse, but both in one stroke, friendly and inimical - absent. It is improbable, of course, but man has always taken to heart to conquer the improbable. The improbable is his aim, the unabated faith in his power to conquer and rule the probable by way of absences, not of enmities or friendships alone, but by taking them together, by annulling them, as it were, in the impossible union of good and evil, or beyond it, in the uncharted horizon of the goodness of evil and the evilness of the good (a mutation which has already melted down the barriers between friends and enemies, their languages, their truths: i.e., "friends, there are no friends"; "enemies, there is no enemy"...). The enmity of friendship and/or the friendship

\footnotetext{
${ }^{377}$ See H. Arendt, Between Past and Future, New York: Penguin Books, 1968; also J. Derrida, The Politics of Friendship, New York: Verso, 2005.

${ }^{378}$ J. Derrida, The Politics of Friendship, New York: Verso, 2005.
} 
of the enemy - this is the new politics of the future, grand-scale and molecular at once, arithmetic and aristocratic perhaps, engulfing, separating, flowing from one place to another, from one version of history to the next, from one configuration of power to its exact opposite.

Perhaps S. Huntington's political motto needs to be reconsidered in this light. The Schmittean reduction of the political to the friend-enemy distinction is more ethereal than its proponents are willing to admit. To put it differently, the friendly-inimical lines of the political have become blurred, incessantly flowing out of bounds, into the open space of empire. To make them (arbitrarily) fold back upon themselves is no longer a metaphor that one could simply label blowback, or foreign policy, or containment, and proceed to assess and prevent its consequences, which is exactly what $\mathrm{S}$. Huntington is proposing:

I would add that a strategy which allows for preemptive war against urgent, immediate and serious threats is absolutely essential for the US and other Western powers in this period. Our enemies - primarily the militant Islam, but also other groups - cannot be deterred, that much is obvious, so it is essential - if they are preparing an attack against us - that we attack first. ${ }^{379}$

As Ferguson would say, the real problem of preemptive strikes is not money - "the real problem is time". 380

The question of the future as the decisive question regarding politics, also as the most intimate coordinate of thought, pushes the answer even further in time, in the non-seeable, impossible time of another history, another variation in the conceiving of time itself. There is no longer any "perhaps", no longer any future to think about, but only the impossibility of succession, the rupture of time, as it were, its rippling around its own disappearance the sage turning himself into a fool is also a fool turning into a sage, a double relationship moving away from and towards the center of the ripple, which is always empty, always full

\footnotetext{
${ }^{379} \mathrm{~S}$. Huntington in conversation with A. Giddens, at the London School of Economics, Spring 2003, New Perspectives Quarterly, 20, (4), Fall 2003. http://www.digitalnpq.org/archive/3003 fall/giddens huntington.html.

${ }^{380}$ N. Ferguson, "Empire: The Rise and Demise of the British World and Lessons for Global Power", speech given in New York, Carnegie Council, Books for Breakfast Program, September 2003.
} 
of meaning. But one no longer takes seriously the sage, or the fool, they both belong to the past, to the not-present, not-here, which is the domain of another, perhaps a friend or an enemy.

The burden of politics is no longer the disappearance of its essence (the friend-enemy divide), but its mutation into an all-pervasive specter, into an omniscient democracy of friends and enemies. Again and again, the persistence of contraries appears to take away the breath of the moment, the incalculable administration of a reasoning accustomed to cover up and uncover the hostilities and proximities of the event, the interchangeable nature of both hostility and proximity, the flexibility and indifference of being hostile and friendly towards friends and enemies, towards two names given to the same relation, to the same process of transfiguration and displacement (hiding) by which one becomes the other and vice-versa. The breath of the moment is also its depth, the finality of having transferred otherness into oneness and vice-versa - this is the horizon of the present, but also the beginning of the future, the intercepted variation, the progression towards the improbable and the hidden. The invariation of the variation, the impossibility of the possible - these are the timelines of the future, the lines that are already here, already mutating back and forth, folding and unfolding the event of life. As E. Balibar explains, the "event repudiates the present understood either as passage or separation", and this, in fact, is the very "paradox of becoming". 381

No matter how cautious one is with regard to the present (I am thinking of $\mathbf{J}$. Derrida's mention of the fall of the Berlin Wall), no matter how discreet one is in tracing the friend-enemy coincidence, a highly hypothetical but also already a mutating maneuver, there is no longer any mystery left in the present since everything happens as if the moment, the event, the thought, has already taken place in all its versions and possibilities,

\footnotetext{
${ }^{381}$ A. Badiou, "The Event in Deleuze", Parrhesia, issue 2, 2007, p. 38. http://www.parrhesiajournal.org.
} 
as if the Berlin Wall is falling/has fallen everywhere, not only in Europe or in that part of Europe which is not yet European, not yet something else, but which is there nonetheless, forging its friendships and enmities according to this moment, this event, this uncertain (in)sight of a falling wall, or a falling present. Whether one suspends his thought in the accursed share of a perfectly excusable silence, whether he voices out his concern with intellectual dignity and courage, or whether he states boldly his intentions, he gives himself away in a friendly and hostile gesture of naming, or conjuring, as Derrida would say, the danger of the present, the moment which has now fallen upon us in an unprecedented way, a new way that has already captured the future - in the ripple caused by the fall of the Berlin Wall. Perhaps N. Ferguson's remark in respect to the future of empire is a good illustration of such a falling wall, falling time: "but there is also the possibility that in its struggle to reconcile overseas commitments with its own republican ideals the U.S. will end up as another kind of empire, rather more akin to the empire we saw in the movie Gladiator". 382

The possibility of the impossible is here, and the more possible it becomes, the more impossibilities we encounter around it. What comes together as possibility is also separated by the impossible achieved in and through that very possibility, better still, the possibilities of alliance that are full of impossibilities for conflict turn around, in a solution very similar to Dumézil's couples of couples; the original and the copies are always connected through some appearances and always disconnected through some depth, some distance, something, that passes between them in order to reinforce their power. It is the most hidden variant, one that splits afterwards in smaller, more manageable, more appealing versions of this double doubling (as in Baudrillard, Lyotard, Deleuze, Levinas, Derrida, among others) - into various alternatives that go from parallelism to equivalence, from distance to

\footnotetext{
${ }^{382}$ N. Ferguson, "Empire: The Rise and Demise of the British World and Lessons for Global Power", speech given in New York, Carnegie Council, Books for Breakfast Program, September 2003.
} 
proximity, from one thing to another, in a search for the other (of) solution, the other (of) answer, the other (of) certainty.

Everything is staged, coupled, played forward and backward in such a way that it appears perfectly real and perfectly virtual, a thing or an event in mutation, a variation of death and life, a sinister coupling of possibility and impossibility. H. Luce might have had in mind something very similar when claiming the creation of a new Century. He proposed: “"'to accept wholeheartedly our duty and our opportunity as the most powerful and vital nation in the world and in consequence to exert upon the world the full impact of our influence, for such purposes as we see fit and by such means as we see fit". ${ }^{383}$

In this kind of policy-polity equivalence, all that is left is the couple, the stage, the mutating background. There is no more room for speculation (everything is speculation), no more room for poetry (all is poetry), no more room for myth (all is myth), there is no more room for anything except the room itself, except space, form. The possible and the impossible switch places, indifferently they become the other, they mutate into one another over the time and space of the double, expanding and contracting it in-between everything and nothing, content and form, future and present, love and betrayal. But there is also the reversal of all of these extreme points of convergence and divergence, of their variable borders and bodies filled with the need for the other, the opposite, the fire, the element of finality and consummation, of death and renewal - the element that switches back and forth between disappearance and appearance, present and future, betrayal and love.

It might be helpful to think in terms of a distant present and a close present, a mutating present, perhaps a fluid web connecting everything in disconnectedness, the sort of medium similar to air or water, perhaps even fire. The closer one gets to distances, the more distant he becomes to the closest, and vice-versa, in an unending chaining of

\footnotetext{
${ }^{383}$ H. R. Luce, The American Century, New York: Farrar \& Reinhart, 1941, p. 23.
} 
movements and events, always contrary to themselves, always passing and stagnating, as if folding and unfolding themselves in a time which stays the same by passing continuously from sameness to sameness, from here to there and back, in the untraceable passages of connectedness and uniformity. Here is similar to there, it is identical, copy of the copy of the copy, in a platonic enchaining of virtualities and realities, of perfections and beauties, words and images. Such is the present in the future and the future in the present - both indistinct copies of one another, pushing us towards the impossible, the exit, the ripple opened between what is being said here and what is being done over there, in another future, or another present. As J. Rancière puts it: "politics means precisely this, that you speak at a time and in a place you're not expected to speak". ${ }^{384}$

Perhaps what is being voiced here is done (over)there, in the present of the future, or the future of the present, we cannot know; we are not there, nor are we here, but always at the same time here and there, in the sameness and identity that connects their disconnectedness. It is an impossible truth, obviously, for its possibility is also at the same time consummated in the impossible, in the very moment which is indifferently possible and impossible, present and future, friendly and inimical. And there is nowhere to turn, no matter how deeply one strives to delve into the present of the future, or the future of the present, they continue to mirror each other narcissistically, they continue to multiply and metamorphose, perhaps even to animate one another through the impossible possibility of difference and repetition, movement and stasis, proximity and distance.

The resuscitation of such mortifying aporias is only superficially true, only half true, genuine, useful. It expands the imagination beyond the ripple of the present into the future of this rippling advance towards everything and nothing, content and form, future and present. These are the last couplings, last realities, last possibilities of the impossible.

\footnotetext{
${ }^{384}$ J. Rancière, "Our Police Order - What can be Said, Seen, Done", an interview with J. Rancière, Palinurus: Engaging Political Philosophy, issue 12, February 2007. http://anselmocarranco.tripod.com/id58.html.
} 
Beyond them, there is obviously the impossible of the possible, the playing backwards of the version, the variation, the ripple that is now full of meaning, empty, entirely empty and barren, but full of all possible meanings of entirety and emptiness, wholeness and nothingness. The playing backwards is also the playing forward, the inevitable enchaining of events that have passed and will continue to pass until they become unrecognizable, different and new.

The fold is simultaneous with its unfolding, an uncertain ripple in the continuity of a discontinuous time, but also always a possibility bringing forth the impossible, the time which is already here and already there, in the future. The moment at which one begins to fold is the moment at which the other begins to unfold - the ripples cross one another, they carry each other into parallel dimensions, parallel timelines, couples, eventualities and variations, of the same parallelism, same dimensionality and timeliness, which never ceases to become knowable, justifiable and practicable, by also becoming the opposite, the countermove, the impracticable, the ghostly. From here on, time is only motion, devastating, incessant movement of thought, of its maddening responsibility of pursuing some evil beyond evil - maddening, enrapturing, who is to say? One is no longer in space, but in time - through time - and yet a strange message resounds from within the imperial present: "in all of American public life, there is hardly a single prominent figure who finds fault with the notion of the United States remaining the world's sole military superpower until the end of time". 385

One no longer looks forward (there is nothing to look for except the sameness of the same - the frail uniformity of time), nor does he look backwards, he is always in the nozone of the beginning, in the imperceptible variation of the end (of time), and he participates in this passage from one to the other, in this survival of time through another

\footnotetext{
${ }^{385}$ A. Bacevich, [of Boston University], quoted in G. Dyer, Future Tense: the Coming World Order, Toronto: McClelland \& Stewart, 2004, p. 8.
} 
(time), which is an impossible possibility, a righting error, or a paradoxical eventuality. The truth of the paradox is also the paradox of truth hiding inside this funerary estimation, inside this immaterial shell of eventuality which is called illusion, faith, ideality, ideology, sovereignty. There is no paradox in the ideal, the ideal itself is a paradox: a non-place of places, a community of non-communers, anything that is empty by being full, friendly by being inimical, close by distancing itself. The paradox itself is an impossibility, but also always possible, always present in the present, in the thought of the present or, in any case, in its event. And this is our point of departure, the moment of the present that is already its own possibility of the impossible, the presenting of the present, which is also, in some way, the presenting of the future, the coming of that which has already passed, which has already been said and done in the event, in the naming, or the opening up of a void that has already been filled with meaning: "the event is neither past nor future. It makes us present to the present".386

Everything repeats itself, subtly and distantly, by ceasing all repetitions in the distant interiority of the whole. Everything is filled with joy and terror, vulgarly and closely, by ceasing to be full of joy and terror in the vulgar and close externality of the present. Places switch, mutate, disappear - their geography changes as rapidly as their history, or their culture, while their memory is being erased on the spot. The danger is no longer this or that, no longer these or those people making up the barriers of civilization and language, no longer the absurd passage through time, but each and all, taken together in the wholeness of an unrecognizable everything that suddenly becomes an unavoidable nothing. In H. Morgenthau's words:

The tendency to disparage the perennial and typical in history and to dissolve the historic process into a series of disconnected disturbances, unique and ephemeral, disarms contemporary man in the face of a phenomenon that is

\footnotetext{
${ }^{386}$ A. Badiou, "The Event in Deleuze", Parrhesia: Engaging Political Philosophy, issue 2, 2007, p. 39. http://www.parrhesiajournal,org.
} 
truly unique: the ability for universal destruction that man has received from nuclear power.... For nuclear power has radically altered the relations that have existed since the beginning of history between the ends of foreign policy and violence as a means to these ends. ${ }^{387}$

Today, as Žižek remarks:

... we are dealing with another form of denegation of the political, postmodern post-politics, which no longer merely 'represses' the political, trying to contain it and pacify 'the returns of the repressed', but much more effectively forecloses it, so that the postmodern forms of ethnic violence, with their 'irrational' excessive character, are no longer simple 'returns' of the 'repressed' but, rather, represent a case of the foreclosed (from the Symbolic) which, as we know from Lacan, returns in the Real. ${ }^{388}$

To this foreclosing of the Symbolic and its return in or as the Real we must now turn, in an attempt to understand what it means to foreclose the political and let it return not as symbolicity, but as the concrete manifestation of the very disappearance of the Symbolic.

${ }^{387}$ H. Morgenthau, "The Intellectual and Moral Dilemma of History", Christianity and Crisis, February 8, 1960. http://www.religion-online.org/showarticle.asp?title=398.

${ }^{388}$ S. Žižek, "The Political and its Disavowals", Palinurus: Engaging Political Philosophy, issue 9, November 2006. http://anselmocarranco.tripod.com/id46.html. 


\section{Chapter 11}

\section{The Practice of Knowing (or the chicken and the egg)}

The problem is not changing people's consciousness - or what is in their heads - but the political, economic, institutional regime of the production of truth.

\section{Foucault ${ }^{389}$}

How could one change the political, economic and institutional regimes without changing what is in people's minds? In Foucault's view, it is impossible to emancipate truth from the mechanisms of power (for truth already is power), while it is certainly possible to detach the "power of truth from the forms of hegemony, social, economic and cultural, within which it operates at the present time". ${ }^{390}$ What we encounter here (and only apparently) is the suspension of truth in favor of the power of truth, the already is suspended by its operation in time, which is none other than its symbolic formation, its truth, perhaps even its power. The problem, indeed, is not changing people's consciousness but changing the forms of power that enter consciousness, the forms of power already in place, already operated by truth.

There is no need to change "truth", as it were, for truth has already been changed by its own appearance, by its own attachment to the forms of the possible, which operate hegemonically, socially, economically and culturally. In this uncommon version of truthtelling in which one needs to detach, to distance, to remove something from sight as it were, truth (in)forms itself by disappearance, absence, delay. In place of Truth, one deals with the power of attachment, with the power truth had already attached to the sovereign, to society, economy and culture. One deals, after all, with the power intended, effected and operated by truth. In this context, "the essential political problem for the intellectual is...

\footnotetext{
${ }^{389}$ M. Foucault, "Truth and Power", Power/Knowledge, New York: Pantheon Books, 1980, p. 133

${ }^{390}$ Ibid.
} 
that of ascertaining the possibility of constituting a new politics of truth". ${ }^{391}$ What does it mean to constitute a 'new politics of truth'? And how does one constitute the 'new' - by a new truth, a new power?

Somewhat unintentionally, Foucault had established that "each society has its own regime of truth, its 'general politics' of truth: that is, the type of discourse which it accepts and makes function as true...." ${ }^{392}$ What then is the nature of imperial regimes and truths at the present time? In its cultural guise, the question raises the ephemeral, but no less concrete, question of power. It raises the question of a culture of power, whose cardinality, as J. H. Wray suggests, seems to be reducible to four characteristics:

In one degree or another, each of these values may be seen in many of the world's cultures, but their most dramatic expression is manifest in the United States. Hence the values that have been described are distinctively American. This nation is easily the most individualistic, the most mobile, the most competitive, and the most materialistic nation in the world. ${ }^{393}$

According to J. H. Wray, the prototypical citizen, then, would be self-absorbed, anxious about his place in the world, and would have little sense of connection to others beyond the immediate family. Normally uninterested in politics, this person would think politically only about the pursuit of narrow self-interest. A primary pursuit would be to outdo others in the accumulation and display of material goods, and so any governmental proposal that helped only others, including future generations, would be viewed with mistrust. Living in a world of competitive others, he would have little empathy for them, and would view the others as either irrelevant to his happiness, or as a competitor to be bested. Quick to see others' faults, he would hold scant concern about common fates, mutuality or interdependence, and so would oppose the view that politics could act as a

\footnotetext{
${ }^{391}$ Ibid.

${ }^{392}$ Ibid., p. 131.

${ }^{393}$ J. H. Wray, Sense and Non-Sense: American Culture and Politics, Upper Saddle River, NJ: Prentice Hall, 2001, p. 141.
} 
positive force in extending his freedom or happiness. ${ }^{394}$ Are these long-standing cultural characteristics? They were certainly around in Tocqueville's time.

The despotism that Tocqueville feared was that of an administered, manipulated, political market: "It would be more extensive and milder. It would degrade men without tormenting them". ${ }^{395}$ It would turn them into what D. Riesman, more than a century later, would describe as a lonely crowd. ${ }^{396}$ However, in Tocqueville's time, humanism was still a concern with man. He writes: "Each of them, living apart, is a stranger to the fate of all the rest, -- his children and his private friends constitute to him the whole of mankind; as for the rest of his fellow citizens, he is close to them, but he sees them not; he touches them, but he feels them not; he exists for himself alone...".397

It might be argued that in our time, tyranny is unnecessary, for society itself is already culturally coercive. Should this culture come to guide world development, as Tocqueville greatly feared it would, then we would all live in societies in which:

The will of man is not shattered, but softened, bent, and guided; men are seldom forced to act, but they are constantly restrained from acting: such a power does not destroy, but it prevents existence; it does not tyrannize, but it compresses, enervates, extinguishes, and stupefies a people, till each nation is reduced to be nothing better than a flock of timid and industrious animals, of which the government is the shepherd. ${ }^{398}$

Sociologist A. Podgórecki takes us a step further into what it means to be reduced to

a 'flock of timid and industrious animals':

Washington embodies an ethos suggesting that if you would like to have a friend you should domesticate a rat. It is submerged into an idolatrous admiration of power.... The political species of Washingtonians have X-ray devices instead of eyes. They immediately screen you to measure your proximity to power (how many telephone connections, if any, are you away from the president). They gauge what type of lobby, if any, is behind you. They

\footnotetext{
${ }^{394}$ Ibid., pp. 140-41.

${ }^{395}$ A. de Tocqueville, Democracy in America, vol. 1, Andrew Hacker, ed., 1964, p. 314.

${ }^{396}$ David Riesman with Nathan Glazer and Reuel Denney, The lonely Crowd: a Study of the Changing American Character, New Haven: Yale University Press, 1969.

${ }^{397}$ Ibid.

${ }^{398}$ Ibid., pp. 314, 315, 316.
} 
avoid answering letters, not due to incivility, but to avoid producing documents that enemies might leak to the press. ${ }^{399}$

What are the cumulative consequences of these cultural traits so avidly hounding the world by means of cultural imperialism?

The inversion of the Clausewitzian definition of war has become something of a rhyme in political discourse, a fashion, or rather a pervasive cultural trend operating at all levels of political formation, in and through the mysticism of newness, change, or even democratic progress. The aporia of the political, the Schmittian political resting on the permanence of war (but also on its Deleuzian limitation), has now been drawn closer to power, inside it as it were, inside its regime of truth. Through this absorption of truth by power, former regimes are being replenished, folded, impatiently expanded and dispersed across a myriad of possible (re)formations and restorations, possible paths and gateways, lines of flight and forceful lineages, leading towards a new horizon, but also anchoring back into the old.

In the process, newness transpires as critique, negativity, betrayal, enmity, nihilistic quest, each presenting itself with an aura of genealogy, phenomenology, ontology - with an aura of truth, or rather of a power of truth indebted to liberation and production, to its becoming a "general politics", a general type of discourse, a general regime of truthfulness and productivity. To be sure, the new is the result of converging contradictory forces, it consists of the certainty and uncertainty of a political aura played out against a milieu of cultural regimentation and discourse; it is null, incendiary, inexistent. In the last analysis, it is something worth a try, something not entirely dismissed, nor entirely absorbed by the specter of human emotions.

Newness proposes, right from the beginning, an empty formulation, a politics of

\footnotetext{
${ }^{399}$ A. Podgórecki, "Nixon's Social Engineering", A. Podgórecki, J. Alexander and R. Shields, eds., Social Engineering, Ottawa: Carleton University Press, 1996, p. 63.
} 
enframing or enframing politics. It is an empty word conjuring an already acclaimed politics of truth, a fullness which is not here yet, but is also already filled with the sense of the present, or simply with the present: with its truth, its politics, its power. So newness also appears to be something else, something that prompts us to decide in its favor, even if only to be numbed by it, to forget and remember it as truth, our truth, whose productivity depends on us, on our sincerity and/or our detachment. The decision as such seems to be a decision for silence - for the incommunicable, or rather for the hardest and faintest of all possibilities: politics and/of truth, survival and/of dementia, world and/of capitalization, alliance and/of betrayal.

Each of these phantasmal apparitions is indebted to the other, each of its becomings turns backwards, becoming in the beginning, before the beginning, instead of the beginning; also, each apparition manifests itself as the impossibility of the other, as the initiation and termination of whatever stands before it in an unrelated, unrecognizable posture. If the beginning is always new, always unrecognizable and often violent, it is also the point at which the present disappears in favor of another future, which is already taking place in and through the beginning. Time stops, it simply evicts itself, surviving in and through the newness of its own death and its own inexistence - truth is always dead, always reaching us from the dead or the not yet alive.

Newness is also death, or perhaps only death, out of sightedness, removal. When J. Derrida speaks of the genealogy of genealogy, ${ }^{400}$ he is undoubtedly referring to this perfect death, which is also already genealogical, curious, indebted to the living - to another type of truth? Truth needs genealogy to help detach itself from the mechanisms and institutions of power, but also its detachment already needs another genealogy to re-attach it to the new mechanisms, new institutions, new political milieus. Newness as death is also the newness

\footnotetext{
${ }^{400}$ See J. Derrida, The Politics of Friendship, New York: Verso, 2005.
} 
of life, the embrace or the voice of the closest friend, or the closest enemy.

Through this newness, the political mutates from the death of emotions (friend/enemy split) to the emotional spectralization of death in such a way that all ties with the other cease to be emotional, or deadly, and become new - non-quantifiable, nonjustifiable relations between adverse/complementary forces. Instead of pretending to emancipate the human psyche by traveling the path from love to hatred and back, the political becomes this path, this emancipation, in which love and hatred flow into one another without ever ceasing to politicize themselves. In this inevitable politicization, the last human emotion appears to be the "I", the Achillean heel of every power, the vulnerable moment at which power is no longer about friends and enemies, but about itself, about friends and enemies taken together and turned into something other than power: lonely crowds, ghosts, shadows. Power begins and ends with the apparition of this ethereal "I", with its friendly and inimical specters entangled in the narcissistic politics of image and persona, praxis and knowledge, wealth and truth. It is itself entanglement, end and beginning, image and persona, haunting and being haunted by friendly and inimical reflections of itself.

The passage through the Narcissistic stage is also the passage towards the Promethean other, the mythical other, whose passion is fire-related, betraying, restless (pertaining to the intimate order, as in Bataille).

The Promethean is an introverted Narcissus - a new type. He turns Narcissus' platonic contemplation into a fire, a gift, an almost Zarathustrean clandestinity: he betrays the loved ones and befriends the betrayed, or, to put it differently, his betrayal turns into knowledge of friendship, while his friendliness turns into knowledge of hostility. The unfolding of history is the unfolding of this promethean intertwining of befriending and betraying postures (not to say archetypes), the historicizing of the posture itself, the 
historicizing of a posturing and performative narrative, in which man evades his narcissistic encounter with himself through the intervention of a restless deity. Man narrates and is being narrated in and through the destiny of befriending and betraying encounters. This is the Narcissistic-Promethean specter of the political - the new ghost, or deity, betraying and befriending friends and enemies alike. ${ }^{401}$

This superficial internalization of the other, this imperceptible, incalculable, sinking of surfaces into depths, or bursting of depths into surfaces, is also already (of) a new impression - a new passion. However, it is not singularity (the singularity of passion) that solves the problem of ideology or of the event of its appearance, but its profundity emerging on the surface, while its appearances sink into the depths of consciousness as modalities and dimensionalities of resistance. Otherness recoils in the depths of being by turning itself into a site of resistance - its triviality, its uncertainty and despair, are overtaken by the affirmation and joy of "otherness" - a variation, a particularity of the event of thinking (or recollecting).

Surface and depth, otherness and resistance, idea and event, are always in contretemp, always (in)formed by succession and dissent, unity and rupture, sameness and singularity - each becoming the mask and the skin of the other, its soul and body. Multiplicity is this contra-temporal relation between surface and depth, indifference and intensity, ideality and passion - this incommensurability of the eventuality of being. Perhaps the singularity of the present rests on this contra-temporality of the multiple, on this becoming one by turning multiplicity into a single composition, a single formula for the event of being. The present multiplies its singularity and singularizes its multiplicity in a new relation of temporization, a new politics - time is composed differently, as

\footnotetext{
${ }^{401} \mathrm{M}$. Berman traces this development in contemporary culture: "At root, there is a fear of any kind of involvement at all, for real friendships require risk and vulnerability, and more and more Americans feel that they lack the psychological strength for that". The Twilight of American Culture, New York: Norton, 2000, pp. 57-8.
} 
accelerated or decelerated pasts and futures, as common and unique genealogies and histories of multiple betrayals, multiple befriending timelines.

Uniqueness as accelerated commonality, as pure speed - this is what P. Virilio had uncovered at the heart of the political: "the fleet in being is logistics taking strategy to its absolute point, as the art of movement of unseen bodies". ${ }^{402}$ The machine, the dispositif, the weapon, appear as models for the uniqueness of the common - the techno-politics of the invisible, still here, still tinged by the hope of (be)coming. Inverting that temporality, inventing and measuring it against the event of its own appearance, which is neither here, nor there, but suspended in between, in the uncertainty of resisting becoming a machine, a dispositif or a weapon. Being what one cannot be, the machine and the impossibility of its existence, the weapon and the termination of war - this is the new beginning of another end, perhaps non-mechanistic, non-human, but altogether different, a-temporal, free.

Perhaps the paradox of the event (of being) consists in the infatuation of time with the privileged alternative of being there before things happen, not after they happen, but precisely before they begin to shape reality in a certain way, always uncertain, but also always deepening and tragic. Being there gets caught in the web of negativities and potentialities, in the syncope of affirming otherness, the deepened otherness, but also the possibility of betrayal, the revisitation of a negativity that does not negate, but affirms its own negation, its own disappearance. The decision one has to make between "otherness" and "betrayal" is no longer possible: deciding has become full of meaning and also, at the same time, empty and insignificant - another time, perhaps even another temporality, bestowed upon no one, but carried within, carried, as it were, in the "in-betweenness" of having to decide and having decided so many times that it no longer makes any sense to do anything else but decide.

\footnotetext{
${ }^{402}$ P. Virilio, Speed and Politics, New York: Semiotext(e), 1986, p. 38.
} 
The computing/information age, the techno-man, the nano-drive, the pluralist spectralization of political science, all are the effects of deciding in favor of decision, the immediate consequences of having decided and having to decide based on anterior and ulterior decisions, based on the entire fabric of decision-making and on its highly idealized or depreciated sets of institutions and principles. There is no dynamism here and no innovation. Decision is ritualized and decided upon each time there is a need for another decision - change itself seems to be the effect of decision, decision making, deciding. In American political science, decision is the basic coin of the realm, just as surely as the dollar is in economics. To put it differently, decision betrays the very realm it proposes to protect - it backfires on it by transforming it into its shadow.

Not to decide is already a decision, an indirect and negative negativity, a menace of the affirmative, as it were - an inverted negativity deciding in regards to the decisive. To understand this, one should take into consideration the political importance of the mobilization of bias. American critics P. Bachrach and M. Baratz ask: "can a sound concept of power be predicated on the assumption that power is totally embodied and fully reflected in 'concrete decisions' or in activity bearing directly upon their making?" ${ }^{, 403}$ Their answer is a resounding no:

Of course power is exercised when A participates in the making of decisions that affect B. But power is also exercised when $A$ devotes his energies to creating or reinforcing social and political values and institutional practices that limit the scope of the political process to public consideration of only those issues which are comparatively innocuous to $\mathrm{A}$. To the extent that $\mathrm{A}$ succeeds in doing this, B is prevented, for all practical purposes, from bringing to the fore any issues that might in their resolution be seriously detrimental to A's set of preferences. ${ }^{404}$

If decision-making is the apparent face of power, then non-decision-making is the other, more subtle, face of power, which involves, requires and fosters the mobilization of

\footnotetext{
${ }^{403}$ P. Bachrach and M. Baratz, "Two Faces of Power", P. S. Nivola and D. H. Rosenbloom, Classic Readings in American Politics, $3^{\text {rd }}$ ed. New York: St. Martin's/WORTH, 1999, p. 115. ${ }^{404}$ Ibid.
} 
bias. Without a doubt, this is the kind of power favored by the last man.

The last man is the menacing type, the least dynamic, least human: for him decisionmaking is always a decision made in favor of aggrandizement. He is the free type, the man of immediate ends. His archetypal figure attaches itself to the end of "decision", to the production of decision-making environments and institutions, which are always already decided upon, already in line with the spirit of production and its ideological impetus war. According to E. Balibar, this is the ghost that haunts the debates of "new wars", "Long Wars", "global wars", "clashes of civilizations", etc. In his view, the threading of a "complex web of religious, social, ethnic, political, colonial, and post-colonial bloody conflicts into a Hobbsean war of "all against all" is itself "a representation and perhaps a strategy used by a would-be sovereign power which seeks global leadership beyond its actual military and economic capacities". 405

Moving beyond Balibar, we must also note that not to decide is also non-decision, non-decisiveness, the antonym presence of another type of war-making, of another way of saying no to decision-making and decision-processes. In the elusiveness of non-decision (the interval that is neither present nor absent, but mere interval, abstractness, indecision), a decision is made for silence, for absence, for desertion. ${ }^{406}$ The deciding criterion is no longer decision, but indecisiveness, interruption, absence. The ideology of decisionmaking institutions and peoples changes into the ideology of the absentee, the apolitical, the irresponsible. The classical realism of the political (e.g., C. Schmitt ${ }^{407}$ ) versus the

\footnotetext{
${ }^{405}$ E. Balibar, "Strangers as Enemies: Further Reflections on the Aporias of Transnational Citizenship", Palinurus: Engaging Political Philosophy, issue 10, December 2006. http://anselmocarranco.tripod.com/id51.html.

${ }^{406}$ During the Vietnam War there were some 350,000 draft resisters and deserters, mainly draft resisters; as of March, 2006, with no draft, the Iraq War had produced some 8,000 deserters from the U.S. all-volunteer forces. To help staunch this disastrously_debilitating desertion rate, the military police began a new drive to arrest Vietnam Era deserters. This was to demonstrate to current personnel that the passage of time would not exempt any deserter from prosecution. B. Nichols, "Decades Later, Marines Hunt Vietnam-era Deserters", USA Today, March 7, 2006. http://www.usatoday.com/news/washington/2006-03-07-deserter-side X.htm.

${ }^{407}$ C. Schmitt, The Concept of the Political, Chicago: University of Chicago Press, 1996.
} 
romancing of the politicized institution, society, state, religion - this is the very process by which ideology turns into a laborious production of war-like environments and structures.

As I. Wallerstein remarks in "New revolts Against the System": "[t]he modern world-system is in crisis, and we have entered an 'age of transition' - a period of bifurcation and chaos...". ${ }^{408}$ In his view, the world as crisis, bifurcation, chaos, calls for a discussion, or outline, of experimenting with 'alternative structures' - it calls for a 'new revolt', or 'new system'. However, if "the world as crisis" is the softer face of war, it is also the softer face of resistance too: "there will always be gaps - but there is no reason why they should be wide, encrusted or hereditary". 409

The crisis of the political is no longer distinguishable from politics as crisis, from the insolence of having cleared all choices in one decision, in one history of making-decide. All that is happening, all that has happened before is making-decide about what is happening (i.e., crisis, war, anarchy), what happened and will happen in the future. The making-decide is the primary order of Dasein, the inevitable struggle to overcome the condition of "being thrown", the universality and singularity of being caught in the uncanny web of politics, war, culture, and capital. Making-decide is also the order of the quiet, the hidden, the shy order of having to decide for something other than one-self, one's own, oneness. In the quietude of such an order (if it exists at all), the decision that is made is always non-decisive or non-decisional - a line of flight, a resisting alternative, a betraying specter. The problem surrounding it is that it does not fit the 'structure', it is not visible, nor categorizable - it slips out of the 'system' into the shadowy realms of dissidence, desertion, rebellion, terrorism. The categorical remedy is to "invest in area and language knowledge", "promote political and economic modernization", "divide the enemy", "help others integrate the enemy" (as is the case in Europe, with Muslim

\footnotetext{
${ }^{408}$ I. Wallerstein, "New Revolts against the System", New Left Review, November/December 2002. http://newleftreview.org/?page=article\&view $=2420$.

${ }^{409}$ lbid.
} 
enclaves), "build anti-terrorism coalitions", and "prioritize intelligence and police work". 410

In this context, the event of deciding is no longer the event of having decided or having to decide, but a compilation of "decrees", a specter of having already decided and having already resisted the need to decide. By contrast, the event of resistance is also an event of disappearance, a closure of decision, a suspension if you wish, which carries within it an indirect and insincere affirmation of decision, a romancing of decision-making, perhaps, or an eventful nostalgia for what is no longer present. The negativity of decision is the negativity of the event of disappearance, the suspension that is always accidental, always calculated in such a way as to make the political event possible and plausible. Time and time again, the decision that is made for decision-making negates the decision made for non-decision-making, non-eventuality, non-timeliness. In this way, the web of political events is also already the web, or shadow, of their evanescence. As E. Balibar writes: "the political problem seems to be a circular one, and therefore an insoluble one.... The only thing to do is to explore projects and efforts, which would be attempts at untying the knot, in the guise of a struggle against time - without illusions, if not without hope". 411

Time guises itself into a struggle against time in order to avoid a (Schmittean) "final war", which finds resonance in the perpetuation of division and enmity, in the politicized event of politics towards which all decisions are directed, resulting in the ideologization of complicity and betrayal of friends and enemies alike. This is precisely what is deepened in J. Derrida's thoughts on friendship, the ethereal alliance between Faust and Mephistopheles (Goethe); Adrian Leverkühn and Mefisto (T. Mann); the Master and the devil (in M. Bulgakov); the idealist tamed by the devil, turned into its friendly enemy in

\footnotetext{
${ }^{410}$ K. Croke, "Rethinking the War on Terrorism", Progressive Policy Institute, November 2006. http://www.ppionline.org.

${ }^{411}$ E. Balibar, "Strangers as Enemies: Further Reflections on the Aporias of Transnational Citizenship", Palinurus: Engaging Political Philosophy, issue 10, December 2006. http://anselmocarranco.tripod.com/id5t.html.
} 
the gravity and indecisiveness of an irreversible struggle. On a similar note, A. Kojève and L. Strauss argued about the 'end' of a politics of enmity, about the great Platonic schism between knowledge and politics, the great footnote not only to western politics but also to human knowledge, the divide which has always been there as an improbable alternative to the possibility of being. ${ }^{412}$

This schism is the last turning point in the process of decision, the last moment in the becoming other, becoming against, which is a becoming absent, becoming (if only apparently) non-decisive. It is the point at which opposites transgress one another, the point envisioned by J. Baudrillard as the passage of the real into the ideal and of the ideal into the real ${ }^{413}$, the passage of friendship into enmity and of enmity into friendship ( $\mathrm{J}$. Derrida $^{414}$ ), of divinity into man and of man into divinity (G. Bataille ${ }^{415}$ ); of speed into immobility and immobility into speed $\left(\mathrm{P}\right.$. Virilio ${ }^{416}$ ), of practices of control into resistant bodies and of resistant bodies into practices of control $\left(\mathrm{M}\right.$. Foucault $\left.\mathrm{t}^{417}\right)$, of repetition into difference and difference into repetition (G. Deleuze ${ }^{418}$ ), of multitudes into singularities and singularities into multitudes (A. Negri ${ }^{419}$ ), of multiplicities into the multiple and the multiple into multiplicities (A. Badiou ${ }^{420}$ ), of (neuronal, psychological, bodily) structures into language and language into structures (J. Kristeva ${ }^{421}$ ) - the moment at which a decision is always a non-decision, a betrayal, a resistance, a singularity - or a form of friendship?

These multiplicities, these moments of the singular and resistant, constitute the decisive/indecisive specter, or rather the decision-making/indecision-making processes, the

\footnotetext{
${ }^{412}$ L. Strauss, On Tyranny, Chicago: University of Chicago Press, 2000.

${ }^{413} \mathrm{~J}$. Baudrillard, Simulation and Simulacra, Ann Arbor, MI: University of Michigan Press, 1994.

${ }^{414} \mathrm{~J}$. Derrida, The Politics of Friendship, New York: Verso, 2005.

${ }^{415}$ G. Bataille, Theory of Religion, New York: Zone Books, 1992.

${ }^{416}$ P. Virilio, Speed and Politics, New York: Semiotext(e), 1986.

${ }^{417}$ M. Foucault, Discipline and Punish: The Birth of the Prison, New York, Vintage, 1979.

${ }^{418}$ G. Deleuze, Difference and Repetition, New York: Columbia University Press, 1994.

${ }^{419}$ A. Negri, Time for Revolution, New York: Continuum, 2003.

${ }^{420}$ A. Badiou, Metapolitics, London \& New York: Verso, 2005.

${ }^{421}$ J. Kristeva, Portable Kristeva, K. Oliver, ed., New York: Columbia Press University, 2002.
} 
consciousness of having made and having to make a decision for or against decision. The inescapable version of escape, the turning point at which Kant no fonger has any say in the affairs of the future, except perhaps for the escaping alternative of the inescapable, the alternate, the double, the hidden, version of the continuous, the decided and the visible. The three-dimensionality of power relations, the always too complicated, too implausible version of the one and the other, the one and the few, or the many, intertwine in the incommensurability of a common and unique possibility of being, the possibility that is neither here, nor there, but always already gone, already of the future and/or of the past.

It is in this sense that all theories of power struggle with the possibility of politics as a particular art of governing people, a singular version of so many possibilities (as in Levinas $^{422}$ ), a variation so dangerous that it requires the assistance of time, or at least the opening of a passage from one moment to another, from interruption to acceleration, from stasis to movement, from singularity to multiplicity. It is in this uncertain and unstable passage that practices of resistance find their expression by deconstructing and genealogizing practices of power, by arresting and accelerating their passage through the uncertain and unstable variations of distinct timeliness.

None of these practices could make sense without the assistance of time, without the passage that begins in time and is always towards time by way of distances, indirections and oppositions, by way of an odd temporality, an odd change of rhythms and appearances of time in and through time. The variation in time is the variation of the passage through time, the always improbable and complicated version of setting up a stage, a theatrical masterpiece, a scene of struggle, in which each movement is connected to the others, flows into, intersects, interrupts, them in new ways - atemporal perhaps, without time, or hope.

The turning point of the passage or of politics (of the passage) is this apparition of

\footnotetext{
${ }^{422}$ E. Levinas, Entre Nous: Thinking of the Other, New York: Columbia University Press, 1998.
} 
time in and through timeliness, the uneventful variation of the passage of time against the event of power, against the immobility and imponderability of power. Resistance falls into the genealogical, into the eventful and mobilizing - it is singular in this respect, but also already reverting, already roman(tic), or rather anti-roman(tic) in its function. Practices of resistance are not atemporal, they work backwards, from the debtor to the creditor, from the condemned to the condemner, from the prisoner to the executioner - another dimension altogether, another variation of genealogy, struggle and complicity, another temporalization of the passage in and through time. Resistance is the unfolding of an already folded force, the strengthening of the other possibility, though it is never that which it seems to be, but always another, distinct, changing. The multitude is this force unfolding asynchronically, this seeming possibility of otherness and change, resistance and power, possibility and event.

The relationship between power and multitude is a relationship of struggle and collaboration, folding and unfolding, singularity and multiplicity, which is, according to Bodin, an essentially monarchical relationship. ${ }^{423}$ The reduction affects both politics and knowledge by modifying their telos and their axes of operation, their unfolding and anamnesis, the very point of departure and return, the destination, if one wishes, and the starting point of the operation of reduction. There is a centrality to decentralization, a decentralizing centrality, a sort of platonic ring of invisibilities drafted around the reduction of politics to knowledge and of knowledge to politics, an (inter)mission of force in the folding and unfolding of concepts at the same time at which the concept (of the fold) intervenes in the folding and unfolding of forces. The evanescence of power is simultaneous with the evanescence of knowledge, they both succumb to the force that folds and unfolds them unconsciously and unintentionally.

${ }^{423}$ J. Bodin, Six Books of the Commonwealth, Oxford: Alden Press, 1955. 
Theories of power are essentially theories of the relationship of force to force, of the unfolding of force in and through successive or diachronic folds as well as of its folding in and through sequential or synchronic unfolding. The middle ground between them is always a force that is simultaneously folded and unfolded - a politics in movement, a nomadology. The force that is folded through practices of control is unfolded through practices of resistance at the same time at which control unfolds its own betraying power and resistance folds its controlling power. Power as relation of force to force (to paraphrase Foucault), is always power to fold and unfold opposing forces, to betray and assist them in becoming powerful, potential, possible.

Control of force by force, resistance of force against force - the modern formula for power - involves the impossibility of the possibility of power opened up in the wake of post-modernity: itself a force, an impossibility, a powerful experiment against power as such. Power as a controlling relationship versus the power of betrayal - the collaborative and conflictive sides of the same coin, the sublimated and destitute faces of a sovereignty in the making. Also, the sameness that splits into a multiplicity of power relations, into a whole that is power through struggles, ruptures, and interruptions, rather than through continuity, homogeneity and concert - the variation that is neither possible nor impossible but always already here, already struggling and powerful.

The decision concerning power is a decision concerning the politics of force (i.e., folding/unfolding), the temporality of the atemporal or rather the relation between the temporality of power and its atemporality, its going beyond the present, beyond the power to control and betray the web of human relations. As has been stressed so many times, politics is no longer about passion (to such an extent that it becomes ludicrous to raise the question of passion), no longer of an amorous or befriending nature (if it ever was), but rather of another nature, one much more complex perhaps and always difficult to untangle. 
We can find its imprints in the current reduction of politics to the processes of socialization and politicization, in the reduction of politicization to the vulgar psychologization of the citizen, in the further reduction of the citizen to the producing-consuming unit, the number, the machine or the laboring tool, which make up the simplified, ordinary, map of a politics that is no longer political, but has been de-politicized, interrupted, emptied. When F. G. Hoffman stated that "we do not face a range of different and separate boxes, but a combination or blurring of forms and means of war" ${ }^{, 424}$, he rushed ahead, concluding that "we have to be prepared to face this adaptive enemy, be equally prepared to out-think and out-adapt an elusive opponent". 425

This rushed projection of the politicizing process into the blurred terrain of elusive threats and enemies, the extra-mundane character of the citizen, the uniqueness of the working class, the numbers numbered in such a way that numbering suddenly becomes amorous, or the machine becoming a futuristic promise, deepen the process of depoliticization, the reduction to, or the inevitable subduing of politics by numbers. This syncope of power also entertains the passage from one extreme of the political specter to the other, it entertains the passage in and through the complex fabric of time, which is the most elusive and most concrete manifestation of the political. The ontology of the political, "the reduction of the Other to the Same", as P. Ricoeur puts $i^{426}$, is unthinkable outside this syncope, outside a genealogy indebted to power, which is neither deconstructive, nor generous, but political through and through. Ontologically, the political is situated within and situates power - the phenomenon of power constitutes and is constituted by the political, or power goes beyond itself in the political.

The syncope of power is also the syncope of the political (insofar as the political is

\footnotetext{
${ }^{424}$ F. G. Hoffman, "The New Normalcy", E-Notes, 2006. http://www. fpri.org/orbis/.

${ }^{425}$ Ibid.

${ }^{426} \mathrm{P}$. Ricoeur, The Course of Recognition, Cambridge \& London: Harvard University Press, 2005, p. 158.
} 
the state, in the Schmittian sense), the inevitable passage from reduction to extrapolation, from locality to globality, from project to projection (with the Nietzschenean emphasis on experiment), which is sabotaged by the simultaneous retreat from extrapolating maneuvers, from globalizing trends and expansive projections. The retreat commences, in turn, another expansion, another conquest - the inevitable passage from here to there, from the proximity of the friend to the distant appearance of the enemy, which is no longer what it seems, nor what it does not seem, but something entirely different, something which is not yet there, not yet conquered or conquerable. The figure of the enemy is no longer the counterpart of the friend, no longer the symmetric face of the political reduction, but something irreducible to friendship, or to enmity, something which is no longer political but undecipherable and chameleonic, the sort of apolitical apparition that one discovers in the Homeric hero, the priest, or the courtly fool.

The turning point is also the point of no return, the moment of decision, as it were, even though there is no decision to be made, but only a deciding upon, which has already taken place somewhere else, for someone else, someone whom we know only partially, and only by exaggeration, by extrapolation, by going beyond this moment in which things begin to unfold in a decisive way, perhaps favorable, perhaps not. Maybe indecisiveness is the mark of the decisive, the imprecise precision with which science measures its objects and tells us what they are, but also the indiscreet discretion of the other, the multitude of erring gazes and gestures that end up in the sanctuary of our knowledge. Maybe decisiveness is also the mark of the undecided and the old Aristotelian saying - "friends, there is no friend" - might have already changed into "friends, maybe there is no friend". The interrogation brought forth by doubt is already an answer, already in doubt, doubting its own provenance and truth. Friends, there is no truth about friendship except this "maybe" which raises the question for us, the singular, ordinary, question of being friendly 
- in truth? As a possibility, this friendly "maybe" immediately threatens the political. In its extreme, the possibility is also ripe with impossible propositions - the Derrida of another century?

To what extent is the syncope of power also a syncope of powerlessness? Powerlessness discloses itself as the interiority of power, the emptiness placed at the heart of politics to conjure or avoid certain events such as the mythical function of war, or the incarnation of a certain narrative. For now, the interchangeability between power and powerlessness, or between function and narrative, is just another possibility, another syncope of the real.

It is a syncope that begins by ending things, by an ideological mutation of myths and origins, myths of origins, or of the very beginning one chooses in place of an end. Reality appears different, always privileged or paramount in relation to functions and narratives, but also already unprivileged and indistinct from its own story. The imperial real is made up of two stories - one ending by beginning things, the other beginning by ending things intertwined in a double politics of the double. This is the inevitable syncope of the political narrative, always theatrical, productive and dull. Always resting on excusable beginnings and ends, always fertile for a politics of the double, the triple, the quadruple - the multiple? Is this a politics of the narrative, the double, the virtual, as opposed to real politics? Is it the end of the beginning, or the other way around? Does it matter?

To this troubling question we must now turn, by way of a re-visitation of the allpervasive narrative of power, or, as one might expect, by way of a seductive detour indebted, as all such detours are, to the very circularity, or imperiality, from which it strives to escape. 


\section{Chapter 12}

\section{The Narrative of Power (or the power of narration)}

If, on the contrary, power is strong this is because, as we are beginning to realize, it produces effects at the level of desire - and also at the level of knowledge. Far from preventing knowledge, power produces it.

$$
\text { M. Foucault } \text { F27 }^{47}
$$

\section{Let us finally free ourselves of the seduction inherent in our vocabulary!

$$
\text { F. Nietzsche } 428
$$

Is it possible to live beyond definitions, beyond the power and will to define, to inscribe and circumscribe the one within the other and the other within the one? Is it possible that one may already be the other and the other one, the past in place of the future and the future already passing? In the narrative of the narrative (of power) everything seems possible, even more than that, everything is possibility, potentiality, virtuality, inasmuch as all possibilities and potentialities are already narrated, already consummated around the narrative, in and through it, through its dependence on definitions and inscriptions, markings and circumferences, as signs and dis/enclosures of absence and fullness, void and presence. The narrative of the already narrated, already finished and abstracted, the beginning (or end?) operating in and through the abstraction of abstraction, removed from all reality, from all beginnings (and ends?), and hence from all narratives this is power without a narrative, power pure and simple.

This is also the backwards movement of a logic commencing with its own narrative, with its own definition and need to justify itself through the reversibility of thought as well as of feelings - the reverse. Always the reversed order of what appears in front of us,

\footnotetext{
${ }^{427}$ M. Foucault, Power/Knowledge, New York: Pantheon Books, 1980, p. 59.

${ }^{428}$ F. Nietzsche, Beyond Good and Evil, Chicago: Regnery, 1955, p. 17.
} 
behind us, or within ourselves: the "other" as complement, as substitute or copy which is never in the same place, never quite the same, nor completely unrecognizable, or separated, but joined together through rupture and disjunction, identity and repetition - a specter without power, without a narrative as it were, which is unique in its absence, perhaps even in its silence. But what is the connection between this joining specter and the narrative that we attribute to power? Is there something that separates and unites them indistinctly?

The narrative of power, as Derrida would argue, is precisely this joining specter which becomes disjointed, expelled, identified with "the other", the stranger, the outsider, the hermit. The ghost of the other, or the ghost of otherness, bends and unbends its time by being placed in the interiority and exteriority of power, by being around, in and through, power. The other as narration has the power to bend the otherness of the other, but also to violate and annihilate it, to unveil the specter of power as narrative, or the violent incursion into the sameness of otherness. The weight of the narrative is also the weight of power of and over the other, the power to fold and unfold a certain possibility, a certain timeline or course of events - a certain specter.

Every regime of power is thought to posses or produce a certain knowledge, a certain culture or cultural affinity between social and political forces, as Kenneth Burke avers: "and in this staggering disproportion between man and no-man there is no place for purely human boasts of grandeur, or for forgetting that men build their cultures by huddling together, nervously loquacious, at the edge of an abyss". 429

All the apparatuses and mechanisms of the state, of society, rest on this affinity of relation, on this rupture and joining together of powerfully narrated and narrating forces, on their struggles and collisions, on their power to assemble and disassemble by virtue of

\footnotetext{
${ }^{429}$ K. Burke, Permanence and Change, Los Altos, CA: Hermes, rev. ed., 1954; quoted in B. F. Ryan, Social and Cultural Change, New York: Ronald, 1969, p. iii.
} 
their affinities and dissenting lineages. Indeed, power entertains its own regime of truth, but also truth produces its own forms of power, its own otherness based on the strange association with and dissociation from simultaneous cultural and political formations. The interplay between thinking and acting, understood until recently as the battlefield of modern consciousness against the primitivism of emotions, no longer concludes itself as the Schopenhauerian will to representation, nor as the Nietzschean will to power, but rather as their juxtaposition, as an unexpected precipitation of the will, or an empty framework, as $\mathrm{H}$. Arendt would say, but also as full spectrality, concreteness, substance.

This inseparable being of being, this human novelty of thinking and acting in and through the will, in and through its representation and power, folds itself indefinitely over and against its own lack of representation and power. It folds itself against its own narrative as it were, against its own absence, or suspension. This inseparability of will and representation, will and power, Platonic in its being suspended, being absent, remains Platonic in its separation as well, in its becoming other, or becoming represented. However, one representation is never reducible to the other, never quite the same, nor comparable. They retain their singularity while reinforcing the specter of their relations, the multiplicity of forms of power and of (in)forming narratives. This spectral multiplicity, this simultaneous refraction of thinking in acting and of acting in thinking, which is called power, or rather the power to act (in and through thinking) and to think (in and through acting) singularly, uniquely, has its own narrative, its own specter and ghosts. Its power has its own narrative, its own way of threading and weaving itself in and through knowledge, as knowledge.

The view that a narrative spells out fictional, or utopian truths is reductionist and pretentious, or rather negatively charged. It makes of the narrative a dull production of 'official' truths by setting it against an ideal, utopian, version. In this sense, literature is 
fictional, physics is fictional, even politics is fictional. Fiction itself becomes a fiction, a narrative giving up its truth in favor of an assemblage of concrete, or lucrative, falsities. The power to narrate, like the power of fiction, rests on the negativity and positivity of its charges, on their capacity to assemble and disassemble positive and negative instances. Beyond this point of intensity and terror, the narrative loses its power, perhaps even its truth, in such a way that it becomes indiscernible from fiction, indiscernible from the enchantment and disillusionment of fictional/powerful encounters.

Reality (as encounter between power and fiction) becomes fictional, narrating and falsifying (J. Baudrillard), but also true, valorous and powerful, the kind of narrative that is no longer anything else but narrating force, simplicity, command. This reduction of the narrative's specter to the beginning of the act of narrating, to the fictitious moment when the force of the narrative begins to unravel its own possibility, its own reality, as it were, supplements the extroversion of that force, its raveling within the possible and the real, its variation and vacillation within their possibilities and realities. The plane of the narrative is the spectral plane of forces, the (in)fraction of forceful struggles and disappearances, of interruptions and continuities: the spirit of power, its memory and its unfathomable secret.

It is somewhat odd to brush over the possibility of a coincidence between power and narrative, acting and thinking, to brush over the point of their departure, the point at which life ceases to make sense by making too much "sense" (H. Arendt), ceases to have a direction by having too many, or to move by moving too rapidly (P. Virilio). The eventuality of a coincidence suffices to brush it aside as just another apparition of the aporetic, another otherness of the other - a lucrative contradiction. But hasn't this contradiction been sought in order to be mediated, synthesized and tranquilized? Hasn't it been brushed aside as just another impossibility and/or (im)posture of the possible? The reduction of the narrative to fictive apparitions is this brushing aside, this extroversion of 
and encounter with the possible, this irresistible quest for the otherness inside, which is none other than we, us, ourselves.

"The whole man is ontology", ${ }^{430}$ writes Levinas, the whole man is us, we, ourselves in the ontological wholeness. The turning point for $u s$ is this statement, this Hegelianism of the absolute, or Hegelianism at its absolute, this commencing by going back, by ending and by going back to the possibility of unending, of eternity, infinity, death. It is also the most volatile incarnation of the political, the most profound atheism of the religious, or religiosity of the atheist, the secret passage from one to the other, from religion to atheism and back, always backwards, always proceeding by looking backwards in order to look forward, to project (or provoke) a thought, a world, a future, through an encounter with the unthinkable, the unworldly and non-present. Through this provocation one conjures the unthinkable, or rather the unthinkable is this provocation to advance by thinking backwards, to become an atheist by becoming religious, to be unfaithful by being faithful, to betray by being loyal - to oppose wholeness and thus become whole, to make in this way a detour, a loop, a sudden move towards the other, towards the "I" as other, or, as in Levinas, towards the other as "us, we, ourselves".

The limitation of (this) fictional $u s$, we, ourselves in the other, the narrative narrating our intuitions and thoughts, our desires and feelings towards otherness, also limits the other to us, we, ourselves, narrating the fiction of selflessness and togetherness. There are no friends and enemies, friends and enemies! We, us, ourselves, have been brought together by neither friendship nor enmity, but by the thread of their narratives, by their substitutes and copies - by their ghosts. Now, there is something odd about saying that, something which is not quite right, not quite accurate, but somewhat wanting and misleading. The story of story telling, the action and the name, the speaker and the listener, the $u s$ and the

${ }^{430}$ E. Levinas, Entre Nous: On Thinking of the Other, New York: Columbia University Press, 1998, p. 2. 
others, are both entangled in a web of deceptions and truths, both deceptive and true, but also moving beyond deceptions and truths - we see them as the zarathustrians of the future, Nietzsche's zarathustrians, ripe for the disillusion of all illusions, for another type of alliances and betrayals, or another Promethean engagement.

And yet there is something not quite right in this precipitation of the story towards story telling. It entails the excruciation of the narrative, the excruciation of the personage the drama of the present, which is also already gone, already apparent, or even common. Our own thinking stops here, grappling with its impossible nature, with its Kantian thrill of being in two places at the same time, while also being nowhere: a thought external to all narratives and all illusions, external to itself and its cause. In the exterior of the interior, thought ceases to be, it ceases to contemplate or narrate its disappearance, and gets bored. Obviously, there is no narrative here, no passion for it, only boredom, fiction, entertainment. The narrative, our narrative, no longer makes any sense, for there is no possible rhythm, no possible passion that can be attributed to boredom except the passion for passion, for the uniqueness of passion as it were, or for its absence.

There where narration ceases, the narrative of ceasing, sizing, ending, replaces tradition, it replaces itself by another, as it were, by a friendly or inimical undertaking, a construction. J. F. Lyotard insisted on the coincidence between narration and tribal identity, between naming and being named in and through the narrative. ${ }^{431}$ Men belonged to the tribe due to the power of the narrative, they were brought together based on their having heard the narrative so many times that it had become one with them, one with their name and their community (of names). This is the classical model of citizenry, the model that runs its course from Aristotle through Rousseau, in and through our time, in and through our narratives on classicism, citizenry, Aristotle, and so on. It lives in them,

\footnotetext{
${ }^{431}$ J. F. Lyotard, The Postmodern Explained, Minneapolis: Minneapolis, MN: University of Minnesota Press, 1997, pp. 43-47.
} 
through them, just as much as they live in it, through it. The event of the narrative lives in the narration (incarnation) of its event, and they both become entangled, intertwined, inseparable - this is how the story and the personage, or rather the story of and for the personage become indiscernible.

The indiscernible model of the future belongs to this suspension, to this ending and inevitable exhaustion of all identities and narratives. It is a non-model, a non-presence of the present, of us, we, ourselves, but also a going beyond narration, beyond its moment of definition and exegesis, beyond all probable definitions and exegeses of the present within and without ourselves. The moment of the future is also this moment, the beginning of imperial power perhaps, or the end - who is to tell? The uncertainty of this literary "who is to know?" is already gone, already spreading its wings over the space of the future - itself a story, an unfolding, ethereal story of knowing and being known, speaking and being spoken of. In the guise of the imperial narrative there is the future relating back to us, to our narrative of the future, of ourselves, or of our own space.

In what way can one predict the disillusionment of the future, the exhaustion of the narrative, the decisive moment for the syncope of power? In what way: in which narrative, which one of its powers? And then again, silence falls. It befalls $u s$, we, our-selves. It befalls the future in and through us. Perhaps today, perhaps tomorrow, no one really knows when and why. But who needs to know? The present is being politically narrated at the same time at which it politicizes its own desire of being or becoming political, in this moment, or in this future. The relation between the present in the future and the future in the present is commensurate with the absence or presence of the narrative (of the political), of time itself in the form of present and future, in the form of narrated moments and powers, in which we encounter the passage from one to the other as a common $u s$, we, ourselves. 
The ideal is this encounter with ourselves in the absence of the other, in this absurd silence of the future, or even of the present. It is no longer the narrative of the present but of a political us, we, ourselves - the return of Narcissus in and through his repudiation, the return of doubles. Ideality, the ideality of the present in any case, is this narcissistic tendency to fall in love with oneself in and through one's own image, here, in the silence of the future, in the complete silence of thought, which is our silence, our tendency, our time. The return of Narcissus calls forth his selfless disappearance, his evanescence from all surfaces and all times, his final act - the last encounter between man and his image, between loving and being loved, between the original and the copy.

Narcissus as selflessness, renunciation, and forgiveness is Narcissus as antidote to narcissism, to selfishness and self-love. The last man, the first, the middleman: the divinity of the secular, the divinity of love, loving, lovence - in the end love of the beginning, in the beginning love of the end, and nothing else, nothing, absolutely nothing else. There is no trace of hatred, no enmity, no divine imperative other than lovence; there is, in and through this lovence, only friendship, friendliness, friends, only proximity, certitude, continuity. There is simply a collaborative history of the narrative, history of/as friendship and amor fati, history in/of the future in and through lovence. This is the beginning: loving the end and/at the end of loving. It is also a revisitation, an end reaching back, a loving of the beginning, a beginning of lovence. One has to read Derrida, into Derrida, through Derrida. There is nothing else there, but reading, lovence of reading of the future - lovence proper.

To the ideal stands opposed the real, the realistic sage, the befriending enemy who is no longer friendly, but wise, ecclesiastically and piously wise, the man of lesser words and many deeds who loves the enemy and envies the friend, the man of today: the other of/in us, we, ourselves. In our imperial age the terms are all reversed, revalued, recalibrated. 
Like a woman, the sage means love in place of hatred, hatred in place of love. His aim is always the other, the not-here-yet, the ideal. Being wise, being in and through the ideal being the ideal (illusion, fiction, narration). The fool is wise! So is the enemy. The other: the not-here-yet. There is an affinity between them, an ideality of wisdom, a possibility slipping between them as if in passing, or in return. It catches our attention precisely because it slips in between, as if in a dream, or a ghost story.

As Derrida tells us, there is love, credence of love, lovence. Their narratives establish the relation between me and you, us and them, the relation between wisdom and foolishness, wisdom and madness - the end. Such a narrative of the end is always full of wisdom, always mad and foolish, a narrative of loving, of the lovence for the other, or of the mad love for being other, in and through oneself. There is no end to it, properly speaking, madness, foolishness, wisdom, do not end, they always begin, they are always already there in the beginning and always there in the end, masking and unmasking themselves in and through their own attributes. One is tempted to go into details, but there are no details, there is no finality and no precision to these attributes, because they belong to chance, to themselves, to the future.

One is also tempted to seek to recuperate what is lost, to delve into depths - but there are no depths anymore, no tempting losses. This is the maddening thing about life, about love, about the tragedy of being caught in the web of the political narrative, or about the privilege of unraveling it in and through ourselves, through our being wise and mad, wise and foolish. There are no real tragedies anymore, no sense of the tragic, no terror of the tragic, but only politicized narratives unfolding tragically and terroristically in and through our wisdom. The depth of the narrative (of love) is the depth of this tragic and terrorist feeling of being wise by being foolish and mad, foolishly and madly wise and tragic. In the end, there is only foolishness and madness to wisdom, only that which appears to be 
foolish and mad, fooled and maddened in and through the privilege of being wise.

The condition of wisdom is the condition of tragedy, the commemoration of life while living, the lovence of love while dying - not necessarily a contradiction in terms, nor a dilemma, but simply being in this way rather than in another - a deadly insufficiency, or a blessing. This condition is also a rejection, a negativity that is twice negated, twice turned over and denounced in the face of otherness - the mad are not mad, the fools are not foolish, the wise are not wise. The trace of the negative, the maddening madness of not being mad enough, not being foolish enough and so on, involve the return of wisdom proper, but also of foolishness and madness. The narrative of being in and through the negative - this is the wisdom of fools and mad men, the wisdom of being wise indirectly, that is, through another insufficiency, another blessing. Being wise means being both mad and foolish, betrayed and loved, unhappy and happy - a sorrowful god of wisdom. There is no power here, only a mere politics of sorrow.

The narrative of wisdom speaks of power without attaching to it any concrete measure, without attaching it to any particular mechanism or apparatus (as in M. Foucault). It speaks of power universally, as if it were a common aim, a common denomination of being and living in society, a common undertaking for the rulers and the ruled - two estranging forces, perhaps wiser, friendlier, happier than they seem. The event of resistance to power is the event of an inversion, the uninterrupted moment of resisting and feeding the violent specter of wisdom - in and through resistance one makes up the map of a new politics, the impressive map of a bio-politics of the other, the irreconcilable and irreversible order of the other of power. What obtains is the logic of being (or seeming) powerful versus the madness of resisting power, techno-politics versus the bio-politics of power, the macro-politics of power versus the micro-politics of betrayal.

Resistance justifies power, bio-politics justifies techno-politics and so on - there is 
no telling whether resistance is the measure of power or power is the measure of resistance, for now, they both seem to be driven by the same desire, the same abstraction of effects and causes. The asymmetry of their relation is overcome by this sameness, by this imperturbable balance between causing and effecting, repeating and differing, controlling and escaping. The power of resistance is the power of power, power turned against itself, against $u s$, we, ourselves - the power to resist the use of power, its drive, its tyranny. But is it techno-power, bio-power, or economic power, that we speak of? Is it another? Other? They? But who are they? Who is the other?

These question do not help, they are no longer the questions to be put to politics, no longer questions of power, for we are all "the other", in and through the other, or in its place; we belong huddling together in the otherness of the other - we, us, ourselves, the ones in the others, the others in the oneness that is us. Like friendship, power invests us with a desire for the other - the other as a relation of power through friendship or of friendship through power, each being the imaged correlate of the other, the possibility and the impossible alternative of the other, the moment at which power ceases to be something other than friendship and friendship ceases to be something other than power; in truth, this is the moment at which power and friendship become indispensable to one another, or to us.

The moment of questioning is the moment at which the Aristotelian saying: "friends, there are no friends" is converted into the Nietzschean conclusion "enemies, there is no enemy". If there are no friends and no enemies, there is no power (C. Schmitt), and if there is no power, there is no world - or the world that exists in the absence of friends and enemies must be a divine world, a world without the bonds of friendship and enmity, a world without bounds or borders, a perfect space traversed by nothing but its own perfection. 
The decision concerning politics is a decision concerning the divine as the absence of choice, but also as the only choice, the only answer to the friend-enemy distinction - to the distinction between being a friend and/or an enemy, of being close and/or at a distance. The choice that is made (for instance in Derrida) is the lack (or death) of choice, the friend that is also an enemy, close and far removed; the political and/or the apolitical choice that is indifferent to being here or there, to being friendly or inimical; the choice that synthesizes Aristotle's affirmation with Nietzsche's nihilism into a new aporia:

"Friendship with God is no longer possible because of his remoteness or separation. Presence of proximity is the condition of friendship, whose energy is lost in absence or in remoteness". ${ }^{432}$ he is ...".

"...friendship wishes me to love the other while wishing that he remain as

"..the man of friendship, qua man of virtue, should nevertheless resemble god". 434

The lack of choice is the residual aporia of another time, but also of our time, which is now without choice, without a real possibility. In this respect, Derrida comes closer to Heidegger than he might have wished, closer to Schmitt as well - or perhaps as far removed from them as possible. The impossibility that up until now seemed a matter of style, is now the only variation that might get us somewhere, the only version that is neither friendly, nor inimical, but simply a way out of the aporia of friendship, a delay, perhaps even an absence which is also already a presence, a preference, a prejudice. Indeed, the whole affair of the political seems prejudiced, personal, intimate, an affair of the heart, impossible to solve, impossible to predict, and so even more intriguing, even more lovable.

It is an event of the other, of the friend and the enemy, of their relation to us, to the event that is us with or without them, with or without their authority. They are as much

\footnotetext{
${ }^{4.32}$ J. Derrida, The Politics of Friendship, New York: Verso, 2005, p. 222.

${ }^{4.33}$ Ibid., p. 223.

${ }^{434}$ Ibid., p. 222.
} 
part of us as we are part of them, they are us inasmuch as we are them, the friendly enemy and the inimical friend, the division and the unitary self, the others in us, the eventual friends instead of enemies, the future enemies instead of a friend for $u s$, for we-ourselves. In this eventuality there is no other solution, no other variant, but the friend that is now an enemy, the enemy that is now a friend - the $u s$, we, ourselves that no longer has a precise name, nor a place, but simply has named them friends and enemies, relations of friendship and enmity, the web of which is the world, the eventual world of possibilities and errors, of friends and enemies without names and places, without other friends and enemies except us, we, ourselves.

The illusion is complete, the version always a version of itself as another, other, they, the remote version of another $u s$, we, ourselves in which there is no name given to us, no place, but rather an ethereal appearance of amicitia and/or inamicitia, a future without a present, another dimension perhaps, or another passion. In this suspension in which we find ourselves without friends and enemies, there is no other possibility than them, the friends and enemies that are not here yet, and yet we already know them, we have already met them.

This occasion and this occasion only leaves room for the possibility of another, the remote possibility of being in and through the other, which is not us, we, ourselves. This is the moment at which the friend that we have becomes the enemy and the enemy becomes the friend, approaching us one last time, to let us know that $u s$, we, ourselves turned into something entirely different, something without a name, a place, or a presence. This "one last time" is not conceivable in any way; it is not even plausible. It is, perhaps, the least possible path, the least possible, and yet, we conceive of it, we even lay it out as if it were never a real possibility, never a real path that one might follow. This moment, the moment that is here and not here yet, the very moment at which we speak by keeping silent, is the 
other of/as possibility, the other of otherness, the remote and reversed order of being, or of being other than the other who has a name, a place, perhaps even a familiar presence.

This possibility of the impossible is silent, always silent and empty, surprising, dreamlike. It is the least resistant, least plausible, least traceable, path - the path that is traveled by thought, the thought of the other, of being in and through the other, not as the other, but in and through it, as if in a dream, or a trap, always in one or the other, always already in both, silencing them, silencing us. We may view the nomad as the most distant other, also as the closest friend or enemy, as the indecisive faith of another, in another - the shocking possibility of a warrior $u s$, we, ourselves, the nomadology of another future, or another version of the future. The silence of the path is also the silence of the trap, the dream, the silence of being caught in two parallel dimensions at a time when there is no time, no dimensionality, no subtlety, but only silencing temporality and simplicity, silencing paths of a time without time, or a time out of joint.

Yet, there is this possibility of an impossible time within time, the dimension of parallelism and subtlety, of paths traveled in advance, scorned paths, noisy paths, complex, uncanny, perhaps even atemporal, but no less real, no less opportune and promising. The marginal is encountered here, the rejected, the unfriendly version of the friend - all possibilities, or copies, of being other in and through us, we, ourselves. The sovereign is this unfriendly version of the friend, the marginal caught in the dream or trap of its own centrality, the mythical figure of another temporality without time, another dimension of being $u s$, we, ourselves. In this encounter between marginality and sovereignty, between the marginal and the central us, we, ourselves, there is another possibility for us, for them, another encounter, another time within or without time.

The principle of narration is the principle of this tremendously problematic $u s, w e$, ourselves - the principle of power, the immediate encounter between the marginal and 
central $u s$, we, ourselves, the very possibility of being in and through the other, for and/or against it, for and/or against us, we, ourselves. One is when the other is not, or where he is not. The name, the place, the presence that is other is never without $u s$, we, ourselves, never quite distinguishable and separable from our name, our place and presence. It is this coincidence that interests us, this impeccable superimposition of us and them, you and me, which commences without delay and passes from one to the other as if in a dream or a trap, as if in another time, another dimension altogether. No one could tell the difference, no one could ever suspect that we are not them or they are not us, just as you and me denominate something which is not you, nor me, but a distinct "we" taken together in the spur (or faith) of the moment.

This is the vortical movement taking us from here to there, without ever leaving our place, without ever reaching a destination, other than this place of ours. It is a vortical movement taken over by the sentiment for the other, by our lovence, our friendship, which is as yet not here, nor there, but vorticing through here and there in search of itself. The encounter between you and me is this vortical movement in and through which we search for our selves in the openness of space, in its presence as it were, or in its name. In this order, there is no longer any sense of space, no longer any sense of belonging - we come from here as well as from there, or from anywhere else, without the protection of privilege. We are all in one place, under one name, in one indivisible presence. In this hypothetical order, there is no you and me, but us, we, ourselves, the collective us, the collective we within our-selves.

The narrative of this collective we is no longer the domain of ideology, no longer under the spell of ideological typologies, but makes itself into another spirit, another spirituality of the collective, another movement in and through $u s$, we, ourselves. The worker as the spirit of class division is no longer the type of the future, no longer the 
fundamental cause of division among "us", his divisiveness operates in and through constant coming together, in and through $u s$, we, ourselves. He is no longer localizable, no longer "in bonds", but already moving, movable, moved, already another within ourselves, already indivisible. The collective is this indivisibility of/as spirit, this non-place, or non-presence, which is the other and yet us, we, our-selves.

In this sense, there is no longer any individuality apart from the collective. The collective is already individual, already singular in the plurality of coming together and moving out of bonds. The spirit that is individual by being collective, singular by being multiple, narrates itself in and through the presence of collectivity, and in and through the singularities of individuation. The collectivization of the singular is complementary to the individuation of the collective, adverse as well, perhaps even deadly. In this process of exchange, in this secular barter between akin spirits, the collective is already singular and the singular is already collective, so much so that exchange is already impossible, already multiple and singular to such an extent that it no longer exchanges anything except itself, its multiplicity and singularity, its being in and through us, as if in a dream or a trap.

The narrative of the collective is the narrative of the singularity trapped within, the narration of a dream, the moving away from that dream or from that collective dreaming that is singularized and trapped, collectivized and narrated. Conversely, the narrative of the singularity that is $u s$, we, our-selves is the narrative of the collective, the narration of a trapping move, the coming together of that dream which is the collectivity of mankind, the singular collectivity that is narrated and trapped in and through a dream - the dream of the collective $u s$, we, ourselves. The power of the narrative is the power of the collective in the singular (or of the singular in the collective); this is the power to collect and dream, to trap collectivities and dreams as if in a singular fashion, in a singular gesture of exchange and salvation, collectivization and narration. If there is no narrative without power and no 
power without a narrative, then in the collectivity of power, of narrative power, of collective powers and narratives, there is no sophism without sophists, no succession of terms which is not also an inversion, a genealogical attempt at turning the power of the narrative into the power of the collective and vice-versa.

There is no trap here, no entrapment other than the collective as such. The preservation of the collective is its power, the power to subsist, to dominate by subsisting. All narratives are narratives of subsistence, hence of the collective. Directly or indirectly, the collective narrates its own subsistence, its existence in and through the power of the narrative, in and through the singularity of its power. The folklore of the collective represents the genealogical tie with the collective us, we, ourselves, with the preceding or the (be)coming us, we, ourselves. We are not here anymore, not here yet, this is how we exist collectively. This is our narrative of how we exist, of how we come together and depart, narrating this very possibility of coming together and departing in and through the collective. This is how we exist collectively in and through the narrative, how we narrate our existence in and through the collective that is us, we, ourselves.

At the center of the narrative there is always the other, the shadow, the friend, the enemy, the ghost that is not of this world, not of this narrative, but of another, perhaps better, or worse, a narrative for better or worse, a narrative about the friend who becomes the enemy and the enemy who becomes friendly, most loved, most hated - the most, the closest, the extreme, each as measure and limit of being friendly and/or inimical, of being another, other, they. Perhaps Montaigne's words express this closeness and extremeness as limit at the limit: "the secret I have sworn to reveal to no other man, I can impart without perjury to the one who is not another man: he is myself'. ${ }^{435}$ Perhaps the secret is not the limit, nor another man, but myself - the " $\mathrm{I}$ " that swears itself to secrecy, the limitation of

\footnotetext{
${ }^{435}$ M. de Montaigne, Selected Works, New York: Everyman's Library, 2003, p. 172.
} 
the limit of another, the revealing that is not mine to reveal, but another's. And this is the secret, the other secret, the other as secret, the Derrida that speaks through the words of Aristotle and Montaigne, Schmitt and Nietzsche, each pairing with the other ethereally, phantomatically, as if in a dream or a trap, as if at the limit.

Again, the limitation is not necessarily limiting, but it is there, it appears as if limiting, but also serves as a warning, a warning in the sense in which Aristotle's words "friends, there is no friend" - warn us. Or incite us? Warn and incite us? The choice is ours, the limitation, the secret too. There is no escape from it, no sworn secrecy, no entrusting. We inherit contradiction as limitation, the secret of limiting contradiction by contradicting it, but also the entrusting of the secret to the one who transgresses the limit. Montaigne's decision, by no means unfamiliar to us, uncovers the status of contradiction as secret, or of the secret of friendship as contradiction - the entrusting, the decision, which sets us, has already set us, on a secret and contradictory course.

The man that is not "Me", the " $\mathrm{I}$ " that is not another, could not be trusted, could not be entrusted the secret of the contradiction between "Me" and another, the secret of contradiction as such. In the end, the question of power submits to this answer, to this secret that is entrusted to everyone except another, except the " $\mathrm{I}$ " that is not another. The narrative itself cannot be entrusted to another except if it is coincidental with myself, if it is "I" - my narrative about myself as secretive friendship to another; my relation to him as contradiction, instigation, and transgression.

The secret of the narrative hides the truth about the other, about our relation as contradiction and transgression; it hides itself from itself, as it were, embarking $u s, w e$, ourselves, on a voyage beyond the limitations of friendship. It hides from us the possibility of having friends, the very possibility for the condition of political existence. In the absence of friends we have no political existence, no real existence as human beings. We 
have no enemies, nor any power to recognize or defeat them. In the last analysis, the friend and the enemy coexist, they often change places (a move that is inconceivable for Montaigne), and become the secret of one another, the very means by which they succeed in deluding, or defeating, themselves. In such a last, lasting, lasted, analysis, there is no longer any need to defeat the other, there are no friends anymore, nor any enemies left, but the address, the opening words (Aristotle's, Montaigne's, Nietzsche's, Derrida's) addressing us: "friends...".; “enemies.."..

The names of the others, the very names of being (an)other, perhaps us, we, ourselves, perhaps they, them, themselves, names naming others, names by which they become us and we become them, apolitically and ahistorically, as if the passage from one to the other would take place in a dream or a trap, or even better, in a narrative about dreams and traps, about friendships and enmities as dreaming and entrapping, fall into the trap of the secret. Derrida's words depict this situation very well: "I understand this French term 'acharner' in the hunter's sense, where it comes down to setting up a decoy of flesh". ${ }^{436}$ The decoy is the incarnation of the secret, the other's fate attached to his flesh, his journey ending in secrecy and terror. The decoy is also the friend, the enemy, us, we, ourselves - in the flesh of the other, in the habit of hunting, where it comes down to setting $u p . .$. The decoy is the secret of the hunter, his power incarnate in a trap, or in the flesh of another. As such, it is also a non-secret, a well known maneuver, a decoyed decoy set up against all possible friends and enemies - it is the spirit of the hunter incarnate in the pleasure of setting up and in the thrill of secrecy.

Secrecy appears as a problem "insofar as there are two friends plus one ('another friend believed equally reliable', notes Kant), and to the extent that this discourse on

\footnotetext{
${ }^{436}$ J. Derrida, The Politics of Friendship, New York: Verso, 2005, p. 264.
} 
secrecy supposes the couple's rupture". ${ }^{437}$ The couple, the hunter and his decoy, the friend and the enemy, the friends, $u s-w e$, they - them, are the names of the couples setting up a discourse on secrecy, on hunting secretly, on secret decoys and friendships, or secret enmities. The other always stands as double, but also as secret and decoding of secrecy: "it is a great enough miracle to be doubled, and those who talk of tripling themselves do not realize the loftiness of the thing: nothing is extreme that can be matched" ${ }^{438}$ Secrecy as limitation, but also as transgression of limits: the double and the triple as copies of the "I", as secrets and limitations of oneness, secrets and limitation of the limit, at the limit.

Friends exist as couples, but couples exist as decoys and secrets, as limits imposed on friendship, but also as transgressions and decodings, as interruptions and ruptures of bonds. Also, one may view enemies as couples and decoys, secret enemies as limits imposed on enmity, but also as possibility and necessity of transgressing and decoding it enmity at the limit, as the limit. At the limit, the limit itself cannot be matched - friendship and enmity as unmatching relations, also as possibilities and conditions for the impossible. "This is why we have been so attentive, in Kant's text, to the uprising of the third friend, and to the question of secrecy that it opens up and forever keeps from closing". ${ }^{439}$ One may view the third party as disclosure, as model of an unattainable friendship (see Derrida), of a divine and perfect sentiment of being one with the other (as in Montaigne), of being one and the other - "the one who is not another man: (for) he is myself".

The one and the other limited by another: "the third person is the cork that prevents the conversation of the other two from sinking into the depth". ${ }^{440}$ The depth may be of secrecy and loneliness, the very limitation of friendship and power, the space and distance between two friends that can never be crossed or exhausted. This is the secrecy of the

\footnotetext{
${ }^{437}$ Ibid., p. 259.

${ }^{438}$ M. de Montaigne, Selected Works, New York: Everyman's Library, 2003, p. 172.

${ }^{439}$ J. Derrida, The Politics of Friendship, New York: Verso, 2005, p. 276.

${ }^{440}$ F. Nietzsche, Thus Spake Zarathustra, New York: Prometheus Books, 1993, p. 80.
} 
secret, as it were, modeling itself after the image of another, in its image, so as to cross over and sink it(self) to the depths. The model is both the original and the copy, the secret secreting itself away in the silence and stillness of the trap, as a decoy of its own limit, or its own friendliness. There is no other model, no other divinity, as it were, but this impossible friendship between the model and the divine, the copy and the original, the other and me, both limits of and limited by another - the third. The decoy, the cork, the presence which is called another, and is not I, nor the other, but something entirely different, something which prevents the I from becoming the other and the other from becoming me; this becomes the secret.

This too is what makes Derrida say there are no other models except this one, except the presence of another, of the third friend who opens up the question of secrecy and prevents it from closing. ${ }^{441}$ The secrecy of friendship stands as the secret of another, the burden that must be entrusted to no one except to this friend of friends, to this friend who is himself sworn to secrecy and silence. This is why the problem of 'treason against humanity' comes out at the end, when everything has already fallen into place, when there is no other alternative but this impossible friendship between " $\mathrm{I}$ " and the other, this impossible "arithmetic of the possible and necessary", which is none other than the history of the narrative - "a history which is made qua the story one tells to oneself and others...,"442

In truth, there is no treason against humanity except this secrecy of secrets, this impossible friendship (brotherhood, fraternity) whose history is made by telling its story, by relating it to oneself and others at the same time at which it condemns them to secrecy and enmity. The arithmetic of the possible as the arithmetic of illusion, not of turning

\footnotetext{
${ }^{44 !}$ A wonderful illustration of such a secretive opening is J. L. Nancy's description of Pierro de la Francesca's painting (Madonna del Parto), in The Ground of the Image, New York: Fordham University Press, 2005, pp.118-21.

${ }^{442}$ J. Derrida, The Politics of Friendship, New York: Verso, 2005, p. 274.
} 
illusion into truth, but of turning truth into illusion, enmity into friendship, narrative into power. This is the gateway for humanity, the passage from one extreme to another, from secrecy to truth, from betrayal to the most enduring friendship, as a guarantee for the time to come, for that which is not here yet, but which is nonetheless possible, perhaps even more than possible - a passage, a coming. This is a story which is no longer ours or theirs, but has already passed beyond belonging, into the uncharted zones of free-consciousness.

In this sense, belonging appears only as rupture, fissure, interrupted passage from relative formations to relative events, from a time of decomposition to a time of composing the texture of relativity, the texture of time, as it were, its subtlety, its mixtures and hybridizations, its fervor for newness and movement, for the end, the stasis, the eternal in the finite, or the "infinitization of the finite". It is the explosion of the finite into the infinite feeling of belonging to another, to a beyond situated outside the finitude of things, outside the finitude of the world and of thought. The story of such an explosion of feeling is also the story of consciousness, the contracted, compressed consciousness of localized perspectives, of rhizomatic and molecular perspectives, bio-political perspectives on the local and singular, bipolar perspectives, always in the composition of another, always decomposing its distances and proximities, its ties and anomalies.

The economy of time turns into an economy of otherness, an economy of distant and disciplined bodies, conditioned bodies moving out of the unconditioned through the passage from enmity to friendship, from illusion to truth, from narrative to power - to narrative power? The economy of the narrative is this economy of the passage, of nomadology and exiling - it is an economy of the desert, of exodus and pilgrimage through the uncharted zones of consciousness. The narrative incarnates this economy of moving bodies (instead of falling bodies), this exodus of disciplined and inoffensive machines (or ghosts) passing through the gateway, passing over and against the abyss of being human all 
too human. In the end, the narrative itself organizes movement and turns against it in order to witness the grand passage from nihilism to affirmation, from enmity to the story of friendship, from an economy of words to an economy of bodies through the asymmetrical incarnation of words into bodies, of passages into stories, and so on.

In the end, there is no end. No proper incarnation, no true story, but pilgrimage from one narrative to another, from one economy to another - the silent power of the warmachine, the power of the future found in the openness of the desert, in the infinitude of the finite, or the explosion of feeling. Everything falls behind the line of the horizon, it falls back into the silence of the machine, into the deadly silence of the infinite deserting of humanity. The economy of the deserted as the incarnation of the most universal friendship - the surpassing of the present through an economizing of friendly and inimical relations, the texture of the present as the betraying and loving spirit of (its) time, the most offensive and defensive status of thinking in and through the maze of the narrative - this is the condition of the present, the status of its (power) narrative. The economy of the present entertains the narrative of economized bodies, it entertains itself by economizing reality through the operation of its own narrating bodies - a bio-economy of the uneconomical and non-technical incarnation of the narrative: an absurd possibility but also an unexpected explosion of feeling.

Narrative as canvas ${ }^{443}$ or film ${ }^{444}$, truth as painting ${ }^{445}$, the word as indelible sovereignty - this is the turning point of all such economizing of living bodies and (out)living thoughts. The turning point of truth, of narrating, of painting - such is the economical truth (par excellence), the truth of the colonized body, or of its imperial soul.

\footnotetext{
${ }^{443}$ Cf. J. L. Nancy: "art as celebration of the groundless space opened by a canvas without a depth...". from, The Ground of the Image, New York: Fordham University Press, 2005, p. 135.

${ }^{444}$ D. M. Lowe, History of Bourgeois Perception, Chicago: University of Chicago Press, 1982, pp. $125-26$

${ }^{445}$ Cf. J. Derrida: "My truth in painting". from The Politics of Friendship, New York: Verso, 2005, p.172.
} 
The truth lying hidden at the heart of things - or rather in their place, silently veiling and unveiling the canvases of reality, its paintings, its sovereign appearances; the truth of friendly encounters, friendly apparitions and disappearances. A brief intermezzo on the subject might not be out of place. 


\section{Chapter 13}

The Truth about Friendship

So many coincidences are needed to build up such a friendship that it is a lot if fortune can do it once in three centuries.

M. de Montaigne 446

Our longing for a friend is our betrayer.

$$
\text { F. Nietzsche } e^{447}
$$

The beginning of friendship (for us) is not in the past, nor in the present, but in the future - in the abstract economization of friendly and inimical bodies, in the explosion of a feeling that is no longer directed toward a friend or an enemy, but towards anybody, perhaps toward a greater humanity, a greater feeling of belonging and/or deserting. The question of friendship has already been answered through this feeling, through this hope of belonging to the human or the super-human, which it holds in respect to the question of another, against the question and/or against another. Love at superlative, promethean love, friendship - every word rings a tone, calls for something outside the present, placed at a distance, but also within the reach of memory, within the reach of imagination. The expectation of love is also already infused with disillusion, conflict, and nostalgia: it limits itself, or rather guards itself against the fall from grace, which is a fall from love, a fall from the graces of the loved one. According to Derrida, this is where friendship finds a new beginning, a new path: "the entire path of this abysmal altercation with Christian fraternity had begun, as we will recall, with the evocation of the hermit". ${ }^{448}$

The hermit is not a Christian friend, he does not belong to a fraternal order. But he will - by giving himself up, by returning to his fellow men after they had repudiated him (e.g., Zarathustra), he will become a friend to all, in the shape of a ghost walking among

\footnotetext{
${ }^{446}$ M. de Montaigne, Selected Works, New York: Everyman's Library, 2003, p. 165.

${ }^{447}$ F. Nietzsche, Thus Spake Zarathustra, New York: Prometheus, 1993, p. 80.

${ }^{448}$ J. Derrida, The Politics of Friendship, New York: Verso, 2005, p. 289; italics mine.
} 
them. The ghost is more than an apparition, more than an absent presence. It is a specter, a widening path of becoming other, of becoming friendly through the specter of the enemy. This becoming friendly is the path (already) opened by Christian fraternity, the path traveled by the ghost in search of friends but also in search of truth - the truth of friendship, the truth of fraternity, or truth qua truth. The Christian path is altercated by this abysmal apparition of the hermit, by his search for the truth of friendship, for the truth of truth. The Christian abyss corresponds to this truth of friendship or friendly truth, which is altercated, betrayed, made true.

The truth about friendship, or abysmal friendship to truth, is this return, this conjecture of truthfulness and loss, friendship and mourning, war and peace, to which one attaches himself as if to an eternal truth, an eternal presence, or to an eternal loss. In Derrida this loss is the desire for friendship, for all friendships, but also for enmity, for all possible enmities against the truth of mourning and of loss. The law of friendship is reversed, it will be reversed once the truth that is being repudiated here will return to us in an acceptable form. The affirmation of friendship is the affirmation of its truth, of the abyss, loss, or mourning that one finds at the heart of truth, or of friendship.

Between the affirmation and the loss of friendship, one encounters the interpolation of enmity, the tempting path of another type of amicitia, another type of friend and/or of truth. In this gap opened between affirmation and loss, friendship lodges itself as inimical and fraternal, as the opposite of what the other friendship, the other amicitia, will become in the future. Indirectly, friendship becomes the enemy of the enemy, the truth of enmity, the very moment of turning against another in search of a friend. At this point, a politics of friendship becomes not only impossible, but also the most probable possibility, the most absurd and perhaps the most realistic option between affirmation and loss, collaboration and betrayal, return and disappearance. A politics of friendship is also a politics of 
renunciation, a path opened up by so many contradictory possibilities that gain and loss become indistinguishable from one another, just as the friend and the enemy become absolutely inseparable from one another - two categories of the same, two names given to the other, but also always denominating one friendship, one rivalry, one category. Politics is not only a stage where one includes his enemy, as $\mathbf{J}$. Rancière argues, but also a stage from which he excludes his friends - a stage of volatile betrayals and loyalties, a strict economy of bodies and plots, a technology of appearances and disappearances.

The friend and the rival coexist in the actor, the neighbor, the brother, the distant apparition. They have been placed in close proximity while also at a distance by the truth of friendship (in rivalry), and they have been placed at a distance while also in closeness by the truth of rivalry (in friendship): two paths, two distinct distances and proximities, two friends and two enemies intertwined in a history of survival, in a history which also reaches into the future, the same future by which the friend becomes the enemy and the enemy turns into a friend in order to outlive one another. The future is here as possibility, also as the most absurd, the most plausible impossibility of being friendly in and through rivalry, and of becoming a rival in and through certain friendships.

"Are you a slave? Then you cannot be a friend. Are you a tyrant? Then you cannot have friends". ${ }^{449}$ The tyrant and the slave have been concealed in woman, in her capacity to love, or rather in her inability for friendship, which is decisive in Nietzsche, perhaps even deceiving: “oh! your poverty, you men, and your sordidness of soul! As much as you give to your friend, will I give even to my foe, and will have not become poorer thereby" ${ }^{450}$ The slave cannot be loved, the tyrant cannot love - their relationship excludes friendship right from the beginning, it excludes the politics of friendship or even the possibility of having friends and enemies - it excludes politics in the Schmittian sense. The

\footnotetext{
${ }^{449}$ F. Nietzsche, Thus Spake Zarathustra, New York: Prometheus Books, 1993, p. 81.

${ }^{450}$ Ibid., p. 82.
} 
exclusion of politics is also the very possibility of the political: one "will not become poorer thereby," nothing will change by giving to the enemy as much as one gives to a friend, nothing but the very possibility of turning one's friends into enemies and viceversa.

In this sense, the very cordiality of the relationship between friendship and enmity, which constitutes the fundamental category of the political, changes into the fundamental category of politics, of a politics of betrayal instead of a politics of friendship. Indeed, Nietzsche had opened the path towards a politics of the future, the path that is now traversed from so many angles, in so many directions, with so many aims in mind, that it is no longer recognizable otherwise than through the mask of the other, through the politicization of close friends and distant enemies alike, through their change of identities, change of hearts, or even of places (or statuses).

The opening of the future is also a closure, a promiscuous reducibility of friendship to enmity, and of enmity to friendship, an alteration of reality, as it were, operating at the very heart of politics - "our longing for a friend is our betrayer". One longs for a friend so that the dialogue with the other may not sink into the depth, into the superficial rivalry of doubles engaged in dialectical/dialogical battles. One longs for betrayal, as it were, for the inimical other, for the presence of the hermit.

The double is a shadow, a ghost, a specter of ideality. It is an ideal model of friendship, one that overcomes humanity by being double, by doubling itself as if in a mirror, or in the other's consciousness. This narcissistic inclination of the "I" is prevented by the presence of the friend who is always the third, the ghost, the impossible eventuality of being loved or loving beyond love. In Derrida, this eventuality loses its weight in the face of the double (just as it does for Baudrillard), it loses its sense, its possibility of being another, in the other's shadow. The double reabsorbs itself into the one by splitting itself 
up into friendly and inimical relations, by becoming the hermit without a friend, the only friend of humanity - the third. He is in the position that his ideal friend, if he had one, would hold. He opens up a path impossible to travel, but all the more so traveled, desired, searched for. This is the path of the future, which is neither here, nor there, but in and through here and there, in and through the presenting of the possibility of a presence here and a presence there, a friendship and an enmity that are no longer of the present, but already of the future, already "not-here" and "not-there".

The third possibility opens in the future, it is the future - a distant and friendly alternative to the present, an operation preventing one from sinking into the depths of the double. This being third, being after the double in order to prevent its fall, does not prevent itself from sinking into the depth, from being that depth which is otherwise unbearable. The return to classicism, to the classical schema of friendship, to the ordinary usage of the word "friendship" (in Aristotle's sense of being above the law), is another moment, another sinking into the depth of betrayal, or of friendship. The recoil is always a recoiling back upon the other, a replica of the present through its moving image - the future. The fate of the friend is already sealed, already inimically sealed, or rather deepened in the silence of betrayal and friendship.

"One is always too many about me - thinks the hermit". ${ }^{451}$ Indeed, one is about me, about being too many in and through me, in and through the replica of a depth that must be avoided if it is only (about) myself. This is the danger inherent in and through the number, the arithmetic of a universality based on numbering, or rather on a certain aristocracy of the number. ${ }^{452}$ In the end, there are too many of "me" in and through the one: too many doubles to prevent them from sinking into the depth of thinking themselves to be too many (a limit encountered by Levinas). The number impedes "me" just as I impede the number;

\footnotetext{
${ }^{451}$ Ibid., p. 80.

${ }^{452}$ J. Derrida, The Politics of Friendship, New York: Verso, 2005, p. 20.
} 
this numerical strategy overwhelms "me", but also releases me from its impediment.

The defeat is always the hermit's defeat, his acknowledgement of himself as the one who cannot win - indeed, he "celebrates the war machine, setting it against the State apparatus in a struggle that is lost from the start". ${ }^{453}$ For him, "every thought is already a tribe, the opposite of a State", 454 "and this form of the exteriority of thought is not symmetrical to the form of interiority;" ${ }^{, 455}$ it is a consciousness set against models, against itself, as it were, or rather against itself as original and copy, model and replica, " $P$ " and me, myself. It is a consciousness set against the very possibility of a thought subordinated to selfishness and injustice, a losing consciousness which no longer wishes to win by subordinating itself to (an)other. For the first time in human history, ${ }^{456}$ Christian consciousness turns against itself and becomes non-Christian - a ghost perhaps, but also a distinct possibility opened up within Nietzsche's thought. ${ }^{457}$

Such an insubordination of thought to the Christian model opens up the very possibility of another truth, another justice - friendship and enmity are defined in terms of this insubordination, but also always counterbalanced by an entire tradition of the overman and of the subordination of reason - "what is unjust toward each of these is also different, and becomes more unjust as it is practiced on closer friends". ${ }^{458}$ Thought frees itself from

\footnotetext{
${ }^{453}$ G. Deleuze and F. Guattari, Nomadology: The War Machine, New York: Semiotext(e), 1986, p. 8. ${ }^{454}$ Ibid., p. 45. a title prefiguring this transformation of Christian consciousness.

${ }^{457}$ In this sense, R. Suskind from the New York Times, has given an instructive account of a meeting with a presidential aide: The aide said that guys like me were 'in what we call the reality-based community,' which he defined as people who 'believe that solutions emerge from your judicious study of discernible reality.' I nodded and murmured something about enlightenment principles and empiricism. He cut me off. 'That's not the way the world really works anymore,' he continued. 'We're an empire now, and when we act, we create our own reality. And while you're studying that reality judiciously, as you will - we'll act again, creating other new realities, which you can study too, and that's how things will sort out. We're history's actors . . . and you, all of you, will be left to just study what we do". R. Suskind, "Without a Doubt", New York Times, October 17, 2004.

http://www.cs.umass.edu/ immerman/play/opinion05/WithoutADoubt.html.

${ }^{458}$ Aristotle, Nicomachean Ethics, Indianapolis \& Cambridge: Hackett Publishing, 1999, p. 129, VIII, chap. 9, 1160a: "It is more shocking, for instance, to rob a companion of money than to rob a fellow citizen, to fail to help a brother than a stranger, and to strike one's father than anyone else.
} 
its own tradition by remaining within it (as in Foucault), which is to say that it creates the illusion of a sudden liberation from the old canons by setting up the most distant enemy as the closest friend and the closest enemy as the most distant friend. The (in)version proves to be strategic, but also dangerous since it keeps open the possibility of an unexpected confusion (an unexpected perhaps): “. . confusion of language of good and evil; this sign I give to you as the sign of the state". 459

In this confusion, nothing makes sense but to look “. . . there where the state ceases pray look there, my brothers! Do you not see it, the rainbow and the bridges of the overman?" ${ }^{460}$ The rainbows and the bridges, the haughty and the ugly ways prefiguring the coming of a future friend, the not here yet, not there: the inexistent, solely probable, possible, plausible - other. One must already look for him outside the state, at the very end of tradition, where everything ceases to be as it is. The friend ceases to be a friend, the brother that is now ceases to be a brother, hence the confusion, and the danger that must be avoided - hence the inevitable return to tradition, the way in. Everything stays the same by not being the same, by not seeming to be the same - the friend continues to be a friend by becoming an enemy and the enemy continues to be an enemy by becoming a friend. The strategy consists in inverting their names, their stations, their relationships: brothers as enemies and strangers as friends, but also enemies as best friends and strangers as perfect enemies.

Tradition subsists subtly, almost pejoratively, side by side with the other, with its end, its counterpart, its friend as enemy, which is also its enemy as friend. This perfect coexistence of opposites brings us to a hypothetical state of equilibrium, a clearing of the notion of tradition as it were, a new path which is no longer in the way of tradition, but

\footnotetext{
Justice also naturally increases with friendship, since it involves the same people and extends over an equal area".

${ }^{459}$ F. Nietzsche, Thus Spake Zarathustra, New York: Prometheus Books, 1993, p. 73.

${ }^{460}$ Ibid., p. 75.
} 
side by side with it. This parallelism - which is best described by Foucault in The Order of Things - this multiplying urge crossing over into the other as if into its own depth, as if into its own possibility, returns to itself as if to another, perhaps the third, the hermit, the longed Zarathustrian of another century.

Because of the movement and the dispersion created by its laws, the sovereignty of the sympathy-antipathy pair gives rise to all forms of resemblance. The first three similitudes are thus all resumed and explained by it. The whole volume of the world, all the adjacencies of 'convenience', all the echoes of emulation, all the linkages of analogy, are supported, maintained, and doubled by this space governed by sympathy and antipathy, which are ceaselessly drawing things together and holding them apart. By means of this interplay, the world remains identical; resemblances continue to be what they are, and to resemble one another. The same remains the same, riveted onto itself. ${ }^{461}$

The sovereignty of the sympathy-antipathy parallelism keeps things as they are, it keeps them unchanged by doubling their convenient relations, their emulations of one another and their analogical liaisons. The doubling is as strategic as the inversion of names, coincidental with it, as it were, with the inversion of the real in the presence of a silent spectator. This spectator is the distant friend of humanity witnessing the sovereign law of the couple, its infinite proliferation, or its infinitized spectacle. The political consciousness of the spectator is this spectacle unfolding above and beyond all comprehension, in the superficial texture of the narrative, where there is nothing else to do but to observe. The world is no longer volume, but image: condensed, superseded, cold, realism of the image. The sovereign couple is such an image, a pastiche of dogmatism and fiction, of sovereign copies and couplings - a duet painted on the spot, according to the law of the visible.

The inversion of terms is also an inversion of values, an irreversible operation

\footnotetext{
${ }^{46 I}$ M. Foucault, The Order of Things: An Archeology of the Human Sciences, New York: Vintage Books, 1994, p. 25.
} 
performed in the absence of both sympathy and antipathy: the couple is sovereign by virtue of its own absence, as it were. The realism of absence is the realism of the spectacle, the realism that presupposes the disappearance of reality in exchange for its image. In it, the only presence is the spectacle, the organization of society according to the visual - the cyberreal, the war-machine, the tyrant-slave couple. Indeed, there is no visibility anymore apart from the law establishing the hierarchy or equivalence of the visual. There is no sovereignty, no couple apart from the sinister brotherhood between the spectator and the spectacle of his own image: "the real consumer thus becomes the consumer of illusion. The commodity is this illusion, which is in fact real, and the spectacle is its most general form". ${ }^{462}$ In J. Canton's terms, the consumers are "collaborating to make the next drugs, design the next products and sell the next services. They are the consumers devouring interactive, real-time, rich media products and services". ${ }^{463}$ The sovereignty of the friend/enemy couple becomes the sovereignty of the producer-consumer, the spectacle of the sovereign commodity par excellence.

Production as conscious desire, and consummation as the desire for consciousness, these are the two heads of the new sovereign, the two moments in the commodification of the spectacle that defines the New World. In it, the only reality is the reality of the commodity, the intimated fraternity between value and exchange, contemplation and making, society and economy, bourgeois and worker. This world survives in and through the commodifying tendencies and aspirations of the producing-consuming specter; it survives as commodified production and consumption, as the desire to produce and consume everything in the form of a commodity or a packaged experience. The world as commodity survives as long as the producing-consuming cycle is not threatened by another, as long as we are not "confronted with the prospect of a society of laborers

\footnotetext{
${ }^{462}$ G. Debord, The Society of the Spectacle, New York: Zone Books, 2006, p. 32.

${ }^{463}$ J. Canton, “The Click-Stream Consumer", Institute for Global Futures. http://www.futureguru.com/.
} 
without labor, that is, without the only activity left to them". ${ }^{464}$ The world of the commodity, or the commodity that is the world survives for as long as man labors toward, in and through it. In its negative form, this survival corresponds to "the abolition of classes and the direct possession by the workers of every aspect of their activity". ${ }^{465}$ It corresponds, more precisely, to "the society of the spectacle, where the commodity contemplates itself in a world of its own making". 466

The commodity as spectacle versus the spectacle as commodity - these are two negativities in the making, two affirmations of the struggle to survive in and through the other, in a world of their own making. These two doubles are brought together by conflict, by the spectacle of conflict, or even worse, by its irremediable commodification and spectralization, by its subsequent transformation into an image or a sign, a voice, or a drive for survival. Survival itself becomes a spectacle, a commodity in the making, an exchangeable product. By following this line of thought, one is tempted to acknowledge the friend as a commodity, the enemy as well, and perhaps even their secret relations, or their resemblances. In the end, there will be nothing left except their interchangeable images, the memory of their metamorphoses, as it were, of their disappearance behind the rupture or disintegration of the real, that is, behind the most paradoxical disintegration of the real, which is its compression into exchangeable images and products.

Differently put, the value of the real is the value of the package, the obsessive process of having something at one's disposal, in one's possession, for one's pleasure. Reality packs and obsesses, and the more it does so the higher its value, the more rewarding its promise. The reversal is perfect, the isolation complete. In its wake there is no possibility of encountering and weighting something other than the package, the spectacular contraction of the world into the compact form of the commodity, triggering

\footnotetext{
${ }^{464} \mathrm{H}$. Arendt, The Human Condition, Chicago: University of Chicago Press, 1989, p. 5.

${ }^{465} \mathrm{G}$. Debord, The Society of the Spectacle, New York: Zone Books, 2006, p. 34.

${ }^{466}$ Ibid., p. 34.
} 
what Bataille would call the festival: "the constant problem posed by the impossibility of being human without being a thing and of escaping the limits of things without returning to animal slumber receives the limited solution of the festival" ${ }^{467}$ The world as festival is the world of things turning slowly into a celebration of celebration, an escaping of escape, an absurd humanization of the inorganic. This is the world created in and through the visual the world impacted by its own image, by its own festivity of the image.

Nonetheless, the commodity that is called the world calls into question this compression, or festivity, of the image, which is a reality condensing itself to the point of evaporation. It does so in and through the compression of thinking thoughts, of movement in thinking, or of thinkable matter, which is to say that it precedes itself in a manner characteristic to the intellect, to that part of the body which has been commodified, compressed and packed to the point of disappearance. The storage of reality becomes congruent to the storage of memory, of thinking thoughts addressing this very compactness of an unrecognizable reality, the celebration of which is another thought, another compactness - compressed as though for long term hard disk storage. The "convenience" (in Foucault's sense) of the world gets confounded with the convenience of thought, that is, with the similitudes between visuality and thinking, between the world and its representation. What is compacted is not the real but our thoughts on the real, our sciences and genealogies, the reality of the double compactness of the real, the packaging of the package.

In sum, the truth of the matter (of friendship) gets transformed in and through the image of the enemy, in and through the compactness of its spectacle - and this has happened to such an extent that friendship is already a commodity, and thus the truth of friendship is already often a political commodity. In essence, the commodification of the

\footnotetext{
${ }^{467}$ G. Bataille, Theory of Religion, New York: Zone Books, 1989, p. 53.
} 
political corresponds to this reversal in the value of friendship, to this inimical transformation of friendship into an exchangeable value, a value that is no longer fixed but mutates from one couple to another, depending on the circumstances of the spectacle. The political is no longer the rule but has become exchangeable, commodifiable, compacted, at best, it has become a machine, or a specter residing within a machine. It is no longer a possessed but an exchangeable image in and through which the political ceases to be political in favor of an exchanging festival, or of a festival of exchange. It becomes an exchange mechanism, or ceremony, a machine for exchanging possessions as images for images as possessions: animism.

The friend-foe distinction is such an exchangeable commodity, such a commodifiable politics, corresponding to the exultation of the image to the status of a genuine possession to such an extent that it becomes problematic to distinguish the politics of the image from the politics of possession, the commodity from its possession, the rule from the law. The automation once attributed to industry is perfectly transferable to the political spectacle: "the same technical infrastructure that is capable of abolishing labor must at the same time preserve labor as a commodity - and indeed as the sole generator of commodities". 468 The society of the spectacle generates commodities, more precisely, it is preserved as a commodity capable of generating itself in the form of the spectacle, the festival, the ritual, the political.

The way out of this impasse (of the spectacle), as G. Debord indicates, is the growth of the service sector: "...on the one hand, the system is faced with the necessity of reintegrating newly redundant labor; on the other, the very factitiousness of the needs associated with the commodities on offer calls out a whole battery of reserve forces". ${ }^{469}$ The fate of the commodity is decided by this "battery of reserve forces", by this

\footnotetext{
${ }^{468}$ G. Debord, The Society of the Spectacle, New York: Zone Books, 2006, p. 31.

${ }^{469}$ Ibid.
} 
factitiousness (of needs) associated with commercial offers, which overcomes the society of the spectacle through a redistribution of commodities towards the service sector, or what amounts to the same thing, towards the transformation of the commodity into a serviceable spectacle. This becomes increasingly important as the consumption of goods gives way to the consumption of experiences. The social spectacle is rescued through the fracture of the economy into redundant and serviceable labor, and the factitiousness associated with it, which is to say that it becomes both a commodifying and generative process. However, the rescuing of the social from its redundancy by giving it a serviceable function is only apparently true; it is a resolve, or turn, of the social commodity into a generator of commodities to be sacrificed in (and for the sake of) the social "festival".

With this suggestion in mind, the Hegelian social scheme is slightly overcome, or rather renewed, as if against its own uniformity of method. The renewal consists in the indirect revolutionizing of the non-revolutionary commodity, in the (re)generating process by which the commodity is rescued from its redundancy and restored to the serviceable, through a factitiousness associated with the generation of offers. The idea of potlatch finds its use here as an obliging gesture accommodating a return and a betrayal, a complicity textured around gifts and an enmity entailed by it, which is to say that both return and betrayal are accomplices of gift giving and receiving, of services obtained and rendered in and through an associative economy of gifts. Indeed, this transitory solution entertains the pervasiveness of divisions, the striated space of a divine economy, the place of offering and betrayal as it were, in which what is being offered is exchanged for some sort of salvation, some sort of solution or way out of an undesirable situation.

There is no neutrality to a gift, any undesirability or indifferent associations. The gift itself is the sign (or mark) of complicity, the very symptom of survival by association, of economizing salvation based on the power to associate through gifts, through their bonding 
power or their associative effects. The role played by the social contract is compressed in the gift, in an obliging and indifferent association based on the power to bond around commodities and around the secret of their generation. This is the secret of potlatch (as in Dumézil, or Bataille), the lucrative instance modifying the economy of salvation by returning it to its own origins in such a way as to permit the continuation of history, its materialization as a divine and graceful gift. The universality of salvation works its way back to the particularity of its gift-giving-and-receiving dynamic - to its genealogical source of associative dealings in such a way that its continuation is ensured by the event or threat of its disappearance:

Intense consumption requires victims at the top who are not only the useful wealth of a people, but this people itself; or at least, elements that signify it and that will be destined for sacrifice, this time not owing to an alienation from the sacred world - a fall - but, quite the contrary, owing to an exceptional proximity, such as the sovereign or the children (whose killing finally realizes the performance of a sacrifice twice over). ${ }^{470}$

The world of potlatch excludes friendship but it does so by becoming the only relationship capable of keeping one alive through the web of gifts of friendship. The gift incarnates the spectacle of an inexistent friendship in the same way in which the society of the spectacle incarnates the real, or the decoy incarnates the pleasure of the hunter, projecting it as the resolve, the way out, or the finality of its own redundancy. The gift itself is the condensation of the spectacle of enmity, the intimation and commonality of exchanging desires for favors, for prestige, for pleasures.

The world of friendship succumbs to the world of gifts, to the exchanging realm of becoming intimate, becoming common, becoming desirable, in such a way that all becoming must give and receive something, must attain some sort of friendship or brotherhood of gift-giving and/or receiving. The truth of friendship is no longer the truth of

\footnotetext{
${ }^{470} \mathrm{G}$. Bataille, Theory of Religion, New York: Zone Books, 2001, p. 61.
} 
a desire for proximity, but of a desire for an exchangeable, negotiable, distance: "this friend of the distant belongs to the finite earth, to be sure, not to the world of Christian hinterworlds". ${ }^{471}$ This friend from a distant future no longer offers us this or that gift, in this or that economy, but gives us the world with all the gifts in it - he gives us the "gift of a finite world", the only gift a friend of the world can truly give us.

This gift, or friendly renunciation, is a promise for something new, for another way of thinking, or another friendship. In its proximity, we can only imagine what has been accomplished and what is being promised in relation to the future: ". . as the classics teach us, the imagination is the most concrete of temporal powers". ${ }^{472}$ It is the most dangerous as well, and the most intimate. Itself a form of proximity - not just of another friendship forged over the remnants of Greekness and Christianity, but the proximity of their disappearance, the true friendliness, the true world given over to absolute friendship. There is, however, no western sense of friendship other than the Greekness and Christianity against which one turns and to which he returns incessantly, looking for a friend - a new friend, a friend capable of disappearing into the distance of enmity, capable of turning friendship into the distance of disappearance and death.

This is the friend of the future, the frightening truth about him, the frightening future - "this is the place of profound pain", which "must accompany friendship into oblivion", 473 and must discover "friends to the point of this state of profound friendship in which a forsaken man, forsaken by all his friends, meets in life he who will accompany him beyond life, himself lifeless, capable of free friendship, detached from all bonds". ${ }^{474}$ True, absolute friendship is without bounds, without bonds or friends - it is itself the bond, the friend who is not here yet, but also already passing away.

\footnotetext{
${ }^{471} J$. Derrida, The Politics of Friendship, New York: Verso, 2005, p. 287.

${ }^{472}$ A. Negri, Time for Revolution, New York: Continuum, 2003, Preamble.

${ }^{473}$ F. Nietzsche, Thus Spake Zarathustra, New York: Prometheus Books, 1993.

${ }^{474}$ G. Bataille, Quoted in Derrida, The Politics of Friendship, p. 295 (from L'Amitie).
} 
The spectacle of friendship is absolute, bonding at the same time at which it detaches one from the truth of friendship, from the truth of a friendship that is no longer lived, but staged and glimpsed from a distance, as if in a film or a poem. Absolute friendship is this spectacle of the spectacle, this absolute of the absolute without bounds, this inversion of boundlessness into a future friend, or a future intimacy of friendship. Indeed, there is no memory of boundlessness, no memory of friendship as such, or no friendship that could detach itself from the bonds of memory. Yet there is the possibility of the possibility of a friend, the very spectacle of having a memory of the absolute, a memory of its intimacy and its truth. Friendship is a transgression, a violence done to this memory of memories, to this distant friend of the future. It is also love, "love that follows the thread of time from its beginning and so weaves its fabric in the common", ${ }^{475}$ in the present that is common, or commonly present.

Friendship as transgression of violence, transgressing back into the serenity of the beginning as the friendship of the future, as an amicitia of time to itself, to the limit it has imposed on itself, which is this particular friendship, this particular moment of a serene beginning. This is the nostalgic moment of friendship, the end, the distance one has to impose on himself in order to remain friendly. Without this nostalgic moment, friendship would be just another form of violence, another transgression, this time against itself, against its own intimacy: its own. To this own(ess) or oneness, we must now (re)turn in order to trace the possibility of a nostalgic, or untimely, transgression.

${ }^{475}$ A. Negri, Time for Revolution, New York: Continuum, 2003, p. 211. 


\section{Chapter 14}

\section{The Idea of the One: Time and Space Revisited}

Terror has collapsed distance, and with this collapse has come a sharpened American focus on the necessity of bringing order to the frontier zones.

M. Ignatieff $f^{76}$

At the center of the principle, always, the One does violence to itself, and guards itself against the other.

\section{J. Derrida ${ }^{477}$}

A. Negri once said that there is only one form of government - monarchy. He had invoked Bodin in an attempt to asses the past against the future, or rather to open up the future as the already present, the already ontological "to come" that works as an antidote to power, as the anti-statist, anti-spatial expansion of governing power and governing method. Through this invocation, Negri (en)folded the past within the future as one (en)folds truth within power, or the power of truth against the truth of power in the future, but also in the past, in the already unfolded ontology of the to-come, which is really an ontology of tomorrow, of happiness, or of an already untimely and unknowable future.

In Negri, the idea of time works against the idea of space, the truth of time (developed in Time for Revolution) works against the truth of space (developed in Empire), in a revolution, or a tandem, whereby the power of time turns continuously into power over space (and vice-versa). Time ceases to be the measure of life and becomes life by being textured into the web of productive relations. As a life-giving-being, time erupts into the temporal by virtue of its equivalence with the product of labor, that is, by virtue of its becoming the sole product of labor, or the sole measure and horizon of production. In this immeasurable possibility, time no longer succumbs to the weight of spatial categories, but

\footnotetext{
${ }^{476} \mathrm{M}$. Ignatieff, The Burden, http://ars.userfriendly.org/users/read.cgi?d=19836\&tid=73415.

${ }^{477} \mathrm{~J}$. Derrida, The Politics of Friendship, New York: Verso, 2005, p. ix.
} 
breaks free into the openness of the to-come: "... we will define the time that is coming as the to-come, and the to-come as ontological constitution in action." 478

For A. Negri, the time that is coming represents the ontological being, the unique being of living time - it is an arrow or an edge, a threshold between poverty and invention, poverty and love. The name that is given to it traces back the affinity between the arrow and the edge, or between the to-come and the past; it traces back its constitution to "the creative relation between poverty and love", to the commonality of being poor and loving, to the creativity of being born in poverty and being loved as the two constructive dimensions of the common.

The trace is always the trace of time, the tip of the arrow searching backwards and forwards, within and outside the ontology of the to-come. It is also the trace of a folding, not of time, but of space - the temporalization of space, its becoming temporal by virtue of its subsumption to capital. Space is no longer the space of the world, but the bio-space/time of a relation of exploitation which modifies the direction of the arrow of time in such a way as to ensure the (re)construction of the common, the reconstruction of the two dimensions of the common: i.e. poverty and love. Space is the striated surface of being poor and loving, the very limit imposed on time by time in the openness of the to-come, or in its place.

Indeed, the common name of the to-come is the common name of the common, the supra-name given to the ordinary in the order of time because it always begins and ends in poverty and in loving. The creative relation between love and poverty opens an alternative to the common, it opens up the dimension of innovation, the to-come that is always free, always new, or at least indebted to newness. In this eventuality, the magic of naming (or inverted mysticism) is dispelled by the power of innovation. Time and time again, the name

${ }^{478}$ Ibid., p. 163. 
falls back upon a world of things and shadows. More exactly, it folds upon a world of changing things against which one must necessarily raise the question: in which direction? In what way do these things change?

Change involves movement, movement may develop speed, and high speed can approach non-time. This logic of space is overcome by the epistemological transformation of time into the texture of being, into the being that is textured according to an exploitative/rewarding relation named capital. Like Negri, A. Roy views capital as a new form of kingship. What kind?

Powerful, pitiless and armed to the teeth. He's the kind of king the world has never known before. His realm is raw capital, his conquests emerging markets, his prayers profits, his borders limitless, his weapons nuclear. To even try and imagine him, to hold the whole of him in your field of vision, is to situate yourself at the very edge of sanity.... ${ }^{479}$

The change that is capital moves at a different speed, in a different time frame: it moves by changing speed and measures, by giving value to speed and speed to the measuring value. The change that is capital is undoubtedly less a king(ship) than a machine, an exploiting machine imaged as the productive source of power. The striated surface of the world corresponds to the space of the machine, to the change that is brought about by capital. The to-come presents itself as an ontological break with the machine, with capital and its power. It presents itself as common.

The uniqueness of the common consists in this break with power, in this revolt against the state-machine, in this singularity of being outside capital, while in it - while being it. Being common means being poor and in love, ontologically poor and ontologically in love, it means being before poverty and love, before their relation, in the openness and fluidity of the to-come. Before and after are not the same, they are ontologically distinct dimensions, ontologically distinct realities and times.

\footnotetext{
${ }^{479}$ A. Roy, The Algebra of Infinite Justice, London: Flamingo, 2002, pp. 129-30.
} 
The flattening of the structure of time, its ontological sufficiency, passes over to the surface of the world - it becomes the world insofar as space becomes time, dispersing itself inside the machine, inside capital - inside itself. This familiar ontology breaks with tradition at the very moment at which it (re)constitutes the world of tradition in the spirit of a before and an after - in a temporal (in)succession from before to after. The familiar becomes the most unfamiliar, the most fluid encounter between the machine and its esprit de corp, between exploitation and that which is constituted by breaking away from exploitive constitution: familiarity as distancing, distance as familiarizing encounters.

The tracing of their coincidence, of all coincidences for that matter, is an act of constitution, an empty, forgetful consciousness, made out of contradictory befores and afters. It is also an act of forgiveness, an after that no longer opposes the before, but forgives and annuls it as soon as it remembers it. The possibility of the future is encountered in this tracing of contraries, in this emancipation of forgetfulness into forgiveness, and of conflict into coincidencia oppositorum. It is the path that opens up by closing all openness, the very trajectory of the Parmenidean "being-non-being" or the consciousness of their relation, the termination and the beginning of their secret affair.

The possibility of the future appears as the possibility of the non-future, the coincidence of to-come with not-to-come, the trajectory of their uncertain endings and beginnings. The trials of coming coincide with the trials of not-coming, the trials of hope and of guilt, of beginning something which has already ended and ending something which has already begun, at the same time at which the fatality and the boredom of beginnings and ends coincide in the sentiment of distance, in the disappearance of the real and its (commodified) resuscitation in and through the virtual.

Tracing coincidences, tracing paths into the future of the past, into the sameness of the different, which is also the most distant and most familiar constitution of different 
similarities, different singularities and virtualities: this is the constitution of time, the ontological convergence of the future into constitutive pasts, constitutive acts and discourses. Time converts itself into its own ontology and its own phenomenological break with itself. It converts the future into the past, and the past into the future, in such a way that ontology and phenomenology become constitutive temporalities of the passage of time. The circularity and inescapability of the passage is healed by its breaking loose into the openness of the to-come, by its hope of becoming the other of the other, the image of the image, or the narrative of the narrative.

This break is profoundly binding, working through chains of resemblances and sympathies, working, more precisely, in and through the amazement of newness, openness and clearing. In short, it binds where there are no bonds, no relations of familiarity, no precise testaments for the future. Through this break (or bond), one discovers the magic and lightness of affirmation against the nihilism and weight of negation, and through them, one traces a fundamental path, a secretive and unbearable truth about the future, a narrative of another time, another cruelty, another innocence, but also another way of tracing cruelty and innocence, time, otherness.

The flatness of ontological time is the flatness of being traced, weighted and narrated, the boredom of not being able to exist otherwise than through the traceable lines of one's tendencies and symptoms, one's fantasies, desires, pleasures and hopes. Being traced means being located, weighted, narrated; it means being uprooted in order to be weighted and tagged, to be made into a function, a measuring-unit or a metaphor. Man as metaphor, man as measuring unit, man as spatiality - he is no longer what he is but what he has become after he has been traced, weighted and numbered: a ghost.

G. Bataille used to designate the animal as "water in water", proposing fluidity as the cipher of the indecipherable, as the symptom of the unsymptomatic, perhaps even inhuman 
way of being identical, coincidental, one with the other. The animal's behavior is like "water in water", it is not distinguishable, readable, symptomatic of anything, it is simply water-like, transparent, clear, cold. The water-like quality of the animal makes it indistinguishable and unreadable, it makes it dangerous - a metaphor for danger, for the aggression and violence that comes after it, in an unavoidable encounter with itself.

Animality is water-like, its violence also is water-like - its aggressiveness and innocence are traces of being dangerous in this way, in an instinctually distinct and fluid way. These traces that trace themselves back to water, to the first element, or first encounter with oneself, become the objects of sacrifice and veneration, of militarism and industrialization; they become the products of their own traceable natures, of their own violence and naiveté. Pure sacrifice is one's own sacrifice, one's renunciation, one's own disposal of himself - one's intimate saying "yes" to death.

The violence that one does to oneself is a violence turned against forgetting true violence, against forgiving it and letting it take over one's life. The aporia of violence is the aporia of survival, the guilty victim versus the innocent executioner, innocence versus the spectacle of guilt, but also the incommensurable possibility of overcoming violence through the innocence of the victim - renouncing violence as the last resort, as the last attempt to go beyond it.

The religiosity of the attempt to overcome violence is the religiosity of the victim, its mechanism of defending itself in the face of death. It is not a victimization mechanism, ${ }^{480}$ but a power-mechanism, a replacement of innocence with the power disclosed in and through death, a final attempt at turning sacrifice into the power of death over life, of victim over the executioner, of the corpse, the ghost, the specter, over the living body. The religiosity of violence is often understood as the religiosity of sacrifice for life's sake, as

\footnotetext{
${ }^{480}$ E. R. Dodds, The Greeks and the Irrational, Berkley \& Los Angeles \& London: University of California Press, 1951.
} 
the sole condition of political existence, or of that political existence which is capable to distribute and justify violence as a substitute for life - as a way of living one's life in and through the violent.

What makes those who have been turned into ghosts take one step further into terrorism? Take the case of the suicide bomber. He pursues and presumably achieves a religious transcendence that imparts a sense of triumph. But this is not the triumph over hated victims. As J. Berger suggests, it is: “. . . the triumph is over the passivity, the bitterness, the sense of absurdity which emanate from a certain depth of despair". ${ }^{481}$

Politics as a state of war, a state of permanent siege, is the perfect example for the religiosity of the violent - it is also a strategic maneuver on the part of the least violent, the least capable of violence. As such, it borders on the indecision regarding politics as a violent means of survival, as opposed to more pacifist ways of existence, to the ways of the "victim", the solitary, the non-violent. Economy, for example, appears to alleviate violence by replacing the killing machine (at least partially) with a "free-market", a less violent assemblage capable of producing the illusion of peace - or of an eternity of exchanges, of virtual collaborations and profits. The economy of the machine is the economy of violence pushed beyond its physical limit, pushed beyond the point at which, in P. Virilio, death is supposed to meet death.

The machine itself, any machine for that matter, compresses death beyond death to the point at which dying becomes the sole reality, the sole motor behind the real. Indeed, reality becomes no more than a compressive drive, a compressing process leading towards its own termination. There is no turning back, no going further, the machine incarnates the unmoving movement of death, the death of death, as it were, the beginning and end of everything and of nothing, the inevitable compression of everything to the point of its

\footnotetext{
481 J. Berger, "Foreword” A. Roy, The Algebra of Infinite Justice, London: Flamingo, 2002, p. xx.
} 
disappearance - the miniaturization of the world.

The machine is the world in miniature, the epitome of maneuvering and controlling massive assemblages by changing their speed and their functions. It settles nothing less than the order of order, the speed of speed, the miniaturization of the miniature - a wholly unrecognizable trait of the small, the insignificant and reposing massiveness of the masses, the oneness of the human envelope, the human world created and recreated from within the machine. The humanization of the machine is directly proportional to the dehumanization of the human, to the speed and the automatic orders attached to it.

From this point of view, it becomes problematic to distinguish between the human and the machine, between the brain and the electronic circuits, or the human body and the shape of a robot. The human world is no longer mechanical, but automatic, spontaneous, spatially infinite. It is the world of the living machine, the world of digital logic and alteration: the space of procedure and infinitization, of succession and accident. The space of the operation: the becoming mechanistic of the human, the becoming super-man, superwoman; this is the sacred space of thinghood (so restlessly criticized by G. Bataille), the becoming thing of the human, the becoming other than human: apparatus, dispositif, tool.

This is the space of the economy, the space of betrayal and salvation, the very means by which man strives to survive his own becoming human, his own humanism. The sacred world of the machine is the sacred world of the arch, the animation of the innate world through the projection of life into the emptiness of its interiority. The sacredness of the machine is the sacredness of absence, the emptiness covered up by the world of things, by the intimation of something other than human nature, i.e., human truth. Truth is embodied in the machine, it is intimated by the machine as the perfect absence of the human, as the complete and irrevocable order of the non-human - this is the condition of becoming thing, becoming sacred. It is also the condition of becoming intimately human, false, irrational, 
and absent - in short, the condition of becoming accident(al). ${ }^{482}$

The logic of accident reverses the logic of the machine to such an extent that there is no longer any emptiness, no longer any trace of space, but only fullness, compression, vortical agglomeration. The accident as a non-event full of events, a non-coincidence made up of coincidences - a becoming other than event, coincidence, order; a becoming outside, becoming exteriority, contour, surface. Obviously, there is no longer any logic to it, no longer an event of logic dictating this or that course of events - there are only clusters of non-events, mediated events, pseudo-events, and clusters of coincidental and possible becomings.

An agglomeration, a stocking of the non-event(ful), non-recognizable, non-logical this is the true accident, the true exteriority of the machine, the form given to the space outside it. The accidented space is maneuvered from within the arch through a whole set of operations and commands, which make it collapse into an arbitrary series of operative/commanding orders. The war-machine is the perfect example of this collapse of the outside and the inside into a serial order of commanding and operating maneuvers. As P. Virilio puts it, all interiority has become exterior: "the skin has been turned inside out. The exterior is not simply the skin, the surface of the Earth, but all that is in situ, all that is precisely localized, wherever it may be" ${ }^{483}$ Exteriority as accident becomes the new animating force of interiority, the site of struggles and perpetual changes, perpetual moves and speeds, the site whereby the skin is turned into flesh and vice-versa, in an endless metamorphosis, or flattening, of realities and human bodies.

The interiority of the body flattens upon its exteriority (as in Foucault): the computer monitor, the TV screen, the cinematographic screen, the picture, the image in the mirror they all become the bi-dimensional worlds of flattened bodies, flatlined, in both time and

\footnotetext{
${ }^{482}$ See E. Tenner, Why Things Bite Back: Technology and the Revenge of Unintended Consequences, New York: Knopf, 1997.

${ }^{483}$ P. Virilio, The Information Bomb, New York: Verso, 2005, p. 10.
} 
space. They all become "spaces" and "times", localizable, deportable, replaceable, dimensions of living in space-time, they become the flattening machines, flattening industries of a flattened world. There is no longer any distinction to be made between the flatness of space and the flatness of time. They have become, if only accidentally, one and the same, one flat world of sameness and uniformity, one dimension, one force set against the bi-dimensionality of the screen, the picture, or the mirror.

In A. Negri, this flattening drive is being displaced through its total subsumption to the world of capital, to the industry of desire representing the narcissistic return to the body, to loving it, but also to the moment of disenchantment, to the innovative constitution of singularity. Displacement is an act of constitution, an act of going beyond desire, beyond the body, in and through the openness of the to-come. It is an act of desiring the non-desirable, an act that begins and ends in and through the body: a going beyond, a becoming other. The singularity of the singular is displaced through the multiplicity of desires, through the multiple lines of composing itself in the image of otherness. To be human means to be displaced (by our own desire), to become other, to become singular, innovative, loving.

The world appears to us as the site of displacements, of singularities and otherness, the open space of the to-come, the ontology of another time, another power (of displacement). The diachronic composition of the world ensures the synchronicity of displacement and vice-versa, in an untimely, a-spatial, a-historical, eventfulness of things to-come. In the eventfulness of the series "before" and "after", the "to-come" is always singular, always already gone and not-here-yet, the event of eventfulness as it were, the spectacle of the spectacular, the thought of thinking thoughts. The series is repetitive, disengaging, disruptive - it supplants itself with a mirror image, a screen, a double. The event doubles itself in eventfulness, the spectacle in spectacularity (and nothing more), 
thought in thinking - the entire world flattens itself onto the plane of such displacements, making itself into their image.

Thinking the world means being the world, being in and through it - being time, in time, through time. The moment of displacement is the moment of rupture, the moment of doubling and disappearance, the anonymous and imprecise presence of the other - the innovative to-come. The constitution of the other (as singularity) represents a new displacement, a secondary rupturing and doubling movement of the displacing subject. The eventfulness of being other, singular, not-here-yet, is the eventfulness of the to-come, the event of being at one with and yet outside of the present, in the openness and closure of movement, temporality and space.

Time is being displaced/constituted in and through space, in and through the multiplying spaces of human endeavors, human poverty and love. The constitution of time pushes forward towards the eventfulness of the to-come, whereas its displacement pushes backwards, towards the event of otherness, passage and doubling. Time, time qua time, is but another productivity of desiring desire, another moment of desiring to become, to be, to exist, outside the undesirable. Its displacement heals the irrationality of desire by making it even more irrational, even more displaceable. This is the moment at which all theory becomes a form of constitution, a pushing forward into the impreciseness and imprevisibility of the future and a pushing backwards into the flatness of the double.

This is the moment at which one looks back upon the genealogical constitution of the subject and subjects it even further to the displacement of subjectivity (as in Foucault), to the irrationality of becoming, being, coming to be, subject-less. The fine line between the constitution and displacement of subjectivity corresponds to the fine line between the constitutive and displacing timelines of spatiality, the territorialization and deterritorialization of the narcissistic relation of being to itself. In the last analysis, the 
other is the imperturbable image of falling in love with oneself, the narcissistic moment of becoming other in and through one's own image. The screen, the mirror, the image, is both reducing and expanding, concentrating and dispersing - it is the perfect surface of the event of being, the perfect source of its (re)sourcefulness.

Behind the image there is another image, another reduction, another contraction of the displacing power of love, of being in love with oneself, or with one's own image. The more displacements there are, the more one ceases to be in love with oneself, with his "first" image encountered in and through the other - in and through the constitution of oneself as otherness and singularity. The more displacements there are, the more constitutions come into being - the more familiar these displacements are, the more distant their compositions, their images and loves. The possibility of violence is suspended in and through these distancing compositions, in and through this surreal event of multiplying oneself by displacing its own images and loves.

The enthusiasm of getting away from one's image, of freeing oneself from the otherness and coldness of the image, corresponds to the moment of love, to falling in love not with oneself, but with the other, with the presence of the other, again, with the image encountered by displacing oneself, or of oneself. Violence against the other is always violence turned against oneself, a force, a constitution of otherness as the genuine counterpart of oneness, as the real enemy, the real lover incessantly falling out of love and out of place. Its suspension is illusory, distant, belonging to another "to-come", belonging, perhaps, to that particular "other" which is no longer an image, no longer a beloved lover, no longer anything else but suspension, non-violent, non-perceptible and non-reproducible singularity - an accident, a non-event, a non-coincidental coincidence, or again, a nonrepeatable repetition, a boring, illogical, logic.

Another type of logic, another venue, another possibility of the impossible relation 
between Narcissus and his imperturbable image: "it is merely a delusion, an evanescent optical illusion - not so much an appearance as a transparence". ${ }^{484}$ The transparency of the image is the transparency of the medium through which it comes into existence and establishes itself as the source of truthfulness - the image is but a substitute, a compression of the real to the bi-dimensionality of emotion, to another type of industry, another economy of the relation between the real and the imaginary, between the lover and the loved one, or between man and his image.

The reduction of space to the bi-dimensionality of the image, the bi-dimensionality proper to the surface of the water, but also to the double relation of the gaze to itself, to its own mobility and transparency, corresponds to this impossible economization of otherness, to the improper, indirect, economization of one's own presence through the economy of his image, through the impossible, impassible gaze of the other, of the one in the mirror or the one on the screen - the double. The economy of the double controls the economy of the one - what we have here is a bi-dimensional relation controlling a three-dimensional reality (i.e., a machine). This is why the flatness of the ontological space is so desired/desirable, why one needs to flatten things, to flatten the entire world in order to get in the position to control it.

The interplay between the violent and the non-violent is no longer a matter of sacrifice, no longer a mythical substitute for the forces of nature, but a volatile notion of doing violence to oneself by falling in love with the other, with one's image in the other, or with one's imagination. Falling in love is no longer narcissistic, no longer passive and contemplative, but rather aggressive, uprooting, violent. One does violence to oneself in and through the other, in and through the image one has of oneself as otherness, separateness, and exception. As Derrida puts it, "One does violence to itself and guards

${ }^{484}$ Ibid., p. 21. 
itself against the other" - and it does so in order to become One and Other, complete, whole, loving. It does so in order to become other than one, other than the other, other than one and other: the third, the ghost, the friend. Otherness and oneness come together violently, each guarding itself against the other, each violating and guarding itself at the center of the principle, where everything appears ghostly and inimical.

At the center of the principle, One(ness) is threatened by and threatens the other in an endless series of becoming Other, becoming One, becoming double, whole, ghostly. The principle at the center is the principle of friendship, the becoming other than oneness and otherness, the ghost and the specter of this new becoming which has the power to reverse the order of things, their centrality, or their principality. At the center of the principle lies the secret of being One by betraying the Other and of being Other by betraying oneness, the secret of being neither One nor the Other, but their double, their replica, their principle.

The principle of centrality ensures the centrality of the principle, the doubling maneuver on the part of oneness and otherness, the meeting ground, the mediating, neutral, ground of being neither oneness nor otherness, but one in the other and the other in one the principle pure and simple. Oneness and otherness replicate each other at the center the center is their home, their ideology, their poem. It is also the site of their struggle to overturn one another and impose a new order, a new principle. The center as the site of struggle, or struggle as the principle of centrality, this is the new order, the new type of centrality, new guise for the principality of oneness. It is also the incarnation of otherness, the opposite of what it has been, the reverse of what is - an illusion, a mortifying spectacle.

The aporia of principality pushes towards another reversal, towards a principle, or a centrality of the center, as it were, an absurdity, of course, an impossible task, a lost cause, but all the more causal, all the more possible and ardent, principled and aporeic: the 
coexistence of the One with the Other in the friend, the ghost, the third party. Oneness passes into the otherness from which it comes at the same time at which otherness loses itself into the oneness it betrays: this is the ghost, the specter, the composition that remains unreadable - like water in water. This is the spectacle of the spectacle, the last frontier of the real but also of imagination and of otherness.

This is, perhaps, the most profound change, the most subtle venue for change: the conjuration of profoundness, the conjuration of otherness as depth. The One ceases to exist as frontier and profoundness of the Other, it ceases to exist by becoming like water in water - by becoming otherness. The singularity of the one loses itself in the depth of otherness, it economizes itself in such a way that otherness is no longer possible, no longer an option (by being the only option). This is the end, the true end, the true disappearance of the One into the ontological fabric of otherness - the real betrayal of otherness, but also of friendship towards it.

In Levinas, one switches from one personality to another, from one copy of oneself to another (from one to its specter). In Badiou, one de-doubles the doubles, de-triples the triple, one reduces multiplicity to the singularity of being one. In Derrida, one maintains its personality, its place, its prestige, by becoming faithful to the other, as the other, by keeping himself unhappy and ready to be sacrificed. In Virilio, the other takes over the one from within, it violates it from within, as it were, and transforms it into its copy, into its warrior faith, its proletarian replica of the police, the army, the state, the bourgeois. In Deleuze and Guattari, the other is expulsed in order to maintain the sovereign couple, to make it whole, to enable it to subsist, to survive, to dominate otherness (i.e., the warmachine). In Bataille, violence is internal, it searches for itself through the loss of religion, through the loss of a faith to which it returns by consummating all its resources, all its negativity and energy. In Lyotard, one sacrifices oneself for the sake of one's double, i.e., 
Narcissus sacrificing himself for the image in the water. In Baudrillard, one simply dies, he simulates his death and vanishes into thin air.

In Negri, there is only oneness, the One in the manifold compactness of otherness and nothing else, nobody else. This is the tacit difference between Spinoza and Marx, between a metaphysics of happiness and its subsequent economization, its subsequent becoming an exchange value, a product or an industry. The Marxist is an inverted Spinozist, an unhappy consciousness. In Negri, his happiness is restored, but only virtually so. He is not happy, nor unhappy, but ordinarily beyond happiness and unhappiness, ordinarily one with happiness and unhappiness, with their entire economy, with their reversals and reductions to one another. There is no verticality in being, no transgression other than the simple and pure existence in the flatness of time: "being is not a given, but a constructed product". ${ }^{485}$

The construction of being is flat, temporal, unhappily happy - it marks the beginning of the end, the continuity of oneness in and through its ghostly apparitions, or its own deceiving routine. This is the being that is not given, the being that is flat and remains flat in the flatness of time and of constructive activity, the being that begins and ends in the same way the vision of a ritual begins and ends, that is, by exposing a series of acts and sounds, a series conducive to another depth, another flatness.

The transparency of flatness is also the best way to conceal its opaqueness, the best way to begin the construction of a metaphysics of happiness: "perhaps someone will reach the end, and these conclusions and be happy. If this happens, this text will not have been begun by chance". ${ }^{486}$ What is chance in the ontology of time? What is time itself if not chance, ontology, hope? And then again, what is there to construct, what is there that is not already given, already aporetic? The tragedy of the happy consciousness is not foreseeable.

\footnotetext{
${ }^{485}$ A. Negri, Time for Revolution, New York: Continuum, 2003, from Alma Venus, p. 210.

${ }^{486}$ Ibid., p. 146.
} 
It is not transparent, present, corporeal, it is rather absent, delayed, suspended in the face of the given, in and through its own lack of foresight. The decisive moment for the happy consciousness is this suspension, this being happy without being, without corporeality, which is, in fact, a delaying affirmation - a fantastic enchantment (as in Derrida).

By deciding against negativity, happy consciousness decides against itself, against its own existence - it agrees to its own sacrifice. The decision carries within itself the weight of Christian renunciation, its force, its power to install itself by sacrifice and absence. It also carries within itself the most profound, most delicate lightness of being, its becoming other than weight, other than negativity and gravity. ${ }^{487}$ The decision as such is no longer palpable, no longer weighty, it renders itself to the lightness of absence, of sacrifice and renunciation. It becomes a silent end, another possibility, another path opened in and through the power of being other than oneself, other than weight, negativity, presence. To this becoming ethereal, becoming light, we must now pay attention, as it is not solely a matter of theory, or knowledge, but also a concrete manifestation of its ephemeralization.

${ }^{487}$ See S. Weil, Gravity and Grace, New York: G.P. Putnam \& Sons, 1952. 


\section{Chapter 15}

\section{(dis)Placement and (trans)Figuration}

It isn't the films which are the stuff of dreams; it's America, which has become a kind of huge Hollywood.

$$
\text { F. F. Coppola }{ }^{488}
$$

The transfiguration inherent in the displacement of knowledge is the transfiguration of reality into a filmic presence, a volatile, light, a-dimensional presenting of presence - a film. The reality of the film (its production) replaces the real, it replaces the sense of being real, its dimensions, its presence. Not just America, but reality itself has become a huge Hollywood, a huge production of effects and dreams, events and accidents, illusions and fantasies - a reflection carrying a quantifiable reality, a quantifiable metaphysics of life.

The first displacement (in Negri) is the overcoming of this filmic reality, the (almost) impossible overcoming of the bi-dimensionality of pellicular existence (i.e., temporality, history, ontology) through the power to confront it, to make it measure itself according to its own speed, its own past, its own presenting force. The bi-dimensional collapses into the oneness from which it comes, into the temporality of the temporal, the history of history, the ontology of ontology.

This is why, at the end of the first displacement, one begins by sketching a less secure trajectory of physical time: "in reality... we find ourselves before a second fundamental displacement, so that the path traveled in these prolegomena is that which goes from the subsumption of labor in capital and of society in the State (first displacement) to the explosion of this relation" ${ }^{489}$ In reality, "we are traveling the path which orthodox theory called the problem of transition, which it flattened onto that of

\footnotetext{
${ }^{488}$ From P. Virilio, The Information Bomb, New York: Verso, 2005, p. 22.

${ }^{489}$ A. Negri, Time for Revolution, New York: Continuum, 2003, p. 46.
} 
socialism". 490

This is the reality traversed by us, the infinitely displacing moment of transition towards and away from flattened existence - towards our non-filmic existence, our reality, which is inseparable from our traversing it, from the reality of moving in and through the film of reality, through its displacement, through its impossible placement of non-being in being, of transition in socialism, of movement in film, or of film into the empty canvas of the real.

In movement, reality becomes pure mobility, trajectory, traveling - it becomes dangerous, explosive, transitory. It becomes non-real, non-traversable substance: time. The flattening of time onto capitalism becomes the new orthodoxy, the new trajectory opened before us in the incertitude of the to-come, as our incertitude, or in its stead. The real subsumption of capital to time corresponds to its displacement, to its transition from the flattening world of things to the explosive world of thoughts and emotions, it corresponds to the (re)mythologization of the real, to its consummation as rite, necessity, immediacy, to its transfiguration into the immobile immensity of existence, into the displacing power of oneness, which is no longer attributable to thought, nor to capital, but to their subsumption to one another, to their displacing structures and functions.

The synchronicity of one rests on the diachronic movement of the other, on the irregular and irreversible displacement of oneness by its dichotomies and vice-versa, in a transitory chaining of events and possibilities in and through the innovation of being productive, common, loving, etc. The displacement of oneness leads to its transfiguration into doubleness in such a way that displacement and transfiguration are really reversible terms, reversible realities. Oneness is dissolved in the indistinction (inseparability) of form and substance, measure and matter, to such an extent that it explodes back into the infinity

${ }^{490}$ Ibid. 
of substance or the incommensurability of matter.

The subtlety of the operation consists in following the aporetic lines of constitution, the opening of certain paths, certain eventualities and potentialities of the real. The paradox of method turns into a methodical paradox, into a relativity in the making as it were, which is overcome by entertaining its apparently insecure formations and discourses, its conflagration of possibilities and eventual inconsistencies, its relativizing, paradoxical, orders. The paradox of existence becomes the paradox of life, the great adventure undertaken in order to escape the inescapable - life itself, relativity, the tendency to encapsulate everything into its scientific rigor.

Under the pressure of speed, relativity slips into nihilism and escapes the threat of positivism and its unforeseeable future. The nihilist produces the negative energy needed in the positivist economy - he is productive insofar as he deconstructs and deconspires relativity, insofar as he relativizes and problematizes the very possibility of positivity. In the absence of speed, nihilism turns into an ephemeral positivism. According to P. Virilio, it turns into a cinematic order, an order in which the gravest of impacts seems manageable, rationalizable, plausible.

The plausibility of the cinematic order is displaced in the real order. It is justified by the real order, solved by it, as it were, in the greatest of silences. In return, reality is "saved" in and through the virtual order of the screen: "becoming progressively a story without words, a silent cinema, an authorless novel, comics without speech-bubbles....,491 Becoming silent, becoming speechless, is the effect of cinematic reality, the effect of moving with different speeds in and through the virtual space of the image - the effect of becoming virtual, becoming imaginary. ${ }^{492}$

\footnotetext{
${ }^{49 !}$ P. Virilio, The Information Bomb, New York: Verso, 2005, p. 72.

${ }^{492}$ R. D. Holsworth and J. H. Wray: “. . . television is a frame that shapes our perception of reality. As we become a nation of television hermits, the real world and the world of television shade into each other". American Politics and Everyday Life, New York: Macmillan, 1987, p. 127.
} 
The subsumption of reality to the imaginary marks the moment of the first displacement, the first materialization of materialism as it were, its becoming concrete, becoming real: "at first glance indifference rules in real subsumption". ${ }^{493}$ The indifference referred to here is transfigured through the concrete tautology of materialism, through the complete subsumption of time to labor, to the industry of stimulating thought (as opposed to desire). Such an industry is further displaced by new pathways to desiring, by the neurological circuits of desiring desire, of desiring the other of "labor", the ethereal presence towards which the arrow of time is pointing, the aim, the teleology of another becoming, of a becoming concrete, becoming animal laborens, becoming indifferently indifferent. The meta-indifferent, the introverted type, the internalization of Prometheus into a narcissistic future, this is the real transfiguration of the materialist displacement.

Perhaps there is more to this transfiguration of the already transfigured, perhaps the placement of the Promethean drive at the heart of the narcissistic ego is no longer indebted to becoming, no longer becoming anything but pure displacement, transfiguration, innovation, end - a promiscuous intimacy of the intimate, a porous skin turned inside out, a screen. The transfiguration of the displacing order coincides with the displacement of transfiguration, they unfold simultaneously, tautologically, as if in a film about films, and indeed, as P. Virilio suggests, "there are films you are tempted to walk into because you believe they are three-dimensional". ${ }^{494}$

The reality of the transfigured is this conditioned unconditionality, this becoming three-dimensional by virtue of walking by, by virtue of attributing its mobility to the cinematic order of the psyche. Beyond this unconditional condition (really, a temptation) of transfiguration lies the illusion of three-dimensionality, the flat image of moving and being tempted, the "switch from the panoptic mechanism of surveillance to a system of

\footnotetext{
${ }^{493}$ A. Negri, Time for Revolution, New York: Continuum, 2003, p. 27.

${ }^{494}$ P. Virilio, The Information Bomb, New York: Verso, 2005, p. 23.
} 
deterrence, in which the distinction between the passive and the active is abolished". ${ }^{495}$ Being active is transfigured by the image of being passive (and vice-versa), through the sudden switch from Prometheus to Narcissus, from the mechanics of the soul to the automation of the psyche.

It is possible that this becoming active through passivity occurs in the Deleuzian sense, in the sense in which passivity itself gets transfigured by going beyond Nietzsche, beyond reaction and resentment, towards a becoming which is no longer reactive. However, one must not forget that "we do not feel, experience or know any becoming but becoming-reactive". ${ }^{496}$ In Deleuze, one must become reactive in order to become active again, in order to overcome resentment and reactivity, passivity, mechanicity. One transfigures all (re)activity into the apparent sentiment(ality) of the active type - one becomes reactivated, small, eternal: "the eternal return of the mean, small, reactive man not only makes the thought of the eternal return unbearable, it also makes the eternal return itself impossible; it puts contradiction into the eternal return".497

Not the eternal return of the reactive man, but the interchangeability of such terms as "active" and "reactive" makes the eternal return unbearable by turning it into a contradiction in the making, into a ghostly coexistence of the nihilist with the positivist, of the sage with the fool, or of the friend with the enemy. The interchangeability of the terms gives the illusion of an eternal return to the relativity of their meaning, to the performativity needed for their transformation into something which they are not (or which they are right from the beginning): eternal reality, eternal contradictoriness.

The eternal returns in the "mean, small, reactive" - in the drama of their displacements, which seems too naivé to be taken seriously, but also too dangerous in its

\footnotetext{
${ }^{495}$ J. Baudrillard, Simulacra and Simulation, Ann Arbor, MI: University of Michigan Press, 2006, p. 29.

${ }^{496}$ G. Deleuze, Nietzsche \& Philosophy, New York: Colombia University Press, 1983, p. 64.

${ }^{497}$ Ibid., p.65,
} 
becoming fashionable, performable, cinematic. In this minute version of meanness, smallness, reactivity, the real becomes an inevitable loop made in the cinematic order of eternal returning - a scenario of scenarios, accommodating dialectic as the ideology of oneness, accommodating, in the last analysis, the tempting illusion of three-dimensionality: the war-machine, the police, the intimate order, the third friend. In this loop towards doubling and tripling the "mean, small, and reactive," diversity and meaning, fashion and performance, otherness and oneness slip into one another, incessantly proposing themselves as economic, political, and cultural scenarios - scenarios that belong to the order of exception, to the order of becoming except, non-dialectical, tautological.

In this sense, the ordering order is no longer that of numbering numbers but that of un-numbering numbers - the accident, the differend, the unfashionable; the element that is not entirely recognizable, not entirely graspable, but all the more desirable and familiar, all the more distant perhaps, secluded and present. The displacement of one alternative brings to the fore the urgency of its replacement, the logic of causality as the secretive fabric of an indifferent reality, inoperative, indeed, but all the more so illusorily apt for displacement, for phantasmal and filmic transfigurations. ${ }^{498}$

Each scenario creates a gap, a dangerous looping, a cinematic impression of being true by virtue of abstraction. It generates itself as genuine gaping, looping, and filming, in a situation, a context, a "reality", which vanishes as soon as another gapping, another looping, comes into view. The line that demarcates or used to demarcate the passage of time from here to there is no longer in sight, no longer timely, familiar, visible. It has itself become a line of passage, a line of flight traveling through the lightness of the image, into

\footnotetext{
498، Clear Channel Communications is the largest radio station owner in the country. It runs more than twelve hundred channels, which together account for nine percent of the market. When hundreds of thousands of Americans took to the streets to protest against the war on Iraq, Clear Channel organized pro-war patriotic 'Rallies for America' across the country. It used its radio stations to advertise the events and then sent correspondents to cover them as though they were breaking news". A. Roy, An Ordinary Person's Guide to Empire, Cambridge, MA: South End Press, 2004, p. 57.
} 
the depth of the different, or of the "mean, small, reactive". It has become an ethereal other, a returning ghost as it were, of gapping and looping, filming and displacing, generating and transfiguring (otherness).

How can we recognize ourselves in the passage from time to timeliness, in the suspension of passages, in the very narrowness of passing, where there is only noise and darkness, movement, struggle? How can we follow the timeline that is not passing into time, nor into ourselves, but into the otherness that is to become us, we, ourselves? The answer is a flowing back, a (re)visitation, a return. It commences, it has commenced, will commence, at the same time at which it stops, it has stopped, will stop: it is nothing but secret, passage, ghost. $^{499}$

It is given in silence, as if in a mortifying mood, or in a thriller in which there is no temptation to create, but only the desire to effect creation, to give the illusion of creating, the illusion of having created illusions. The loop is perfect, perfectly morbid, perfectly creative. It borders nothing but itself, its own insanity and creativity, its own created reality - a film, a poem, a broken line.

Becoming creative, becoming illusory: this is the end, but also the beginning, the immemorial moment at which beginnings end and endings begin in such a way that time no longer makes any sense except perhaps for its passage, its flight, its rhizomatic constitutions and destitutions. Time proposes its own exit, its own deserting trajectory, its own death; it proposes its own transfiguration and displacement in and through its own passing: a double death.

The death of death that is time affirms itself in the life of life that is eternal. The

\footnotetext{
${ }^{499}$ Let us recall how the B'ath Party and eventually Saddam Hussein came to power in Iraq, through a coup d'etat whose every detail was known in advance by the American Central Intelligence Agency, because the CIA had agents within the group of plotters. As H. Rositzke says: “. . [H] aving secret contacts with plotters implies at least unofficial American complicity in the plot". The CIA's Secret Operations: Espionage, Counterespionage, and Covert Action, New York Thomas Y. Crowell, 1977, pp. 109-10. The United States military and intelligence appear to be ghost factories par excellence.
} 
syncope, the transition, the gap between them is but another timeline, another loop, another eternity, perhaps meaner, smaller, cheaper, but nonetheless returning, dying and living in the sameness of its own evanescence and illusionism. Against affirmation and nihilism, life and death, one chooses affirmative negativity, he chooses a living death - a strategy, an automatic device, a machine. Man becomes the living dead, the machine of lively death, the incarnation of his own dying moments - the postponing device of his own disappearance. If "for a human being to be 'alive while dead' is to be colonized" "500 by symbolism, to be 'dead while alive' means to incarnate the very escape from symbolism.

Man incarnates death and life, himself, his condition, but he does so in order to become something other than life and death, or at least other than the life and death that are his own by virtue of his living and dying. He is no longer human, no longer animal-like, but living and dying in between his own humanity and animality. Silently, his consciousness opens in between life and death, in their colonizing and decolonizing passages and exchanges.

In the openness (or closure) of consciousness, one no longer thinks, nor does he desire thinking, or a thoughtful life. He desires the other, he hungers for the emotion that is absent in thought, for the intensity of living. He crosses the border into the non-present of the present, into the non-being of the being that he is. Living in-between the imperial lines of force, he encounters the other of himself, the anchoring thread to another world, another life. He becomes the passage, the transitory ghost, the specter of his own becoming other of his own, pure and simple. This is the man of the present - or the present of man.

Far from being the dimension of separation and difference, or of identification and incorporation, as in Kristeva, the present is the dimension of secrecy and death, sacrifice and salvation, faith and objectivity - the decisive point between being and nothingness (in

\footnotetext{
${ }^{500}$ S. Žižek, The Plague of Fantasies, London and New York: Verso, 1997, p. 89.
} 
the Heideggerian sense), the point at which the present opens itself up as the death of being and the being of death: the double movement, or moment, between being and its disappearance. $^{501}$

The " $\mathrm{I}$ " is inseparable from the "non-I", from its counter-measure, or counter-image, to such an extent that they both cease to exist, cease to be. Oneness becomes the otherness of its own disappearance, the nothingness of its own presence. It becomes both presence and absence, life and death, principle and measure, separation that unites and disuniting inseparability; it becomes its own paradoxical condition of survival, its own condition of disappearance. The law that is life no longer has any law, but rules by non-ruling, by inducing, offering, alluring. This is the life of the present, the paradox of living within the death of all paradoxical presenting - time as paradoxical encounter, as accident, or extraneous commitment; time as its own ontology of disappearance. ${ }^{502}$

The paradox of (dis)placement is the paradox of disabling time in and through its own (trans)figurations and delusions, in and through its own hesitations and incredulity: the becoming "other" of time, or rather the becoming time of the other, the slippage of one into the other at the same time at which the other pours itself into the one - this is the passage, the grand pilgrimage of the human species, its facing the abyss of living. Time pours itself into the abyss, it fills it up, as it were, so as to prepare the way out of itself, out of its own condemnation and unhappiness.

Time vanishes and returns to this vanishing moment, to this sacrifice or incommensurable truth about its being. The return of the same bears witness to its disappearance, but also to its renewal as the betrayer and savior of its own existence. The unhappy consciousness that is time becomes happy in the face of its own disappearance, it

\footnotetext{
${ }^{501}$ See J. Derrida, The Gift of Death, Chicago: University of Chicago Press, 1996.

${ }^{502}$ See for example Lyotard's, Postmodern Condition, his idea of disappearing, of renouncing everything in the face of danger, in the face of the future. There is no way out of the present but the conscious renunciation, the conscious death one must assume in the face of inevitability.
} 
becomes oriental, estranging and disengaging, it becomes a non-consciousness, a double, a wondering ghost.

The otherness that is non-Time doubles the oneness that is Time through its own happiness, innocence and positivism. It becomes the image in the mirror, the copy of an untimely Narcissus. Time as other is this silencing happiness, this impenetrable image of falling in love with oneself. It is a stereotype, or rather a stereotypic film about love (as lovence, or loving one's own), an esthetic of the most profound and most delicate of feelings, a transfiguration of love into its own displacement, its own disappearance. Perhaps all ontology is reducible to this displacement, to this inevitable disappearance; perhaps all ontology is a footnote to falling in love with, being loved by, or loving death.

Man's destiny embodies and dis-embodies the ontological adventure (or ghost) of falling in love (i.e., with death). The positivism of the happy gaze is not the positivism of life, but the mysticism of being in love with the dead, its supernatural tendency to resurrect them and make them live again, this time in a world beyond death (i.e., our world). The positivism of the happy gaze is the positivism of living before death, as if living after it in an eternal moment of resurrection. Nihilism, on the other hand, is the affirmation of death, the recognition of death as the end of illusion, the terminal point of life, the ethereal pilgrimage through the life of dying men. It constitutes itself as a dying death, as a double (indirection) of living.

Positivism and nihilism reflect one another in the doubling forces of life and death, in the affirmation (of death) and negation (of life) that make up the resurrection of the one through the eternal damnation of the other (and vice-versa). Positivism as the resurrection of the death of life binds religiously a world devoid of religion, it binds the world blindly, through the religiosity and creativity of illusion, through which it ends up in the esthetics of the gaze - the happy gaze encountering itself, its falling in love with its own reflection. 
Nihilism is the fall from the grace of this loving feeling, the contestation of the ultimate esthetics of being in love - the unbinding feeling of loving love.

Being in love is both a fall from the grace of feeling and a feeling of deja-vu, a renunciation and a recognition, an unbinding distance and a binding familiarity. The unbinding distance that is in time is also binding, distancing, silent. It promises a different path, a different love. It promises to bind elsewhere, in the openness and newness of the future. In itself, this unbinding distance is a simple promise, a simplification. It opposes the binding familiarity of the present, the complicated present of affirmative and performative bindings - the religiosity of falling in and out of love with the world.

"The occasional ability to see men and things as mere phantoms or dreampictures", 503 permits imperial subjects to rule over their dream world in such a way as to make life possible and worth living. It permits one to cross the threshold of dreams into the reality of making them, into the non-creative world of Dionysian drunkenness where man is attuned to the selflessness of joy and forgetting. One either rules over these shadows and becomes a god or they rule over him and turn him into a lover of dreams.

Sometimes this ruling separation is reconciled and the two protagonists exchange gifts of esteem - they become one in a world of dreaming and dream-like lovers. Their fall from love is the fall from this ethereal reconciliation, from this oneness which is never truly bridged, never truly attained in the real world. The reconciliation seems to be purely ritualistic - a necessity to fall in love, a reduction. The gap is bridged but only superficially, as is the case with rituals. One is whole by falling in love with the other, by loving the other, while his love appears inconstant and unbinding, a helpless dream.

The occasional reconciliation between dreaming and loving finds its expression in the occasional exchange of gifts, which is the last resort of unbinding love, its last resource

\footnotetext{
${ }^{503}$ F. Nietzsche, The Birth of Tragedy, New York: Dover Publications, 1995, p. 2.
} 
in the face of its unrecognizable limit - "and so the drama becomes the Apollonian embodiment of Dionysian perceptions and influences, and therefore separates itself by a tremendous gap from the epic". ${ }^{504}$ The epic tells the tragedy of dismemberment, of falling apart, or falling out of love, which remains irreconcilable and unbridgeable as long as one does not see it as a shadow or dream-picture of the real.

The dream-picture is the Apollonian embodiment of Dionysian dismemberment, of the drunkenness characteristic to the artistic (esthetic) transfiguration of the world - it is a naive picture of art, the moment of intoxication to which one returns in search of his creativity. Through the ritualization of the artistic moment the gap between the two deities is bridged (they slip into one another), while the bridge between them is broken, or gapped, in such a way as to permit a periodical reconciliation.

Man's active and creative energies are reconciled through the brief coincidence of Apollonian and Dionysian cultures; his energies become identical copies of one another, identical images of the Apollonian-Dionysian tension. The two deities return to life indirectly and re-divide it into creative and active elements, into lightness and darkness, depth and naiveté, each becoming, slipping into, transfiguring the other so as to mark a new reconciliation, a new ritual.

In ritual, becoming other is inseparable from becoming one - becoming Dionysian, becoming dismembered, is inseparable from becoming Apollonian, creative, whole. Their inseparability is effected by their separation, by their creative opposition and tension, which is reconciled through their active becoming other, becoming one. Their union is based on their separation, their becoming one depends on their becoming two: the wholeness of their tragedy is the manifoldness of their naivéte, or vice-versa, in a deepening, or rather superficializing process of becoming whole and separated, Dionysian

\footnotetext{
${ }^{504}$ lbid., p. 27 .
} 
and Apollonian, naivé and creative.

The passage from one to the other is always present, in the present, as if taking place in a continuous time, in a continuous dimension, which can never be broken down, never replaced with something other than time, something other than the actual presenting of time - not time, but the passage of time is always present, always here, as if continuous, homogeneous, whole. The reconciliation between Apollonian and Dionysian moments is the reconciliation between the passage which is the present and the stasis which is the past, or the future (in the present); it is their renewal through the force of presenting, their animation, their creativity become live a posteriori and a priori.

Time as continuous passage from past to future, from Apollonian to Dionysian dimensions, presents the possibility of their reconciliation, of their coming together in a renewed whole(ness). Time as discontinuous whole(ness), time qua time, brings Apollo and Dionysus together. The dismembering quality of time passes into quantity, into the non-time of embodiment, or the absence of time. Outside time, time itself becomes dismembered, passing, quantifiable. It becomes non-time.

The passage that is time dissolves in the absence that is non-time, into the quantification of time qua time, or the embodiment of dismembered, disjointed timelines. The unifying quality of time subsists in and through this disjointing quantification - in and through this becoming non-time. From now on, the paradoxical coincidence of time and non-time marks a reconciliation that is no longer recognizable, no longer ontologically recognizable, but solely unfamiliar, out of joint, and spectacular.

This becoming unfamiliar, becoming spectacular, or uncommon, is no longer the mark of atonement, no longer the mark of tension, but the reconciled tension and the tensed reconciliation that is the absence of time, its end, or disappearance. Time is no more, nor is there any non-time, but solely the memory of having lived in time, through 
non-time. Time disappears into its own eternity, into its own non-being. It becomes the other of passing, the otherness of having passed, or having to pass from non-time to time qua time.

The becoming that is time no longer deserves that name, for there is no other becoming than becoming other, becoming the opposite of time, the opposite of becoming. In the last analysis, the passage that is time loops back into its absence, into its own indifference, from which it emerges transfigured, timely, and different. The apathy of time is commensurable to the fervor of non-time, to the becoming untimely of the naive artist, or naivé (over)man. In this commensurability, the time that passes into indifference turns itself into the naiveté of the other, into the fool that is also a sage, an anonymous, clandestine, figure, who is neither in time, nor in non-time, but in both, as their absence and presence, their identity and separateness, their love and betrayal.

The paradoxical figure of the fool and the sage (nowhere fully developed) bridges, or reconciles, the passage of time from non-time to eternity, from stasis to stasis, as it were, in a temporal looping that is neither absent nor present, but paradoxically constituted as the coming together that consists in dismembering the continuity of time, its ontological disappearance, as it were, or its creative, Apollonian, appearance.

The dismemberment of time qua time is the task of genealogy, the separation of the whole into superficial, indirect, energies - its transfiguration through the secularized displacement of its religiosity. Genealogy as indirection, or transfiguration of the displaced, is the Dionysian task of dismembering Apollo, the becoming un-timely of (non)time. It is also a return, a reconstitution of (non)time qua (non)time in the dimension that is non-timely, non-Apollonian - the becoming Dionysus of Apollo. The parallelism between the two transfigurations overcomes the Straussian-Kojevian argument regarding the relation between active and creative men - neither active, nor creative, one is both by 
being neither one nor the other.

Finally, the third transfiguration, the third displacement which has been there all along, comes forth as an absence, a non-presence, perhaps even as a delaying mechanism. It is the brief moment of friendliness, the favorable moment of gift exchanges, the moment of recognition and of falling in love. In this briefness, in this shortness of time, the reconciled parties consume their energies in becoming one, in loving and favoring one another, in changing the "game of the double from a subtle exchange of death with the Other into the eternity of the Same". ${ }^{505}$ In this shortness of time, or "stealing" of time, that which is the Same exchanges death with the other. It exchanges death (its own death) as a favor, or gift, as a sign not of recognition and falling in love, but of estrangement and enmity, a sign of becoming other.

This is the imperial war-machine, the becoming warrior, becoming man. It runs counter to becoming woman, again, to becoming animal, and reconciles them in the briefness of passages and exchanges between woman and animal, between being at war and being a machine. Becoming other than woman, becoming other than animal, other than a war-machine - perhaps a god or a beast, a god of beasts or a beast of gods: the ruinous prospect of becoming, the hope of overcoming otherness by falling pray to it, or again, the artistic becoming other, becoming naivé, feminine, animal-like.

The animal situation does contain a component of the human situation; if need be, the animal can be regarded as a subject for which the rest of the world is an object, but it is never given the possibility of regarding itself in this way. Elements of this situation can be grasped by human intelligence, but the animal cannot realize them. ${ }^{506}$

Dissimilar from man, the animal is like "water in water" - it moves in and through a medium to which it belongs entirely, being identical with and inseparable from it. The animal is the other of the human, the intimate order of being or becoming human - the

\footnotetext{
${ }^{505}$ J. Baudrillard, Simulacra and Simulation, Ann Arbor, MI: University of Michigan Press, 2004, p. 95. ${ }^{506}$ See G. Bataille, Theory of Religion, New York: Zone Books, 2001, p. 19.
} 
fluidity or transparency of oneness as opposed to the solidity and opaqueness of the human world: two media in opposition, two worlds separated and united through the intimacy of one and the exteriority of the other.

Man's animality is as much an intimate order as it is external, enveloping, water-like: the world of the other. The other gains human qualities, human desires and appearances it gains a world of similarities and debaucheries, an intimate, conspirational order of inimical properties and tendencies. The humanity of the animal becomes one with the animality of the human, a world of animalistic and human intimacies, of inconsistencies and superfluities. This is the world of the beast of pray, the non-Nietzschenean world, the Deleuzian world of becoming animal, becoming woman.

The war-machine is this becoming animal, this unexpected becoming human, which takes place by separating itself from the power of the State and by becoming one with it, by becoming its order and measure, its timely incarnation and its untimely spirit. The war machine is the "third friend", the warrior turned into a humanized animal, or a befriending piece of machinery. The expulsion of the war-machine (as in Deleuze and Guattari) is simultaneous to its containment within the State (as in P. Virilio) - to its becoming a machinery of expulsion and inclusion, a piece of equipment and/or a program destined to economize the becoming animal, becoming human, on a global scale.

The absorption or the expulsion of the machinery (its economy) opens the possibility of striating the space of the world according to an inclusive-exclusive process of humanization. The world of good and evil is the same with the world as good and evil: they are water-like orders, transparencies of one another, machineries striating the empty space of a fluid planet. The economy of emptiness stands against the emptiness of the economy, two radically unintelligible intelligibilities, two vortical movements arbitrarily separating the good from the wicked, the human from the animal, the state from the 
machine.

The externality of imperial war is also internal, hidden, intimate. It presupposes the coincidence of the exterior with the interior, the consummation of war by other means, the Foucauldian condition of consistent and continuous struggles, of a politics of war capable of including and excluding these struggles according to their potential for wealth. This is the politics of truth, the becoming wealthy by producing the truth of truth, or rather the truth of wealth, which can only mean truth as wealth.

This unexpected subsumption of wealth by truth (which is resolved, at least partially, in Negri's work) and of truth by wealth (as in the work of Foucault), maintains the doubling movement of a world completely estranged from both truth and wealth - the world of the machine, the becoming animal, becoming human. The economy of wealth and truth, of innocence and guilt, intimacy and humanity, is the economy of wholeness, the unsolvable riddle of economizing the emptiness of good and evil - the project of overcoming the other in and through otherness, or the project of overcoming us, we, ourselves by becoming they, them, themselves. ${ }^{507}$

The economy of this double becoming, the becoming animal of the other and the becoming human of the trinity $u s$, we, ourselves, fills the emptiness of space, the stillness of the animal-like, water-like, transparency. It fills it with the Apollonian vision of a Dionysian dismemberment, with becoming humanized and beastly, inimical and intimate, cautious and friendly.

The friend is both a humanized beast and a beastly human, a distant enemy and a

\footnotetext{
${ }^{507}$ According to A. Roy, Empire operates to win markets, to find infrastructures that can be privatized for a profit, and to gain control over natural resources, a set of goals she calls a blueprint. "This brutal blueprint has been used over and over again, across Latin America, Africa, Central and Southeast Asia. It has cost millions of lives. It goes without saying that every war empire wages becomes a just war. This, in large part, is due to the role of the corporate media. It's important to understand that the corporate media doesn't just support the neo-liberal project. It is the neo-liberal project. This is not a moral position it has chosen to take, it's structural. It's intrinsic to the economics of how the mass media works". An Ordinary Person's Guide to Empire, Cambridge, MA: South End Press, 2004, pp. 84-85.
} 
close acquaintance. He is the young man next door who is absent to us because he is fighting in the Middle East. He is the incarnation of contraries, the indifferent and empty presence that is time, passage, flow. There is no succession, no sequence to this presence, but only encounter, stillness, switching from one mood to another, from friendship to enmity, or from love to betrayal. The automation that is time (or the absence of time) turns the friendly acquaintance into an inimical beast, expulsing it from our world (of good), or from its picturesque consistency.

The expulsion is never real, never enacted at the will's command, but always extraneous and accidental. The humanized world of the machine compliments the inhuman consciousness of the human by turning the inimical beast into a friend and by including him into its intimate order: the order of the machine is the order of the enemy inasmuch as it is also the familiar order of the friend. One is no longer capable of deciding, no longer capable of doing anything else except economize the relation between friend and enemy, human and animal, machine and warrior. In such a relation, economy, decision, the terms are interchangeable, indifferent, serial. They number, categorize, define, something which cannot be numbered, categorized or defined - man. One might ask: what man, who?

The question is reminiscent of friends and enemies, it resides within them in a hidden posture, perhaps inhuman, unfriendly, but all the more so familiar and endeared (at least indirectly, or rather negatively). This is the posture of intimacy, the hidden side of all fashionable numbers and categories, the non-manly, feminine, side of being a man - a noncategorizable, unnumbered, singularity (familiarity). The closeness of the singular is anonymous and ungraspable, hidden so to speak, in the indirection that is familiar and seductive. The quietness and docility of the other (image) brings out this hidden indirection, this singularity which is, as yet, unfamiliarized with the closeness of otherness, with the emptiness in its heart. The intimacy that is this coming forth and/of emptiness, this 
presumptive and naivé reaction to the perception of otherness, distances itself from itself, or rather from its image in the other, and moves away as it were, disappearing in the fullness of the imagined.

The coldness that is this distance and fullness, this prerogative, this rationality, of having fallen out of love with oneself, pushes one closer and closer to the point of departure, to the inevitability of turning back and moving away, in an endless forking of possibilities and singularities. This precipitation, this unsure moment of man's beating heart, or of his falling in and out of love, marks his transfiguration, his indifference, or rather his incalculable, unforeseeable absence - his becoming other than closeness and distance, other than friend and enemy (e.g., the friend of the enemy), lover and loved one.

Man's absence within the fold - the place of intimacy, the emptiness and fullness of being folded, doubled, mirrored - is omniscient, incalculable, almost mystical. It goes beyond the artistry of the master, beyond the confusing violence of the warrior, or of the unhappy priest, into the clearing mood of the pacifier, or of the happy fool. This is the beginning of another fold, another temporality, perhaps one that will outdo itself, or has already done so. There is no ontology here, or at least no other ontology than that of disappearance - another footnote to Plato, or to the ancient understanding of dying.

In this stillness of the intimate, which is no longer aversive, no longer human, there is no likeness, nor otherness, but simplicity and silence, as if in a beginning or a wonderful narration. There is no movement here; narrating does not know ontology, it is ontological without ever realizing it. It is a suspension of ontology by the ontological: a trick. It is also a serious endeavor, an incommunicative principle bordering the insanity of the divine, the maddening truth about sacrificing oneself, one's own, oneness. It is an indelible sacrifice, a reality that has already passed innumerable times in and through the sameness of the intimate, which is really the presence of sorrow, of joy, or as Derrida suggests, of "a 
question of secrecy that it opens up and forever keeps from closing". 508

J. L. Nancy also talks about such an opening, or presence, which is "always-alreadythere and always-there-again, inexhaustibly withdrawn into itself, relentlessly exposed before us, womb traversed by a leap: ourselves before being born, after dying, always once again...". 509

The specter of the hidden is dispelled by this sacrifice of intimacy, by this refusal to return to the appearance of things and its sorrow. It is a return to the already-gone, to the silent, hidden, sacrificed. A mirage, a silent encounter, a return of returning ghosts: this is the space of the fold, the obscure, or intimate, space of sacrifice. The scaffold of Greek tragedy is no longer present, no longer apparent; in Nietzsche also this scaffolding meant something other than power and death, or power over death. It meant something other than sacrifice in and through the tragedy of living: it meant a birth, or rebirth of the tragic in the openness of closing thoughts and memories. More than anything, it meant a promise for the future, a different temporality.

The display of the tragic takes place somewhere else, in the vicinity of the hidden or on a distant scaffold, where everything becomes visible, apparent, perhaps even virtual. This is the nature of birth, the tragic birth which one witnesses from a distance. There is no other sense for giving birth than the becoming pregnant, which is to say, feminine, weak, animal-like. There is no other tragedy, no otherness to the tragic, than this transfiguration taking place in intimacy as if in the opening of the hidden, inside it, inside the real tragedy of the already dead (or not-here-yet), already visible to a certain extent, already virtualized.

Here, human tragedy is no longer transfigured, nor displaced in and through the assemblages of the scaffold, or of authority. There is no longer any sense of the tragic, no longer any intelligibility that could be attached to the production of sorrow and of hope.

\footnotetext{
${ }^{508} \mathrm{~J}$. Derrida, The Politics of Friendship, New York: Verso, 2005, p. 276.

${ }^{509}$ J. L. Nancy, The Ground of the Image, New York: Fordham University Press, 2004, p. 121.
} 
The tragic disappears behind its image, behind the scaffold that was once erected in order to make power communicable and bearable. It disappears inside the intimacy of the image, inside the hidden space of the fold, as if preparing to give birth to its own prodigy, or its own secret (power). The return of man is the return to this intimacy beyond the tragic, to this unbearable prospect of being in the fold, being hidden from the eyes of the other, be it a lover or a loved one, a friend or an enemy, someone who is not $I, m e$, myself, and who can only incarnate the "presence of an immemorial absence", 510 - the imperceptible, the hidden.

This return to the returning tragedian, to the interiorization not of tragedy, but of its scaffolding, its characters, its symbiotic choruses and sequences, its moving bodies, moving sounds, moving principles, is not tragic, not in the real sense anyway. This return to the returning man, returning tragedian, is nothing but scaffolding, tragedizing, humanizing - pure and simple distance, death, lyrics. Behind it, there is an entirely different picture, an entirely different metaphor, different intimacy, different future. Perhaps another tragedy, another man as well. But who is to tell?

One begins by returning to the hidden, the tragic, by way of the non-tragic, by way of a loop, if you wish, which is pierced through and through by the invisibility, the avoidance, the absence of tragedy. One outlives the tragic by returning to it, by beginning it anew. To this new beginning we must now turn, as if to an opening of, or a meditation on, its unavoidable end.

\footnotetext{
${ }^{510}$ Ibid., p. 122.
} 


\section{Chapter 16}

\section{Beginnings}

The depth of the city and of the eyes: always-already-there, therefore always to come again like the return of a past more ancient than any past...

$$
\text { J. L. Nancy }{ }^{511}
$$

To start something and end it at the same time at which it has started, to start the end as it were, by initiating its beginning, the end as beginning, not as in A. Badiou, the end as the end of truth, but the end and the beginning of truth in one suspension, one unending, initiating, detouring, illusion: this is the task for the future. The end begins in suspension, by suspension, as if it were true, truthful, truth. It hides itself indefinitely in this suspending mechanism or suspending economy which is, as Derrida suggests, an economy of secrets, an economy hiding from the very fact of its secretive existence, from the secret of secrets, from the beginning of the end of truth, or of that truth which is no longer uttered, no longer present or recognizable, but simply outmoded, simply forgotten - the truth of truth, the secret of being in truth, true, truthful: the secret of being suspended in, through, and as truth.

Questions arise: truthful to what, truthful to whom? Truthful in the sense in which one could become Rousseaunean by being non-Rousseaunean, in the sense in which one could become the common will by being uncommon, by thinking uncommonly, by feeling outside the common - in this sense? In another? Perhaps the sense in which one could become the other is no longer a sense, no longer a trajectory, nor a projection, but the lack of trajectories and projections, the lack of sense, sensing, sensation, in a word, the lack of direction, of logic, or space. One speaks of sense in its absence, in the profound and silencing way in which sensing dissolves itself in the heart of darkness, in the heart of

\footnotetext{
511J. L. Nancy, The Ground of the Image, New York: Fordham University Press, 2005, p. 118.
} 
things, or of desires. One speaks without speaking, or to paraphrase Derrida, one senses without sensing, one makes sense by not making any sense, by hiding behind this notmaking, this untruth which is most true, most familiar and intimate.

The way out is the way in, at least that is how Foucault would answer the question of truth, the question of faith, of modernity, of language, or what amounts to the same thing, the question of remaining true by being untruthful, the question of truth pure and simple, or of its untruth, of its lack of truthfulness, its lack of majuscules, lack of grand narratives, or of grandeur. The question of "ways" is the question of truth versus untruth, the question of faith versus unfaith, the most profound and most disturbing question about man, about his existence, his habitat, his happiness, even his science.

It is also a question of reversals and timing, of surviving in time by reversing it, by making it our own, our thought, our faith, our "way out". It is also a question of politics, of surviving by deceit in the midst of truth, in the midst of questioning, or of a multiplicity of questions and answers, of suspended directions, suspended alternatives and times. A multiplicity in the making, as it were, a multiplicity in movement, moving backwards and forwards, left and right, up and down, just as man does, the whole man, man as ontology, man as multiplicity of thoughts, presences, and personalities, or man as the presence of absence - the presence of desire, of sorrow, even of hope.

Through these movements one refreshes the present, one does not project any light upon it, nor does he make something of it, something other than what it already is - a sketch. This refreshing sketch comes forth as the present of the present, the presence which passes itself off as absence, as the impossibility of the possible, the non-genealogical in genealogy, the multiple in the singular and the singular in the multiple, which is none other than this moment, this debt (to thought, to science, to economy), this unfamiliar becoming other and becoming one; this presenting which is suspended in the future, as it were, in that 
future in which $\mathrm{H}$. Arendt uncovered the past and the present, the secret of their passing, the secret of hiding, or of thinking in hiding, through hiding, as hiding.

There is no consciousness beyond good and evil, Nietzsche understood this better than anyone else when he projected good beyond evil and evil beyond the good of having understood good and evil, of having gone with them beyond them, in their coexistent and coextensive futures and pasts, in their present, in their hiding places and their passages. ${ }^{512}$ Good and evil surpass one another beyond themselves, beyond us, beyond the I-you-he triad in which evil and good trade places, negotiate, barter, and buy one another off. This is the moment at which one begins to search, to look back in order to look forward in time, through time, as if already beyond good and evil, as if already questioning this beyond, this time situating itself outside time, outside evil and outside goodness.

Through this inevitable detour, we are back at the beginning, at the starting point at which Hegel meets his absolute in the coexistence of a Kantian and a Nietzschenean consciousnesses, in a minute deserting from and an explosive affirmation of the present, in a coextensive consciousness of becoming evil by becoming good and becoming good by becoming evil, or in an unexpected disappearance of history, of thought, of reality. A simulated absence, a repetition perhaps (in Deleuze's sense), a temporary confusion of good and evil: this is the beginning. It is also a memory, a sad consciousness, an unhappy, guilty beginning, a return of the same in the different, the dissimilar, the dissimulated sameness of the past, or the dissimulative order of the present (in the future). This beginning is also faith, faithful, fated; it is credence at its absolute, simplicity, knowing. Knowing one's place, one's fate, one's future, but also unknowing it, renouncing it indefinitely and indifferently.

The absolute in Hegel is the absolute in God, the voice that speaks inside time from

${ }^{512}$ F. Nietzsche, Beyond Good and Evil, Chicago: Regnery, 1955. 
without, from the distance of history and of faith - it is an absolute of speculation, of desire and elation. It speaks to no one by making its voice heard everywhere, which is to say that it speaks the language of the end of languages, it speaks the absence of language, its not being needed, not being useful, not being economic - the language of a non-economy, this play of words which, as Derrida puts it, "seems to contain the very possibility of a secret that hides and reveals itself at the same time within a single sentence and, more than that, within a single language". 513 To hide and reveal, to hide by revealing, by making something known, heard, seen. One hides truth by unveiling it, by encoding it into the language of the common, by turning its secret into everybody's secret, into everybody's language and curiosity. This is the place of truth - where everybody can see it, where language makes it known, seen, tangible.

The economy of truth begins here, in the visibility and non-secrecy of speaking and seeing, knowing and making it known. This is the secret of the secret, the economy of being seen, being known, being spoken of as if in secret, as if unbeknownst to no one. This secret that is spoken of economizes the gaze, it economizes speech, knowledge, sacrifice it economizes the mind, the body through the mind, man as we know him, the whole of man, the whole of what man thinks and feels while speaking and seeing, feeling and hearing. This economy of the non-economical, this secret unveiling itself by veiling its gaze, its truth, its economy, is once again traced back, located, economized, hidden. It is turned back into the absolute that it is, into the infinite, the eternal - into a god without a name, without a place or a timeline.

In this infinite turning, "philosophy must examine the possibility of a point of interruption, - not because all this must be interrupted - but because thought at least must be able to extract itself from this circulation and take possession of itself once again as

\footnotetext{
${ }^{513}$ J. Derrida, The Gift of Death, Chicago: University of Chicago Press, 1995, p. 87.
} 
something other than circulation". 514 The absolute that is this economy of absoluteness must extract itself from itself, as it were, it must interrupt itself so as to delay its finale, its demise, its bankruptcy. It must delay its becoming common, becoming infinitely banal, infinitely boring. It must refuse itself the privilege of absoluteness by interrupting its economy, its circulation, its thinking. It must sacrifice itself-for-itself, its own circulation for its own possession, its own possessiveness for its own circulation - its own pure and simple.

The absolute comes so close to the common that it becomes the common by slipping into it, by engulfing itself within it, by taking itself to be in and through the common, or by taking its secret to be the common, in the common, through the common, and so on. The absolute is not absolute by displacing the uncommon, as in Negri, nor by flattening itself upon the horizontality of the common, but by immersing itself in the common, by hiding itself within the common, for the common, as if it were its faith, its destiny, its secret. This time, philosophy does not hide itself in the flatness of its economy, nor does it allow this economy to take over the place of its hiding, it rather makes itself into a destiny, into a place of hiding, an economy of the non-economical - a non-absolute, non-common. It makes itself into that destiny which is uncommon and yet commonly held to be destined, made, privileged, into a destiny that is also a non-destiny of the destined, an impossible, implausible task, but all the more ardent, all the more necessary.

This doubling of the double is reflected in love, or rather in the mirror of love and poverty, but also in the mirror of hatred, in the shadow that is cast beyond all shadows and all doubt, in another beginning, or another end. The end is no longer metaphorical, no longer spectral, but loved, appropriated, possessed. This is where one begins to love, to live in the poverty and immateriality of hatred, in the poverty and immateriality of

\footnotetext{
${ }^{514}$ A. Badiou, Infinite Thought, New York: Continuum, 2005, p. 36.
} 
betrayal. In Derrida, one recovers this immateriality of betrayal in European history, European Christendom, European consciousness - it recovers the source of Europeaness, the source of economizing by betraying the economical, the loved one, the neighbor. It also uncovers the possibility of European politics, the possibility of becoming the other by sacrificing one's own, by betraying it out of love, out of lovence. The possibility of European politics rests with a going beyond good and evil, beyond Athens and Rome, beyond love and hatred - in the (in)difference of being loved and of being in love, in the (in)difference of being the enemy or the friend, the specter or its ghost(s).

In L. Strauss, one dialogues his way out of Athens and Jerusalem, one goes beyond them in and through language, in and through the power of argumentation and reasoning around language, in and through the absence of language. One is already indifferent to love and hatred, to their economy, to the history of their betrayals: he is already beyond them, in the clearing opened up by their friendships and their enmities. One is already political, already discursive in the language of friends and enemies, already Schmittean - one is already betrayed by and betraying all friends and enemies, all alliances and conflicts; he is acting politically, not ethically, nor economically, but politically correct, politically just and true. This justice, this truth, this correctness, which is political, or of the political, but also outside of it, outside its alliances and misalliances, its friendly and inimical specters, is no longer dialogical, no longer argumentative or reasonable, but rather ethical, totalitarian and hierarchical. It betrays its own politics, its own logic, its own, and goes to the other side by betraying them, by economizing their death, their love of death, or of one another.

This sacrifice, which is also a return after one has traveled beyond good and evil, anticipates what is going to happen, what is going to begin in and through the end of good and evil, what (or who) is going to economize the beyond, its anticipation, or its event. This sacrifice situates the economic event within the political, as the political, as if there 
were nothing else but this anticipation of politics, this going beyond and betraying it so that it can come into its own, for its own. This situating of the beyond, or of anticipation, within the reach of politics, creates a new politicality, a new governmentality of the ungoverned and the apolitical, wherein their sacrifice is also their escape, their becoming political, becoming situated within the eternal. For Derrida, their gift is death, their death is infinite gift, infinite sacrifice - infinite economy, as it were. For A. Badiou, "death is the return of the multiple to the void from which it is woven", ${ }^{515}$ it consists of nullity, or rather of a return of being to this nullity situated inside itself: "there is nothing to be thought in death, even if it be the death of an empire", ${ }^{516}$ nothing not-thinking-itself-within-itself, or again, nothing(ness) not thinking anything, being the non-thought of being, the hole in knowledge as Lacan would say.

The circularity of concepts, especially of the concept of death - death as infinite nonthought, infinite sacrifice, infinite gift (for-the-other) - simulates eternity, or rather the eternal return of the same, the repetition of the event of returning, of sameness and of eternity. The examples abound, from Foucault's panoptical vision of modern power to Levinas" "man as god", from Negri's singularity to Derrida's uncovering of the one in the other and of the other in the one; from Dumézil's notion of potlatch to Bataille's clear consciousness as the consciousness of excess, of lavish spoiling of gifts; from the Kojevian time of desire, of animality and biology, to. Baudrillard's simulacra, from Žižek's phantasmal content to Nancy's 'immemorial absence'. The invisible thread connecting all these examples is the circularity of being and the illusion (or hope?) of its escape from itself, its looping out of itself, its doubling and its incessant returning to itself - in the mirror, in real-time, in eternity. This invisibility of connection, this incessancy of the invisible in connection to itself provides us with a new conception of the absence, or

\footnotetext{
${ }_{515}^{51 \text { bid., p. } 97 .}$

${ }^{516}$ Ibid.
} 
circularity, of time: time as roundness in motion, as the complete and incomplete movement of a circle around its axes, time as evolving fixity, time as threading inconsistency - a ghost.

Time as the trace of life, the trace of death tracing life, or rather as the tracing of possible traces of living and dying. Time as the inconsistency of living time, as the eternity of consistent being and consistent dying. Time qua time in place of time qua space, in place of spatialized time, of innovative, creative, rewarded time of eternities in the making, or of what amounts to the same thing: eternal variations of the absent, the invisible, the ghostly. This thoughtful effort, this Nietzschenean effort of going beyond the mere duration of time, beyond the good and evil of living in time, through time, is indifferent to both, different in its indifference from both logic and economy, order and sacrifice, or rather from the logic and order of economy and sacrifice. Consciousness does not judge. It does not recognize itself in the Kantian vigilance, or in its defunct duty. It rather slips behind itself - like the mists of an April morning - in an effort to become something other, something indirectly conscious and responsible, indirectly alive.

The singularity that escapes consciousness is this liveliness, this unconscious responsibility to life, for life, which is always evading death, always evading the consciousness of death that is the imperial world, the place and horizon of that world - its time. This consciousness of escape, this escape from escaping, from fleeing death, the world, space, time - reverberates and resonates in the emptiness of its own singularity, in the death that comes from within and from without, incessantly, as if in a coma, or a dream. This consciousness of being conscious about death, about dying in the middle of nowhere, in the singularity of a moment, or of a place without a name, but also in the singularity (not nullity) of being there, being in the grasp of death, at the last moment, in the last place of all places, interrupts and erupts in life, through life. Death is a mirror, a 
simulated presence. To consciousness, death is the source of all evading, and hence of all life.

This obsessive and recurring theme of death which is also an obsession with economy, with life, with the possibility of survival but also with the possibility of possessing, of surviving through violent possession, through violence and possession, repeats death, or rather, as Baudrillard would convey, doubles death in and through the simulation of the real. In the imperial world, the real is dead, which is to say that its economy coincides with the economy of death, dying, the dead. The economy is this death of the real, this possession of the real by death, the dead, dying. It is a vicious circle, an infinite return of death to the real, for the real. It commences nowhere and ends nowhere, as if it were itself only beginning and end, incommensurability of beginning and end, infinite beginning and infinite end - the beginning within the end and the end within the beginning, this post-Hegelianism of the guilty consciousness, which emerges as a continual trembling in the face of life and death alike. What would be the gift of life without the gift of death, without the credence that is in life through death and in death through life, without the secret compromise of consciousness, or the spectacular horizon that opens and closes ahead of us as a specter of death, a specter of life also - or rather a specter of life and death?

Illusion is making believe by making disappear, which is to say that there is a correspondence between death and illusion, between the illusion of death and the death of illusion, which is none other than the infinity, the haunting specter of making believe, making disappear. In the fabric of illusion there is only disappearance, only death turning slowly into the life of another, the life of dying for life at the last moment, in the last place, with one last name. These interruptions of the illusion of living, these names, these detours into naming and placing, into the moment of death, or of living death, living by dying, 
living dead, are illusorily interrupting the illusion of interruption, the agony as it were of the illusorily alive, or the illusorily dead - a spectacle of agony, an illusive tragedy of the illusory. Perhaps this is the most profound condition of politics, the condition of becoming political, becoming economically advantageous in and through the illusion of becoming other, becoming illusory (i.e., becoming animal, becoming woman).

From becoming other, becoming illusory, one passes to becoming political, becoming economic, except that now "becoming" is only illusorily attached to the other, to its economy, or its politics. The illusion of illusion that is "becoming" no longer passes from the political to its beyond, but from the political illusion to the illusorily political and economic other. The terms are invariably interchangeable, as all terms are in this illusion of the illusory, they reject and attract each other incessantly, interposing themselves in between one another, upsetting, interrupting, suffocating one another. These terms are the terms of living in and through the phantasm of living, in and through the illusion of thinking human life, thinking its disappearance and death, thinking politically. They hide within themselves this illusion, they become this illusion of illusions, this incommensurability that is political through speech and secrecy, through absence and death.

Death as the secret of the illusion of language, death as the secret of language, of the illusion called language, is also non-secretive, non-illusory, immemorial. The secret of being secret is this immemoriality of speech, this openness that is in language (in J. L. Nancy's sense $e^{517}$ ), in the secret of being spoken of, or being in the open. This coincidence between the secret of language (being in the open) and the closing horizon of the political, the secret of becoming political (becoming other, becoming illusory), is another death, another closure, or another possibility. It opens itself in the closure of the political as such,

\footnotetext{
${ }^{517}$ J. L. Nancy, Hegel: The Restlessness of the Negative, Minneapolis \& London: University of Minnesota Press, 2002.
} 
in the secret of becoming apolitical (as the essence of the political), subjective, knowledgeable - a secretive becoming other. The horizon (or specter) of this becoming is the horizon of empire, the possibility of surviving politically in and through the illusion of a secretive becoming other, becoming imperial, becoming whole. It is also a becoming in the sense in which Levinas speaks of the third dimension: "a third way emerges, in which we can understand the totality as a totality of $m e$ 's, at once without conceptual unity and in relationship with one another". 518

The presence of the third way is a necessary illusion in the incommensurability of the doubles undergoing and escaping death, a necessary thread of the narrative, or narrating thread as Kristeva would call it, positing it subliminally, introvertedly, but always with a care for openings, for breaks and possibilities, always ex-centric and (de)structuring, always (de)generative, (im)plicating, mutating and expanding from the interiority of the body to the exteriority of language, from the silence of the principle to the noise of its dissemination. From now on, structures are no longer silent, precarious, and banal, they no longer belong exclusively to buildings (as $\mathrm{H}$. Arendt warned they might), they rather mutate into the organic (or mutate the organic into the inorganic, which amounts to the same thing), into a lively "I-you", a lively/lovely he - an outsider, an image of outside, a presence of absence.

Again and again, one returns to this presence of absence, to this incorporeality of the corporeal, to this testamentary ghost of having been present, having witnessed, having threaded an important event - a narrative, a dream, an illusion. Again and again one fails to unite the theme with the absence of a theme, one fails perhaps in abolishing and affirming the same theme, the same absence, the same, or the sameness which is always present and absent, failing and succeeding, abolishing and affirming.

\footnotetext{
${ }^{518}$ E. Levinas, The-Thinking-of-the-Other entre nous, Columbia University Press, New York, 1998, p. 27 , italics mine.
} 
This incorporeal failure, this tremendous attempt at rupturing the continuum of a theme of absences and ruptures, this structure of threads and odd ends, of inconsistencies and variations fluctuating and destabilizing the chora $^{519}$ of its own narrative, its own substantiation and subjectivation of failure, also succeeds by becoming small (in Nietzsche's and later in Derrida's sense of an eternal return of the small, the insignificant, the immature), becoming corporeal. This alienation of the incorporeal, always in a sense Hegelian, principled, rarefied, commences where there is no principle, no practicality to the principle proposing a lack of principles; it commences in the presence of an absence, as it were, in the heart of things, or of man; it commences, once again, by presenting itself as the principle of absence, the principle of losing, sacrificing, becoming other. In it, there is no duration, no succession, no marginality, everything happens spontaneously, provisionally, necessarily. Everything succumbs to this lack of principles, to this suspension that becomes the only principle, the only testament, the only reality.

In suspension, everything is structured and destructured according to an impossible disappearance (absence), an impossible movement of the unmovable, or an impossible principle of a lack of principles. Everything rotates around a lack of axes, around an emptiness being generated by this principle of lacking, of vacating or clearing axiological thinking, axiological evolutions and movements. This choratic space, or outer-space as it were, which is so characteristic of language without being linguistically determined - in the sense in which sound is and is not space, spatial, spatialized - is not about the formation, nor the aim of language, but about its arbitrariness, its hovering around, its nimbus, as it were, its being there as exteriority, as outer-limit, but also as the most profound interiority, the most hidden, most intimate, promise of interiority. In this sense, language precedes thought, but also (post)cedes it, it follows it into the formation of its

\footnotetext{
${ }^{519}$ I use it in J. Kristeva's sense of "an essentially mobile and extremely provisional articulation constituted by movements and their ephemeral stases...".; The Portable Kristeva, New York: Columbia University Press, 2002, p. 35.
} 
own space, its own sounds; it follows it into the formation of something which is neither space, nor sound, but the space around, in and through ${ }^{520}$ sound, the sound's presence (as roundness, passage, flow) in space - as pure reflection, or principle.

The lack of structures, the de-structuralist, de-constructivist, approaches to the dissymmetry of symmetric choras, of symmetric economics and bio-politics, proposes only a superficial advancement, a superficial becoming, or a superficial destructuring, which in turn composes another structure, another constructivism, another symmetry. The point of failure in all these approaches is this Kristevian (dis)adjustment, this beyond Derrida, along Derrida, with Derrida, in which language is a ghost and a specter, a singularity and a plurality, a principle and a structure. By this beyond, along, with, one means the life after death that is implied in the life of death, the life that is death and the death that is life, conjointly, vividly, deadly. This implication of the "beyond" in the affairs of the imperial present, this irresistible coincidence of the specter of the dead and the living alike, this impossible unity in disunity that is in, through, and around thought, in and through the presence of thought in itself, disappears in the absence that is thought-in-itself, in the death, the void, the emptiness that becomes, around it, the specter of its own presence - a ghost.

In our imperial age, the ghost is the ghost of death, of thinking death, of economizing the disappearance of the living, their passing through, and their passing beyond or passing in silence. This specter, which is no longer a "hole in knowledge" but knowledge pure and simple, turns into a passage, a clearing, an emptiness - knowledge beyond knowledge, beyond passing, beyond all clearing. Knowledge emerges as nothingness, as pure and absolute nothingness, pure and absolute absence. This is knowledge in the Heideggerian sense, in which Dasein awakens to life by betraying death, by being thrown in its way, or

\footnotetext{
${ }^{520} \mathrm{Cf} .$, Ibid., p. 31.
} 
within its grasp. This knowledge of the clearing, this unknowing knowledge, or unknowing thought, commences another passage, another becoming. If only in the wake of death, if only from beyond all possibilities, at least in thought, it commences a return home, a return to the sameness of all homes, the sameness of all returns through death and disappearance, through the clearing that has commenced in and through knowledge, or through the clearance that is knowledge.

For us, it is no longer a matter of escaping modernity (if it ever was), but a matter of escaping life, escaping the specter of knowing imperial life through death, of economizing it in such a way that an escape from it becomes a return to it, a return to the knowledge of death, dying, deadliness; a return to this illusory escape from the wasteland of thought, of ghosts and of history. It is a return to escaping, an escaping return, a double mixture of promises and truths, a complete package of becoming whole, becoming nomadic, becoming in passing. All of this transpires on the condition that this becoming, this time, is nothing but nothingness - not negativity, not death, not ghostly alibi, but absolute nothingness, absolute absence of life and of thought, absolute silence. In this absoluteness of the absolute, in this stillness of the wasted, the dead, the dying, there is nothing to ponder upon, nothing to grasp, or to violate. Man clears not only his past, but his consciousness as well, his memory, his language. He does not clear it in the Nietzschenean sense of becoming childish, becoming naivé, inoffensive, but in the sense in which one never has had a past, never has had anything except the present, this moment, this passing by, passing through, in and through which one becomes present, absolutely present in its own absence, or its own death.

This is the ghost of becoming other, becoming in death, his death, which is no longer a simple metaphor, a religious metaphor, but an intractable reality, a becoming intractable, 
becoming "real". It is also a specter, a pulverization of this becoming - a dissemination. ${ }^{521}$ The real becomes ghostly, it becomes, as Baudrillard would suggest, the dream of the simulated: the Freudian dream logic, the phantasm of a phantasm - another indirection, another space. One becomes intractable by tracing himself in this way, one hides in the transparency of dreams, in their dramas and their escapes - one becomes transparent, dramatic, evading. One becomes, as G. Bataille once hoped, like "water in water". One awakens to the discovery that one is becoming transparent, becoming one with, becoming indiscernible - becoming imponderable, immaterial, ghostly.

This becoming toward, in and through knowledge, this imponderability of thought thinking its own becoming real, its own becoming dream, becoming drama, falls behind Kristeva's becoming neuronal, becoming less than psychotic, or less than schizophrenic; it falls behind its own consciousness, its own knowledge of becoming conscious, becoming thought. Kristeva's semiotico-symbolic ${ }^{522}$ structure of language (of speaking, of being in and through speech), is very much in tone with McLuhan's vision of an essentially neuronal world, or with Heidegger's, even H. Arendt's networking in and through being there (being the consciousness of being there, being the thought of being there), or with Deleuze's and Guattari's becoming schizophrenic, becoming non-thought, becoming dispersed, except that now this structure (ghost, specter, phantom) speaks itself in and through the wasteland of its own becoming. Kristeva's ireligiosity seems to be exactly this becoming religious, this becoming ghostly and spectral in the face of certitude (of language), this archaic return to the symbolic in and through the semiotic, in and through becoming less psychotic, less schizophrenic, less absolute.

The question of power rests, at least for now, with this becoming ethereal, this

\footnotetext{
${ }^{521}$ Perhaps this is the sense in which A. Negri and M. Hardt envision the utopia of empire.

${ }^{522}$ According to J. Kristeva, the semiotic (drive) is the precondition of the symbolic (judgment), but also inevitably its conclusion, its drama, its DNA; in "Revolution in Poetic Language", Portable Kristeva, New York: Columbia University Press, 2002, pp. 23-70.
} 
becoming archaic, this becoming mythical, or ghostly. Power in the real, or of the real, is this attempt at becoming invisible, becoming transparent, becoming omniscient, in the face of the other, against the other, or as the other. In Kristeva this power is structural, neuronal, networked. It aligns itself with Foucault's thought, with the arid and apolitical thought of being toward, in and through power, as if in a simulation, or a repetition. Empire is simulated and repeated herein, its power, its sovereignty as well - in the sense in which Marxism was performed by the communist party? In the sense in which liberalism repeats and simulates liberty, libertanianism, liberalizing? In the sense in which one produces repetitively, simulatively, as if in a film, or as a film? One could only answer by saying yes to this triad of becoming communist, becoming liberal, becoming image. One also says no by simulating and repeating the answer yes.

The reduction of the ideological triad to the dialectic of part and whole, freedom and equality, justice and right, is but another way of answering the question by propelling it outside of its own affirmation and negation, outside of its absence, as it were, into the full presence of simulation, of repetition and productivity. The question of power boils down to the question of survival, to the question of surviving this absence of power, of traversing its wasteland (what A. Badiou calls "a repulsive mixture of opinion and power",523), its suspension in and through simulation, language, or thought. Power, like language in Kristeva, or structuralism for the Frankfurt school, feeds its own suspension, its own simulation, it feeds itself not as in Foucault, where everything is power precisely because power is nowhere to be found, it feeds (perhaps as in Baudrillard) through its ghosts, its specters, its simulacra. These ghosts, captured by Derrida in The Politics of Friendship as well as in other works escape politics precisely because they escape power, because they themselves are the suspension of power, the very presence that is absent, unnatural, and

\footnotetext{
${ }^{523}$ A. Badiou, Infinite Thought, New York: Continuum, 2005 , p. 53.
} 
apolitical.

One returns thus to Levinas, and perhaps in a very subtle way to Hegel (not to the dialectical Hegel, but to Hegel gazing at Napoleon passing by, realizing that he was watching history's, and imperialism's, leading edge), to the mirror image of a mirror image of a mirror image, finally, to an image of an image, an image facing another, a chain of images, events, or ghosts, facing each other, facing backwards and forwards, as if in a dream, or a thinking thought. One returns to the symbolic chain of mimesis, to the harmonized coexistence of an infinity of human copies, human thoughts, human desires. One assists, one lives through the ordinary description of such places, such gatherings of the multitudes in the imperfection of their copies, their images, their portraits, only to return to the gathering of the real, the gathering of the multiple, the gathering dust.

One is always the one of power, the one in the narrative - the one narrative, one power, one desire, which is not in the other, not like the other, but the other. The variation of this archaic difference is also a variation of similitude, a going back to the archaism of power, to the archaism of narrating in and through, but also around the power of archaism. Oneness revives this archeological fever of narrating, this despotism of the ghost, of being indivisible, invulnerable, and (im)permanent, in and through division and permanence, vulnerability, multiplicity. One is simply by not being, by becoming a ghost, a specter, a haunting memory of something other, something else, something which is neither dead, nor alive, but simply dead and alive: a compromise, a truce, a suspension, perhaps even an alibi, an excuse, a myth. For now, this blurring oneness presupposes another becoming altogether, it presupposes more than that, a ghostly becoming, a specter haunting not only Europe, but the others as well: a becoming spectral, becoming spirit. The becoming spirit of spirit $^{524}$, the non-Hegelian spirit of Hegel, the non-Marxist spirit of Marx, the non-spirit

\footnotetext{
${ }^{524}$ See J. Derrida, Specters of Marx, New York: Routledge Classics, 2006 , p. 4.
} 
of spirit, the ghost, the spectral lines of becoming other, becoming the opposite, becoming spiritual.

This linearity, this becoming linear, spectral, (a)temporal, which comes about in opposition (i.e., narration), or in disjointing, strives to set everything right, on the right path, at the right time. Man appears haunted by this memory of setting right, setting in time, which is also a setting in nothingness, through nothingness. He comes into a life of death and casts himself off at the same time at which he recollects this casting off, this disjoining, which he must set right, set in time. The ghost is this spectral figure of becoming spiritual by remembering the opposite of spirit. As specter, man is more than a simple apparition. He is a plurality of ghosts, a plurality of spirits following their own destinies, their own death and faith. This plurality (almost neuronal) of becoming one, becoming ghostly, becoming spirit, is also a dense presence, an indiscernible, ethereal, totality of spirits, ghosts, specters - of oneness, uniqueness, singularity. Spirits becoming spirits, becoming unique, becoming singular - spirits of spirits.

The indirection that is this presence of plurality, this becoming spirit of man, is also the indirection of the end, the end proper, the narrative of ending, of becoming through some end, through some spirit which ends things only to begin them anew, to set them right, set them in time. This indirection is double, an end and a beginning, a setting off and a setting right, a disjoining and a joining together: a specter. The specter of a plurality of such indirections, or of indirect worlds, indirect beings: this is the present, "a passage, to be sure, and thus by definition a transitory moment, but whose transition comes, if one may say that, from the future". ${ }^{525}$ Indirection as passage, indirection as a ghost haunting us from the future, not from the past, which is the ghost of ghosts (the specter), but from that which is not here yet and can only be what it is, or has already been - spirit, consciousness,

\footnotetext{
${ }^{525} \mathrm{~J}$. Derrida, Specters of Marx, New York: Routledge Classics, 2006, p. 28.
} 
subject.

This indirect becoming of the future (in and through the present), but also of the present (in and through the future), is also present, passing itself off in passing, as passing. It is the presence of absence, the indistinguishable presence of totality, completeness, oneness, the becoming totalitarian, becoming complete, becoming one. This is the future, the future in/of the imperial present but also the present in/of the future - the disjointed lines, disjointing passages of becoming ghostly, becoming through the ghost of becoming, through the presence which is absolute and necessary absence, absoluteness, necessity. Through it we become ghostly, become backwards, we become by returning to the same moment of the present, to the same future, the same return. We relapse, relay, replay in time, through time, we, the disjointed apparitions, the ghosts of ghosts. A new specter haunts us, it is the specter of the future, the specter of becoming backwards, becoming by return. It meets us half way, just as the other (specter) does. And "this already suffices to distinguish the specter not only from the icon or the idol but also from the image of the image, from the Platonic phantasms, as well as from the simple simulacrum...."526

\footnotetext{
${ }^{526}$ Ibid., p. 6.
} 


\section{Conclusion}

History smiles at all attempts to force its flow into theoretical patterns or logical grooves; it plays havoc with our generalizations, breaks all our rules; history is baroque.

W. and A. Durant ${ }^{527}$

In the past few years the charge of 'betrayal' has become all too common. Yet, with all the fanfare and publicity attached to these charges, there has been surprisingly little written about what we even mean by the term.

$$
\text { R. L. Jackson }{ }^{528}
$$

The most important thread linking the American and European literatures on empire is the primacy of acknowledging imperial presence and constitution. Both literatures submit from the start to the primacy of conceiving empire, and they seem to be doing so due to some pressing, realistically determined, or rhetorically generated "ends". At the most profound level, the primacy of "ends" determines the primacy of thinking and projecting the possibility of empire. In this sense, the beginning of imperial constitution is already marked, or rather moved, by the possibility of its "ends". Thinking about empire commences its ordeal by betraying what one wants to keep in closeness (i.e., the imperial solution), in the intimacy of one's decision, or in the eventuality of a new possibility, or a new friendship. Yet, no matter how hard one tries, ends fail to submit to the rigor of categories; they rather slip out and inhabit, or prefigure, the non-categorizable nature of imperial beginnings, or imperial practice. Since in the imperial ordering of the political spectacle there are no recognizable tragedies, nor any recognizable ends, one cannot say with certitude that a happy ending is indeed happy (for who? when?), or that a tragic finality is really tragic. The end, in all of its appearances, is a limit. And as a limit, it is

\footnotetext{
${ }^{527}$ W. and A. Durant, The Lessons of History, New York: Simon \& Schuster, 1968, p. 13.

${ }^{528}$ R. L. Jackson, "The Sense and Sensibility of Betrayal: the Meaning of Treachery through Jane Austen," Humanitas, vol. 13, no. 2, 2000, p. 72. http://www.nhinet.org/jackson 13-2.pdf.
} 
indifferent to the narrowness and strictness of categories and definitions. It is oblivious to the certitude or ideality of its own happy ${ }^{529}$ traces.

In the American discourse, "primacy" transpires as the politically prevailing school of thought, which advises that the U.S. must retain its unipolar moment by preventing the rise of bipolarism or multipolarism for as long as possible. In contrast with the European literature, which attempts to extend the imperial experience beyond the unilateral horizon (not to say syncope) of power, the Americans advance a top-down or 'objective' view of empire. A good example of this school's apologetic gestures is M. Mandelbaum's The Case for Goliath, in which he argues that the US is not an empire (except for its excessive energy needs, and its penchant for militarily imposed nation-building), but that it certainly provides a world government, an imposed peace, a set of structuring institutions, services, practices, and the leadership upon which global peace, prosperity and the pursuit of happiness now rely. ${ }^{530}$ Such apologetic gestures, recurring as they are, appear to freeze the American moment under the spell of a curious indecisiveness, or a curious tendency to deny the primacy of empire, or at least its simulative "end".

A contemporary protagonist in the American primacy discourse, C. Johnson, takes us a step further into the imperial/empirical maze of power, and he does so not but questioning the fact of primacy, but its desirability. He is not pursuing an 'internal', 'subjective', view of how the imperial age is being experienced by those upon whom it is imposed, but rather shows how the imposition of imperialism impacts US 'domestic' affairs. In a trilogy of closely knitted works on empire, he argues that the imperial role is

\footnotetext{
${ }^{529}$ The use of the word "happy", or happiness, is not arbitrary, least of all poetic, it rather threads a line of argument that runs its course from, say, Baudrillard's contention that machines are primarily deterring machines, whereas my point is that they are primarily indulging machines (i.e., indulging the fantasy of happiness, eternity, bliss, even terror), to the opposite point, in Negri, where the ontological propels the 'to-come' towards a "happy" materialism (itself a seduction and nothing more). My point would be that it propels man towards a radically nihilist stance, whereby happiness and unhappiness become quite indistinguishable - and, as we know, this is the terrain of tyranny par excellence.

${ }^{530}$ M. Mandelbaum, The Case for Goliath: How America Acts as the World's Government in the Twenty-first Century, Cambridge, MA: Public Affairs [Perseus Book Group], 2005.
} 
destroying both the republican constitution and its democratic heritage. Following $\mathrm{H}$. Arendt $^{531}$, he claims that empire and democracy are incompatible, and have been clearly understood to be so ever since the Romans stumbled over this discovery in the early Christian era. For C. Johnson, the duties of empire are not only creating the blowback of terroristic ghosts against which the imperial military forces are now overextendedly jousting; these duties are also rapidly and powerfully undermining the 'democracy' of domestic institutions. ${ }^{532}$ In short, the inside-outside divide has gained somewhat of a primacy in American political and scholarly discourse, migrating back and forth between the notions of empire and democracy, foreign and domestic, practice and leadership, desirability and end, in an effort to conceal and to oppose, or rather to postpone, the very moment (not to say history) of the unilateralism it wants to establish.

As imperial limit, the "end" commences perpetually by invoking its own finalities, its own failures or dangers, which in retrospect embody some logical sets of operations, techniques, or effects of an "ending" intervention that is no longer visible, nor localizable, but rather deflected and deferred through the unrecognizable venues of being operated upon, operating, becoming operative, and so on. Imperial consciousness settles in as an attempt to escape the end of imperial operative order, the primacy of "the end", or the primacy of having to betray such an "ending" order of imperial constitution(alism). Perhaps this is the most profound insight outlined in the present thesis, an insight that traces the workings of a politics of betrayal to its own finalities, failures and dangers, but also to the possibility of overcoming them by moving beyond their limitations, towards a genuine politics of "the other", which is no longer a politics of "endings", but rather a

\footnotetext{
${ }^{531}$ Esp. her Origins of Totalitarianism, New York: Schocken, 1951.

${ }^{532}$ This trilogy consists of C. Johnson: Blowback: The Costs and Consequences of American Empire, $2^{\text {nd }}$ ed., New York, Henry Holt, 2004, (O2000; The Sorrows of Empire: Militarism, Secrecy, and the End of the Republic, New York: Henry Holt, 2004; Nemesis: the Last Days of the American Republic, New York: Henry Holt [Metropolitan Books], 2007.
} 
politics of beginnings in which the conflicting lines of betrayal open themselves up to the scrutiny of loyalty and/or of friendship.

From this perspective, the "end" begins to occupy its proper place, that is, the imperial place whereby it no longer finalizes anything, but rather virtualizes all things, or replenishes them, by making them disappear, by volatilizing, or suspending them, and by constructing, or materializing, them anew, this time differently, perhaps less imperialistic, or less violent, but surely as if "in truth", truthfully, truly. The multitude of "truthful" or virtual ends replenishes the multitude called life, the happiness of going through existence as if 'against death', or against 'all odds'. There is a distinct type of nihilism at work in the perception of the end, in the immanent and permanent ends that mould human existence in its daily rhythms and activities. By being nihilistic (and there is no other mode of existence), one is truthfully in touch with the non-existent, the non-lively, the non-human; one incarnates all these negativities without ever realizing what, or who, he is. The end is a true end in this sense, an unrecognizable, unlocalizable, being: atemporal being. ${ }^{533}$

A politics of "the other" attempts to escape this atemporality of imperial constitution, or imperial being, by uncovering the negative traces of its atemporality, or of its constitution. What are these negative traces? As R. L. Jackson indicates, they seem to reflect the presence of betrayal in the twin domains of 'sense' and 'sensibility':

Betrayal acts as an assault on the integrity of individuals, affecting the capacity to trust, undermining confidence in judgment, and contracting the possibilities of the world by increasing distrust and skepticism. Betrayal changes not only our sense of the world, but our sensibility toward the world. ${ }^{534}$

The other is neither constitutive of imperial paradigms, nor resistant to them, he incarnates them over and against their own atemporality, or their own negativity. This is

\footnotetext{
${ }^{533}$ Imperial consciousness in this sense is the consciousness of vanishing realities, vanishing landscapes, vanishing lives - it settles in as their memory, their ghost also.

${ }^{534}$ R. L. Jackson, "The Sense and Sensibility of Betrayal: the Meaning of Treachery through Jane Austen," Humanitas, vol. 13, no. 2, 2000, p. 72. http://www.nhinet.org/jackson13-2.pdf.
} 
perhaps the second major contribution of the present thesis to the subject of empire, whereby "the other" is no longer seen as the apriori incarnation of some Schmittean friend and/or enemy, but rather as the possibility of moving beyond such a politics of divisionism by uncovering its atemporal and negative holds on the present course of imperial constitution.

Because the intelligence warfare approach is thoroughly permeated by duplicity, transparency and betrayal, the new primacy of intelligence warfare method reveals a politically violent world that was previously hidden from the gaze of the multitudes. The primacy of imperialism thereby brings the politics of betrayal to light and lets it appear fully nihilistic and at least partially unerased - as the imperial method par excellence. One might rightly wonder if there is any place, within the imperial folds of transparencies and betrayal, where one could live with, work with, cooperate with, or at least take into consideration, the views of the other.

This, of course, raises the important question regarding imperial politics: who is "the other"? Throughout the dissertation, the other migrates from the volatile projection of an imperial center to its doubling in the concreteness of global capitalist traces, technological embodiments, militaristic interventions, and ideological stakes, while also migrating from the concrete knowledge of such doublings to their ethereal manifestations under the banner of terroristic ghosts, resistant peoples, back-clashing and blowback operations, or inimical specters of otherness. The most profound, or rather fragile, limit of otherness to be encountered in the present dissertation is the ethereal presence of a doubly articulated sovereignty (whose presence finds its traces in authors like G. Dumézil, G. Deleuze, P. Virilio, J. Derrida, among others), whereby "the other" splits in two simultaneous, complementing, orders of imperial formation. This split reveals the theoretical lines of agreement and disagreement between the American and European literatures on empire, 
between the complementary and disruptive roles played by each in the constitution of a politics of "the other", in which otherness displays itself not as a rigid framework of constitution but as a mobile, ethereal web of constitutive forces. It might be added that whereas the American paradigm appears indebted to classical forms of imperialism, the European specter of imperial approaches goes beyond classicism into a proper opening of a politics of "the other".

While the American form of imperial classicism thrives on the atemporality of capitalist and technological embodiments, the European non-classical approaches thrive on their temporality, on their de-composition, de-structuralization, de-centralization, which inevitably reverses the American paradigm, setting it on a less progressive, or rather less equivocal, course of action. In turn, the European break with imperial classicism is folded back upon its self-assertiveness, de-temporalizing its new constitutive venues. Differently put, whereas the atemporality of imperial constitution (broadly defined, since there is, as yet, no definitive scenario as to what the future empire will look like) rests on the negativity of classic imperialism, which unfolds based on "ends" (and here we may include the fabrication of the imperial spectacle, of enemies, of economic and ideological landscapes, of military air-shows); its temporality (its actual constitution) rests on the very de-construction, or negativity, of ending, or attempting to end, imperial classicism.

In each case, as A. Ronell puts it, "something is taken back, disqualified, without ever leaving the scene.. ${ }^{, 535}$ There is also a popular saying that qualifies very well what is at stake here: "what god gives with one hand, it takes with the other." Indeed, far from being a simple matter of unipolarity or amassed multiplicity, the constitution of the imperial space crosses the threshold of both and establishes an ambivalent relation with, or between, them. This is perhaps the third major contribution of the present dissertation to the

\footnotetext{
${ }^{535}$ A. Ronell, "Testing Your Love, or, Breaking Up", Lecture given at the European Graduate Faculty, Aug. 2002, online: http://www.egs.edu/faculty/ronell/ronell-testing-your-love-lecture2002.html.
} 
understanding of imperial formations, which, despite their paradigmatic character, migrate into nomad, or ghostly, formations at once temporal in their de-centralizing, deconstructive, roles, and atemporal in their various incarnations of centralizing, constructive, relations and milieus.

At first glance, each of these formations promises to escape the aporia of time (or of imperial consciousness) by betraying or deflecting its terrorizing constitution. The promise itself hides the paradoxical nature of time, its uncategorical maneuvering of events, its conceiving of itself as duration and escape from it, measure and non-measurable presence, limit and limitlessness, each term bringing forth the other, or the otherness in the other. Properly speaking, there is no atemporality here, no ideality, only the silence of decision, the impenetrable, concrete, silence of performing or having to perform a duty, a sacrifice a role?

Sacrificing and role-playing maintain their mystery, their obscuring, spectacular, mimesis of beginnings and ends. They consist of a virtualization of truth and authority, friendship and betrayal; of a facade, or an icon, of what it means. (or what it takes) to live politically. Life in the imperial age appears, at first, as a betraying spectacle, a virtual relation to happiness, or to the happiness of authority based on a minute economy of love and hatred, friendship and enmity, salvation and damnation. This constitutes an important thread in the unfolding of imperial power, in which authority projects its aura by betraying, or setting up, the omniscient spectacle of power and terrorism: anything can become a warmachine - a sentence, a body, a measuring devise. In this authoritarian version of imperial constitution, terror, or even power, is embodied by being suspended, delayed, postponed, until the economy of betrayal establishes its value and its aim. ${ }^{536}$ As Nietzsche tells us:

\footnotetext{
${ }^{536}$ This idea differs from conventional perspectives on terrorism. A typical definition is that of $\mathrm{C}$. Townshend: "Terrorism is a distinctive form of modern political agency, intended to threaten the ability of a state to ensure the security of its members' - and thus its claim to legitimacy." Terrorism: a Very Short Introduction, Oxford: Oxford University Press, 2002, p. 5. Such a view dismisses, out of
} 
At these turning points of history there shows itself juxtaposed and often completely entangled with one another a magnificent, manifold, jungle-like growing and striving, a sort of tropical tempo in rivalry of development, and an enormous destruction and self-destruction thanks to the egoisms violently opposed to one another, exploding as it were, battling each other for sun and light, unable to find any limitation, any check, any considerateness within the morality at their disposal. ${ }^{537}$

When this occurs, the distinction between betrayal and truth, profit and defeat, economy and power, is no longer visible, no longer discernible within the paradoxical composition of the imperial realm. Scaffolding (virtual, or otherwise) turns into a real, lifethreatening experience, or rather into a global spectacle exploiting the illusion of salvation from the immanence of destitution and death. In this psychological terrorism, the economy of punishment turns into an economy of the privileged, the disciplined, the quiet - an economy of happy and docile bodies. Their legality and illegality is determined according to the profitability of the uses to which they can be put, to their role in the grand scheme of things, or their overall effect. Everything becomes an effect of betrayal, an effect of its dismissive and violent economization of the body - a spectacle of the spectacle, a double profit or a double suicide. ${ }^{538}$

At a second glance, the problem seems to be that there is no longer any human distinction between man and his techniques, or machines, between the organic and the automated, or between productivity and production - they all belong to the same chain of

hand, the significant fact that, for imperial states themselves, terrorism is a major form of political control, one in which betrayal often plays a crucial role. On this point, see, e.g., J. Alexander, For the Minds of Men: The Central Intelligence Agency, the Free Europe Committee and the Early Cold War, Athens: Research Institute for European and American Studies, Monograph No. 65, 1999.

${ }^{537}$ F. Nietzsche, Beyond Good and Evil, Chicago: Gateway, 1955, p. 210.

${ }^{538}$ Consider the following definition: "Betrayal, as a form of deception or dismissal of prior presumptions, is the breaking or violation of a presumptive social contract (trust, or confidence) that produces moral and psychological conflict within a relationship amongst individuals, between organizations or between individuals and organizations. Often betrayal is the act of supporting a rival group, or it is a complete break from previously decided upon or presumed norms by one party from the others." Wikipedia,

http://en.wikipedia.org/wiki/Betrayal. Obviously this definition excludes betrayal's mythical function of reestablishing order. My point here, however, is not that betrayal organizes and disorganizes the Real, but that it has itself become the Real to such an extent that it is no longer possible to speak of anything else but betrayal. Betrayal is no longer the break fracturing the bond of the Real, but the Real breaking and bonding as such $-\mathbf{a}$ double articulation of breaks and bonds, a double betrayal. 
betraying practices, to the sameness of betraying, or of living. They all belong to the passage from one stage of development to the next, from one stage of terror to another. They pass from a presumed humanity to the spirit of the machine, from terror to terrorism, from betrayal to discipline, or perhaps to silence:

Even his eyes betrayed him. They looked weary, as though they had not had a wink for days. If you looked into them, you would get the sense that this man had gone through hell. Betrayed is probably the right word... ${ }^{539}$

The spirituality of the machine consists in the automation (or conditioning) of the human psyche, in the volatile passage from spirituality to terrorism, from scaffolding as betraying spectacle to its mise en scene - a terrible vortex of meaning and representation, and a terrible becoming. This is the war-machine, the becoming-woman, becoming-other of the other - an alternative to the State, an alternative to becoming political, or becoming Schmittean, an alternative to the enlightened humanity of modern times, or an alternative to enlightened despotism. The betraying-machine turns out to be an all too human, or rather an all too technical affair, after all. As J. Ellul suggests:

... when technique enters into every area of life, including the human, it ceases to be external to man and becomes his very substance. It is no longer face to face with man but is integrated with him, and it progressively absorbs him. In this respect technique is radically different from the machine... When I state that technique leads to mechanization, I am not referring to the simple fact of human adaptation to the machine. ${ }^{540}$

In the end (if there is such a thing), the human proves to have become solely technical, solely mechanistic. There seems to be no other dimension to human life but this mechanistic encounter between technique and the human world, really, between one techno-citizen and another, between one automaton and the next generation. The echo of the machine is the echo of speed, of infinite space compressed to the point of

${ }^{539}$ C.H. Conde, "The Politics of Betrayal", Sunday Inquirer Magazine, issue 41, November/December 2001;online: http://www.bulatlat.com/archive2/041 Nur7Betrayal.html.

${ }^{540} \mathrm{~J}$. Ellul, The Technological Society, New York: Vintage Books, 1964, p. 6. 
disappearance - the "aleph"541 of imperial space, which seems to contain everything, or rather to make it accessible by compressing it to manageable dimensions and storing it as such. With the emergence of global imperialism, time is banished from the relation of the local to the universal, or rather this is what time becomes - simultaneous projection of one into the other, automatic switching, nano-psychology, socio-science, all compressed and accelerated to the point of disappearance. Each becomes a ghost of automation, or, as P. Virilio puts it, "a body without soul...a body assisted by technical prosthesis." add, with McLuhan and Ellul, that the body itself becomes such a ghostly prosthesis of humanism and technicality, whereby the local and the universal become entangled beyond recognition.

The subsumption of time to the machine (or to its speed) seems to be the same, or at least to merge, with the subsumption of the machine to time: the Borgesean aleph, which is the point of convergence of all places, is also the point of their divergence, the becoming time of the machine and the simultaneous spatialization of time. The reciprocity of the terms and names given to the new spirituality (of the machine) is no longer dangerous, no longer avant guardist: it sets the present in its own terms, as if in the eternity of living outside of time, or living where time no longer makes any sense. This place is the paradoxical space of the present, the paradoxical coexistence of all times and all places in the present - the machine that is the present, or the presence of the machine. Classical imperialism has been overcome (if only by incarnation) through the metamorphosis of the present into the ethos of the machine - the imperial machine appears to be the empire of the present.

\footnotetext{
${ }^{541}$ J. L. Borges - the "aleph" is the point of passage from three-dimensional space to the fourth dimension. "The Aleph was probably two or three centimeters in diameter, but universal space was contained inside it, with no diminution in size. Each thing was (the glass surface of a mirror) infinite things, because I could clearly see it from every point in the cosmos." Collected Fictions, New York: Penguin Books, 1999, p. 283.

${ }^{542}$ P. Virilio, Speed and Politics, New York: Semiotext(e), 1986, p. 110.
} 
The engulfing of time within the transparency of the machine (really, the transparency of imperial operations), its zeroing in relation to speed, marks the passage from finitude to infinity, from present to eternity. The present, as we know it, is eternal in the same way in which eternity is present: the imperial machine does not produce time, simply is time. The time machine, the allegorical time-machine, is never quite engaged with the present, except to escape it and move forwards and backwards through spacetime. The concrete time-machine appears to be or to engage the present in search of ways to escape itself - time wants to escape time as present. Such is the secret of the machine: its unstoppable drive to escape the present. In this sense, the war-machine, the capitalist global network, the technological specter modifying the cardinality of the household or of corporative milieus, are relentless manifestations of escaping the present by compressing or reducing it to manageable dimensions.

The tendency to view violence guised in the happy formula of the machine uncovers imperial space as mere conquest of human time, or mere drive to conquer the world by escaping its temporality. In G. Grant's words: "what makes the drive to technology so strong is that it is carried on by men who still identify what they are doing with the liberation of mankind." 543 The imperial tandem between ideology and technology, however, marks the presence of the imperial spectacle, of the identification of men not with the drive to liberate, but with the drive to transform liberation into an imperial spectacle dependent on technological advancements only. This technological imperative leads to what G. Grant has termed as "pure will to technology", that is, a conquering drive which presupposes the "closing down of willing to all content except the desire to make the future by mastery.",544 In Heiddeger's view, however, this is precisely the kind of reduction one needs to perform in order to liberate oneself from technology: "we will, as

\footnotetext{
${ }^{543}$ G. Grant, Technology \& Empire, Concord: Toronto: House of Anansi, 1969, p. 27.

${ }^{544}$ Ibid., p. 40.
} 
we say, 'get' technology 'spiritually at hand'. We will master it. The will to mastery becomes all the more urgent the more technology threatens to slip out of control. ${ }^{, 545}$ As has been shown throughout the thesis, "slipping out of control" often means the fabrication, or rather the violent projection, of such "slippages" in order to stage a definitive technological mastery over ('spiritually') resistant milieus. Besides 'imperial ghosts' ("ghost-soldiers"; "rogue states"; "evil forces") this process is already generating if not a proper technological will to mastery, at least a technological frenzy. A brief example should be in order:

A particularly worrisome case is the ongoing arms race over impoverished explosive devices. The first IEDs were triggered by wires and batteries; insurgents waited on the side of the road and detonated the primitive devices when Americans drove past. After a while, US troops got good at spotting and killing the triggermen when bombs went off. That led the insurgents to replace the wires with radio signals. The Pentagon, at frantic speed and high cost, equipped its forces with jammers to block those signals, accomplishing the task this spring. The insurgents adapted swiftly by sending a continuous radio signal to the IED; when the signal stops, or is jammed, the bomb explodes. The solution? Track the signal and make sure it continues. Problem: the signal is encrypted... ${ }^{546}$

Being in the present, being the present, and for that reason attempting to master all (possible) presents by folding and unfolding them back and forth (towards and away from all possible pasts and futures), is the Aleph that Borges suggests might be false; not inexistent, not improbable, but simply a copy of "another point at which all other points converge," platonically an ideal point of convergence, or an ideal platitude (i.e., its function of compressing, serializing, stocking, reality). The present that is this platitude ${ }^{548}$, this flattening of an ideal point of convergence, which turns into an ideality of the absolute time, or of absolute mastery, secrets its own disappearance, its own vanishing dimensions

\footnotetext{
${ }^{545}$ M. Heidegger, The Question Concerning Technology, New York: Harper Books, 1977, p. 5.

${ }^{546}$ S. Johnson and M. Liu, "The Enemy Spies", Newsweek, June 2006, issue 27, online: http://www.msnbc.msn.com/id/8272786/site/newsweek

${ }_{547}$ Ibid., p. 285.

${ }^{548}$ In the sense in which Grant speaks of it: i.e., as a reduction of the will to performing mastery.
} 
and temporalities. ${ }^{549}$ This incredible point of convergence of the absolute and the common, of ideality and platitude, is also, already, the point of their evanescence. As such, it appears to constitute itself into an imperial center, a world united under the banner of democracy, or a panoptical milieu indebted, as J. Baudrillard remarks, to the fact that every relation of force dissimulates itself as such, acquiring further energy, or mass, by dissimulating its own dissimulative, or betraying, constitution ${ }^{550}$. In this context, "power is no longer present except to conceal that there is no more power."

In the platitude of imperial formation, of mechanicity, or of the present, the absolute ceases to be the absolute and becomes common, platonically common - a copy. The ideality of the absolute is flattened upon the common simultaneously with the elevation of the common to the point of absoluteness: this is the false aleph, the decoy, the presupposed absoluteness of the common in the commonality of the absolute and vice-versa, indeed, as if in a "cat and mouse" game, or in a spectacular set up, which is never quite real, never quite entirely virtual, but rather mysterious and unsettling, perhaps even frightening. In its presence, we all know that "we are afraid of the fear, we anguish over anguish, and we tremble., 552

This unsettling sentiment, this virtuality of fright, or of mystery, is no longer dissimulative, perhaps no longer accountable, or accounted for - it is simply there, articulating itself in ever new forms and formulations. One could trace terror back to this sentiment - one could even write an entire genealogical treatise based on this vulnerability to terror, on this false Achillean heel, or this fantastic remake of terror, discipline and

\footnotetext{
${ }^{549}$ Differently put, human will (to mastery) idealizes its technological compression, that is, its vanishing point (the point that, in McLuhan for example, becomes predominant by separating sight from all the other senses). It is the vanishing point that is idealized, not the will to mastery as such. My point here, however, is that the compression brought about by the machine (social, political, economic) is already such a vanishing point, which in turn gets idealized and flattened upon the imperial body.

${ }^{550}$ J. Baudrillard, Simulacra and Simulation, Ann Arbor: University of Michigan, 2006, p. 14, he quotes Bourdieu.

551 Ibid., p. 26.

${ }^{552}$ J. Derrida, The Gift of Death, Chicago \& London: University of Chicago Press, 1996, p. 54.
} 
punishing.

In the age of global imperialism, this might be a story about how one learns by osmosis, by absorbing and being absorbed by terrorism, by its sentimentality or its fatality. The only trace to this unsettling sensation is the unsettled body, the disappearing corporeality of the docile, or the phantasmic presence of the disciplined subject.

Small black dots move in a line against a backdrop of gray - Tibetan pilgrims walking through the snow near the Nepalese border, trekking to see Dalai Lama in India.

On a ridge, a Chinese soldier plants his feet, takes his aim, and shoots. One pilgrim falls, dead. A second falls, dead. It's all captured by a European TV film crew. ${ }^{553}$

This is the documented body, the imperial map of the present, or the present pure and simple. However, as S.L. Foster suggests, "the body is never only what we think it is...Illusive, always on the move, the body is at best like something, but it never is that something." ${ }^{\text {554 }}$ The body is also a non-cartographic specter, a likeness perhaps, or a ghost attempting to escape the terror of terror. The body of terror reacts to itself, to its terrorizing disappearance, attempting to deliver itself to a death of its own choosing: "the smooth functioning of its economic, political, and legal affairs, the smooth functioning of its moral discourse and good conscience presupposes the permanent operation of this sacrifice." 555 As A. Giddens remarks, "a positive embrace of risk is the very source of the energy which creates wealth in modern economy." ${ }^{556}$ This is perhaps a very good metaphor for the end of the $20^{\text {th }}$ century - the grand century of infinite dominion, infinite accumulation, infinite positivity. It is also a dissimulation of modernity, or of its absence - an imperial ghost in the proper sense of the term, operating at the level of the body (social, political, economic)

\footnotetext{
${ }^{553} \mathrm{~J}$. Rose, "The politics of betrayal", The Standard, Nov. 2006, http://www.phayul.com/news/tools/print.aspx?id=14893\&t=0

${ }^{554}$ Quoted by C. Weber in "Performative States", Millennium: Journal of international Studies, 1998, vol. 27 , issue 1, p. 77.

${ }^{555}$ J. Derrida, The Gift of Death, Chicago \& London: Chicago University Press, 1996, p. 86.

${ }^{556}$ A. Giddens, Runaway World, New York: Routledge, 2003, p. 23.
} 
and encouraging it to accumulate all of itself by way of fissures, interruptions, gaps, ruptures, displacements, and ends.

The driving force behind the falsity (or virtuality) of "endings" ceases to be an end in itself and becomes a movement, a getting even, getting ahead, getting somewhere - this is the obsessive present, the over-dozed, over-reactive body of imperial formation. The definition, or rather the attempt to phantomize the unknown begins with this body. Its politicization corresponds to its inactivity, to its massiveness, or to its knowledge of itself as the authentic embodiment of power. It is a concrete body, an already massive, inoffensively obese corporeality of a power erasing itself from the memory of its subjects. As such, it embodies an alternative to the erasure of power whereby, as I. Wallerstein remarks, "the categories are health, education, and lifetime income." ${ }^{557}$ One might wonder where does 'Disney Land' come from? For it certainly incarnates the phantasm of such "fundamental demands" as health, education and lifetime income, while it also presupposes their equally fundamental absence, since "one doesn't assert one's identity," but rather "pays to assert it." 558 Irony aside, one might find here the profound link between the terrorized body and the pleasurable body, the enchanted, Narcissistic body, to which A. Negri attributes a happy gaze and, as Heidegger would say, 'leaves it at that'. A seductive proposition, indeed, or rather an unexpected revisitation of an all too familiar, or an all too old, saying: "render unto Caesar that which is his...", and leave it at that.

The imperial body is constantly separated from what it can do - this has become its secret, but also its inexhaustible promise. Its appearance hides this unintelligible secrecy, this promising separation, in a way that is no longer recognizable, no longer attributable to this or that motive. One simply performs secrecy - one becomes it. One becomes a seducing metaphor, obviously, but all the more appealing, all the more prone to misguide

\footnotetext{
${ }^{557}$ I. Wallerstein, The Decline of American Power, New York/London: New Press, 2003, p. 155

${ }^{558}$ Ibid., p. 141.
} 
us, since the politicized body is all we encounter, all we desire. The function of the metaphor, or of the imperial metaphor, is to separate the body from what it can do; to flatter and terrorize the body until there is nothing else to do but to enjoy betraying its own desires and functions, and to forget the violence entailed by such an enjoyment.

This is how betrayal generates its ghosts, how it fabricates their psychological landscapes and their returning routes - by becoming their secret, their ethos. It also becomes their end, the very condition of their eternal return. The body itself as metaphor for betrayal - this is the imperial well of infinite wealth, but also of infinite authority. Modern sovereign space is the space of infinite betrayal, infinite economization of betraying and saving bodies. Its politics of betrayal administers a purely economic, purely technological, escape from and return to the body of the condemned - a purely mythological, purely Christian, way of dealing with the social body, against which resistant bodies respond in equally volatile, equally "Christian” ways.

As has been argued throughout this dissertation, power no longer erases its own traces, or even its own scene. ${ }^{559}$ Instead, it openly perpetuates its effect, not only to generate terror, but also to make sure that even more power gets to be produced and accumulated, packed and displayed, indulged and even 'sabotaged'. From this point of venture, imperial power erases itself by dissimulating its own erasure: the more erasures there are, the more authentic the power indulging the fantasy of imperialism. The returning ghosts (i.e., terrorists, enemies, 'evil institutions') become the source of its authenticity, of its phantasmal constitution and destitution. They are the 'intended effects' of imperial power as much as they are the 'unintended consequences' of its betrayal, forging a new regime, or new ideology, in which breaking, deceit, trespassing, treachery, enmity, become

\footnotetext{
${ }^{559} \mathrm{~A}$ story that made the rounds of bureaucracy some years back in Washington, D.C. tells of an official to whom a memorandum was inadvertently routed, who along with the others on its proper mailing list absent-mindedly initialed it. The sender noticed an unauthorized initial and returned the memorandum to the official with instructions to erase his initials, and then to initial his erasure.
} 
contractual orders engaged in shaping the spectacular landscape of world politics.

One becomes non-secretive, or resistant, insofar as he severs himself from the whole (severance as secret, or terror), insofar as his presence becomes disruptive, or disrupted. In the economy of resistance, one no longer looks for genealogical traces of wholeness, but for the volatile traces of betrayal - for the disruptive, the uncommon, or the apolitical. In this way, resistance sells itself out, it gives itself away as the other of betrayal, the other of politics; it betrays itself in order to become the other of power. As otherness of power, resistance falls into the very trap it wants to avoid, namely, the propagation of a political horizon in which betraying becomes the means and the end of all political bodies. However, one cannot unite the body to what it can do - this is the limit of all economy, the limit of all becoming, but also the limit of the political. In the last analysis, one has to raise the question of truth - truth as limitation, as introspective horizon.

Truth as metaphor for sincerity; truth as secret. In the end, one has to make a decision for or against truth - for or against sincerity, hope, secrecy. What decision is there to be made, what secrecy to reveal? What' truth? Or rather, against which metaphor should we decide, for what reasons?

These have all become rhetorical questions. Rhetorical ghosts hunting an already given answer: the primacy of imperial constitution, imperial faith, imperial narration. There is nothing else to the resuscitated Aristotelianism of the political, not even the question of truth, or of man. These questions (resistant as they may seem) succumb to the seduction of an all too human will to power, will to control, or to posses. In this context, betrayal is inexistent - it is the very generative force of willing power, willing subjects, or willing fools. As Nietzsche puts it: "the willer believes, with a considerable degree of certainty, that will and action are somehow one. He credits the success, the execution of the willing, to the will itself, therewith luxuriating in an increase of the feeling of power 
which all success produces". 560

Truth itself is seductive, indecisive, irremediably severed from what it can do - truth as metaphor, as indirection, as governmentality. As such it luxuriates into its own success, its own politics of betraying by being truthful, of becoming inimical by being friendly, and so on. This is truth as present, indeed, truth as the secret of the present, of that secret and that present which coincide in the presence of the machine, in the presence of an absence, a compression, or a disappearance. This is the limit, the way truth reaches its own trueness, its own time. The indirection that is truth slips into all directions and sets things right, sets them in their own time, in the luxury of their own power, or of their own willing.

The political makes truth into its aleph, into its point of converging indirections, converging versions of the indirect, the apolitical, the true. In the first instance, truth is false then, illusory, optical. It shows all indirections, all becomings, in the mirror of betrayal, and, often times by means of self-fulfilling prophecies, turns them into true directions, true beings, true virtues. The illusion is perfect by maintaining itself in the trueness of reflection, it is also untrue by reflecting itself in betrayal. ${ }^{561}$ In truth, nothing is as it seems, not even the illusion of truth or the truth of illusion - they too converge in the indifference and dullness of practice, in the distance one interposes between them, in the short interval in which they separate to form two distinct memories, two distinct genealogies: becoming true versus becoming untrue, in a word, becoming ideological, becoming political. In the imperial context this becoming in tandem, becoming ideologically present by means of an absence, involves the question of the double - is the

\footnotetext{
${ }^{560} \mathrm{~F}$. Nietzsche, Beyand Good and Evil, Chicago: A Gateway Edition, 1955, p. 21.

${ }^{561}$ Sociologists refer to both self-fulfilling and self-suicidal prophecies, those in which a belief makes for truth, and those in which a belief generates counteractions that nullify the prophecy. The classic source is R. K. Merton, "The Self-Fulfilling Prophecy", Antioch Review, vol. 8, 1936, pp. 193-210. The principle here is the so-called Thomas Theorem: if men believe things to be true, they will be true in their consequences. This line of approach lies at the heart of social constructionism.
} 
double a real double, or a fabrication meant to induce an optical illusion $?^{562}$

In the (virtual) space of empire, the truth of context coincides with the context of truth, which is to say that the political articulates itself doubly in the production of truth and of its context. As we have seen, it does so by separating truth from what it can do, but also by separating context from its content; it does so by betraying both truth and context, by fabricating and severing them from one another. They both return, as if in a hunter's game, but only to be fabricated, contextualized, and even authenticated, in ever new forms. Their identity rests on their separation, just as their separation rests on their identity $-\mathbf{a}$ maneuver that works its way through, or rather constitutes, the whole field of imperial constitution. This moment of constitution through a double betrayal, double separation, or articulation, comes into its own by de-structuring, dismissing, de-doubling, all betraying constitutions; as A. Ronell suggests, "dialectics re-absorbs what it separates and cuts, what it holds on to, changes its character, accommodating the severance as part of its unfolding."

Let us take an almost trivial but concrete example, namely, the highly speculative rumor that the Iraqi government had tried to buy some uranium yellowcake - a form of lightly processed ore - from the African country of Niger, as part of an attempt to develop weapons of mass destruction. It quickly turned out that the rumor had been based upon a faked document. Retired Ambassador J. Wilson was sent to investigate the case and found

\footnotetext{
${ }^{562}$ The question works both ways: towards the duplicity of the imperial couple, where it tries to distinguish Narcissus from his image (in the water); and away from it, in the openness of imperial space, where it plays itself off as the simultaneous negation and affirmation of such imagery. The centrality of imperial power is at once problematized and obscured through the projection of a double (be it friendly or inimical) which hovers in front of it, as its platonic copy. Imperial theories escape the aporia of the double by returning to the centrality of power, and escape the centrality of power by projecting it into a double, or a triple formula. The question of the realism of centrality is replaced by the question of the centrality of realism - a very clever reversal at a time when realism hovers around in its guised forms of neorealism, neopositivism, neoliberalism, neoconstructivism, and so forth. This is the point of departure of the two literatures on empire (American and European), but also the point of their agreement: imperial duplicity is not only a ghost returning from the depths of history, but also a double of history itself.

${ }^{563}$ A. Ronell, "Testing Your Love, or, Breaking. Up, Lecture given at the European Graduate Faculty,Aug.2002; http://www.egs.edu/faculty/ronell/ronell-testing-your-love-lecture-2002.html.
} 
no evidence of such an attempt, confirming that indeed it would have been highly unlikely to occur, given the security in place. At the time, the U.S. ambassador to Niger had already conveyed this conclusion, as had another independent U.S. military study group. Nonetheless, when the decision to invade Iraq reached its apogee, the discredited rumor was treated as a "fact" and included in the 2002 State of the Union Address. ${ }^{564}$

Four months later, J. Wilson published an article in New York Times, complaining that the Congress and the people had been misled in an effort to elicit their support for an attack on Iraq. Just eight days later, a leak from the White House revealed that Wilson's wife, V. Plame, was a CIA agent. ${ }^{565}$ This example shows that betrayal and truth are often times interchangeable dimensions, that a confrontation between them often times leads to their deepening in the realm of betrayal rather than of truth, and that, triviality aside, it is not always an imperial cause that moves the tides of both truth and betrayal, but rather a deep seated tendency to simulate the imperial spectacle in the guise, or in the name, of both. 566

In an attempt to rationalize and understand betrayal, J. L. Jackson defines it as an intelligible, purposive, puncture, or rupture, of the mundane (i.e., bi-dimensional) texture of trust, or rather as a specific kind of manipulation, which finds its apologetic venues and energies either in the calculated abandonment of trust or in its purposeful "end". As he puts it, "spies and undercover agents are not evil because they are betraying; [sometimes] the

\footnotetext{
${ }^{564}$ J. C. Wilson, "What I Didn't Find in Africa", New York Times, July 6, 2003. http:/l select.nytimes.com/gst/abstract.html?res=F30D12F7355E0C758CDDAE0894DB404482.

${ }^{565} \mathrm{~J}$. C. Wilson, The Politics of Truth: inside the Lies that Led to War and Betrayed My Wife's CIA Identity, New York: Carroll \& Graf, 2004, pp. 2-3. This example also reveals that what the Americans call "Whistleblowing" can manifest itself as a form of double or reflexive and retaliatory betrayal.

${ }^{566} \mathrm{~A}$ far more serious case of imperial betrayal occurred during the run-up to the second invasion of Iraq. G. Dyer recounts how the government of Iraq essentially surrendered, offering to give in to all of the Americans' demands - and even to grant any sort of oil concessions the prospective invaders might require - in return for the Americans' calling off the invasion. That the U.S. government ignored offer demonstrated that the invasion was not simply about oil, as many of the global protesters have professed and believed. Oil was, of course, not unimportant. However, the U.S. apparently also wanted an old-fashioned occupied colony, from which to project power throughout the Middle East. See G. Dyer, Future Tense: the Coming World Order, Toronto: McClelland \& Stewart, 2004, pp. 138142.
} 
only way to eliminate evil is through betrayal." ${ }^{, 567}$ While betrayal takes its cues from the flat surface of trust relationships, it nonetheless resolves itself into some instrumental incarnation set against the danger, or the immoral choice, of trusting 'evil' intentions as opposed to 'good' ones. The betrayer "is vital to the successful completion of the intended effect," or, as one might expect, its tendency to "achieve extrinsic goals" imbues and colors (not to say enlivens) the entire texture of trust relationships. In this sense, "individuals who engage in such actions knowing the dangers to their soul deserve some praise for what they have risked". ${ }^{568}$ Praise too is another facet of betrayal, a more concealed, more subtle facet of falling in love with or being seduced by betrayal. If praise is lost, the betrayer can always cast himself "as the victim of unfortunate circumstances", as opposed to someone "who has committed a great wrong.,, 569

The relationship between betrayal and truth, or trust, breaches, trespasses, manipulates, 'evil' in such a way as to appear manageable, solvable, diminished. "Evil" is suspended, or rather concealed, by the interplay between sense and sensibility, or between an "evil sense" and a presumably evil-less sensibility. The suspension of evil is only apparently a resolve of betrayal, just its evil-less counterpart is, because "their objective is not the care of the object of trust, whatever it is, but the use of the relationship" to satisfy some extrinsic goals, or at least to attach to it an intelligible meaning.

In the last analysis, life is already ideological, already political - it is at once contextual and betraying, at once falsely true and truthfully false, which is to say that it relates indirectly to what is already given, already made true and false. As Baudrillard puts it, "ideology corresponds to a betrayal of reality by signs; simulation corresponds to a

\footnotetext{
${ }^{567}$ J. L. Jackson, “The Sense and Sensibility of Betrayal: Discovering the Meaning of Treachery through Jane Austen", Humanitas, vol. XIH, issue 2, 2000, pp. 72-89.

${ }^{568}$ Ibid., p.87.

${ }^{569}$ Ibid., p. 88.

${ }^{570}$ Ibid., p. 85
} 
short-circuit of reality and to its reduplication by signs." ${ }^{571}$ The double betrayal of the real folds back upon the absence of the real, upon emptiness pure and simple - perhaps this is the point at which things appear to converge without ever coming together, without really composing anything except betraying signs, truths, contexts, short-circuits.

This is what ceases to make sense for Borges, the point at which truth turns into betrayal, the very point at which everything suddenly falls into place by falling out of it. There is no time, no timeliness that could be attributed to this falling in and falling out of place, only remembrance and performance, emptiness, nihilism - the emptiness and nihilism of being full and ready to affirm, of being Zarathustrean, Nietzschenean, or simply epigonean. Such an emptiness is no longer negative, no longer guilty, it carries itself beyond the threshold of nihilism towards innocence and affirmation: it is itself an affirmation, a posthumous fulfillment, a happy gaze (as in Negri).

One could even say that emptiness is made to appear full, that it is fullness, end, progression. Emptiness is then indiscernible, inseparable from the sort of mad discontinuity, mad naivete, which is so characteristic of the epigonic phase. In this sense, emptiness appears as a desirable return to origins, to the inexplicable continuity of an unbreakable form of individuality, to a continuous time which is always the same, always enchanted: happy, lovable, naive, ghost-like. As such, it aliments the constitution of the imperial field as a unifying and smooth space of enchanted subjectivities - the growing role of entertainment in contemporary society is a good example of such an emptiness put to use in the name (or in place) of imperial constitution. In P. Virilio's words:

In weightless worlds, those who can no longer walk find themselves back on their feet, moving at supernatural speeds. Those who can no longer embrace hug each other for all their worth, those who can no longer see the light now devour it with eyes filled of wonder... ${ }^{572}$

\footnotetext{
${ }^{571}$ J. Baudrillard, Selected Writings, Stanford University Press, 1998, pp. 166-84.

${ }^{572}$ P. Virilio, The Information Bomb, London/New York: Verso, 2005, p. 40.
} 
The economy of emptiness obliterates space by filling it with the profitability of ends, with the consistent business of turning everything into a volatile gain. Space is already conquered, already profitable, before being turned into an end, an ending, or finality, which is no longer anything else but pure and simple emptiness. The emptiness of space marks the end of succession, the end of time, but also of movement and intensity. Space is non-existent, non-existential. It has already been filled with the fullness of the existent, or of existence pure and simple. It has been emptied and filled, finitized and infinitized, conquered and made unconquerable: space qua space is this paradoxical coexistence of contraries, this becoming zero, becoming extinct of both finitude and infinitude, emptiness and fullness. As Foucault puts it:

At the crossroads, in the gardens, at the side of the roads being repaired or bridges being built, in workshops open to all, in the depths of mines that may be visited, will be hundreds of tiny theatres of punishment...Scenery, perspectives, optical effects, trompe-l'oeil sometimes magnify the scene, making it more fearful than it is, but also clearer. ${ }^{573}$

The becoming extinct of space, the becoming other than its finitude and infinitude, is but another spatiality, another finitization and infinitization, this time of the psyche, of the epigonic man who is both wise and foolish, conquered and unconquerable, existing and non-existential. Becoming woman and becoming animal are both possible only now, in the absence of space, or rather in and through its interiorization: finally, man can move in the world "like water in water;" he can be one with the world because he $i s$ the world in movement - a moving aleph; a moving mirror in a hall of mirrors within the immovable.

Becoming animal engenders this volatile movement of the immovable, this becoming still, becoming image, of the world - it engenders a reduction and "in doing so it will have reached the highest degree of clarity, but it will so fully realize the possibility of man, or of being, that it will discover the night of the animal intimate with the world - into which it

\footnotetext{
${ }^{573}$ M. Foucault, Discipline and Punish; The Birth of the Prison, New York: Vintage Books, 1995, p. 113.
} 
will enter." ${ }^{574}$ The night in which man enters is the imperial world, his worldliness, his self-consciousness. That is why Bataille suggests that clear consciousness is only partially, only in a sense, clear. By regaining its intimacy, clear consciousness loses itself in "the night of the animal intimate with the world", it loses its clarity, its individuality - it becomes what it has been right from the beginning: night, wondering ghost.

This unexpected, undesirable, becoming is always there, always threatening to become what is or has been right from the beginning. It has always threatened expectancy and desirability, otherness, self-consciousness, or rather it has delayed them through the intimation of their betrayals. Self-consciousness becomes clear consciousness by entering the "night of the animal"; it becomes other than "becoming", other than the night from which it comes.

What further research needs to be done? If the argument of this dissertation has followed the volatile lines of imperial formation in and through the conceptualization of betrayal, then a further theoretical work on imperial constitution would have to consider betrayal as a doubly articulated reality, not just as an unexpected break, or rupture, in the smooth fabric of globalization, policy making, or military interventions. In the past, there has been a lot of research done on intelligence warfare that has privileged the concept of betrayal in an unequivocal relationship to truth, trust, or legitimacy, which has been treated as a highly specialized area of study and has not been integrated in our understanding of the imperial world. It is certainly clear that acts of betrayal have been extremely frequent and to a certain extent transparent to our understanding of the imperial world, but it is our contention that betrayal, as an essentially volatile component of imperialism, needs to be detached from the categorical shell which makes it appear as an unequivocal, or undesired, form of deception and/or dismissal of prior engagements and contracts.

\footnotetext{
${ }^{574}$ G. Bataille, Theory of Religion, New York: Zone Books, 1992, p. 100.
} 
The ghosts of terrorism evoke a need to fight them through betraying strategies involving government sanctioned assassinations, kidnapping, brutal interrogations, torture, denial of civil and human rights, trials by military tribunals, etc, which proves that betrayal is constantly_linked with the undesired presence of "the other", with an "original" betrayal against which all acts of treachery and deceit become legitimate and permissive. The concept of blowback is a good example of the volatile relationship with the other (ghostly or otherwise), in which the urge to fabricate the other as a prime betrayer, a real enemy, a terrifying combatant, is played back and forth in an effort to project an imperial presence indebted to an essentially betraying military-industrial complex. One needs to provoke, invoke, evoke, opposition (and then 'suffer' blowback) in order to sustain the primacy of imperial presence, or imperial constitution, which is to say that one betrays the very concept of opposition by inventing, or projecting it, as an essentially betraying adversary. The relationship with the other is a doubly articulated betrayal in which, as J.L. Jackson puts it, "it is impossible to distinguish which actions and words are sincere and which are merely efficacious," since all such actions and words are pointing not only to the instrumentality of the relationship with the other, but also towards "an object beyond it." 575

A summarization of the problematics of imperial formation (as outlined above) from the point of view of deserting, resisting, and nomadic approaches implies a need to develop a distinct project in which otherness and betrayal form a genuine politics of "the other". Such a task would require a further scrutiny of the relationship between the two, an indepth treatment of the notion of desertion (i.e., to what extent truth, understood as betrayal, becomes a deserting practice), and a proper revisitation of the political realm, in which betrayal and desertion often change places and guise themselves in the cloak of the other.

\footnotetext{
${ }^{575}$ J. L. Jackson, "The Sense and Sensibility of Betrayal: Discovering the Meaning of Treachery through Jane Austen", Humanitas, vol. XIII, issue 2, 2000, p. 85
} 
This project might bring forth a provocative contribution to the field of international relations but also to the field of theory, where "the other" is politicized and de-politicized in such a way that a politics of otherness, or of betrayal, is either hidden under multiple layers of meaning, or made to appear as an all too human, or an all too technical, affair. 
G. Agamben, Infancy and History, London \& New York: Verso, 2007.

G. Agamben, "On Security and Terror", Frankfurter Allgemein Zeitung, September 20, 2001. www.wgs.edu.

G. Agamben, "We Refugees", 1994. www.wgs.edu.

F. Adamson, "International Terrorism, Non-State Actors and the Logic of Transnational Mobilization: A Perspective from International Relations", SSRC, Global Security and Cooperation Program.

J. Alexander and J. MacAulay. "An Archaeology of Technics and the Working Life", S. Bennett, ed., Technology and Work in Canada, New York: Edwin Mellen Press, 1990.

J. Alexander, For the Minds of Men: The Central Intelligence Agency, the Free Europe Committee and the Early Cold War, Athens: Research Institute for European and American Studies, Monograph No. 65, 1999.

Anon, "Blowback", July 26, 2001:

http://www.janes.com/security/international_security/news/jir/jir010726_1_n.shtml.

H. Arendt, Between Past and Future, New York: Penguin Books, 1968.

H. Arendt, The Human Condition, Chicago: University of Chicago, 1989.

H. Arendt, The Origins of Totalitarianism, Orlando: Harvest Book, 1976.

Aristotle, The Politics, London \& New York: Penguin Books, 1992.

Aristotle, Nicomachean Ethics, Indianapolis \& Cambridge: Hackett Publishing, 1999.

A. Artaud, The Theatre and its Double, New York: Grove Press, 1958.

R. K. Ashley, "Untying the Sovereign State: A Double Reading of the Anarchy Problematique", Millennium: Journal of International Relations, vol. 17, issue 2, 1998.

R. K. Ashley and R. B. Walker, "Speaking the Language of Exile: Dissident Thought in International Studies", International Studies Quarterly, 34, 1990.

P. Bachrach and M. Baratz, "Two Faces of Power", P. S. Nivola and D. H. Rosenbloom, eds., Classic Readings in American Politics, $3^{\text {rd }}$ ed., New York: St. Martin's/Worth, 1999.

A. Badiou, Being and Event, London \& New York, Continuum, 2005.

A. Badiou, Infinite Thought, London \& New York: Continuum, 2005.

A. Badiou, Metapolitics, London \& New York: Verso, 2005.

A. Badiou, "The Event in Deleuze", Parrhesia, No. 2, 2007.

A. Badiou, "On Evil: An Interview with Alain Badiou", Palinurus: Engaging Political Philosophy, issue 8, Aug. 2006.

E. Balibar, "Strangers as Enemies: Further Reflections on the Aporias of International Citizenship", Palinurus: Engaging Political Philosophy, issue 10, Dec. 2006.

J. Barbero, "The Media: Memory, Loss and Oblivion", GSC Quarterly, no. 4, Spring, 2002.

J. P. Barlow, "The Economy of Ideas: a Framework for Rethinking Patents and Copyrights in the Digital Age (Everything You Know about Intellectual Property is Wrong)", Wired, vol. 2, no. 3, March 1994.

R, Barthes, Mythologies, New York: Hill and Wang, 1972.

R, Barthes, Empire of Signs, New York: Hill and Wang, 1984.

G. Bataille, The Accursed Share, New York: Zone Books, 1991.

G. Bataille, Theory of Religion, New York: Zone Books, 1992.

J. Baudrillard, Simulacra and Simulation, Ann Arbor: U of Michigan Press, 1994.

J. Baudrillard, The System of Objects, New York: Verso, 2005.

J. Baudrillard, "Photography or The Writing of Light", CTheory, March, 2000, trans. Francois Debrix.

J. Baudrillard, "Radical Thought", Canadian Journal of Political and Social Theory, vol. 
18, nos. 1-3. 1995, pp. 41-57.

J. Baudrillard, "The Evil Demon of Images and the Precession of Simulacra", in T. Docherty, ed., Postmodernism: A Reader, New York: Columbia Univ. Press, 1993.

Z. Bauman, "Communism: A Post-Mortem", Praxis International, vol. 10, nos. 3/4, October/January 1990/1991.

Z. Bauman, "Living in Utopia", paper presented at the London School of Economics, Melting Modernity Series, Oct. 2005.

Z. Bauman, "Each Time Unique", Paper presented at the London School of Economics, Modernity Lecture Series, November, 2005.

P. Bennis, Challenging Empire, Northampton, MA: Olive Branch Press, 2006.

P. Bergen \& P. Cruickshank, "Kashmir on the Thames", London Broil, September 4, 2006.

P. L. Berger and T. Luckman, The Social Construction of Reality, Harmondsworth, Middlesex: Penguin, 1972.

M. Berman, The Reenchantment of the World, Ithaca, NY: Cornell University Press, 1981.

M. Berman, All that is Solid Melts into Air: The Experience of Modernity, New York: Penguin Books, 1988.

M. Berman, The Twilight of American Culture, New York: Norton, 2000.

J. Bodin, Six Books of the Commonwealth, Oxford: Alden Press, 1955.

R. Boguslaw, The New Utopians: a Study of System Design and Social Change, Englewood Cliffs, NJ: Prentice-Hall, 1965.

D. Bohm, Wholeness and the Implicate Order, London: ARK Paperbacks, 1980.

J. L. Borges, Collected Fictions, New York: Penguin Books, 1998.

D. Boorstin, The Image: a Guide to Pseudo-events in America, New York: Harper \& Row, 1964.

M. Boot, The Savage Wars of Peace: Small Wars and the Rise of American Power, New York: Basic Books, 2002.

G. C. Bowker, "The Past and the Internet", Items and Issues, winter 2003/2004.

M. Bright, E. Vulliamy, and P. Beaumont, "Revealed: US Dirty Tricks to Win Vote on Iraq War", The Observer [London], March 2, 2003.

P. Buchanan, "The Retreat of Empire", The American Conservative, September 13, 2004.

G. W. Bush, "President Bush Delivers Graduation Speech at West Point, United States Military Academy, West Point, New York", press release, 2002.

K. Burke, Permanence and Change, Los Altos, CA: Hermes, rev. ed., 1954.

J. Butler, Giving an Account of Oneself, New York: Fordham University Press, 2005.

C. Calhoun, F. Cooper and E. W. Moore, eds. Lessons of Empire: Imperial Histories and American Power, New York \& London: New Press, 2006.

E. Canetti, Crowds and Power, New York: Penguin, 1960.

J. Canton, "The Click-Stream Consumer", Institute for Global Futures, http://www.futureguru.com.

E. H. Carr, The Twenty Years' Crisis, Wiltshire: Anthony Rowe Ltd, 2001.

E. Cassirer, The Myth of the State, New York: Doubleday Anchor Books, 1955.

M. Castells, "The Network Society: A Cross-Cultural Perspective", 2004. http://www.allnoble.nevarticles by manuel castells.htm.

D. Cater, The Fourth Branch of Government, New York: Vintage Books, 1965.

N. Chomsky, "Terror and Just Response", James P. Sterba, ed., Terrorism and International Justice, Oxford: Oxford University Press, 2003.

E. Cioran, The Heights of Despair, Chicago: Chicago University Press, 1992.

S. Cohen and L. Taylor. Escape Attempts: The Theory and Practice of Resistance to Everyday Life, London; New York: Routledge, 1992.

C.H. Conde, "The Politics of Betrayal", Sunday Inquirer Magazine, issue 41, 
November/December 200.

W. E. Connolly, "Democracy and Territoriality", Millennium: Journal of International Studies, vol. 20, no. 3, 1991.

F. Cooper, "Modernizing Colonialism and the Limits of Empire", Items and Issues, vol. 4, no. 4, Fall/Winter 2003.

R. W. Cox, "Multilateralism and World Order", Review of International Studies, vol. 18, 1992.

S. Critchley and O. Marchart, eds., A Reply: Glimpsing the Future, Laclau: A Critical Reader, New York: Routledge, 2004.

K. Croke, "Rethinking the War on Terrorism", Progressive Policy Institute, November 2006.

I. P. Culianu, Travels to the Other World, Bucharest: Nemira, 1996.

K. E. Dahlberg, "Technological Ethic and the Spirit of International Relations", International Studies Quarterly, vol. 17, no. 1 (March).

G. Debord, The Society of the Spectacle, New York: Zone Books, 1995.

G. Deleuze, L'image: mouvement, Paris: Editions de Minuit, 1983.

G. Deleuze, Nietzsche, New York: Columbia University Press, 1983.

G. Deleuze, Difference and Repetition, New York: Columbia University Press, 1994.

G. Deleuze, Foucault, Minneapolis: University of Minnesota Press, 2000.

G. Deleuze \& F. Guitari, A Thousand Plateaus: Capitalism and Schizophrenia, Minneapolis: University of Minnesota Press, 2003.

G. Deleuze and F. Guattari, Nomadology: the War-Machine, New York: Semiotext(e), 1986.

G. Deleuze, "What is a Dispositif?", Two Regimes of Madness, New York: Semiotext(e), 2006.

J. J. Derian and M. Shapiro, International/Intertextual Relations, eds., Toronto: Lexington, 1989.

J. Derrida, The Gift of Death, Chicago: The University of Chicago Press, 1996.

J. Derrida, The Politics of Friendship, New York: Verso, 2005.

J. Derrida, Rogues, Stanford: Stanford University Press, 2005.

J. Derrida, Specters of Marx, New York: Routledge Classics, 2006.

V. Descombes, Modern French Philosophy, New York \& Melbourne: Cambridge University Press, 1994.

E. R. Dodds, The Greeks and the Irrational, Berkley \& Los Angeles \& London: University of California Press, 1951.

T. Donnelly and C. Monaghan, "The Bush Doctrine and the Long War", National Security Outlook: AEI Online, March 6, 2007.

P. F. Drucker, Post Capitalist Society, New York: Harper Business, 1993.

G. Dumézil, Mitra-Varuna, New York: Zone Books, 1988.

W. and A. Durant, The Lessons of History, New York: Simon \& Schuster, 1968.

M. Dver, The Weapon on the Wall; Rethinking Psychological Warfare, Baltimore: Johns Hopkins University Press, 1959.

T. A. Dye, Who's Running America: the Carter Years, $2^{\text {nd }}$ ed. Englewood Cliffs, NJ: Prentice-Hall, 1979.

G. Dyer, Future Tense, Toronto: McClelland \& Stewart, 2004.

M. Edelman, Language as Symbolic Action, Berkeley: University of California Press, 1966.

M. Edelman, Enemies in Politics, Chicago: Rand McNally, 1967.

M. Edelman, Constructing the Political Spectacle, Chicago: University of Chicago Press, 1985. 
M. Eliade, The Sacred and the Profane, New York \& London: Harvest/HBJ, 1959.

M. Eliade, Myth and Reality, New York: Harper \& Row Publishers, 1963.

J. Ellul, The Technological Society, New York: Vintage Books, 1964.

P. Emberley, "Technology, Values, and Nihilism", Jon Alexander, ed., Science, Technology \& Politics, Ottawa: Institute for Technology Policy, 1988.

N. Ferguson, "Empire: The Rise and Demise of the British World Order and Lessons for Global Power", paper presented in New York, Carnegie Council, Books and Breakfast program, September 16, 2003.

M. Foucault, Power \& Knowledge, New York: Pantheon Books, 1980.

M. Foucault, Madness and Civilization, New York: Vintage Books, 1988

M. Foucault, The Order of Things, New York: Vintage Books, 1994.

M. Foucault, Discipline and Punish, New York: Vintage Books, 1995.

M. Foucault, The Politics of Truth, Semiotext(e), 1997.

H. B. Franklin, "Fantasies of Power", appeared originally as "Fatal Fiction: A Weapon to End all Wars", Bulletin of the Atomic Scientists, November 1989.

S. Freud, Civilization and its Discontents, London \& New York: Penguin Books, 2002.

F. Fukuyama, “After Neoconservatism", New York Times Magazine, February 19, 2006.

A. Giddens, Beyond Left and Right, Cambridge: Polity Press, 1998.

A. Giddens, The Runaway World, New York: Routledge, 2003.

A. Giddens and S. Huntington, "Two Wests", New Perspectives Quarterly, vol. 20, no. 4, Fall, 2003.

P. Gowan, L. Panitch and M. Shaw, "The State, Globalisation, and the New Imperialism: A Roundtable Discussion", Historical Materialism: Research in Critical Marxist Theory, vol. 9, autumn 2001.

G. Grant, Time as History, Toronto: University of Toronto Press, 1995.

J. Habermas, The Structural Transformation of the Public Sphere, Boston: MIT Press, 1991.

G. W. F. Hegel, Phenomenology of Spirit, Oxford: Oxford University Press, 1977.

M. Heidegger, Basic Writings, New York: Harper \& Row, 1977.

M. Heidegger, An Introduction to Metaphysics, New Haven/London: Yale University Press, 1987.

M. Heidegger, Nietzsche, New York: Harper San Francisco, vols. I-IV, 1991.

D. Held and A. McGrew, "The End of the Old Order? Globalization and the Prospects for World Order", British International Studies Association, 1998.

B. Herber, "From Gook to Raghead", New York Times, May 2, 2005.

M. Hirst and I. Abraham, "Changing Nature of State and Security: Then and Now", SSRC, Global Security and Cooperation Program, Oct. 2002.

F. G. Hoffman, "The New Normalcy", E-Notes, 2006: http://www.fpri.org/orbis.

R. D. Holsworth and J. H. Wray, American Politics and Everyday Life, New York: Macmillan, 1987.

J. Hosten-Craig, The Effect of a North American Free-Trade Agreement on the Commonwealth Caribbean, New York: Edwin Melen Press, 1992.

Samuel P. Huntington, "Why International Primacy Matters", International Security, Spring, 1993.

M. Ignatieff, The Burden, http://ars.userfriendly.org/users/read.cgi?d=19836\&tid=73409.

M. Ignatiev, The Rights Revolution, Anansi, Toronto, 2000.

H. A. Innis, The Bias of Communications, Toronto: University of Toronto Press, 1964.

R. L. Jackson, "The Sense and Sensibility of Betrayal: the Meaning of Treachery through Jane Austen," Humanitas, vol. 13, no. 2, 2000 
C. Johnson, "Blowback", The Nation, September 2001.

S. Johnson and M. Liu, "The Enemy Spies”, Newsweek, June 2006, issue 27

R. Kagan, Of Paradise and Power: America and Europe in the New World Order, New York: Knopf, 2003.

R. Kagan, "America as Global Hegemon", National Interest, vol. 2, issue 29, June 2003.

R. Kagan, "America and Empire", Interview with R. Kagan by J. Glazov, December, 2006.

I. Kant, Political Writings, New York: Cambridge University Press, 2002.

R. Keohane and J. S. Nye, "Power and Interdependence in the Information Age", Foreign Affairs, vol. 77 no. 5, September/October. 1998.

S. Kierkegaard, Fear and Trembling, New York: Penguin Books, 2005.

J. Kristeva, The Portable Kristeva, K. Oliver, ed., New York: Columbia University Press, 2002.

A. Kojève, Introduction to the Reading of Hegel, New York: Cornell University, 1969.

H. J. Laski, A Grammar of Politics, London: George Allen \& Unwin, 1967.

H. D. Lasswell, Power and Personality, New York: Viking, 1966.

E. Levinas, Thinking of the Other entre nous, New York: Columbia University Press, 1998.

P. Lewis, "Insights from History: The Next Great Empire", Futures, February 1982.

P. Lindfield and J. Alexander, "Science Technology and Strategic Management: the Bad News for Democracy", V. Subramaniam and J. Alexander, eds., The Comparative Policy Reader, Delhi: Ajanta Books, 1999.

S. M. Lipset, The First New Nation: The United States in Historical and Comparative Perspective, New York: Basic Books, 1963.

L. Lomarski, "Double Betrayal", Reason Magazine, http://www.reason.com.

D. M. Lowe, History of Bourgeois Perception, Chicago: University of Chicago Press, 1982.

H. R. Luce, The American Century, New York: Farrar \& Reinhart, 1941.

J. F. Lyotard, The Postmodern Condition: a Report on Knowledge, Minneapolis: University of Minnesota Press, 1984.

J. F. Lyotard, The Postmodern Explained, Minneapolis: University of Minnesota Press, 1997.

J. F. Lyotard, The Differend, Minneapolis: The University of Minnesota Press, 2002.

H. Maiba, "Social Movements in the Age of Globalization", GSC Quarterly, Spring 2003.

M. Mandelbaum, The Case for Goliath: How America Acts as the World's Government in the Twenty-first Century, Cambridge, MA: Public Affairs [Perseus Book Group], 2005.

H. Marcuse, One-Dimensional Man, Boston: Beacon Press, 1966.

W. Marshall, "Polar Opposites", Blueprint Magazine, February 9, 2006.

K. Marx, Selected Writings, Indianapolis \& Cambridge: Hackett Publishing, 1999.

M. McLuhan, The Gutenberg Galaxy, Toronto: University of Toronto Press, 1995.

R. K. Merton, "The Self-Fulfilling Prophecy", Antioch Review, vol. 8, 1936

D. Moisi, "Fear, Humiliation, Hope, and the New World Order", Foreign Affairs, January/February 2007.

M de Montaigne, Selected Works, New York: Everyman's Library, 2003.

H. Morganthau, "The Intellectual and Moral Dilemma of History", Christianity and Crisis, February 9, 1960. http://www.religion-online.org/showarticle.asp/title=398.

A. J. Motyl, "Empire Falls", Foreign Affairs, July/August, 2006.

C. Mueller, The Politics of Communication: a Study in the Political Sociology of Language, Socialization, and Legitimation, London: Oxford University, 1973.

J. L. Nancy, Being Singular Plural, Stanford: Stanford University Press, 2000.

J. L. Nancy, Hegel: The Restlessness of the Negative, Minneapolis \&London: University of Minnesota Press, 2002. 
J. L. Nancy, The Ground of the Image, New York: Fordham University Press, 2005.

J. L. Nancy, "Between Story and Truth", The Little Magazine, vol. II, issue 4, 2006.

A. Negri, Time for Revolution, New York: Continuum, 2003.

A. Negri, "Ruptures Within Empire, The Power of Exodus", An Interview with Toni Negri by Giuseppe Cocco and Maurizio Lazzarato", translated from the French journal Multitudes (Issue No. 7) by Thomas Seay and Hydrarchist. http://www.generationonline. org/t/empireruptures.htm.

A. Negri \& M. Hardt, Empire, Cambridge: Harvard University Press, 2001.

D. T. Nguyen and J. Alexander, "The Coming of Cyberspacetime and the End of the Polity", R. Shields, ed., Cultures of Internet: Virtual Spaces, Real Histories, Living Bodies, London: Sage, 1996, pp. 99-124.

D. T. Nguyen, "Technologies of Time Measurement and Ethics: The Case against Mechanical Timekeeping in Ancient China", J. Alexander, ed., Science, Technology and Politics Yearbook, Ottawa: Odda Tala Press, 1990, pp. 77-96.

R. Niebuhr, Irony of American History, New York: Charles Scribner's sons, 1962.

B. Nichols, "Decades Later, Marines Hunt Vietnam-era Deserters", USA Today, July, 2006.

H. L. Nieburg, Political Violence: the Behavioral Process, New York: St. Martin's, 1969.

F. Nietzsche, Beyond Good and Evil, New York: Vintage Books, 1966.

F. Nietzsche, The Genealogy of Morals/ Ecce Homo, New York: Vintage Books, 1989.

F. Nietzsche, Thus Spake Zarathustra, New York: Prometheus Books, 1993.

F. Nietzsche, The Birth of Tragedy, New York: Dover Publications, 1995.

D. Nimmo and J. E. Combs, Mediated Political Realities, $2^{\text {nd }}$ ed., New York \& London: Longman, 1990.

J. Nye, "The American National Interest and Global Public Goods", International Affairs, vol. 78 , no. 2, 2002.

J. S. Nye, "Seven Tests: Between Concert and Unilateralism - International Relations", National Interest, Winter 2001.

J. Rancière, "The Police Order - What can be Said, Seen, and Done: An Interview with J. Rancière", Palinurus: Engaging Political Philosophy, issue 12, February 2007.

B. O'Neill, “America, Iran and 'Impotent Imperialism", February 16, 2007.

T. E. Patterson, The American Democracy, $7^{\text {th }}$ ed. Boston, MA: McGraw Hill, 2005.

D. F. Pocock, "The Anthropology of Time-Reckoning", J. Middleton, ed, Myth and Cosmos: Readings in Mythology and Symbolism, Garden City, NY: Natural History Press, 1967, pp. 303-14.

A. Podgórecki, "Sociotechnics: Basis Concepts and Issues", A. Podgórecki, J. Alexander and R. Shields, eds., Social Engineering, Ottawa: Carleton University Press, 1996, pp. 23 58.

R. Presthus, Elites in the Policy Process, New York: Cambridge University Press, 1974.

M. Renner, State of the World, New York: W.W. Norton, 1989.

Paul Ricoeur, The Course of Recognition, Cambridge \& London: Harvard University Press, 2005.

D. Riesman with N. Glazer and R. Denney, The Lonely Crowd : a Study of the Changing American Character, New Haven: Yale University Press, 1969.

A. Ronell, "Testing Your Love, or, Breaking Up", Lecture given at the European Graduate Faculty, Aug. 2002.

J. Rose, "The politics of betrayal", The Standard, Nov. 2006.

H. Rositzke, The CIA's Secret Operations: Espionage, Counterespionage, and Covert Action, New York Thomas Y. Crowell, 1977.

J. J. Rousseau, The Basic Political Writings, Indianapolis \& Cambridge: Hackett 
Publishing, 1987.

J. J. Rousseau, The Social Contract, New York: Penguin Books, 1968.

J. J. Rousseau, Discourse on the Origins of Inequality, Indianapolis \& Cambridge: Hackett Publishing, 1992.

A. Roy, The Algebra of Infinite Justice, London: Flamingo, 2002.

A. Roy, An Ordinary Person's Guide to Empire, Cambridge, Mass: South End Press, 2004.

A. Roy, "People versus Empire", In These Times, January 2005.

B. Russell, Power, London/New York: Routledge, 2004.

B. F. Ryan, Social and Cultural Change, New York: Ronald, 1969.

E. Saada, "The History of Lessons: Power and Rule in Imperial Formations", Items and Issues, vol. 4, no. 4, Fall/Winter 2003.

E. Said, Orientalism, New York: Vintage, 1978.

E. Said, Culture and Imperialism, New York: Vintage Books, 1993.

R. Sanders, "Going to war: Unraveling the Tangled Web of American Pretext Stratagem (1846 - 1989), COAT (Coalition to Oppose the Arms Trade), issue 50, Jan. 2003.

C. Schmitt, The Concept of the Political, Chicago: The University of Chicago Press, 1996.

R. E. Scholes and R. Kellogg, The Nature of Narrative, New York: Oxford University Press, 1966.

A. Schopenhauer, The World as Will and Representation, New York: Dover Publications, 1969.

B. S. Silver and N. A. Stanlick, Philosophy in America: Interpretive Essays, vol. II, Upper Saddle River, NJ: Pearson Prentice-Hall, 2004.

C. Simpson, Blowback, New York: Weidenfeld \& Nicolson, 1998.

P. Singer, "Beyond the Law", The Guardian, Monday May 3, 2004.

R. Slotkin, Regeneration Through Violence: The Mythology of the American Frontier, 1600-1860, Middletown, CT: Wesleyan University Press, 1973.

C. Strathausen, "A Critique of Neo-Left Ontology", PostModern Culture, vol. 16, no. 3, May 2006.

L. Strauss, Platonic Political Philosophy, Chicago: University of Chicago Press, 1990.

L. Strauss, What is Political Philosophy, Chicago: Chicago Press, 1997.

L. Strauss, On Tyranny, Chicago: University of Chicago Press, 2000.

R. Suskind, "Without a Doubt", New York Times, October 17, 2004.

C. Taylor, The Malaise of Modernity, Toronto: Anansi, 2003.

C. Taylor, "Foucault on Freedom and Truth", Political Theory, vol. 12, May 1984.

E. Tenner, Why Things Bite Back: Technology and the Revenge of Unintended Consequences, New York: Knopf, 1997.

A. de Tocqueville, Democracy in America, vol. 1, A. Hacker, ed., 1964.

C. Townshend Terrorism: a Very Short Introduction, Oxford: Oxford University Press, 2002.

P. Virilio, The Information Bomb, London \& New York: Verso, 2005.

P. Virilio, Speed and Politics, New York: Semiotext(e), 1986.

T. Voss and M. Abraham, "Rational Choice Theory in Sociology: A Survey", S. R. Quah and A. Sales, eds., International Handbook of Sociology, London: Sage, 2000.

I. Wallerstein, The Decline of American Power, New York \& London: The New Press, 2003.

I. Wallerstein, "America and the World: The Twin Towers as Metaphor", November 2002. http://www.binghamton.edu/fbc.iwbk/n02.htm.

I. Wallerstein, "New Revolts against the System", New Left Review, November/December 2002.

S. M: Walt, "Taming American Power", Foreign Affairs, September/October 2005. 
K. Waltz, "Realist Thought and Neorealist Theory", Journal of International Affairs, vol. 44, issue 1, Spring/Summer 1991.

K. Waltz, "Intimations of Multipolarity", The New World Order, London, 2000.

P. Watzlawick, How Real is Real: Confusion, Disinformation, Communication, New York, Vintage Books, 1976.

C. Weber, "Performative States", Millenium: Journal of International Relations, vol. 27, issue $1,1998$.

M. Weber, The Protestant Ethic and the Spirit of Capitalism, London \& Boston: Unwin Hyman, 1930.

S. Weil, Gravity and Grace, New York: G.P. Putnam \& Sons, 1952.

S. Weil, Oppression and Liberty, London/New York: Routledge, 2002.

A. Wendt, "Anarchy is What States Make of It", International Organizations, vol. 42, no. 2, Spring, 1992.

N. Wiener, The Human use of Human Beings, Garden City, NY: Anchor Books, 1954.

J. C. Wilson, The Politics of Truth: inside the Lies that Led to War and Betrayed My Wife's CIA Identity, New York: Carroll \& Graf, 2004.

J. C. Wilson, "What I Didn't Find in Africa", New York Times, July 6, 2003.

J. H. Wray, Sense and Non-Sense: American Culture and Politics, Upper Saddle River, NJ: Prentice Hall, 2001.

S. Žižek, The Plague of Fantasies, London \& New York: Verso, 1997.

S. Žižek, On Belief, London \& New York: Routledge, 2001.

S. Žižek, "Desire: Drive = Truth: Knowledge", Umbra, 1997.

S. Žižek, "Multiculturalism or the Cultural Logic of Multinational Capitalism", New Left Review, September 1997, pp. 28-51.

S. Žižek, "The Specter is Still Roaming Around", CTheory: Civil Society, Fanaticism, and Digital, 1999.

S. Žižek, "The One Measure of True Love is: You can Insult the Other", interview by S. Reul and T. Deichmann, Spiked, November 2001.

S. Žižek, "Are we at War? Do we have an Enemy?", London Review of Books, vol. 24, no. 10, May, 2002.

S. Žižek, "The Cyberspace Real", World Association of Psychoanalysis. www.wapol.org.

S. Žižek, "The Political and its Disavowals", Palinurus: Engaging Political Philosophy, issue 9, Nov. 2006. 